Faculdade de Engenharia da Universidade do Porto Departamento de Engenharia Mecânica

\title{
Efficiency of a Gearbox Lubricated with Wind Turbine Gear Oils
}

\author{
Pedro Miguel Teixeira Marques \\ Master's Degree Dissertation presented to the \\ Faculdade de Engenharia da Universidade do Porto \\ Dissertation supervised by \\ Doutor Jorge Humberto O. Seabra Doutor Ramiro Carneiro Martins \\ Full Professor of FEUP Auxiliary researcher of INEGI
}

Porto, July 2012 


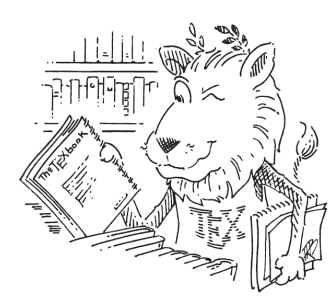

IATEX

FEUP-U.PORTO

pedro marques

2012 
to my family 



\section{Acknowledgements}

I would like to acknowledge and give my sincere thanks to a few people without whom this thesis couldn't have been possible.

I would like to thank my family for all the help and support even during the toughest times I spent during the entire duration of this Mechanical Engineering Degree.

I also would like to thank both of my supervisors, Prof. Jorge H. O. Seabra and Dr. Ramiro C. Martins for their constant support, availability, readiness and transmitted knowledge.

I would like to express my gratitude to my fellow colleagues at CETRIB, (Unidade de Tribologia, Vibrações e Manutenção Industrial): Armando Campos, Beatriz Graça, Carlos Fernandes, David Gonçalves, Jorge Castro, José Brandão, Luís Magalhães, Pedro Amaro and Tiago Cosseau, not only for their constant help and support but also for the great moments we spent.

Last but not least my sincere thanks to the Faculdade de Engenharia da Universidade do Porto and its staff, for their contribution in time and resources to my graduation in Mechanical Engineering. 



\section{Keywords}

Wind Turbine gear oils

Power loss

Heat dissipation

Transfer Gearbox

Efficiency

Coefficient of Friction

Gears friction loss

Churning power loss

Rolling bearings power loss

Wear

\section{Palavras chave}

Lubrificantes para engrenagens de turbinas eólicas

Perdas de potência

Dissipação de calor

Caixa de Transferência

Eficiência

Coeficiente de atrito

Perdas de potência por atrito nos engrenamentos

Perdas de potência por chapinagem

Perdas de potência nos rolamentos

Desgaste 



\section{Abstract}

In recent years people have been giving increasing importance to the environmental questions related to carbon emissions. In order to reduce it, a wide range of renewable energy sources has been developed in order to satisfy not only the growing energy needs, but also to replace some of the old high carbon emission facilities. Wind turbines are one of the machines that take advantage of the wind energy to generate electrical power. Some of these have multiple stages gearboxes that operate in order to convert the high input torque, coming from the low speed wind propelled turbine, to an adequate higher speed for the generator. It is of great interest to have the maximum possible efficiency on this speed multiplying process. In fact, these gearboxes already have good efficiency. Nevertheless, any small increase of efficiency has a significant impact not only due to the high power involved, but also due to the increasing number of wind turbine farms all across the globe.

The main objective of this work is to analyse the influence of wind turbine gear oils on gearbox efficiency.

Four fully formulated wind turbine gear oils, two Mineral,(MINE, MINR) a Polyalkylene Glycol,(PAGD) and a Poly- $\alpha$-olefin (PAOR) were tested on a back to back gearbox test rig with recirculating power in order to evaluate the torque loss performance of each oil. Input speeds ranging from 100 to 500 rpm and input torques ranging from 500 to $1000 \mathrm{Nm}$ were tested. Low speeds and high torques were chosen in order to have conditions closer to the ones found on a real wind turbine gearbox application. Wear performance was evaluated through oil analysis by Direct Reading Ferrography $(D R I I I)$, particles concentration $(C P U C)$ and wear particles severity $(I S U C)$.

Using the experimental data collected during the tests, a power loss model including load and no-load power losses was implemented and calibrated. The model calibration was performed through the adjustment of mean coefficient of friction between gear teeth and churning loss. Additional experimental testing was performed and the predicted power loss was in agreement with the the results derived from the experimental testing. This model also can also be used to predict the relative influence of each one of the components of the global power loss. 



\section{Sumário}

Nos últimos anos tem-se vindo a dar uma importância crescente às questões relacionadas com o ambiente, nomeadamente no que diz respeito às emissões de carbono. No sentido de diminuir estas emissões um leque variado de fontes de energia alternativas tem vindo a ser desenvolvido não só para alimentar as necessidades crescentes de energia, mas também para substituir algumas das velhas centrais eléctricas responsáveis por grandes volumes de emissões. Os aerogeradores são máquinas que tiram partido da energia contida nas correntes de ar da atmosfera para gerar energia eléctrica. Estas máquinas tem caixas de engrenagens com vários andares que funcionam no sentido de converter os elevado binários e baixas velocidades de entrada geradas nas pás da turbina, numa velocidade mais elevada e mais adequada para a geração de corrente eléctrica no gerador. É óbvio o interesse em que esta multiplicação de velocidade seja feita da forma mais eficiente possível. As caixas de engrenagens já tem uma boa eficiência, mas mesmo uma pequena melhoria pode fazer uma grande diferênça dado que não só estão envolvidas grandes potências, mas também existem cada vez mais instalações de aerogeradoes.

O principal objectivo deste trabalho é a análise da influência dos lubrificantes para aerogeradores na efficiência de uma caixa de engrenagens.

Num banco de ensaio com recirculação de potência foram ensaiados quatro óleos certificados para o uso em turbinas eólicas, dois Minerais, (MINE, MINR) um Polialquilenoglicol, (PAGD) e uma Poli- $\alpha$-olefina, (PAOR). Os testes foram efectuados com a caixa de teste a funcionar como multiplicadora, a baixas velocidades (100 a $500 \mathrm{rpm}$ ) e altos binários (500 a $1000 \mathrm{Nm}$ ) na entrada com o objectivo de melhor simular as condições de funcionamento numa aplicaa̧ão em turbinas eólicas. O objectivo será distinguir a performance dos lubrificantes ao nível das perdas de potência e do desgaste. Para acompanhar a evolução do desgaste na caixa de teste são usadas a Ferrometria de Leitura Directa $(D R I I I)$, e Ferrometria Analítica (FRIII). Os indíces de concentração, $(C P U C)$ e severidade das partículas, (ISUC) foram também avaliados.

Foi implementado um modelo numérico com objectivo de prever as perdas de potência no interior da caixa de teste. Este modelo foi calibrado com o auxílio dos 
resultados experimentais, sendo que esta foi efectuada actuando quer ao nível das perdas por atrito nos engrenamentos quer ao nível da chapinagem. Após calibração do modelo numérico foram feitos testes experimentais adicionais e as perdas de potência foram comparadas com as previstas. As perdas previstas estão de acordo com as medidas. Este modelo ajudou também a ter uma ideia da influência de cada uma das componentes de perdas na perda de potência global. 


\section{Nomenclature}

\begin{tabular}{|c|c|c|}
\hline Symbol & Units & Description \\
\hline$A_{c a}$ & $m^{2}$ & Global heat transfer reference area \\
\hline$b$ & $m$ & Tooth face width \\
\hline$C_{c h}$ & $N m$ & Churning Torque \\
\hline$c_{f}$ & - & Churning power loss speed correction factor \\
\hline$C_{m}$ & - & Dimensionless drag torque \\
\hline$D_{p}$ & $m$ & Pitch diameter \\
\hline$F_{b t}$ & $N$ & Tooth normal force, transversal section \\
\hline$g$ & $m / s^{2}$ & Acceleration of gravity \\
\hline$h$ & $m$ & Immersion depth of the pinion \\
\hline$H_{\text {tooth }}$ & $\mathrm{m}$ & Tooth height \\
\hline$H_{v}$ & - & Gear loss factor \\
\hline$l_{\min }$ & $m m$ & Minimum length of contact \\
\hline$m$ & $m$ & Module \\
\hline$M_{d r a g}$ & $N m m$ & Bearing drag torque loss \\
\hline$M_{r r}$ & $\mathrm{Nmm}$ & Bearing rolling torque loss \\
\hline$M_{s l}$ & $N m m$ & Bearing sliding torque loss \\
\hline$m_{t}$ & $m$ & Transverse module \\
\hline$n$ & rpm & Rotational speed \\
\hline$n_{I N}$ & rpm & Input speed on the transfer gearbox \\
\hline$n_{O U T}$ & rpm & Output speed on the transfer gearbox \\
\hline$P_{V}$ & $W$ & Global power loss \\
\hline$P_{V D}$ & $W$ & Seals power loss \\
\hline$P_{V L 0}$ & $W$ & Bearing no-load power loss \\
\hline$P_{V L P}$ & $W$ & Bearing load power loss \\
\hline$P_{V Z 0}$ & $W$ & Gears no-load losses \\
\hline$P_{V Z P}$ & $W$ & Gear Load power loss \\
\hline$Q_{C a}$ & $W$ & Global heat loss \\
\hline$Q_{c n d}$ & $W$ & Conduction heat flow \\
\hline$Q_{c n v}$ & $W$ & Convection heat flow \\
\hline$Q_{\text {rad }}$ & $W$ & Radiation heat flow \\
\hline
\end{tabular}




\begin{tabular}{|c|c|c|}
\hline$Q_{\text {exp }}$ & $W$ & Heat loss derived from experimental torque measurements \\
\hline$R_{a}$ & $\mu m$ & Roughness average \\
\hline$R_{p}$ & $m$ & Pitch radius \\
\hline$T_{\text {room }}$ & ${ }^{\circ} \mathrm{C}$ & Room temperature \\
\hline$T_{\text {Oil }}$ & ${ }^{\circ} \mathrm{C}$ & Oil sump temperature \\
\hline$T_{W a l l}$ & ${ }^{\circ} \mathrm{C}$ & Test gearbox wall temperature \\
\hline$u$ & - & Conduction ratio \\
\hline$V_{0}$ & $m^{3}$ & Volume of lubricant on the test gearbox \\
\hline$v_{\sum c}$ & $m / s$ & Sum velocity at pitch point \\
\hline$X_{L}$ & - & Oil correction factor \\
\hline$\alpha$ & - & Pressure angle \\
\hline$\alpha_{t}$ & - & Transverse pressure angle \\
\hline$\alpha \cdot A_{c a}$ & $W / K$ & Global heat transfer coefficient derived from experimental results \\
\hline$\alpha_{c a}$ & $W /\left(m^{2} \cdot K\right)$ & Global heat transfer coefficient \\
\hline$\alpha_{c n d}$ & $W /\left(m^{2} \cdot K\right)$ & Conduction heat transfer coefficient \\
\hline$\alpha_{c n v}$ & $W /\left(m^{2} \cdot K\right)$ & Convection heat transfer coefficient \\
\hline$\alpha_{\text {rad }}$ & $W /\left(m^{2} \cdot K\right)$ & Radiation heat transfer coefficient \\
\hline$\beta$ & - & Helix angle \\
\hline$\beta_{b}$ & - & Helix angle at base radius \\
\hline$\epsilon$ & - & Emissivity coefficient \\
\hline$\varepsilon_{1}$ & - & Addendum contact ratio of pinion \\
\hline$\varepsilon_{2}$ & - & Addendum contact ratio of gear \\
\hline$\varepsilon_{\alpha}$ & - & Transverse contact ratio \\
\hline$\eta_{O i l}$ & $m P a \cdot s$ & Dynamic viscosity of the lubricant oil \\
\hline$\theta$ & rads & Angle between pinion/wheel centre and oil sump level \\
\hline$\mu_{m z}$ & - & Coefficient of friction at gear mesh \\
\hline$\nu$ & $m^{2} / s$ & Kinematic viscosity \\
\hline$\rho$ & $\mathrm{kg} / \mathrm{m}^{3}$ & Bulk density \\
\hline$\rho_{c}$ & $m m$ & Equivalent curvature radius at pitch point \\
\hline$\omega$ & $\mathrm{rad} / \mathrm{s}$ & Angular frequency \\
\hline
\end{tabular}




\section{Contents}

Keywords ....................... vii

Palavras Chave ......................... vii

Abstract ..................... ix

Sumário . . . . . . . . . . . . . . . . . . xi

Nomenclature . . . . . . . . . . . . . . . . . . xiii

1. Introduction 1

1.1. Thesis Outline . . . . . . . . . . . . . . . . . . . . 1

2. Wind Turbines 3

2.1. Wind turbine Gearboxes . . . . . . . . . . . . . . 3

3. An introduction to Lubricants 5

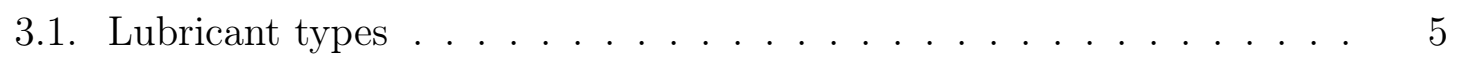

3.1.1. Liquid lubricants - lubricant oils . . . . . . . . . 5

3.1.2. Lubricant Greases . . . . . . . . . . . . . . . . . . 8

3.1.3. Gaseous Lubricants . . . . . . . . . . . . . . . . . . . 9 9

3.2. Additive Package . . . . . . . . . . . . . . . . . . . 10

3.3. Physical properties of the lubricant oils . . . . . . . . . . . . 12

3.3.1. Viscosity . . . . . . . . . . . . . . . . . 12

3.3.2. Viscosity variation with shear strain rate . . . . . . . . 19

3.3.3. Other properties . . . . . . . . . . . . . . 20

3.4. Lubricant oils specifications . . . . . . . . . . . . . . 21

3.4.1. Viscosity specifications . . . . . . . . . . . . . . 21

3.4.2. Green Certifications . . . . . . . . . . . . . . . . 23

4. Characterization of the wind turbine gear oils 25

4.1. Viscosity . . . . . . . . . . . . . . . . . . . . 25 


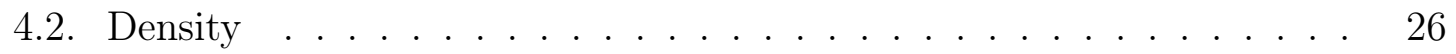

5. Gearbox test rig and Transfer Gearbox 31

5.1. Test Bench Rig . . . . . . . . . . . . . . . . . . . . 31

5.2. Transfer Gearbox . . . . . . . . . . . . . . . . 33

6. Thermal balance 37

6.1. Heat dissipation . . . . . . . . . . . . . . . . . . . . 38

6.1.1. Radiation .................... 38

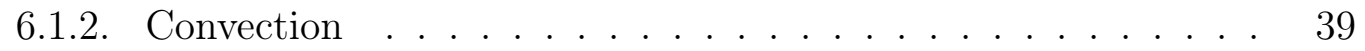

6.1.3. Total heat dissipation . . . . . . . . . . . . . . . . 39

6.2. Power Loss Model . . . . . . . . . . . . . . . . . . . . . . . . . . . . . 40

6.2.1. Gear Loss . . . . . . . . . . . . . . . . . . . . . 40

6.2.2. Seals power Loss . . . . . . . . . . . . . . . . 47

6.2.3. Rolling bearing power loss . . . . . . . . . . . . . . . . . 48

7. Experimental procedures and results 53

7.1. Experimental procedures . . . . . . . . . . . . . . . 53

7.2. Wear evaluation through lubricant analysis . . . . . . . . . . 55

7.2.1. Ferrography . . . . . . . . . . . . . 55

7.2.2. Analytic Ferrography (FMIII) . . . . . . . . . . . . . 57

7.2.3. Results from wear evaluation through lubricant analysis . . . . 59

7.3. Power loss results . . . . . . . . . . . . . . . . . . . . . 64

7.4. Stabilization temperature and measured torque loss . . . . . . . . . 64

8. Calibration of the power loss model and numerical results 71

8.1. Power loss model results and its optimization . . . . . . . . . . . . . 71

8.1.1. Calibration of the gears churning power loss model . . . . . . 71

8.1.2. Calibration of the coefficient of friction on the gear mesh . . . 76

8.2. Power Loss dependence on input speed and input torque . . . . . . . 88

8.2.1. Prediction of the oil sump temperature based on the input power 88

8.2.2. Power loss predictions over a range of working conditions . . . 88 
$\begin{array}{lr}\text { 9. Conclusions and Future work } & 97\end{array}$

9.1. Conclusions . . . . . . . . . . . . . . . . . . . . . 97

9.1.1. Conclusions based on experimental evidence . . . . . . . . . 97

9.1.2. Conclusions based on numerical results . . . . . . . . . . . 98

9.2. Future work . . . . . . . . . . . . . . . . . . . . 99

$\begin{array}{ll}\text { A. Appendix } & 105\end{array}$

A.1. Reports from the experimental tests . . . . . . . . . . . . . . 106

A.1.1. MINE Oil . . . . . . . . . . . . . . . . . 107

A.1.2. MINR Oil . . . . . . . . . . . . . . . . . . . 119

A.1.3. PAGD Oil . . . . . . . . . . . . . . . 129

A.1.4. PAOR Oil . . . . . . . . . . . . . . . 139

$\begin{array}{ll}\text { B. Lubricant Analysis Reports } & 147\end{array}$

B.1. MINE Oil . . . . . . . . . . . . . . . . . . . . . . 147

B.2. MINR Oil . . . . . . . . . . . . . . . . . . . 154

B.3. PAGD Oil . . . . . . . . . . . . . . . . . 161

B.4. PAOR Oil . . . . . . . . . . . . . . . . . . . . 168

B.5. Power Loss dependence on Input Speed and Input Torque, (Extended plotting) . . . . . . . . . . . . . . . . 174

B.5.1. MINE Oil . . . . . . . . . . . . . . . . 175

B.5.2. MINR Oil . . . . . . . . . . . . . . . . . . . 177

B.5.3. PAGD Oil . . . . . . . . . . . . . . . . . 179

B.5.4. PAOR Oil . . . . . . . . . . . . . . . . . . 181

B.6. Determination of the global heat transfer coefficient, (Extended results) 183 B.6.1. Results considering $\Delta T=T_{\text {wall }}-T_{a m b} \ldots \ldots \ldots 184$

C. Detailed results of the implemented Numerical Approach, (Program $\begin{array}{ll}\text { Printouts) } & 185\end{array}$

C.1. Results before numerical adjustment . . . . . . . . . . . . . . 186

C.1.1. MINE Oil . . . . . . . . . . . . . . . . . . 187

C.1.2. MINR Oil . . . . . . . . . . . . . . . . 190

C.1.3. PAGD Oil . . . . . . . . . . . . . . 195

C.1.4. PAOR Oil . . . . . . . . . . . . . . . . . . 199 
Contents

C.2. Results after numerical adjustment . . . . . . . . . . . . 203

C.2.1. MINE Oil . . . . . . . . . . . . . . . . . . 204

C.2.2. MINR Oil . . . . . . . . . . . . . . . . . . 209

C.2.3. PAGD Oil . . . . . . . . . . . . . . . . . . . . 214

C.2.4. PAOR Oil . . . . . . . . . . . . . . . . . . . . . . . 219

C.3. Torque sensors manufacturer specifications . . . . . . . . . . . . . . 223 


\section{List of Figures}

2.1. Size evolution of wind turbines over time. . . . . . . . . . . . . . 3

2.2. Main parts of a turbine. . . . . . . . . . . . . . . . 4

3.1. Laminar flow between two planar surfaces. . . . . . . . . . . . . . . . 13

3.2. Variation of shearing stress with rate of shearing strain for several types of fluids, including common non-Newtonian fluids. . . . . . . . 14

3.3. Viscosity Index definition. . . . . . . . . . . . . . . . . . . . 16

3.4. Kinematic viscosity variation with temperature using different laws, MINR Oil. . . . . . . . . . . . . . . . . . . . . . 18

3.5. Viscosity variation with shear strain rate for several lubricants. . . . . 19

3.6. Green certifications. . . . . . . . . . . . . . . . . . . . . . 24

4.1. Picture of the Engler viscometer used to perform the viscosity measurements. . . . . . . . . . . . . . . . 26

4.2. Rotational viscometer Contraves Rheomat 115. . . . . . . . . . . . 27

4.3. Picture of the Anton Paar DMA35N densimeter used to perform the density measurements. . . . . . . . . . . . . . . . . 27

4.4. Variation of the wind turbine gear oils properties with temperature . 29

5.1. Top view scheme of the gearbox test rig. . . . . . . . . . . . . . . 31

5.2. Gearbox test rig and its control command: a) Gearbox test rig; b) Control station; . . . . . . . . . . . . . . . . . . 32

5.3. Scheme of the transfer gearbox installed on a vehicle. . . . . . . . . . 33

5.4. Rolling bearings numbering on the transfer gearbox. . . . . . . . . . . 34

5.5. Gearbox speed diagram. . . . . . . . . . . . . . . . . . 34

5.6. Gearing mechanism of toothed ring and fork. . . . . . . . . . . 36

5.7. Transfer gearbox installed on the test rig . . . . . . . . . . . 36 
6.1. Different mechanisms of power dissipation and heat evacuation on a generic gearbox. . . . . . . . . . . . . . . . . 37

6.2. Geometrical data of the gear immersed surface. . . . . . . . . . . . . 41

6.3. Definition of the senses of rotation of a gear pair. . . . . . . . . . . 43

6.4. Schematic representation of the swell effect. . . . . . . . . . . . . . 43

6.5. Lubrication conditions. . . . . . . . . . . . . . . . . 45

6.6. Lubrication conditions along the gear mesh. . . . . . . . . . . . 45

6.7. Stribeck curve. . . . . . . . . . . . . . . . . 46

6.8. Types and surface roughness. . . . . . . . . . . . . . . . . . 46

7.1. Evolution of the input power on the transfer gearbox over the range of tested conditions. . . . . . . . . . . . . . . . . 54

7.2. Example of tree of the oil samples collected during the experimental testing and the vacuum pump used. . . . . . . . . . . . . . 55

7.3. Direct Reading Ferrography by Predict Technologies. . . . . . . . . . 56

7.4. Direct Reading Ferrography (DRIII) . . . . . . . . . . . . 57

7.5. Analytic Ferrography (FMIII) by Predict Technologies. . . . . . . . . 58

7.6. Analytic Ferrography (FMIII) . . . . . . . . . . . . . . . 58

7.7. Ferroscope - IV by Predict Technologies. . . . . . . . . . . . . . . . 59

7.8. Evolution of the wear indexes with the number of cycles . . . . . . 60

7.9. Specific film thickness . . . . . . . . . . . . . . . . . . 60

7.10. Nucleus of the Ferroram, (third oil sample) . . . . . . . . . . . 61

7.11. Typical particles on the ferrogram nucleus, (third oil sample) . . . . . 62

7.12. Evidence of wear by corrosion on MINE and PAOR . . . . . . . . 63

7.13. Stabilization temperatures and power loss . . . . . . . . . . . 66

7.14. Heat Loss and $\alpha \cdot A$ against $\Delta T=T_{\text {Oil }}-T_{\text {room }}$ : a) Heat loss; b) $\alpha \cdot A \quad 68$

7.15. Power Loss based on the global heat transfer coefficient. . . . . . . . 69

8.1. Power loss prediction and its components vs experimental results for MINE oil. . . . . . . . . . . . . . . . . . . . . . . . 71

8.2. Difference between oil sump and external wall temperature of the housing $\left(T_{\text {oil }}-T_{\text {wall }}\right)$ of the transfer gearbox against the difference between oil sump and room temperatures $\left(T_{\text {oil }}-T_{\text {room }}\right) \ldots \ldots 73$

8.3. Critical Reynolds number evaluation . . . . . . . . . . . . . . 74 
8.4. Critical Reynolds number evaluation, considering the angular speed correction factor . . . . . . . . . . . . . . . . 75

8.5. Power loss model behaviour including the churning loss correction factor $\left(c_{f}=3.3\right) \ldots \ldots \ldots \ldots \ldots \ldots \ldots \ldots \ldots \ldots \ldots \ldots \ldots \ldots \ldots \ldots$

8.6. Loss prediction $v s$ experimental results for MINE oil. . . . . . . . . . 78

8.7. Loss prediction $v s$ experimental results for MINR oil. . . . . . . . . . 78

8.8. Loss prediction $v s$ experimental results for PAGD oil. . . . . . . . . . 79

8.9. Loss prediction $v s$ experimental results for PAOR oil. . . . . . . . . . 79

8.10. Optimized loss prediction vs experimental results for MINE oil. . . . 82

8.11. Optimized loss prediction vs experimental results for MINR oil. . . . 82

8.12. Optimized loss prediction vs experimental results for PAGD oil. . . . 83

8.13. Optimized loss prediction vs experimental results for PAOR oil. . . . 83

8.14. Optimized loss prediction and its respective components for MINE oil. 84

8.15. Optimized loss prediction and its respective components for MINR oil. 84

8.16. Optimized loss prediction and its respective components for PAGD oil. 85

8.17. Optimized loss prediction and its respective components for PAOR oil. 85

8.18. Relative distribution of the loss components; . . . . . . . . . . . 87

8.19. Predicted and experimental oil sump temperature as a function of the input power for the wind turbine gear oils. . . . . . . . . . . 89

8.20. Efficiency prediction as a function of speed and torque. . . . . . . . . 91

8.21. Coefficient of friction on the gear pair $1 / 2$ as a function of speed and torque. . . . . . . . . . . . . . . . . . 92

8.22. Power loss prediction as a function of speed and torque. . . . . . . . 93

8.23. Torque loss as a function of speed and torque. . . . . . . . . . . . 94

8.24. Predicted efficiency maps over the range of tested conditions. . . . . . 95

B.1. Global losses depending on both input speed and input torque . . . . 175

B.2. Mean coefficient of friction on both geared pairs . . . . . . . . 175

B.3. Gear Mesh losses depending on both input speed and input torque . . 176

B.4. Bearing load losses depending on both input speed and input torque . 176

B.5. No-load losses depending on both input speed and input torque . . . 176

B.6. Global losses depending on both input speed and input torque . . . . 177

B.7. Mean coefficient of friction on both geared pairs . . . . . . . . . 177

B.8. Gear Mesh losses depending on both input speed and input torque . . 178 
List of Figures

B.9. Bearing load losses depending on both input speed and input torque . 178 B.10.No-load losses depending on both input speed and input torque . . . 178 B.11.Global losses depending on both input speed and input torque . . . . 179 B.12.Mean coefficient of friction on both geared pairs . . . . . . . . . . . . 179

B.13.Gear Mesh losses depending on both input speed and input torque . . 180

B.14.Bearing load losses depending on both input speed and input torque . 180

B.15.No-load losses depending on both input speed and input torque . . . 180

B.16.Global losses depending on both input speed and input torque . . . . 181

B.17.Mean coefficient of friction on both geared pairs . . . . . . . . . . . . 181

B.18.Gear Mesh losses depending on both input speed and input torque . . 182

B.19.Bearing load losses depending on both input speed and input torque . 182

B.20.No-load losses depending on both input speed and input torque . . . 182

B.21.Heat Loss and $\alpha \cdot A$ against $T_{\text {wall }}-T_{A m b} \ldots \ldots \ldots$ 


\section{List of Tables}

4.1. Physical properties of the wind turbine gear oils (reference). . . . . . 28

4.2. Physical properties of the wind turbine gear oils (measured). . . . . . 28

5.1. Gearbox test rig motor characteristics. . . . . . . . . . . . 32

5.2. Geometrical parameters of the pinions in the transfer gearbox. . . . . 33

5.3. Mechanical properties of DIN $15 \mathrm{NiCr} 6$ steel. . . . . . . . . . . . 35

5.4. Chemical composition of DIN $15 \mathrm{NiCr} 6$ steel. . . . . . . . . . . . 35

5.5. Rolling Bearing types on the transfer gearbox and its characteristics. 36

7.1. Planned experimental test points. . . . . . . . . . . . . 53

7.2. Sequence for the experimental tests. . . . . . . . . . . . . 54

7.3. Wear indexes at the end of all testing for each wind turbine gear oil . $\quad 59$

7.4. Stabilization temperatures, $\left(T_{\text {oil }}-T_{\text {room }}\right)$, from the experimental testing 65

7.5. Power loss results from torque sensors readings. . . . . . . . . . . 65

7.6. Torque sensors performance specifications. . . . . . . . . . . . 67

7.7. Numerically adjusted coefficients for the prediction of the global heat transfer coefficient, $\left(\Delta T=T_{\text {Oil }}-T_{a m b}\right)$ and correlation factor $\left(R^{2}\right) . \quad 68$

7.8. Power Loss results from the global heat transfer coefficient. . . . . . . 68

8.1. Optimized lubricant factor coefficients. . . . . . . . . . . 80

8.2. Correlation factors $\left(R^{2}\right)$ considering the optimized lubricant factor coefficients $\left(a_{1}, b_{1}, b_{2}\right)$ and the churning loss correction factor, $\left(c_{f}=\right.$

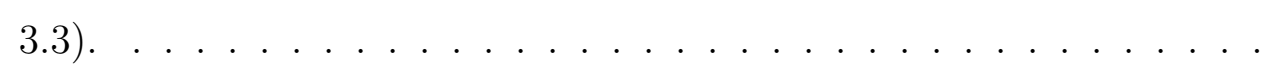

8.3. Comparison between the experimental and predicted power loss for two experimental points in between the test matrix points. . . . . . . 86

8.4. Optimized coefficients for the oil sump temperature prediction and correlation factor $\left(R^{2}\right) \ldots \ldots \ldots \ldots$. . . . . . . . . . . . 89 



\section{Introduction}

It is of great importance to have means of predicting the behaviour of a gearbox at the design stage. Accurate predictions on this area will allow the development of more efficient and reliable designs in less time, ultimately saving resources not only at the design stage but also during operation. Having methods to accurately predict the power loss on a gearbox is of great importance. In a gearbox usually two types of power losses can be identified, the load and no-load dependant losses. The load losses are all the power losses that result directly from the effect of the applied torque and power transmission. No-load losses are all the power loss that can occur even when there is no torque applied. During this work several semi-empiric models, that evaluate each one of the several components of the load and no load losses were implemented on Matlab R2010a. The power loss was calculated and compared with the experimental results. Different methods were employed in order to adjust the numerical model to better predict the experimental results. During the efficiency tests oil samples were collected and the wear was evaluated through the analysis of the oil samples.

\subsection{Thesis Outline}

On chapter 2 a brief description on what is a wind turbine with particular focus on its gearbox is made.

Chapter 3 is dedicated to lubricants basics. The most common types of lubricants along with the usual additive packages and common certifications are presented. An introduction to the basic properties of the lubricant oils, such as viscosity and density is given, while introducing the effects of pressure and temperature on those properties.

On chapter 4 a brief description of the methods and devices used to measure the basic lubricants properties (viscosity and density) is provided. After this description the results from the measurements are presented. 


\section{Introduction}

Chapter 5 presents the Gearbox Test Rig, the test gearbox and its components.

Chapter 6 is dedicated to describe the power loss model implemented. It begins by exposing and decomposing the various components related to the heat dissipation, followed by the presentation of the models related to the internal loss in the gearbox.

On chapter 7 some of the results and procedures related to experimental testing are exposed. The methods used to perform the wear analysis are described and the results presented. The power loss results and stabilization temperatures are presented and the global heat transfer coefficient calculated.

On chapter 8 several considerations are made and model corrections are performed. The results are compared with the experimental results. Finally, predictions are made for a range of operating conditions and comparisons between the four lubricant oils based upon these predictions are also done.

The last chapter is dedicated to the conclusions based on experimental and numerical results. Future work is also suggested. 


\section{Wind Turbines}

Wind turbines are machines that take advantage of the wind energy to generate electrical power. Over the last few years, not only the number of installed wind turbines, but also the power that each unit is able to generate has been increasing as shown on figure 2.1 .

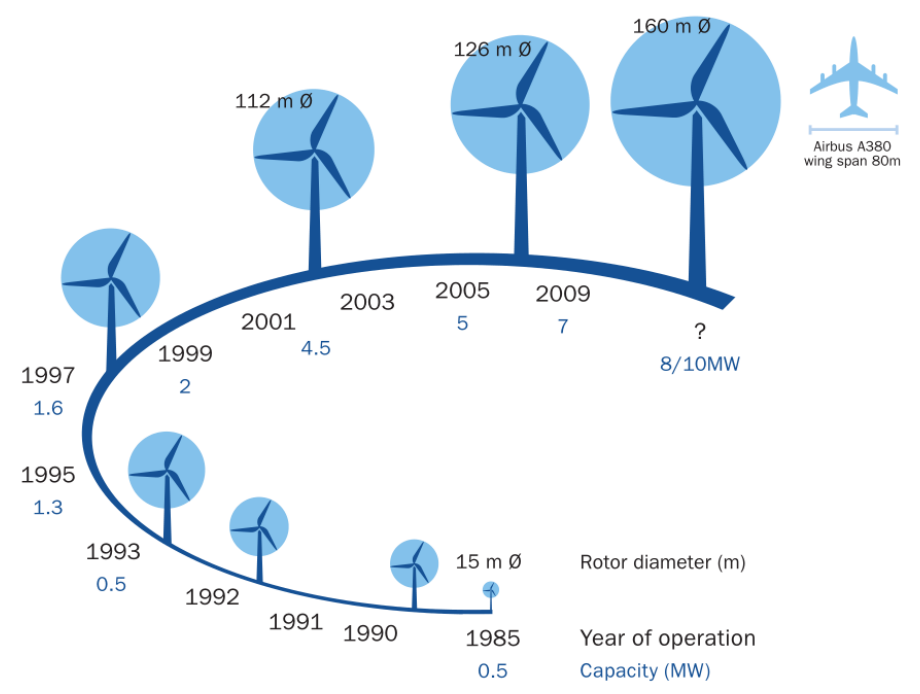

Figure 2.1.: Size evolution of wind turbines over time [11].

Most wind turbines are three-blade units comprising the major components illustrated in figure 2.2. Driven by the wind, the blades and rotor transmit energy via the main shaft through the gearbox to the generator, the main shaft being supported by the bearings, and the gearbox being such that the generator speed is as near as possible to optimal for the generation of electricity. Alignment with the direction of the wind is controlled by a yaw system and the housing (or nacelle) is mounted at the top of a tower, [20].

\subsection{Wind turbine Gearboxes}

The wind turbine gearbox mission is that of transforming the low speeds and high torques at the gearbox input into higher speeds and lower torques at the output. 


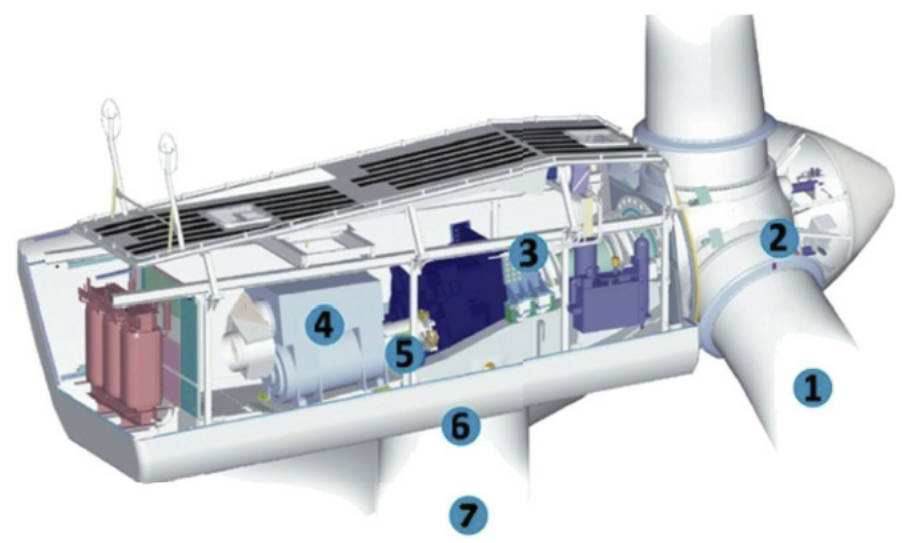

Figure 2.2.: Main parts of a turbine [20]:

1-blades; 2-rotor; 3-gearbox; 4-generator; 5-bearings; 6-yaw system; 7tower;

Thus, according to their kinematics type, wind turbine gearboxes can be classified as follows [6]:

- standard gearboxes that constantly transform input torque and speed values into those at the output;

- torque-limiting gearboxes can control or, at least, limit the output torque (and with it the input torque). The speed is thereby not controlled.

- The most complex forms of gearbox are the CVTs (continuously variable transmissions) that permit the control of the gearbox output speed and torque within a determined range.

Most wind turbine installations are equipped with similar gearboxes; typically these are three-stage spur wheel gearbox (lower capacity area), one-stage planetary gearbox with two spur wheel stages (middle capacity area) and two-stage planetary gearbox with one spur wheel stage (higher capacity area) [6]. Since low speeds and very high torques are verified at the first gearbox stage and high speeds and lower torques at the last stage, distinct lubrication conditions may be found at the gear teeth contacts.

The majority of wind turbine installations has one rotor only that generally is upwind oriented. Likewise, most installations have one generator only, i. e., the gearbox has exactly one input and one output [6]. 


\section{An introduction to Lubricants}

\subsection{Lubricant types}

Nowadays there is a great variety of lubricants on the market, from animal origin to fully synthetic. Lubricants can be divided into four major categories: liquid lubricants, lubricant greases, solid lubricants and gaseous lubricants. On the following paragraphs liquid lubricants will be characterized with more detail than the other types of lubricants, since these are of greater importance considering the aim of this work. This first chapter is based on the information presented on [25].

\subsubsection{Liquid lubricants - lubricant oils}

On this category, liquid lubricants can be divided on more sub categories: Vegetable and animal origin lubricants, Mineral and Synthetic based oils.

\section{Vegetable and Animal Oils}

Certainly, vegetable and animal lubricants were the first to be used by mankind.

Due to their chemical inertia and due to the increasing demands on the lubricant specifications these were progressively abandoned and replaced by synthetic and petroleum based products. Although these were abandoned, like it was stated before, their usage has seen an increase due to environmental reasons. As an example, their usage on Nordic countries where to lubricate equipment used on forestry activity. As its biggest weakness it can be said that these types of oils have rapid oxidation and show low resistance to high temperatures.

\section{Mineral Based Oils}

Petroleum based lubricants are mainly made of natural hydrocarbons resulting from organic residue decomposition and are usually referred to as Mineral oils. These lubricants can be classified by the type of basis. 


\section{An introduction to Lubricants}

\section{Paraffin Basis}

These oils are characterized by its low specific weight, low freeze point, great oxidation resistance and low viscosity variation with temperature thus making its viscosity index high, (about 100).

On one hand, paraffin based oils are usually elastomer friendly, (elastomers used to build seals and others). On the other hand, the high molecular weight of certain molecular chains present on this basis may carry the crystallization point just below the ambient temperature.

\section{Naphthenic basis}

These oils are characterized by its high specific weight, high freezing point, little oxidation resistance and great viscosity variation with temperature making its viscosity index quite low, (about 50).

Naphthenic based oils are relatively aggressive to the elastomers used on seals. These are greatly miscible, highly volatile and exhibit great fluidity at low temperatures.

Mineral oils are then designated as paraffin or naphthenic based depending on the predominance of one of the basis on its constitution. There are other products that are a mixture of both basis, these are largely used as lubricants because it allows for a combination of the following properties:

- Availability on a wide range of viscosities

- Low volatility

- Good/high degradation resistance

- Creation of a good corrosion protection

- Low price

\section{Synthetic based oils}

Synthetic based oils are lubricants synthesized from hydrocarbons or its constitutive elements, having as its basis petroleum derived products, vegetable oils, (this type of basis seems to have grown the most during the last years), and others. The knowledge on the hydrocarbons's basic structure and the understanding of the basic properties needed for lubrication have allowed for the development of different synthesis methods. These basis have been in development on the last decades with the goal of solving particularly difficult lubrication problems. 
Generally synthetic based oils have higher performance than the mineral based ones, specially on:

- Oxidation resistance

- Viscosity Index

- Coefficient of friction

The advantages of using synthetic based oils are more expressive at high or low temperatures. The main disadvantage of these oils is just the much higher price when comparing to other solutions like the mineral based ones. There is a huge variety of these synthesised oils. On the following paragraphs some groups will be highlighted.

\section{Synthetic Hydrocarbons}

Polyalphaolefins and benzenes are the most common types.

Some of the most important characteristics of these lubricants are enumerated below.

- Similar to the mineral hydrocarbons on its chemical structure

- Good compatibility with the elastomers usually used on seals

- Good miscibility with mineral oils

- Excellent thermal stability

- Great behaviour at low temperatures

- Need for Anti-Oxidation additives

- Food and Pharmaceutical industry grade oils can be produced.

\section{Polyglycols}

One of the main characteristics of these lubricants is that they allow for a low coefficient of friction. This makes them specially attractive for applications where high sliding is expected (worm gears).

Compatibility with seals and other polymers must be carefully analysed, specially if the working temperature is above $100^{\circ} \mathrm{C}$.

Generally very low miscibility with mineral oils is observed. 


\section{Esters}

Ester based oils result from a reaction between acids and alcohols followed by water separation. There are several types of esters, each one of them with its own characteristics that will greatly influence the final lubricant properties.

High thermal resistance and great behaviour at low temperatures are generally observed.

Some esters despite being biodegradable are fastly biodegradable. This factor seems to have increasing influence on the choice of a lubricant, since nowadays people are more aware of the environmental questions.

A good choice of an ester base can allow for a coefficient of friction on the same level of the Polyglycols.

One of the problems shown by ester based lubricants is the low hydrolytic stability. Hydrolytic stability depends not only on the ester type but also on the additive package used on the final blend of the lubricant.

\section{Silicons}

Some of the most important characteristics of these lubricants are enumerated below.

- Chemically inert;

- Fire resistant;

- Non mixable with water;

- Non toxic;

- High oxidation resistance at high temperatures;

- Good thermal stability.

\subsubsection{Lubricant Greases}

Lubricant greases result from the dispersion of a thickening agent on a lubricant oil. Most of the lubricant greases have soap as thickener, but some organic products can be used as thickeners too.

Lubricant greases are used when continuous oil lubrication is not viable and when protection against possible outside contaminant particles is required and outside contamination is to be avoided, like on pharmaceutical and food industries.

This type of lubricants have its properties limited by the thickening agent, base oil and additives. 


\section{Solid Lubricants}

A solid lubricant is a film of solid material constituted by organic or inorganic compounds, that is between the lubricating surfaces.

\section{Inorganic solid lubricants}

There are three different types of compounds used as inorganic solid lubricants.

\section{Gelatinous solids}

Materials like graphite and molybdenum disulphide are disposed in different layers. Inter atomic forces inside a layer are quite strong but the inter atomic forces on the interface between layers is quite weak allowing for easy sliding between the layers.

\section{Soft solids mixtures}

There is a huge variety of inorganic solids like lead, calcium oxide, talc, silver iodide and lead monoxide that are used as lubricants.

Surface protection by chemical reaction with the surface

There are countless compounds that can chemically react with the surface. Surface coatings like chlorides, oxides, phosphates and sulphides are well known.

\section{Organic solid lubricants}

This types of lubricants are usually divided in two categories.

Soaps, waxes and fat

On this category metallic soaps like calcium, sodium and lithium can be included. As for the waxes one can mention beeswax and fat acids.

\section{Polymeric films}

On this last category synthetic substances like Teflon (PTFE), can be included. One of the main advantages of this coatings is its great resistance to environmental aggressions.

\subsubsection{Gaseous Lubricants}

Gaseous lubrication is in some aspects analogous to liquid lubrication, since the principles of hydrodynamic lubrication can be applied. Both are viscous fluids, but 
there are some fundamental differences that separate them. Gases have much lower viscosity than the liquids despite having much higher compressibility. The load carrying capacity of a gaseous lubricant is much lower than the one of a liquid lubricant.

\subsection{Additive Package}

Adding chemical agents to the lubricant oils, (usually called additives), has the objective of giving the lubricant certain desired properties. Some additives give the lubricant new properties of great utility that were not initially available, and others just improve its natural properties.

Additives were firstly used on lubricant oils around 1920 and since then it has been increasing over the years. Nowadays practically almost every lubricant has at least one additive, but some have more than 5 types. The quantity of the used additive can vary from from a few hundredths to $30 \%$.

Additive packages have been increasing the available oils properties, thus paying a big role on the developing of engines and all of the industrial machinery.

On the following paragraphs the most common types of this products are described.

\section{Viscosity index improving additives}

Viscosity Index improving additives are used in order increase the Viscosity Index of the base oil, namely lower the viscosity at low temperatures and/or increase the viscosity at high temperatures.

The Viscosity Index of a lubricant is improved by adding high molecular weight polymers.

The viscosity of a lubricant, that has been added with polymers, is modified to an higher extent at high temperatures than at lower temperature. So, if at a lubricant oil of low viscosity is added a viscosity index improving additive a small increase on its viscosity is observed at low temperatures, (the lubricant keeps its fluidity), but an higher relative viscosity increase is observed at high temperatures.

This additives are used for engine oils, on fluids for automatic gearboxes and on hydraulic systems.

\section{Anti Wear and Extreme Pressure additives}

Anti Wear and Extreme Pressure additives are used to reduce the friction at extreme lubrication conditions. This products can be classified on three general categories: 
- Lubricity agents;

- Anti Wear additives;

- Extreme Pressure additives.

\section{Lubricity agents}

The lubricity agents are usually added to the base oils in order to reduce the friction on limit film lubrication conditions. It should be noted that the application should dictate the type and quantity of lubricity agents. This type of additives is used, for example, when phenomena like stick and slip is to be avoided.

\section{Anti-Wear $(A W)$ additives}

The anti-wear additives are used to increase the anti wear properties of the base oil forming a protective film from the reaction with the metallic surfaces on contact.

\section{Extreme Pressure $(E P)$ additives}

These additives have the objective of avoiding the adhesion between metallic surfaces, when the conditions of extreme pressure and relative sliding are verified. The $E P$ additives can chemically combine with the contacting metallic surfaces forming a protective layer. When the rupture of the lubricant film is verified, (due to high sliding speeds and/or high contact pressures), this thin layer will protect the surfaces from extremely severe failure phenomena.

$E P$ additives are usually used on gears where the contact pressure between the teeth can be well above $700 M P a$.

Nowadays there is a huge variety of extreme pressure additives. Lubricant oils can be prepared in order to satisfy practically all of the operational demands on gear applications.

When formulating these lubricants the oil thermal and chemical stability must be ensured, since the EP additives are prone to induce lubricant instability.

\section{Antioxidants}

These are used to avoid, modify or delay the reaction of the hydrocarbons with oxygen in order to avoid all of the harmful situations that oil oxidation can cause.

Oil oxidation can generate acid compounds soluble on the lubricant. These oxide compounds can usually not only increase the oil viscosity, but also make it corrosive to some metals forming sludge and varnishes that can adhere to the mechanical organs. 
An antioxidant additive can actuate in different manners. It can directly affect the lubricant oil, or it can affect the metallic surfaces that usually it is in contact with. In order to have the desired stability and corrosion resistance the base lubricant oil should be meticulously refined and its anti-corrosion additives should be carefully selected in order to have the best lubricant properties.

\section{Other additives}

Other types of additives are often used on a lubricant:

- Detergents - These are used to avoid the formation of deposits of extremely viscous compounds on the lubricant.

- Corrosion inhibitors - These are usually the same additives as Antioxidants, since oxidation can result on the formation of acid components that can deteriorate the surfaces.

- Surface Oxidation inhibitors - By physical or chemical interaction with certain metals, these form a continuous and extremely strong layer over the metallic surfaces that does not allow water to be in contact with those surfaces.

- Foam inhibitors - The most used foam inhibitor is silicon. Usually foam inhibitors are extremely effective because only a few parts per million are enough to have the desired effect. These avoid foam formation caused by intense lubricant agitation during operation. It can be used on any type of liquid lubricant.

\subsection{Physical properties of the lubricant oils}

Physical properties of the lubricants are usually defined by the base lubricant.

\subsubsection{Viscosity}

From all of the physical and chemical properties that need to be considered on lubrication, viscosity is the most important.

\section{Definition of viscosity}

Viscosity of a fluid is defined as the resistance opposed by the fluid at all of the internal shear deformation. This opposing force can be calculated using the Newton's formula relative to the laminar flow between a mobile surface with a velocity $V$ and a fixed surface, as it is shown on figure 3.1. 


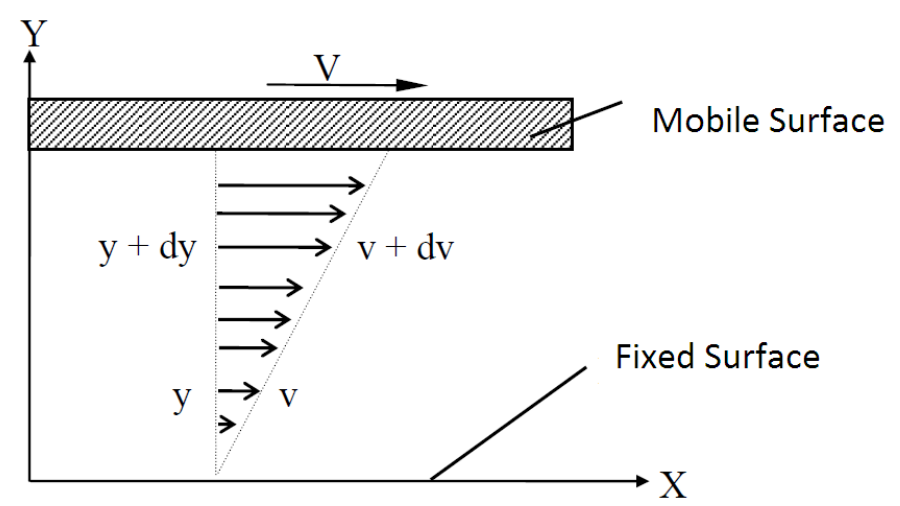

Figure 3.1.: Laminar flow between two planar surfaces.

Since there is relative movement between both surfaces and the no slip boundary condition needs to be verified, it is of obvious understanding that there will be different "layers" of fluid moving at different speeds ranging from 0 to $V$.

At any distance $y$ from the fixed surface the speed of the fluid is $v$, at a distance $y+d y$ the speed will be $v+d v$. So the shear stress, represented by $\tau$, can be given by

$$
\tau=\sigma_{x y}=\eta \frac{d v}{d y}
$$

where $\eta$ is a characteristic coefficient of the fluid designated by dynamic viscosity.

The hypothesis stated above can be experimentally verified for many fluids. This type of fluids are designated as Newtonian fluids. Common fluids such as water and several oils show this type of behaviour under laminar flow conditions. The presence of macro molecules or the severe utilization (high loads) of these fluids may modify their behaviour, making the linear proportionality relation between shear stress and shear strain rate no longer verified. If the linear relation stated above is no longer valid, then the fluid is classified as non-Newtonian.

Lubricant behaviour is described by a rheological law. A rheological law is a mathematics law that describes the relation between the deformation speed and the applied shear stress. Newton's law stated on equation 3.1 is the simplest of the rheological laws. On figure 3.2 a comparison between the several types of rheological behaviours is shown.

When considering non-Newtonian fluids several models are available depending on the behaviour exhibited by the fluid in question. 


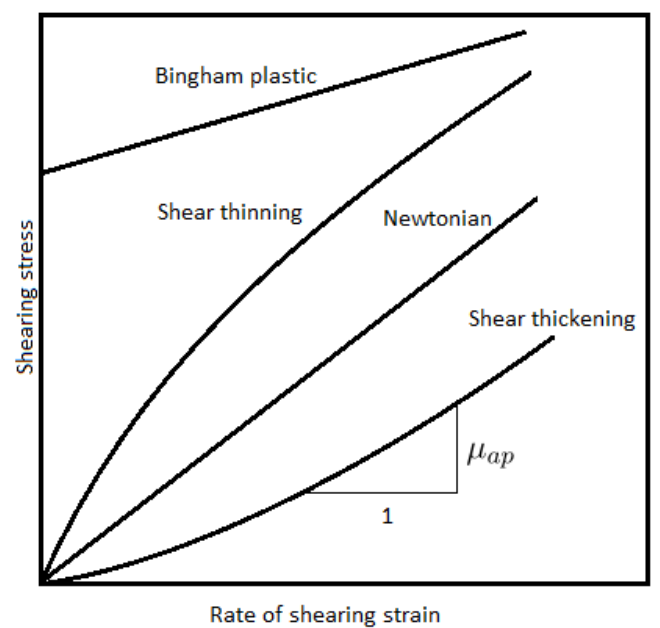

Figure 3.2.: Variation of shearing stress with rate of shearing strain for several types of fluids, including common non-Newtonian fluids.

\section{Viscosity Units}

From equation 3.1 the dimensional equation for the dynamic viscosity can be easily derived.

$$
\eta=M L^{-1} T^{-1}
$$

Dividing the dynamic viscosity, $(\eta)$ by the bulk density of the fluid, gives:

$$
\nu=L^{2} T^{-1}
$$

This quantity is defined as kinematic viscosity and it is commonly used in lubrication.

Dynamic viscosity is expressed as $P a \cdot s$ on the $S I$ units. Since most current oils have viscosity values between 0.001 and $1 P a \cdot s ~ m P a \cdot s$ units are usually used. Kinematic viscosity has SI units of $\mathrm{m}^{2} / \mathrm{s}$, although the most widely used units are $c S t,\left(1 c S t=1 \mathrm{~mm}^{2} / \mathrm{s}\right)$

\section{Viscometry}

In order to measure the viscosity of a liquid two types of viscometers are used:

- Absolute viscometers;

- Empirical viscometers. 


\section{Absolute Viscometers}

There are several types of absolute viscometers:

- Capillary viscometers are made of calibrated capillary tubes, where a fluid flows through it at constant temperature and pressure differential. The kinematic viscosity is then deducted from the time it takes to the volume of fluid to flow through the capillary. These viscometers can measure viscosities with quite good accuracy.

- Couette's viscometer measures the resistant torque by the fluid between two coaxial cylinders, where the inner cylinder is rotating and the outside one is fixed.

- The disc and conic viscometers work by the same principle as the Couette viscometer, but instead of the fluid being between two cylinders, it is between the conic or planar surface and a fixed plane.

For all of the absolute viscometers there are mathematical equations, depending on the type of viscometer, that express the viscosity as a function of several physical parameters. The coefficients that appear in such equations are sometimes of difficult determination. So, the calibration of such devices is made using another viscometer on which the viscosity for a certain fluid is known, allowing precise viscosity measurements.

\section{Empirical Viscometers}

For industrial measurements the viscosity is evaluated using empirical devices. On such devices the viscosity is not evaluated with an exact equation like on the absolute viscometers. The most common of these devices are the Saybolt (USA), Redwood (UK) and Engler (Continental Europe) viscometers. The viscosity measurement is performed by comparing the time it takes for a certain volume of fluid completely flow off a recipient with the corresponding time of a reference fluid. These viscosities are usually evaluated at a constant temperature and each type of viscometer has its own viscosity units.

Since on such devices the flow does not occur at steady state, the law that allows for the evaluation of the kinematic viscosity is of empirical nature.

\section{Viscosity variation with Temperature}

Generally, on most fluids the viscosity is greatly dependant on temperature. Around $20^{\circ} \mathrm{C}$, water shows a viscosity variation around $2.5 \%$ per ${ }^{\circ} \mathrm{C}$, variations ranging from 


\section{An introduction to Lubricants}

10 to $15 \%$ can be observed on mineral oils.

Usually both synthetic and mineral oils show viscosity decreases with the increase of temperature (at constant pressure).

\section{Viscosity Index}

The viscosity index was created because there was the need to specify how the different oil grades react to similar temperature variations. The method suggested by Dan and Davis in 1929 is one of the most used nowadays.

These authors have classified all the oils known to them by their kinematic viscosity value $(S U S)$ at $210^{\circ} \mathrm{F}$. Between all the oils with the same viscosity at $210^{\circ} \mathrm{F}$ they chose the two that had the highest and lowest viscosity at $100^{\circ} \mathrm{F}$. The oil with lowest viscosity variation with temperature was paraffinic. The oil with lowest viscosity variation with temperature was naphtenic. They randomly chose an index of 100 (paraffinic) for the first oil and an index of 0 for the second oil (naphtenic). The Viscosity Index of an oil between these two can then be calculated using the following equation

$$
\text { V.I. }=\frac{L-U}{L-H} \times 100
$$

where $L$ and $H$ are the reference oils viscosities at $100^{\circ} \mathrm{F}$ and $U$ is the viscosity, at the same temperature, of the oil which the Viscosity Index is to be calculated.

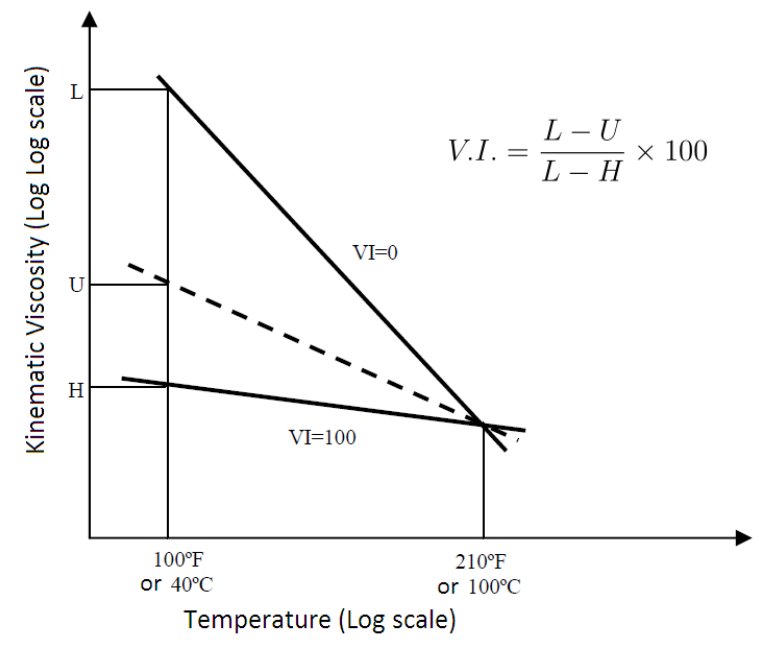

Figure 3.3.: Viscosity Index definition.

Since 1975 temperatures of 40 and $100^{\circ} \mathrm{C}$ are used on Europe and USA.

It should be noted that the Viscosity Index is not enough to fully characterize an oil. Generally two oils with the same Viscosity Index don't exhibit the same viscosity variation with temperature. 


\section{Thermoviscosity}

Thermoviscosity represents the way viscosity changes with temperature variations.

There are several formulations that try to represent thermoviscous behaviour. On the following paragraphs some of those laws will be presented.

The simplest thermoviscosity law was proposed by Cameron:

$$
\nu_{1}=\nu_{0} e^{(-\beta \Delta \theta)}
$$

where

- $\nu_{1}$ - Lubricants's kinematic viscosity at temperature $\theta_{1}$,

- $\nu_{0}$ - Lubricants's kinematic viscosity at a reference temperature $\theta_{0}$,

- $\beta$ - Thermoviscous coefficient,

- $\Delta \theta$ - Lubricant's temperature variation $\Delta \theta=\theta_{1}-\theta_{0}$.

Although equation 3.5 is quite simple, it is valid only for small temperature variations around the reference temperature $\left(\theta_{0}\right)$.

Another equation that expresses the thermoviscosity of a lubricant is the one referenced on $A S T M D 341$ standard:

$$
\log \log (\nu+a)=n-m \log (T)
$$

where

- $\nu$ - Kinematic viscosity $(c S t)$,

- $T$ - Temperature (Kelvin),

- $m, n, a$ - Experimentally determined lubricant dependent. constants.

There is another equation for the approximation of the thermoviscosity of a lubricant, it is Vogel's equation:

$$
\nu=K \exp \left[\frac{b}{\theta+c}\right]
$$

where

- $\nu$ - Lubricant's kinematic viscosity at temperature $\theta$,

- $K, b, c$ - Experimentaly determined lubricant dependent constants,

- $\theta$ - Temperature, ${ }^{\circ} \mathrm{C}$.

Figure 3.4 presents a comparison between the results given by the laws described above. 


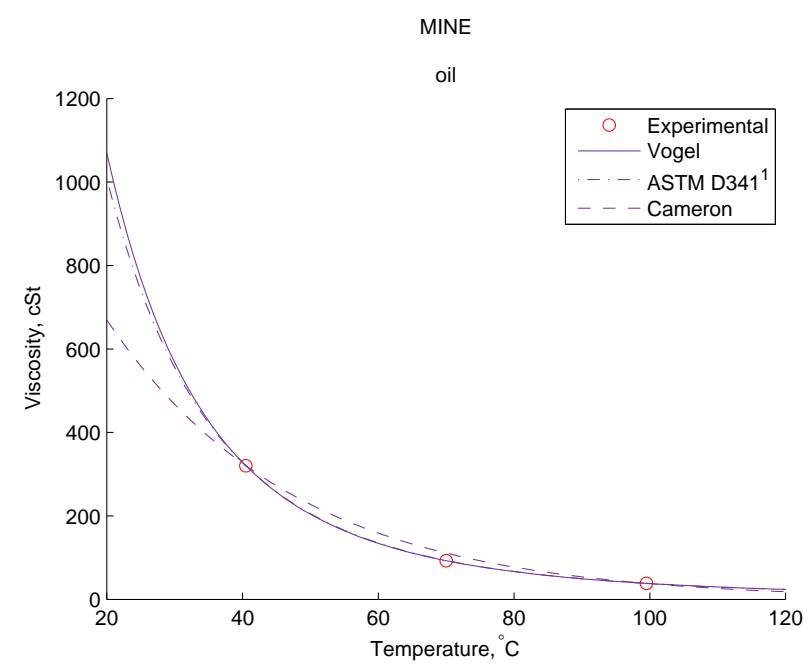

Figure 3.4.: Kinematic viscosity variation with temperature using different laws, MINE Oil.

$1-a=0.7$

\section{Viscosity variation with pressure}

For the majority of the lubricants, viscosity increases with pressure.

\section{Range of variation}

This phenomena of viscosity increase with pressure is of great practical importance, since the lubricant can be submitted to pressure values of about $1 G P a$ during operation, specially in the case of rolling bearings and gears.

It is observed that the viscosity variation with pressure is exponential. This behaviour depends on the lubricant's nature, being more important on naphthenic based oils than on paraffin based ones.

\section{Piezoviscosity}

The way lubricants behave under extreme pressures, $(0.5-4.0 G P a)$, that occur in $E H D$ contacts is very important since piezoviscous properties are of great importance on the film thickness generation. If the lubricant is tested on a viscometer at high pressure and the ambient temperature is kept constant a relation between pressure and viscosity is given by Barus's law:

$$
\eta_{s}=\eta_{0} e^{(\alpha p)}
$$

where

- $\eta_{s}$ - Dynamic viscosity at pressure $p$, 
- $\eta_{0}$ - Dynamic viscosity at atmospheric pressure $p=0$,

- $\alpha$ - Coefficient of piezoviscosity, $\mathrm{Pa}^{-1}$.

Equation 3.8 considers that the coefficient of piezoviscosity is pressure independent and it is defined at the oil temperature in contact inlet. This equation is also proven to be quite inaccurate for pressures above $0.5 G P a$ and for high ambient temperatures.

Other relations between pressure and viscosity have been derived in order to solve the problems associated with equation 3.8.

\subsubsection{Viscosity variation with shear strain rate}

When the shear strain rate imposed to the lubricant film does not affect the dynamic viscosity, it can be said that this lubricant is of Newtonian nature. When the shear strain rate affects the lubricant's viscosity the fluid is considered nonNewtonian.

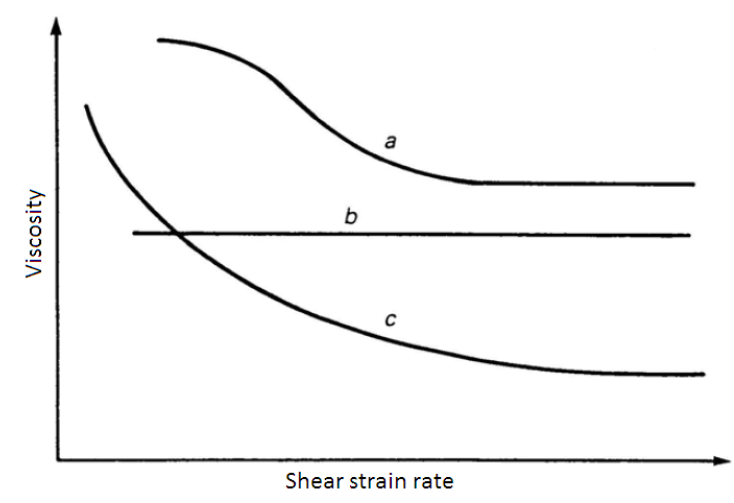

Figure 3.5.: Viscosity variation with shear strain rate for several lubricants: a) Grease; b) Newtonian Fluid; c) non-Newtonian Fluid;

Due to the fact that in some contacts the lubricants operate at extremely high shear strain rate conditions, a viscosity decrease of the lubricant is observed.

With what was stated above it is of easy comprehension that a rheological model needs to be established in order to take into account the effects of pressure, temperature and shear strain rate since Newton's model (equation 3.1), is no longer valid.

\section{Amorphous state of the lubricant}

When a lubricant is cooled down at constant pressure its viscosity progressively increases until it reaches a state where it behaves like an amorphous solid. The temperature that defines the point when it happens is called Vitrous Transition Temperature. 
This same transformation occurs if the temperature is kept constant and the pressure is progressively risen.

It is observed that the pressures and temperatures inside $E H D$ contacts are enough for such transformations to take place, or at least extremely high viscosities are observed.

\subsubsection{Other properties}

\section{Bulk density and specific gravity}

The bulk density is defined as the ratio between a mass of a body and its volume, $\left(\mathrm{kg} / \mathrm{m}^{3}\right)$. Its variation with temperature is not very relevant when calculating the specific film thickness on a contact. Its variation with pressure is quit significant thus making it relevant when calculating the specific film thickness.

Specific gravity is defined as the ratio between lubricant and water's bulk density.

\section{Thermal conductivity}

Thermal conductivity is the heat flow transferred due to a unitary temperature gradient per unit of time in a normal direction to a surface of unitary area. Higher thermal conductivity favours heat evacuation, (eg.: when the lubricant is cooled on an heat exchanger). This property has linear variation with temperature and its expressed on $W / m K$.

\section{Specific Heat}

This property is of great importance since it defines how much energy is necessary to have a temperature variation of a single degree for an unitary mass. For example at the convergent zone at an EHD contact the higher specific heat of a certain lubricant favours lower increase of temperature on the convergent zone. Like the thermal conductibility, specific heat varies linearly with temperature and it is expressed on $J / k g K$. 


\section{Thermal diffusivity}

Thermal diffusivity is the property that describes the propagation of temperature on bodies and its defined as the ratio between thermal conductivity and the product of the bulk density by its specific heat. This property is expressed on $\mathrm{m}^{2} / \mathrm{s}$.

\subsection{Lubricant oils specifications}

Two types of specifications are available for the lubricant oils:

- Viscosity specifications,

- Service specifications.

\subsubsection{Viscosity specifications}

Viscosity specifications can be established with two ends:

- Identification: There are refining or manufacturing specifications that take into account viscosity tolerances for certain ranges of viscosity

- Usage: These are imposed by the consumer and are function of the use given to the lubricant oils. There are certain ranges of maximum and minimum viscosity at certain temperatures.

These classifications are based only on the lubricant oil viscosity.

There are various professional societies that classify lubricants by viscosity range. Some examples of these societies are:

- $S A E$ - Society of Automotive Engineers,

- ISO - International Standards Organization,

- AGMA - American Gear Manufacturers Association,

- ASTM - American Society for Testing and Materials.

\section{SAE Viscosity classification}

This classification is used and almost universally accepted for the classification of automotive lubricant oils (with or without additives). It is exclusively based on the oil viscosity and it doesn't evaluate the oil quality it just gives the information about the its viscosity at a certain temperature. 


\section{An introduction to Lubricants}

A different classification is proposed depending on the oil application. For example the $S A E J 306$ is the classification given to the lubricant oils for automotive gearboxes and differentials, and the $S A E J 300$ is for engines. 


\section{ISO Viscosity classification}

ISO's classification of industrial oils is of a notable simplicity. Each oil grade is defined by a round number that corresponds to the kinematic viscosity (centiStokes $[c S t]$ ) of the lubricant at the temperature of $40^{\circ} \mathrm{C}$. The limits for each class correspond to $\pm 10 \%$ of the nominal.

\section{Service classifications}

The most usual service classifications for automotive lubricant oils are:

- $A P I$ - American Petroleum Institute,

- ACEA - Association des Constructeurs Europèens d'Automobiles.

The service classifications specify the desired properties of a lubricant oil for a given application.

\subsubsection{Green Certifications}

More than 10000 tons of lubricants get into the environment every year when properly used [10]. On the last few years a growing concern about these matters have lead to the development of environmentally friendly lubricants.

Some of the objectives that need to be pursued in order to develop environmentally friendly lubricants are.

- Reduce and, if possible, eliminate sulphur, phosphorus and aromatic components;

- Reduce volatility in order to reduce its impact on the surrounding atmosphere and users;

- It should be partially or fully recyclable;

- Efforts should be made in order to increase its biodegradability and reduce its toxicity;

- By increasing its oxidation resistance and thermal stability higher working temperatures and longer oil change periods can be achieved;

- Modifications on the oil formulation and additives should be implemented in order to reduce even more the friction power loss. 


\section{An introduction to Lubricants}

These environmental concerns have lead to the foundation of institutions that certificate the lubricant oils in terms of toxicity, biodegradability and its capacity to be recycled.

With the foundation of these "Green" certification institutions the consumer is lead to buy these "green" products, thus creating the need on the producers to develop environmentally friendly products and obtain these certifications.

The emblems of some of the certificates that can be applied to lubricants are shown on figure 3.6

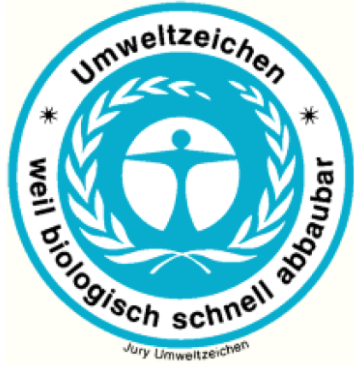

(a)

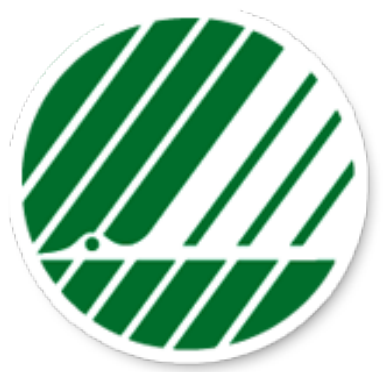

(c)

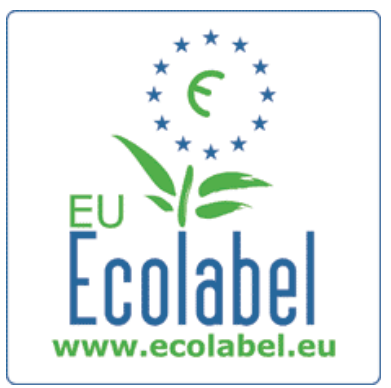

(b)

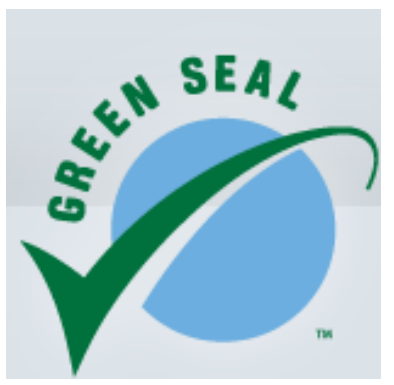

(d)

Figure 3.6.: Green certifications,
a) Blauer Engel; b) EU Eco-Label; c) White Swan; d) Green Seal, [9, 7, $8,13]$

Blue Angel labelled forming oils, lubricating oils and lubricating greases are an environmentally friendly alternative to conventional products. Eco-labelled lubricants often consist of vegetable or animal oils that distinguish themselves by a good biodegradability. Also, the additives added to improve the technical properties do not contain any eco-toxicologically critical substances. 


\section{Characterization of the wind turbine gear oils}

Four fully formulated wind turbine gear oils were tested. Among them two Mineral,(MINE, MINR) a Polyalkylene Glycol,(PAGD) and a Poly- $\alpha$-olefin (PAOR). All of these lubricants are marketed as high performance gear oils for application in wind turbine gearboxes, and all of them are ISO VG 320 lubricant oils.

The gear oils physical properties (viscosity and bulk density) need to be evaluated before any other test.

This process consisted on the use of an Engler viscometer to determine the engler viscosity at three different temperatures in order to later on calculate the Vogel and ASTM D341 constants for each oil. The dynamic viscosity was also evaluated on a rotational viscometer. Various density measurements were performed at various temperatures in order to assess its variation with temperature.

\subsection{Viscosity}

In order to have accurate values for the viscosity at a specified temperature, the Viscosity vs Temperature curve had to be determined for each oil. It is of great interest to have accurate values for the viscosity at a given temperature, since it will, not only, affect the way the implemented power loss model will respond, but also will help on the experimental results interpretation.

\section{Engler viscometer}

The Engler viscometer has a recipient where the oil to be evaluated is poured. There is a small hole at the bottom of that recipient where a wood pointer should be inserted or removed in order to stop or allow the oil to flow from it. To keep the oil at a selected temperature, this recipient is inside another recipient with a fluid between them (oil or water). This fluid is heated by a resistor thus allowing for temperature control. This two recipients are supported by a three legged support that allows adjustments in order to keep both recipients levelled. There are two thermometers, 
one on the tested oil, and the other one on the heat carrying fluid. This allows one to control the temperature that is desired for the viscosity measurement.

The measurement procedure used follows what is stated on the IP 212/92 standard.

Figure 4.1 shows a picture of the Engler viscometer used.

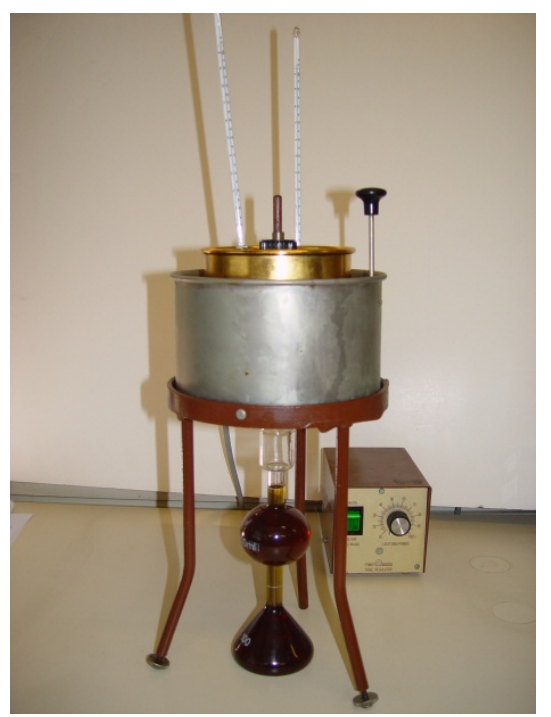

Figure 4.1.: Picture of the Engler viscometer used to perform the viscosity measurements.

\section{Rheometer}

In order to evaluate the character of the gear oils, (Newtonian or Non-Newtonian at atmospheric pressure) tests were performed on the available rheometer.

The rheometer seen on figure 4.2, Contraves Rheomat 115, is a coaxial measurement system according to Searle's principle. The measuring shaft is rotating inside the testing substance, and it is powered by an electrical motor. The opposing torque is then measured and shown on the control instrument display.

By knowing the opposing torque and the angular speed, the viscosity of the fluid can be determined. By performing tests at various shear strain rates the fluid behaviour (Newtonian or Non-Newtonian) can be tested.

\subsection{Density}

The evolution of the density with temperature at atmospheric pressure was performed for gear oils. The density is used to calculate the dynamic viscosity, the thermal expansion coefficient, etc.

The densitometer used (figure 4.3), has two ways of evaluating the oil sample: 


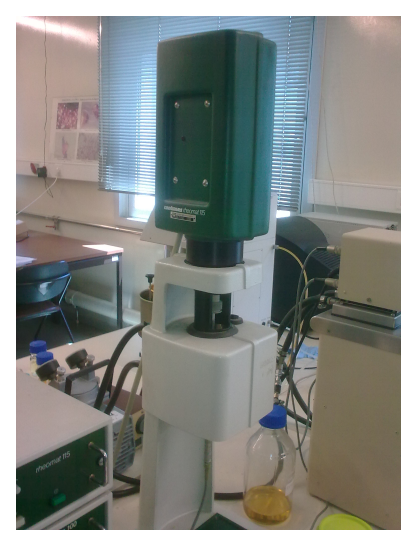

Figure 4.2.: Rotational viscometer Contraves Rheomat 115.

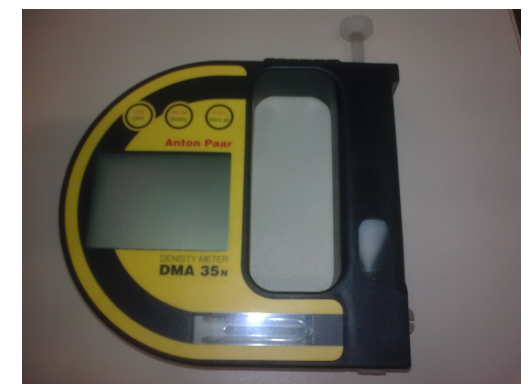

Figure 4.3.: Picture of the Anton Paar DMA35N densimeter used to perform the density measurements.

- It can directly extract a $2 m l$ oil sample from a recipient;

- The oil sample can be injected on the device with a special syringe;

The oil sample temperature should be within the range from 0 to $40^{\circ} \mathrm{C}$.

In order to obtain the density curve three values for the density at three different temperatures were registered, and the thermal expansion coefficient was calculated.

Figures 4.4(a), 4.4(b) present the obtained curves for viscosity and density.

Since it has an high percentage of additives using a Vibro-Viscometer a another viscosity measurement was performed at a constant temperature of $100^{\circ} \mathrm{C}$ in order to evaluate if there was a viscosity change over time. No changes were observed.

Table 4.1 shows the properties according to the manufacturers data sheets.

The physical properties and chemical composition of the four gear oils were characterized and are shown in the table 4.2.

All wind turbine gear oils are ISO VG 320 grade, meaning they have aviscosity of $320 \mathrm{cSt}$ at $40^{\circ} \mathrm{C}$.As presented on table 4.2 the measurements show that these oils satisfy the ISO standard. 
Table 4.1.: Physical properties of the wind turbine gear oils (reference).

\begin{tabular}{|c|c|c|c|c|c|c|}
\hline Parameter & Unit & Standard & MINE & MINR & PAGD & PAOR \\
\hline Base Oil & {$[-]$} & & Mineral & Mineral & Polyalkylene Glycol & Poly- $\alpha$-olefin \\
\hline \multicolumn{7}{|l|}{ Physical Properties } \\
\hline Density@15ㅇ & {$\left[\mathrm{g} / \mathrm{cm}^{3}\right]$} & ASTM D4052 & $\mathrm{n} / \mathrm{a}$ & 0.904 & 1.051 & $\mathrm{n} / \mathrm{a}$ \\
\hline Viscosity @ $40^{\circ} \mathrm{C}$ & {$[c S t]$} & ASTM D445/DIN $51562-1$ & 320 & 320 & 320 & 320 \\
\hline Viscosity@ $100^{\circ} \mathrm{C}$ & {$[c S t]$} & ASTM D445/DIN 51562 - 1 & $\mathrm{n} / \mathrm{a}$ & 24.03 & 54 & 35.5 \\
\hline Viscosity Index & {$[-]$} & ASTM D2270/DIN ISO2909 & $\mathrm{n} / \mathrm{a}$ & 95 & 237 & 158 \\
\hline Inflammability Point & {$\left[{ }^{\circ} \mathrm{C}\right]$} & ASTM D92/DIN ISO2592 & $\mathrm{n} / \mathrm{a}$ & 210 & 102.33 & 210 \\
\hline Pour Point & {$\left[{ }^{\circ} \mathrm{C}\right]$} & ASTM D97/DIN ISO3016 & $\mathrm{n} / \mathrm{a}$ & -9 & -39 & -42 \\
\hline \multicolumn{7}{|l|}{ Corrosion Resistance Properties } \\
\hline Copper corrosion, $3 \mathrm{~h}$ at $100^{\circ} \mathrm{C}$ & {$[-]$} & ASTM D130 & $\mathrm{n} / \mathrm{a}$ & $1 \mathrm{a}$ & Pass & $\mathrm{n} / \mathrm{a}$ \\
\hline Rust, method A & {$[-]$} & ASTM D665 & $\mathrm{n} / \mathrm{a}$ & Pass & Pass & Pass \\
\hline $\begin{array}{l}\text { Rust, method B } \\
\text { Wear Properties }\end{array}$ & {$[-]$} & ASTM D665 & $\mathrm{n} / \mathrm{a}$ & Pass & Pass & $\mathrm{n} / \mathrm{a}$ \\
\hline FAG FE-8 Roller wear & {$[m g]$} & DIN 51819-3 & $\mathrm{n} / \mathrm{a}$ & 3 & Pass & $\mathrm{n} / \mathrm{a}$ \\
\hline Micropitting test & {$[-]$} & FVA $54 / 7$ & $\mathrm{n} / \mathrm{a}$ & $\mathrm{GF}>10$ & $\mathrm{n} / \mathrm{a}$ & $\mathrm{n} / \mathrm{a}$ \\
\hline FZG A20/8.3/100 & {$[-]$} & DIN 51354 & $\mathrm{n} / \mathrm{a}$ & $>12$ & $\mathrm{n} / \mathrm{a}$ & $>12$ \\
\hline
\end{tabular}

Table 4.2.: Physical properties of the wind turbine gear oils (measured).

\begin{tabular}{|c|c|c|c|c|c|}
\hline Parameter & Unit & MINE & MINR & PAGD & PAOR \\
\hline \multicolumn{6}{|l|}{ Chemical composition } \\
\hline Zinc $(\mathrm{Zn})$ & [ppm] & $<1$ & 0.9 & 1 & 3.5 \\
\hline Magnesium (Mg) & [ppm] & $<1$ & 0.9 & 1.4 & 0.5 \\
\hline Posphorus (P) & [ppm] & 460 & 354.3 & 1100 & 415.9 \\
\hline Calcium (Ca) & [ppm] & 2 & 2.5 & 0.8 & 0.5 \\
\hline Boron (B) & [ppm] & 36 & 22.3 & 1.0 & 28.4 \\
\hline Sulfur (S) & [ppm] & 6750 & 11200 & 362 & 5020 \\
\hline \multicolumn{6}{|l|}{ Physical properties } \\
\hline Density @ $15^{\circ} \mathrm{C}$ & {$\left[\mathrm{g} / \mathrm{cm}^{3}\right]$} & 0.893 & 0.902 & 1.059 & 0.859 \\
\hline Thermal expansion coefficient $\left(\alpha_{t}\right)$ & {$\left[\mathrm{K}^{-1}\right]$} & $-6.7 \times 10^{-4}$ & $-5.8 \times 10^{-4}$ & $-7.1 \times 10^{-4}$ & $-5.6 \times 10^{-4}$ \\
\hline Viscosity @ $40^{\circ} \mathrm{C}$ & {$[c S t]$} & 328.59 & 319.25 & 290.26 & 324.38 \\
\hline Viscosity @ $70^{\circ} \mathrm{C}$ & {$[c S t]$} & 92.72 & 65.87 & 102.33 & 87.92 \\
\hline Viscosity @ $100^{\circ} \mathrm{C}$ & {$[c S t]$} & 37.88 & 22.41 & 51.06 & 35.27 \\
\hline VI & {$[-]$} & 166 & 85 & 241 & 155 \\
\hline \multicolumn{6}{|l|}{ Vogel Constants } \\
\hline $\mathrm{k}$ & {$[-]$} & 0.2033 & 0.0815 & 1.5068 & 0.1875 \\
\hline $\mathrm{b}$ & {$[-]$} & 1072.492 & 1051.819 & 638.4922 & 1043.2304 \\
\hline c & {$[-]$} & 105.173 & 87.129 & 81.3362 & 100.5561 \\
\hline
\end{tabular}




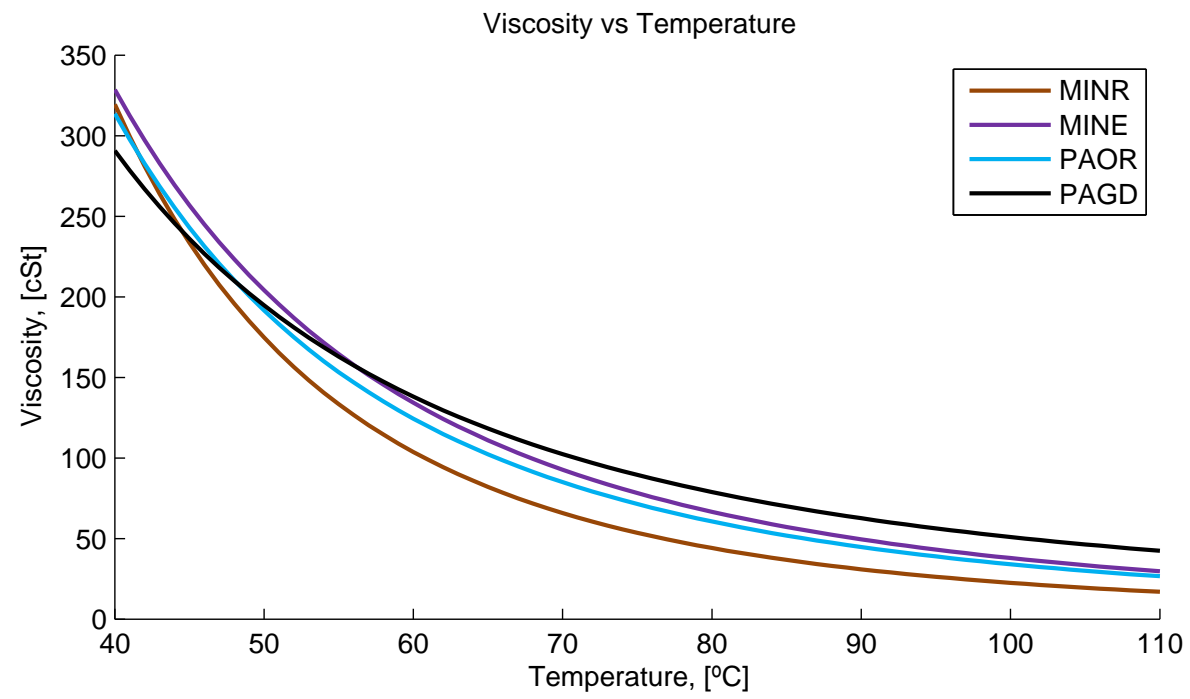

(a)

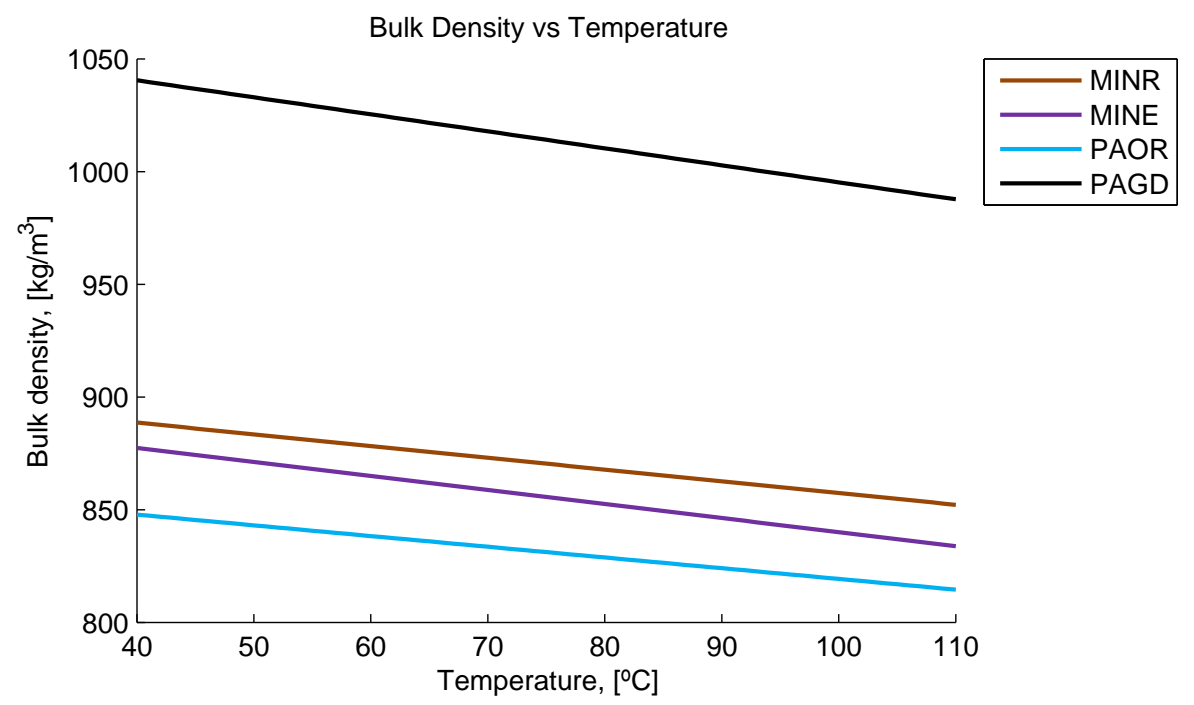

(b)

Figure 4.4.: Variation of the wind turbine gear oils properties with temperature: a) Viscosity; b) Bulk Density

Viscosity curves calculated according to ASTM D341 procedures; Bulk density curves derived from measurements performed in the range of 15 to $35^{\circ} \mathrm{C}$ 
The measurements performed on the rheometer showed that all of the gear oils have a Newtonian behaviour at the tested conditions.

It should be observed that the MINR oil shows the highest viscosity variation with temperature between all wind turbine gear oils. PAGD oil shows a viscosity $52.76 \mathrm{cSt}$ at $100^{\circ} \mathrm{C}$, which is quite high since it is more than twice the viscosity of the MINR oil at this temperature. MINE oil sits in between both and shows great improvements on its viscosity at higher temperatures, comparing with MINR. As for the density one should remark that PAGD is more dense than water at $40^{\circ} \mathrm{C}$. 


\section{Gearbox test rig and Transfer Gearbox}

\subsection{Test Bench Rig}

The gearbox test rig works on a back-to-back configuration with recirculating power. In order to have recirculating power there are two sets of gears at each end of the gearbox test rig inside the cases number 2 and 7 as shown on figure 5.1. These sets are lubricated in dry case by oil injection.

This gearbox test rig was designed to test different gearboxes, so it has positional adjustment capabilities. On figure 5.1, three platforms can be seen $(12,13,14)$. Platforms 12 and 14 allow for planar adjustment of the gearboxes, (testing and slave). The output torque sensor, (5) can have its height and depth adjusted using platform 13.

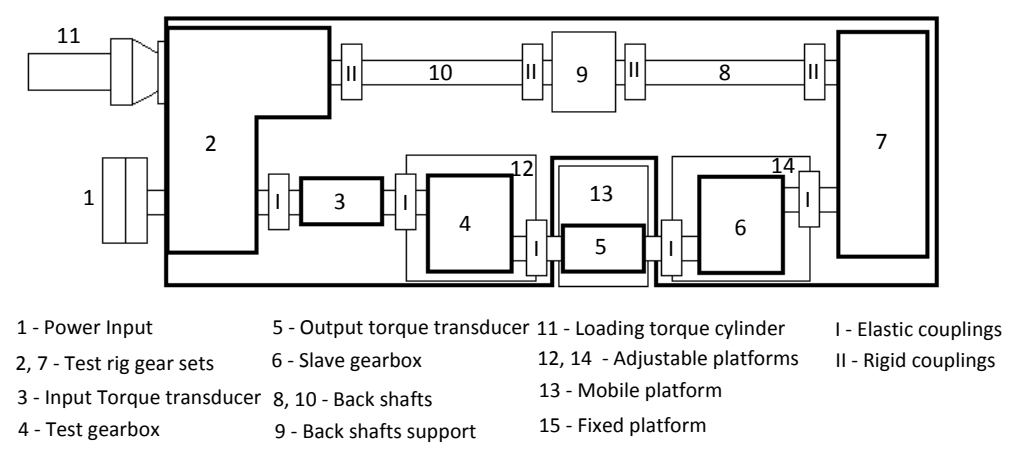

Figure 5.1.: Top view scheme of the gearbox test rig.

The torque loading mechanism consists of a hydraulic cylinder that introduces an axial displacement on one of the helical gears on the gear set 2 . This axial movement makes the wheel slightly rotate around its axis, creating then a torsional displacement thus loading the gearbox test rig with a static torque.

The back shafts aren't made of a single piece in order to avoid critical speeds.

The testing and slave gearboxes work on a back-to-back configuration so that the output speed on the slave gearbox will be the same as the input speed on the test 


\section{Gearbox test rig and Transfer Gearbox}

gearbox. Only reversible gearboxes can be tested.

The test rig allows the following settings at the input of the test gearbox:

- Input speed: 100 - 1900rpm [motor@250 - 4500rpm]

- Input torque: up to $1300 \mathrm{Nm}$

In order to have information on the operating conditions of the gearboxes several sensors are installed. On the test rig there are four temperature sensors, two speed sensors and two torque sensors that measure:

- Input and output torques on the test gearbox,

- Room Temperature,

- Oil temperature on the test gearbox,

- Wall temperature on the test and slave gearboxes,

- Input and output speeds on test gearbox.

The test rig is driven by an electrical motor with the characteristics listed on table 5.1 .

Table 5.1.: Gearbox test rig motor characteristics.

\begin{tabular}{rrr}
\hline Type PFMH-250M83 & & \\
\hline Nominal Speed & 1480 & $\mathrm{rpm}$ \\
Nominal Power & 55 & $\mathrm{~kW}$ \\
Frequency & 50 & $\mathrm{~Hz}$ \\
Cos F & 0.87 & - \\
Voltage & $220 / 330$ & $\mathrm{~V}$ \\
Current intensity & $181 / 104$ & $\mathrm{~A}$ \\
\hline
\end{tabular}

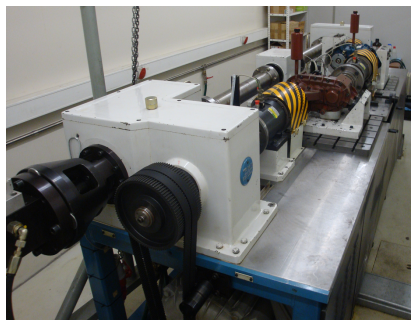

(a)

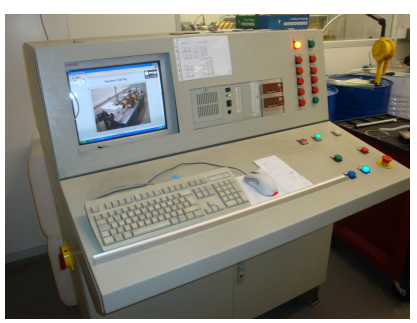

(b)

Figure 5.2.: Gearbox test rig and its control command: a) Gearbox test rig; b) Control station; 


\subsection{Transfer Gearbox}

The gearbox that is installed on the test rig is a transfer gearbox used at the end of a regular gearbox in order to allow the vehicle where it is installed to have four wheel drive. The transfer gearbox can also have a complementary exit that allows to connect it to auxiliary equipment, (figure 5.3).

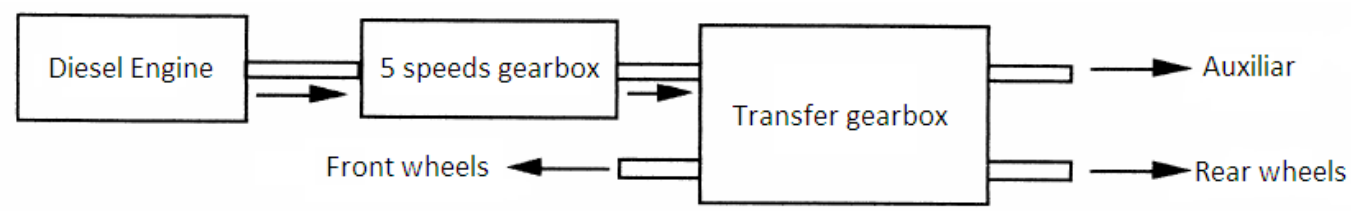

Figure 5.3.: Scheme of the transfer gearbox installed on a vehicle [21].

The vehicle where this transfer gearbox was used has a main gearbox of five speeds and just only one drive shaft. The Diesel engine used by this vehicle has a maximum torque of $252 \mathrm{Nm}$ at $2000 \mathrm{rpm}$, and a maximum power of $75 \mathrm{~kW}$ at $4310 \mathrm{rpm}$. The input speed and torque on the transfer gearbox are those that come out of the main gearbox.

This transfer gearbox works on the vehicle as a torque multiplier (speed reducer), but on the tests performed during this work it was used as a speed multiplier (torque reducer), since these conditions are closer to what is found on wind turbine gearboxes.

The transfer gearbox is shown in figures 5.4 and 5.6. The transfer gearbox has three shafts where five pinions are mounted. The pinions in the middle shaft (pinions two and three) are keyed while the the pinions of the first and third shafts are mounted over needle bearings. All of the shafts are supported by ball or roller bearings.

Table 5.2.: Geometrical parameters of the pinions in the transfer gearbox.

\begin{tabular}{|c|c|c|c|c|c|c|}
\hline \multirow[b]{2}{*}{ Parameter } & \multirow[b]{2}{*}{ Units } & \multicolumn{5}{|c|}{ Pinion Number } \\
\hline & & 1 & 2 & 4 & 3 & 5 \\
\hline Modulus $(m)$ & $m m$ & 3.5 & 3.5 & 3.5 & 4 & 4 \\
\hline Number of teeth $(z)$ & - & 32 & 23 & 27 & 28 & 17 \\
\hline Addendum moddification $(x)$ & - & 0.381 & 0.415 & 0.161 & -0.240 & 0.051 \\
\hline Face width $(b)$ & $m m$ & 35 & 35 & 35 & 33.5 & 35 \\
\hline Pressure angle $(\alpha)$ & $\circ$ & 20 & 20 & 20 & 20 & 20 \\
\hline Helix angle $(\beta)$ & $\circ$ & 20 & 20 & 20 & 20 & 20 \\
\hline Gear ratio $\left(\mathrm{i}=z_{2} / z_{1}\right)$ & - & \multicolumn{2}{|c|}{0.7188} & & \multicolumn{2}{|c|}{0.6071} \\
\hline
\end{tabular}

This transfer gearbox has two speeds both torque multipliers (when installed on the vehicle that this is installed on), doubling the kinematic possibilities of the main gearbox, allowing for 10 kinematic relations. 
5. Gearbox test rig and Transfer Gearbox

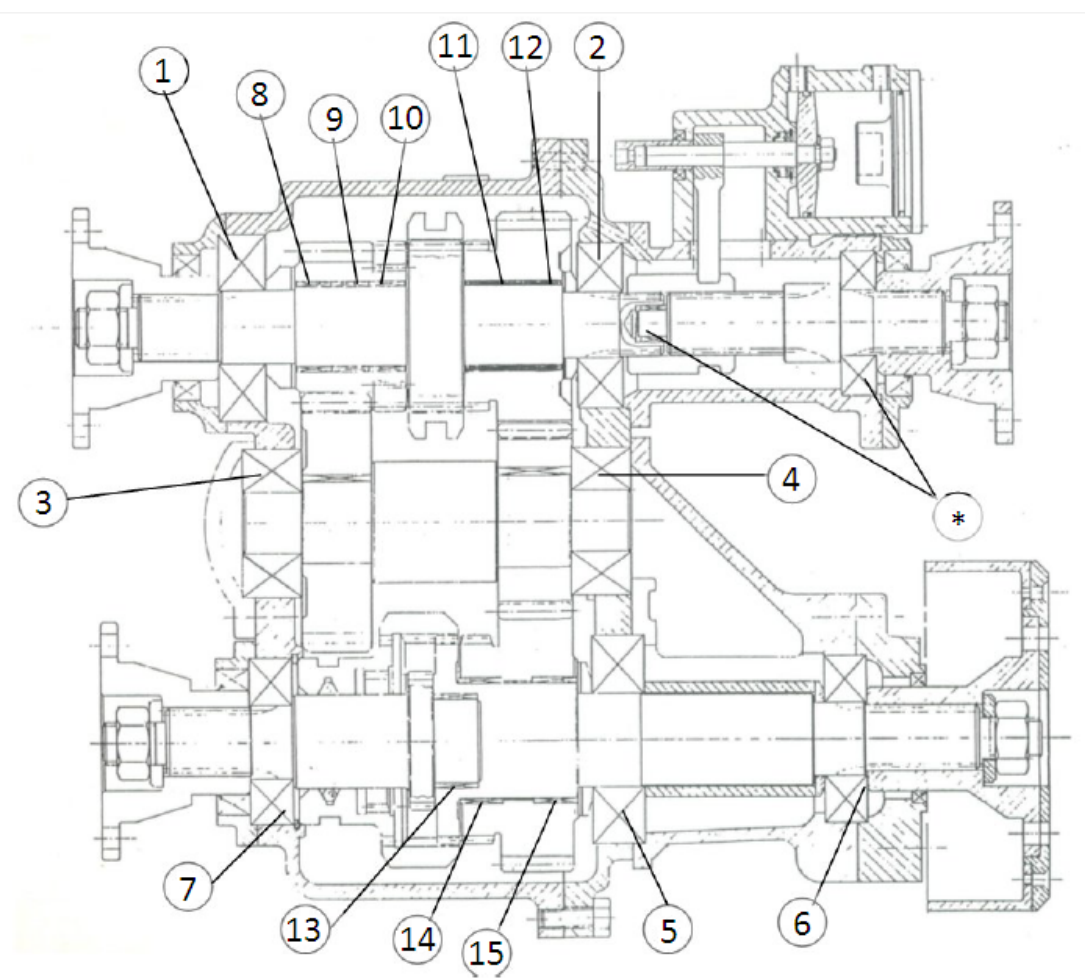

Figure 5.4.: Rolling bearings numbering on the transfer gearbox [21].

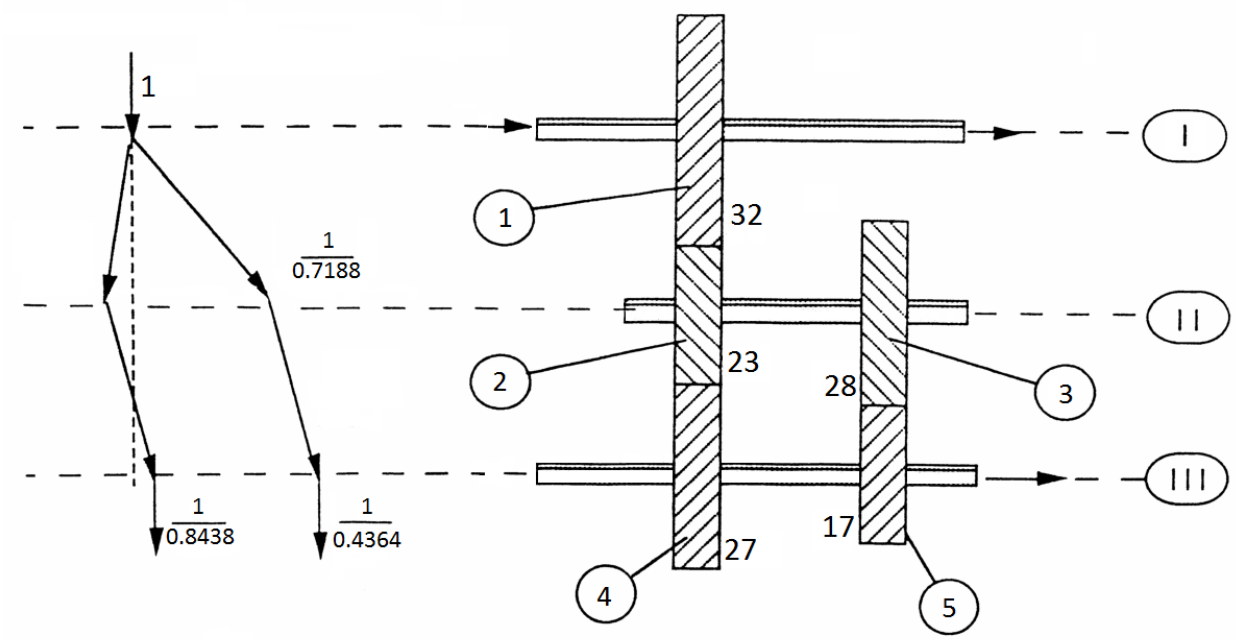

Figure 5.5.: Gearbox speed diagram. 
Table 5.3.: Mechanical properties of DIN 15NiCr6 steel (gears steel), [22].

1 - Hot rolled supplied (maximum); 2 - Core strength in hardened condition (63 mm core diameter); 3 - Core strength in hardened condition (11 mm core diameter); 4 - $30 \mathrm{~mm}$ from the quenched end; 5 - $10 \mathrm{~mm}$ from the quenched end; 6 - Tempering temperature of $300{ }^{\circ} \mathrm{C} ; 7$ - Tempering temperature of $100{ }^{\circ} \mathrm{C}$;

\begin{tabular}{lccr}
\hline Mechanical Properties & Symbol & Units & Value \\
\hline Hardness, Brinell & HBr & Brinell & $217^{1}$ \\
& & & $200-350^{2}$ \\
& & & $300-405^{3}$ \\
Hardness, Rockwell C & HRC & Rockwell C & $\leq 25^{4}$ \\
& & & $21-35^{5}$ \\
& & & $55^{6}$ \\
& & & $64^{7}$ \\
Tensile Strength, Ultimate & $R_{m}$ & $\mathrm{MPa}$ & $690-980^{2}$ \\
& & & $980-1320^{3}$ \\
Tensile Strength, Yield & $R_{e}$ & $\mathrm{MPa}$ & $\geq 440^{2}$ \\
& & & $\geq 640^{3}$ \\
Elongation at break & & & $\geq 1 \%^{2}$ \\
& & & $\geq 8 \%^{3}$ \\
\hline
\end{tabular}

Table 5.4.: Chemical composition of DIN 15NiCr6 steel.

\begin{tabular}{cccccc}
\hline $\begin{array}{c}\text { Carbon } \\
\mathrm{C}\end{array}$ & $\begin{array}{c}\text { Chromium } \\
\mathrm{Cr}\end{array}$ & $\begin{array}{c}\text { cManganese } \\
\mathrm{Mn}\end{array}$ & $\begin{array}{c}\text { Molybdenum } \\
\mathrm{Mo}\end{array}$ & $\begin{array}{c}\text { Nickel } \\
\mathrm{Ni}\end{array}$ & $\begin{array}{c}\text { Silicon } \\
\text { Si }\end{array}$ \\
\hline $0.15 \%$ & $0.8 \%$ & $0.9 \%$ & $1.2 \%$ & $0.1 \%$ & $0.25 \%$ \\
\hline
\end{tabular}




\section{Gearbox test rig and Transfer Gearbox}

The selection of the speed range on the transfer gearbox is made possible by the use of a simple mechanism of toothed ring and fork, figure 5.6. This simple constructive arrangement allows both of the pinions 4 and 5 to be permanently rotating even when the gearbox is engaged on the other position, causing additional churning loss.

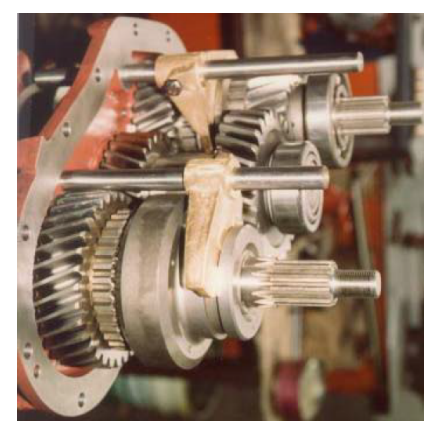

Figure 5.6.: Gearing mechanism of toothed ring and fork, [21].

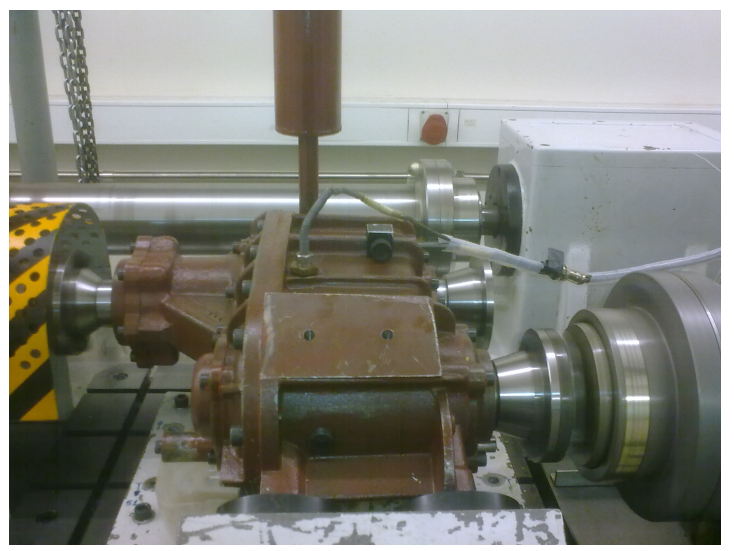

Figure 5.7.: Transfer gearbox installed on the test rig.

On table 5.5 the rolling bearings used on the transfer gearbox on its full configuration are listed.

Table 5.5.: Rolling Bearing types on the transfer gearbox and its characteristics.

\begin{tabular}{cccccccc}
\hline Number & Type & Reference & $C[N]$ & $C 0[N]$ & $d[\mathrm{~mm}]$ & $D[\mathrm{~mm}]$ & $n_{\text {max }}[\mathrm{rpm}]$ \\
\hline 1 & Ball & RMS 11 & 31500 & 22000 & 35 & 89 & 9000 \\
2 & Ball & RMS 10 & 23500 & 16100 & 32 & 79 & 10500 \\
3,4 & Tapper Roller & 32306 & 67000 & 53000 & 30 & 72 & 6500 \\
5 & Cylindrical Roller & NJ 309E & 91500 & 62000 & 45 & 100 & 6700 \\
6,7 & Ball & 6307 & 26000 & 18300 & 35 & 80 & 9000 \\
8 to 12 & Needle & K38 $\times 43 \times 27 \mathrm{~F}$ & 30500 & 68000 & 38 & 43 & 11000 \\
13 to 15 & Needle & K14 $\times 18 \times 13$ & 9150 & 12500 & 14 & 18 & 26000 \\
\hline
\end{tabular}




\section{Thermal balance}

When the thermal balance is reached heat evacuated by conduction, convection and radiation through the gearbox housing, shafts and support feet equals the power loss generated inside it.

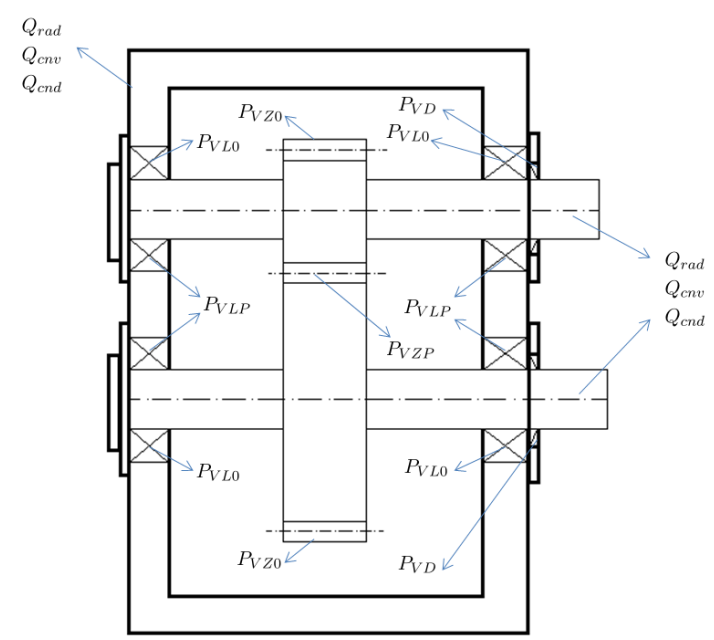

Figure 6.1.: Different mechanisms of power dissipation and heat evacuation on a generic gearbox.

Then it can be said that:

$$
Q_{c a}=P_{V}
$$

where:

- $Q_{c a}$ is the evacuated heat,

- $P_{V}$ is the total power loss.

On the following lines the dissipated heat, $Q_{c a}$ will be broke down on the different contributions and on the following section a model for the total power loss will be presented. 


\subsection{Heat dissipation}

The total heat dissipation can be defined as

$$
Q_{c a}=Q_{r a d}+Q_{c n v}+Q_{c n d}
$$

where

- $Q_{\text {rad }}$ is the heat evacuated by radiation,

- $Q_{c n v}$ is the heat evacuated by convection,

- $Q_{c n d}$ is the heat evacuated by conduction.

Part of the heat is evacuated by convection and radiation on the gearbox housing. A minor portion of the heat is evacuated by radiation and convection through the rotating shafts, also some of the heat is evacuated by conduction to the foundations. When an adequate oil volume is present in the gearbox it can stated that the oil sump temperature is uniform thus allowing for an even temperature distribution on the gearbox housing. For gearboxes with low oil volume the heat dissipated by the mechanical elements cannot be evenly distributed, thus allowing the possibility for hot spots on the gearbox housing.

According to reference [15] on stationary gearboxes the heat transmission through the walls of the housing, which consists of internal heat transfer, conduction through the wall and external heat transfer, can be fairly approximated by only the external heat transfer as the governing portion. Only for external forced convection with high air velocities the internal heat transfer has to be taken into account.

\subsubsection{Radiation}

The heat flow by radiation from the surface of the gearbox housing can be calculated from:

$$
Q_{\text {rad }}=\alpha_{\text {rad }} \cdot A_{\text {rad }} \cdot\left(T_{\text {wall }}-T_{a m b}\right)
$$

and

$$
\alpha_{\text {rad }}=0.23 \times 10^{-6} \cdot \epsilon \cdot\left(\frac{T_{\text {wall }}-T_{a m b}}{2}\right)^{3}
$$

where

- $\alpha_{r a d}$ is radiation heat transfer coefficient,

- $A_{\text {rad }}$ is the radiant area, 
- $T_{\text {wall }}$ is the gearbox housing wall temperature,

- $T_{\text {room }}$ is the room ambient temperature,

- $\epsilon$ is the surface emissivity.

\subsubsection{Convection}

Previous investigations [15] showed that due to the movement of the shafts, cooling air from the driving motor etc, real free convection is never verified on practical applications.

The free convection coefficient suggested on [15] is the empirical equation

$$
\alpha_{c n v, \text { free }}=18 \cdot h_{c a}^{-0.1} \cdot\left(\frac{T_{w a l l}-T_{a m b}}{T_{a m b}}\right)^{0.3}
$$

Even for low air speeds there is a substantial increase on the convection heat transfer coefficient.

The heat transfer coefficient for forced convection is then given by

$$
\alpha_{\text {cnv }, \text { forced }}=8.6 \cdot I_{x}^{-0.34} \cdot V_{\text {air }}^{0} .64
$$

When only part of the housing is subjected to an air flow, the combined convective transfer coefficient can be determined from

$$
\alpha_{c n v, \text { combined }}=\alpha_{c n v, \text { free }} \cdot\left(1-\frac{A_{a i r}}{A_{c a}}\right)+\alpha_{c n v, \text { forced }} \cdot \frac{A_{a i r}}{A_{c a}}
$$

\subsubsection{Total heat dissipation}

The total heat transfer coefficient is then the sum of various heat transfer coefficients.

$$
\alpha=\alpha_{\text {cnv,combined }}+\alpha_{\text {rad }}
$$

In order to take into account the heat dissipation due to conduction an increase on convective and radiant areas should be considered. Some authors suggest $1.5-2.5$ times the respective areas.

The total heat dissipation from the housing surface can be calculated from

$$
Q_{c a}=Q_{c n v}+Q_{r a d}=\alpha \cdot A_{c a} \cdot\left(T_{o i l}-T_{a m b}\right)
$$




\subsection{Power Loss Model}

According to Höhn et al. [14], power loss in a gearbox consists of gear, bearing, seal and auxiliary losses. Gear and rolling bearing losses can be separated in: "noload" losses which occur even without power transmission; and "load" dependent losses that occur in the contact of the power transmitting components. Besides operating conditions and internal housing design no-load losses are mainly related to lubricant viscosity and density as well as immersion depth of the components on a sump lubricated gearbox. Load losses depended on the transmitted torque, coefficient of friction and sliding velocity in the contact areas of the components. For nominal power transmission the load losses of the gear mesh are typically dominant. No-load rolling bearing losses depend on the bearing type and size, rolling bearing arrangement, lubricant viscosity and immersion depth. Load dependent bearing losses depend also on bearing type and size, rolling and sliding conditions in the bearing and on lubricant type.

The model implemented takes into account gears, rolling bearings and seals losses. So, it can stated that the power loss in the test gearbox will be

$$
P_{V}=\sum P_{V Z 0}+\sum P_{V Z P}+\sum P_{V L 0}+\sum P_{V L P}+\sum P_{V D}
$$

where the $Z, L$ and $D$ indexes refer respectively to gears, rolling bearings and seals. The 0 and $P$ indexes refer to no-load and load losses respectively.

\subsubsection{Gear Loss}

\section{Gear Churning Loss}

For splash-lubricated gears, oil churning is usually considered as a major source of power loss which is strongly related to the fluid circulations generated by rotating gears partly immersed in a lubricant.

The model for gear churning loss present by Michaelis et al. [15] seems to be an attractive option. Despite this model being of simple implementation it is not applicable in the present situation. It cannot be used for predicting the churning loss on the transfer gearbox since it considers the losses generated by a gear pair, thus considering the double of churning losses caused solely by the pinion 2 as shown on the gearbox speed map, figure 5.5.

The model implemented for the individual churning gear loss follows what was suggested by Changenet et al. $[3,16]$ since it is considered and proved to be the most 
robust model [16].

On this churning power loss model the loss torque is of the form:

$$
C_{c h}=\frac{1}{2} \cdot \rho_{\text {oil }} \cdot \omega^{2} \cdot R_{p}^{3} \cdot S_{m} \cdot C_{m}
$$

where $C_{m}$ is the drag dimensionless group, $S_{m}$ the immersed surface of the pinion/wheel, (flanc and teeth), $R_{p}$ the pinion reference radius, $\omega$ the angular frequency and $\rho$ the bulk density of the lubricant at the working temperature.

The dimensionless drag group was derived by dimensional analysis using the VashyBuckingham theorem. Then the dimensionless drag group is expressed as:

$$
C_{m}=\psi_{1} \cdot\left(\frac{h}{D_{p}}\right)^{\psi_{2}} \cdot\left(\frac{V_{0}}{D_{p}^{3}}\right)^{\psi_{3}} F r^{\psi_{4}} \cdot R e_{c}^{\psi_{5}} \cdot\left(\frac{b}{R_{p}}\right)^{\psi_{6}}
$$

where $\psi_{i}$ coefficients are derived from experimental results. The $\psi_{i}$ numerical values depend on the working conditions, and four sets of coefficients (depending on the nature of the flow regimes), are used depending on the value of the following parameter:

$$
\gamma=\omega^{2} \cdot\left(R_{p} \cdot b \cdot m\right)^{\frac{1}{3}}
$$

This parameter resembles to a centrifugal acceleration.

The Froude $(F r)$ and critical Reynolds $\left(R e_{c}\right)$ numbers are defined as:

$$
\begin{gathered}
F r=\frac{R_{p} \cdot \omega^{2}}{g} \\
R e_{c}=\frac{R_{p} \cdot b \cdot \omega}{\nu}
\end{gathered}
$$

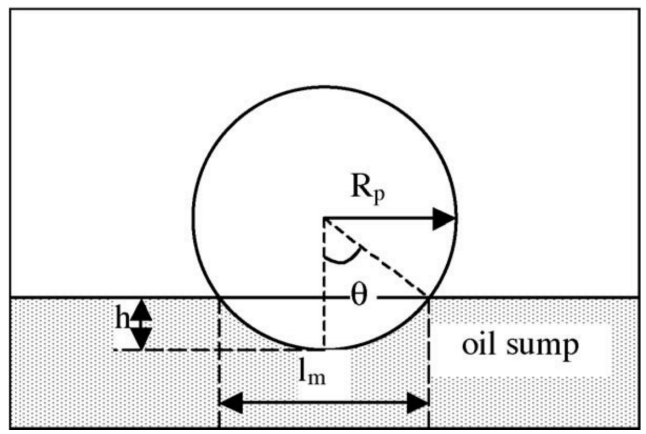

Figure 6.2.: Geometrical data of the gear immersed surface [4].

The $C_{m}$ parameter to be used for each one of the flow conditions depends not only on the parameter defined by equation 6.13 but also on the critical Reynolds number 
defined on equation 6.15 , as stated on the following expressions:

a) if $\gamma<750 \mathrm{~m} / \mathrm{s}^{2}$ and $R e_{c}<4000$

$$
C_{m}=1.366 \cdot\left(\frac{h}{D_{p}}\right)^{0.45} \cdot\left(\frac{V_{0}}{D_{p}^{3}}\right)^{0.1} \cdot F r^{-0.6} \cdot R e_{c}^{-0.21} \cdot\left(\frac{b}{R_{p}}\right)^{0.21}
$$

b) if $\gamma<750 m / s^{2}$ and $R e_{c}>4000$

$$
C_{m}=0.239 \cdot\left(\frac{h}{D_{p}}\right)^{0.45} \cdot\left(\frac{V_{0}}{D_{p}^{3}}\right)^{0.1} \cdot F r^{-0.6} \cdot\left(\frac{b}{R_{p}}\right)^{0.21}
$$

c) if $\gamma>1250 \mathrm{~m} / \mathrm{s}^{2}$ and $R e_{c}<4000$

$$
C_{m}=20.797 \cdot\left(\frac{h}{D_{p}}\right)^{0.1} \cdot\left(\frac{V_{0}}{D_{p}^{3}}\right)^{-0.35} \cdot F r^{-0.88} \cdot R e_{c}^{-0.21} \cdot\left(\frac{b}{D_{p}}\right)^{0.85}
$$

d) if $\gamma>1250 m / s^{2}$ and $R e_{c}>4000$

$$
C_{m}=3.644 \cdot\left(\frac{h}{D_{p}}\right)^{0.85} \cdot\left(\frac{V_{0}}{D_{p}^{3}}\right)^{-0.35} \cdot F r^{-0.88} \cdot\left(\frac{b}{D_{p}}\right)^{0.85}
$$

It should be noted that an interpolation between the equations should be performed when $750 m / s^{2}<\gamma<1250 m / s^{2}$.

This model is usually applied to spur gears, but it can be extended to helical gears as it was demonstrated by Gauthier Leprince $[16,3]$. The only thing that needs to be changed on this model is the geometrical parameter that accounts for the immersed surface of the pinion $S_{m}$. This parameter is now defined as it follows:

$$
S_{m}=R_{p}^{2} \cdot(2 \cdot \theta-\sin 2 \cdot \theta)+D_{p b} \cdot \theta+2 \cdot \frac{z \cdot \theta \cdot H_{\text {tooth }} \cdot b}{\pi \cdot \cos \alpha \cdot \cos \beta}
$$

The $\theta$ angle in expression 6.20 is determinated according to figure 6.2. Finally to obtain the churning power loss on a single pinion one only needs to multiply the churning loss torque, $\left(C_{c h}\right)$ by the angular speed, $(\omega)$, resulting on:

$$
P_{V Z 0}=C_{c h} \cdot \omega
$$

Changenet et al. [3] have pointed out that these equations give a good correlation between experimental and numerical results. Since these equations do not take into account the aeration of the lubricant on the oil sump during operation, some deviations between the experimental and numerical results at higher speeds and/or temperatures above $55^{\circ} \mathrm{C}$ are expected for certain lubricants, [16, 17]. 


\section{Lubricant aeration}

The presence of air in a lubricant manifests itself by the production of a significant number of very fine spherical air bubbles. This phenomena is called aeration and it was found that the amount of bubbles in the lubricant is closely related with the churning power loss. This model was implemented but it is extremely sensitive to some of the oil chemical constants that that are unkown for the tested lubricants.

\section{Influence of the rotation sense}

The total churning power loss on the gearbox, $\left(\sum P_{V Z 0}\right)$, are calculated as the sum of the individual losses on each pinion/wheel. This method was demonstrated to give good results for pinion/wheel pairs working at clockwise rotation, figure 6.3. When working at a counter-clockwise rotation additional loss mechanisms appear making inappropriate to estimate the churning power loss as the sum of the individual losses on each pinion and wheel [4].
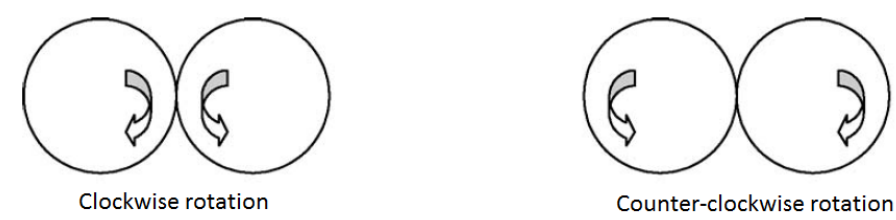

Figure 6.3.: Definition of the senses of rotation of a gear pair [4].

From a physical point of view, Changenet et al. [4], pointed out that this difference is probably due to the trapping of lubricant by meshing teeth and by a swell effect, see figure 6.4, which dissipates energy and increases the immersion depth of the pinion.

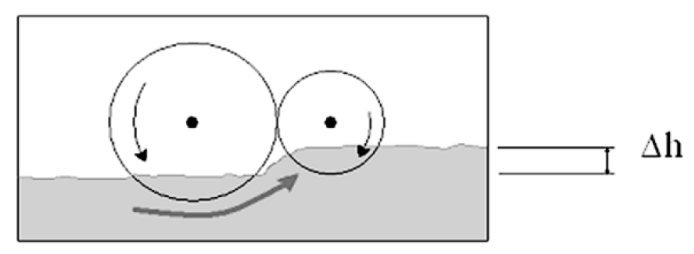

Figure 6.4.: Schematic representation of the swell effect [4].

This variation in the churning loss is expressed in terms of a dimensionless variation of the churning torque $\Delta C_{m}$ and $\Delta P$ is sought under the form

$$
\Delta P_{V Z 0}=\frac{1}{2} \cdot \rho \cdot \omega^{3} \cdot R_{p}^{3} \cdot S_{m} \cdot \Delta C_{m}
$$

in which all the geometrical data are those of the gear. 
From the experimental results, Changenet et al. [4] drawn the following conclusions:

- For isothermal conditions the viscosity of the lubricant has a weak influence on $\Delta P$ and the Reynolds number is discarded in the formulation.

- $\Delta P$ is sensitive to angular frequency thus making it proportional to $\mathrm{Fr}^{\psi 7}$

- For identical pinions and gears, no swell effect can be generated due to symmetry. In these conditions $\Delta P$ is found to be close to zero, thus demonstrating that the air-lubricant trapping by the teeth is negligible and consequently proving that the swell effect is prominent.

After these conclusions $\Delta C_{m}$ was derived as:

$$
\Delta C_{m}=17.7 \cdot F r^{-0.68} \cdot \frac{u-1}{u^{8}} \cdot\left[1-\left(\frac{h}{R_{p}}\right)_{\text {gear }}\right]
$$

\section{Gear mesh power Loss}

The coefficient of friction between the teeth of a gear pair has a crucial importance on the gear mesh analysis since it is directly influential on the contact temperature, power loss and failure probability.

The definition of the coefficient of friction is extremely complex in the case of gears since all of the lubrication regimes can coexist along the meshing line.

Function of the specific lubricant film thickness, $\Lambda$, three lubrication regimes can be defined:

- Boundary film: $\Lambda<0.7$

The Normal force to the contact, $\left(F_{N}\right)$, is fully supported by the metal - metal contact between surfaces rugosities peaks. Non existent hydrodynamic film.

- Mixed film: $0.7<\Lambda<2.0$

The Normal force to the contact is both supported by the metal - metal contact between surfaces rugosities peaks and the EHD lubricant film.

- Full film: $\Lambda>2.0$

The Normal force to the contact is fully supported by the $E H D$ lubricant film.

On figure 6.5 a visual representation of the three lubrication conditions is presented.

The specific film thickness varies along the meshing line, so all of the lubrication conditions can happen along the meshing line, as it is shown on figure 6.6. 


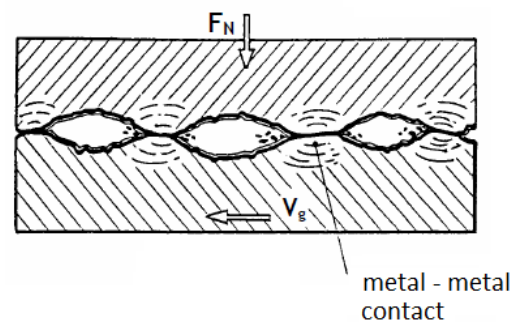

(a) Boundary film

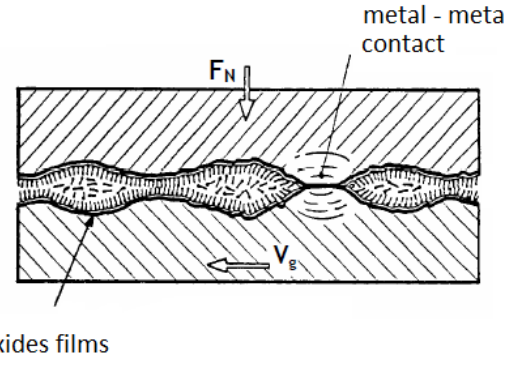

(b) Mixed film

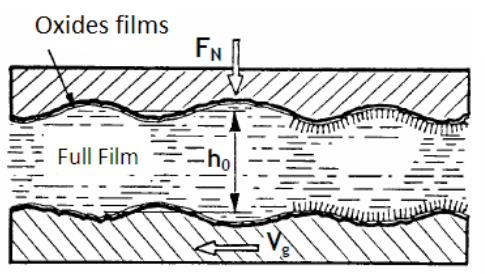

(c) Full film

Figure 6.5.: Lubrication conditions, [24].

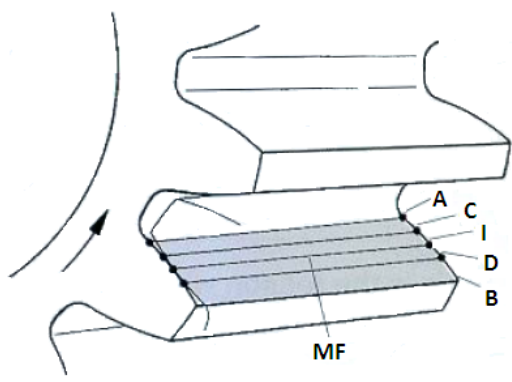

MF: Mixed Film lubrication

FF: Full Film lubrication

(a) Low peripheral speed

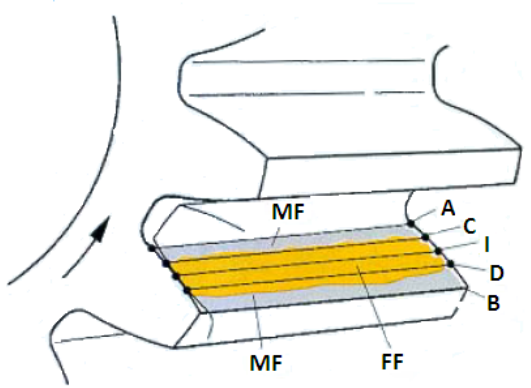

(b) High peripheral speed

Figure 6.6.: Lubrication conditions along the gear mesh, [18]. 
6. Thermal balance

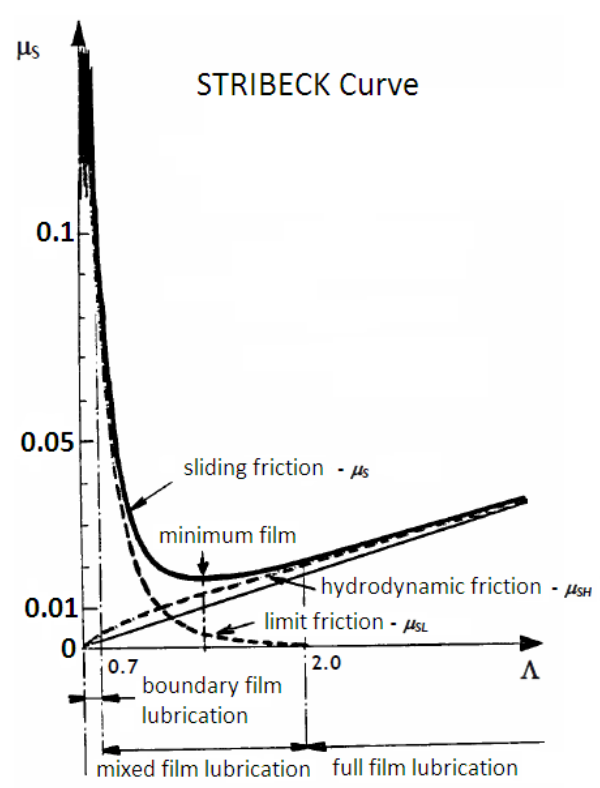

Figure 6.7.: Stribeck curve [24].

As can be seen on figure 6.7 there is a close relation between the coefficient of friction and the specific film thickness.

It is common practice to use empirical formulations based upon experimental results obtained on twin disk machines, or on experimental power loss testing with gears. Such empirical formulations are valid for all of the lubrication regimes since they consider factors that take into account the tooth flank roughness.

Amplitude and orientation of the surface roughness have a crucial influence on the coefficient of friction, making it more severe if the asperities have a transversal orientation than if they have longitudinal or oblique, (considering the same working conditions).

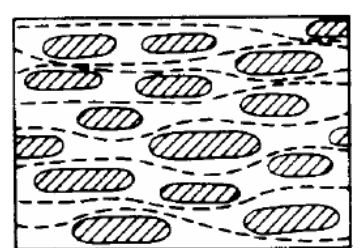

(a) Longitudinal

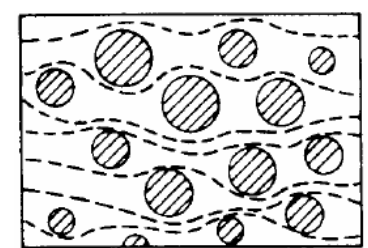

(b) Isotropic

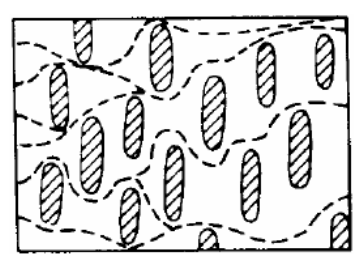

(c) Transverse

Figure 6.8.: Types and surface roughness. 
It can be shown that the mesh power loss only depends on the transmitted power, the average coefficient of friction in the gear contact and a gear loss factor $H_{v}$, which can be determined only from gear geometry. The problem is then reduced to the determination of the average value of the coefficient of friction. The load dependent gear power loss $P_{V Z P}$ is then

$$
P_{V Z P}=P_{i n} \cdot \mu_{m z} \cdot H_{v}
$$

with the gear loss factor for cylindrical gear pairs:

$$
H_{v}=\frac{\pi \cdot(u+1)}{z_{1} \cdot u \cdot \cos \beta_{b}}\left(1-\varepsilon_{\alpha}+\varepsilon_{1}^{2}+\varepsilon_{2}^{2}\right)
$$

From the investigations in twin disk machines and gear test rigs an empirical equation for the average coefficient of friction between gear teeth was derived [15]:

$$
\mu_{m z}=0.048 \cdot\left(\frac{F_{b t} / l_{m i n}}{v_{\sum C} \cdot \rho_{C}}\right)^{0.2} \cdot \eta_{o i l}^{-0.05} \cdot R_{a}^{0.25} \cdot X_{L}
$$

where $X_{L}$ is the lubricant correction factor $\left(X_{L}=1\right.$ for non-additivated mineral oils). It should be mentioned that $l_{\text {min }}$ on equation 6.26 was calculated according to the numerical approach suggested by M. Maatar and P. Velex on [19]. To mention that the sum velocity at pitch point, $v_{\sum C}$, and the equivalent curvature radius at pitch point, $\rho_{C}$, are calculated by the standard equations that do not take into account the effect of the helix angle, [23].

The generalised lubricant parameter $X_{L}$ is defined on equation 6.27.

$$
X_{L}=\frac{a}{\left(v a r_{1}\right)^{b_{1}} \ldots\left(v a r_{n}\right)^{b n}}
$$

\subsubsection{Seals power Loss}

In most cases the seals power loss are very small compared to the transmitted power and are thus negligible compared to other losses in a gear drive, [15], this is valid on the present case since the tests were performed at low tangential speeds. Nevertheless an equation, (equation 6.28), for the prediction of the no-load power loss due to seals is presented.

$$
P_{V D}=7.69 \times 10^{-6} \cdot d_{s h}^{2} \cdot n
$$




\subsubsection{Rolling bearing power loss}

The power loss model that was implemented took into account the rolling bearing power loss, as it was stated in the beginning of this chapter. It was chosen to implement the New SKF model for the calculation of the frictional moment, [1], since it is believed that this model derives more realistic results. On the following lines a brief explanation of the method will be presented, including the most relevant equations.

\section{New SKF model for the calculation of the frictional moment}

To accurately calculate the frictional moment in a rolling bearing, four different torque loss sources must be taken into account

$$
M=M_{r r}+M_{s l}+M_{\text {seal }}+M_{\text {drag }}
$$

where:

- $M$ is the total frictional moment, $N m m$,

- $M_{r r}$ is the rolling frictional moment, $N m m$,

- $M_{s l}$ is the sliding frictional moment, $\mathrm{Nmm}$,

- $M_{\text {seal }}$ is the frictional moment of the seal(s), Nmm,

- $M_{\text {drag }}$ is the frictional moment of drag losses, churning, splashing etc, $\mathrm{Nmm}$.

The total bearing power loss is then

$$
P_{V L}=M \cdot n \cdot \frac{\pi}{30} \times 10^{-} 3
$$

On each one of the following subsections each one of the individual components stated above will be more closely defined.

\section{Rolling frictional moment}

The rolling frictional moment is calculated from the equation

$$
M_{r r}=G_{r r} \cdot(\nu \cdot n)^{0.6}
$$


where:

- $G_{r r}$ is a variable that depends on the loading conditions, bearing type and mean diameter,

- $\nu$ is the kinematic viscosity of the lubricant, $c S t$,

- $n$ is the angular speed, rpm.

In order to more closely follow the real behaviour of the rolling bearing, additional effects should be considered. Between these effects the considered ones are:

- inlet shear heating reduction,

- replenishment/starvation speed effects for oil-spot, oil jet, grease and low level oil bath lubrication,

- mixed lubrication for low speeds and/or low viscosities.

In order to account for these effects the rolling frictional moment should be multiplied by two correction factors, the inlet shear heating reduction factor, and the kinematic replenishment/starvation reduction factor.

When sufficient lubricant is available in the rolling bearing, not all of it can go through the contacts since only a tiny amount of lubricant is used to build up the film thickness. The excess lubricant will form a separated reverse flow bubble that by shearing effects will produce heat and by consequence will lower the viscosity of the lubricant entering the contact. For the effect described above, the inlet shear heating reduction factor can be obtained approximately from

$$
\phi_{i s h}=\frac{1}{1+1.84 \times 10^{-9}\left(n \cdot d_{m}\right)^{1.28} \cdot \nu^{0.64}}
$$

\section{Sliding frictional moment}

The sliding frictional moment is calculated using

$$
M_{s l}=G_{s l} \cdot \mu_{s l}
$$

where:

- $G_{s l}$ is a variable that depends on the loading conditions, rolling bearing type and mean diameter 
- $\mu_{s l}$ is the sliding coefficient of friction.

Due to the rolling bearing speed or high viscosity, the lubricant at the edges of the contacts might not have enough time to replenish the raceways, this effect is called 'kinetic starvation' and causes a drop in the film thickness and in the rolling frictional moment. For the conditions described above the kinematic replenishment/starvation reduction factor can be obtained approximately from

$$
\phi_{r s}=\frac{1}{e^{k_{r s} \cdot \nu \cdot n \cdot(d+D) \cdot \sqrt{\frac{k_{z}}{2 \cdot(D-d)}}}}
$$

where:

- $K_{r s}$ is the replenishment/starvation constant,

- $K_{Z}$ is a rolling bearing type related geometry constant.

The sliding friction coefficient $\mu_{s l}$ can be calculated using the following equation

$$
\mu_{s l}=\phi_{b l} \cdot \mu_{b l}+\left(1-\phi_{b l}\right) \cdot \mu_{E H L}
$$

where:

$\phi_{b l}$ is the weighting factor for the sliding coefficient of friction and can be calculated using the following equation

$$
\phi_{b l}=\frac{1}{e^{2.6 \times 10^{-8} \cdot(n \cdot \nu)^{1 \cdot 4} \cdot d_{m}}}
$$

- $\mu_{E H L}$ is the coefficient of friction in full film conditions, which depends on the oil type.

- $\mu_{b l}$ is the coefficient of friction in boundary lubrication regime, being implemented by the oil additives.

These last two coefficients have values recommended by $S K F$ depending on the oil type and additive package, but values obtained experimentally, [2], for each one of the tested lubricants will be used.

\section{Drag losses in oil bath lubrication}

In oil bath lubrication, the rolling bearing is partially, or in special situations, completely submerged. Under these conditions the size and geometry of the oil reservoir 
together with the oil level used can have a substantial impact on the bearing friction moment. Depending on the rolling bearing type, $S K F$ suggests the following equations for the rolling bearing drag losses.

For ball bearings:

$$
M_{\text {drag }}=V_{M} \cdot K_{\text {ball }} \cdot d_{m}^{5} \cdot n^{2}
$$

and for roller bearings

$$
M_{\text {drag }}=10 \cdot V_{M} \cdot K_{\text {roll }} \cdot B \cdot d_{m}^{4} \cdot n^{2}
$$

where:

- $V_{M}$ is a variable as a function of the oil level,

- $K_{\text {ball }}$ and $K_{\text {roll }}$ as ball and roller bearings related constants.

It was already mentioned that the gearbox has a total of 17 rolling bearings on its full configuration. To perform the calculation to estimate the power loss on the rolling bearings only six of them were considered since the remaining rolling bearings did not have relative movement or were not installed on this configuration. Only one rolling bearing that generated torque loss was not considered since it is a needle bearing that only introduces no-load power loss, and rotates at a low speed making, its losses negligible. 



\section{Experimental procedures and results}

This chapter is dedicated to explain the experimental procedures and present the experimental results obtained. After the introduction of the experimental procedures the basics of ferrography are presented, then followed by the wear evaluation through lubricant analysis results. Afterwards, the stabilization temperatures and torque loss measurements are presented and discussed, and the global heat transfer coefficient is determined.

\subsection{Experimental procedures}

Four fully formulated wind turbine gear oils were tested at different working conditions. A square matrix with a dimension of $3 \times 3$ testing points was chosen.

Initially the following matrix of testing points was considered:

Table 7.1.: Planned experimental test points.

$$
\left[\begin{array}{ccc}
100 / 500 & 200 / 500 & 400 / 500 \\
100 / 750 & 200 / 750 & 400 / 750 \\
100 / 1000 & 200 / 1000 & 400 / 1000
\end{array}\right]
$$

The testing points on table 7.1 are expressed on the form $\left[n_{I N}[\mathrm{rpm}] / T Q_{I N}[N m]\right]$, where $n_{I N}$ is the input speed in rpm and $T Q_{I N}$ is the input torque expressed in $N m$.

On figure 7.1 a graphic representing the range of variation of the input power on the gearbox with both input speed and input torque is presented.

The tests were performed starting at the lower speed and torque. For each speed, (starting at the lower speed) the three values of torque were tested, (starting at the lower torque), table 7.2.

For each test point the gearbox test rig was operated for about four hours in order to get stabilized conditions. After this warm-up period the slave gearbox was set to the neutral position and the test rig was calibrated. After this adjustment, the 
7. Experimental procedures and results

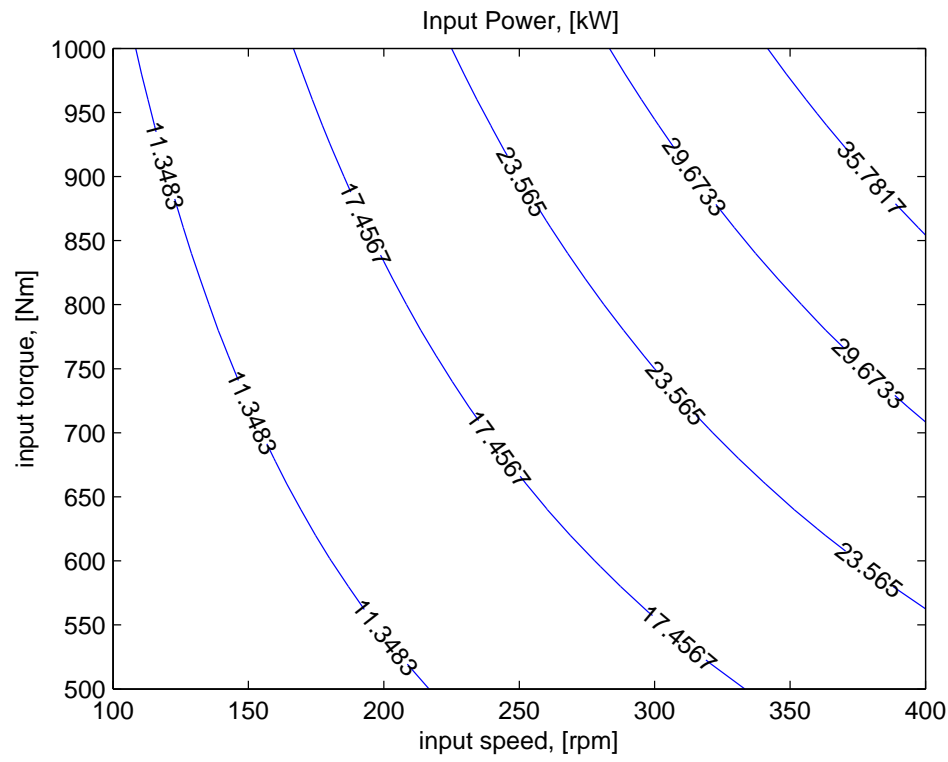

Figure 7.1.: Evolution of the input power on the transfer gearbox over the range of tested conditions.

Table 7.2.: Sequence for the experimental tests.

\begin{tabular}{ccccc}
\hline $\begin{array}{c}\text { Test Sequence } \\
{[/]}\end{array}$ & $\begin{array}{c}\text { Input speed } \\
{[\mathrm{rpm}]}\end{array}$ & $\begin{array}{c}\text { Input torque } \\
{[\mathrm{Nm}]}\end{array}$ & $\begin{array}{c}\text { Input Power } \\
{[\mathrm{kW}]}\end{array}$ & $\begin{array}{c}\text { Total test time } \\
{[\mathrm{h}]}\end{array}$ \\
\hline 1 & & 500 & 5.236 & 8 \\
2 & \multirow{2}{*}{100} & 750 & 7.854 & 8 \\
3 & & 1000 & 10.472 & 8 \\
4 & & 500 & 10.472 & 8 \\
5 & \multirow{2}{*}{200} & 750 & 15.708 & 8 \\
6 & & 1000 & 20.944 & 8 \\
7 & & 500 & 20.944 & 8 \\
8 & \multirow{2}{*}{400} & 750 & 31.416 & 8 \\
9 & & 1000 & 41.888 & 8 \\
\hline
\end{tabular}


gearbox test rig was run at the test conditions for another four hours, since it was found that this period was enough to reach the thermal equilibrium.

The reason for such a long warm-up period is that it was found that at the end of each test the calibration values were closer to the ideal ones, than if one calibrated it with less warm-up time. During the testing, the values of all the sensor reads on the test rig were automatically recorded with a frequency of $0.5 \mathrm{~Hz}$. At the end of each test point the results were collected and processed. In order to perform any calculations the average values of the last 30 minutes (stabilized operating conditions) of each test were considered.

After each set of tests, at a certain speed was complete, an oil sample was collected from the test gearbox oil sump in order to perform a lubricant analysis. The oil sample was collected immediately after the last test at a given input speed was complete, to avoid particle deposition at the bottom of the gearbox housing. An effort was made to take the sample always from the same place, to make relative comparisons between tests and gear oils possible.

After completing the tests with each gear oil, the transfer gearbox was removed from the gearbox test rig, the oil was drained and the gearbox was filled with solvent and shaken in order to remove particles and lubricant from its housing and components. After the clean-up process the gearbox was refilled (2 litres) with the next wind turbine gear oil to test and mounted back on the gearbox test rig.

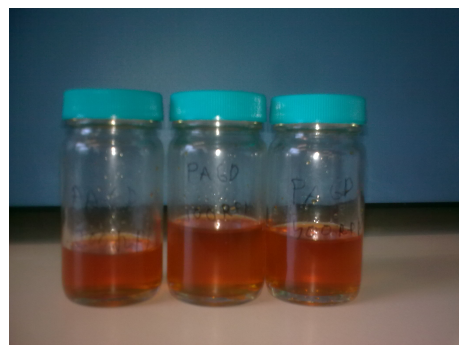

(a)

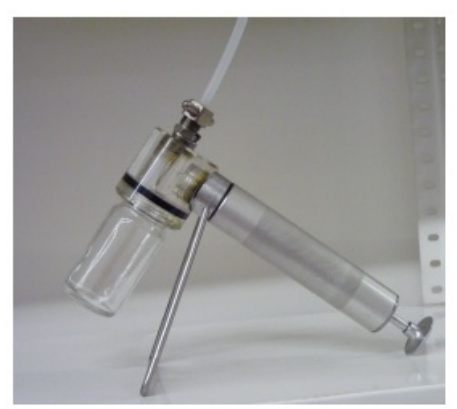

(b)

Figure 7.2.: Example of tree of the oil samples collected during the experimental testing and the vacuum pump used.

\subsection{Wear evaluation through lubricant analysis}

\subsubsection{Ferrography}

Ferrography is a method that allows the evaluation of the wear condition of the mechanical organs of a machine. It allows the separation, classification, measurement 
and visualisation of the existing particles on an oil sample (Analytic Ferrography). Ferrography methods are not only used to evaluate the performance of a lubricant but also to perform preventive maintenance. These can also be used to evaluate the failure mechanism of a component.

\section{Direct Reading Ferrography (DRIII)}

This method makes use of an apparatus called Direct Reading Ferrographer, that allows for rapid and objective relative quantification of large and small particles on an oil sample.

On this process a small volume of oil, $(1 \mathrm{ml})$, goes through a capillary tube which has a segment that passes over a permanent magnet. This segment is illuminated on this area by two light sources with the same origin, then the light that goes through the capillary is detected by two optical detectors. The light source that is at the beginning of the capillary illuminates the local where the larger particles will preferably sediment. The light that goes through the capillary is then limited by the amount of particles on this particular location. At the tube exit a second sourcedetector pair is mounted in order to evaluate the amount of small particles on the sample. The light that goes through the capillary tube is proportionally inverse to the amount of the particles deposit on that spot. The signals detected on the light detectors are then processed and shown as two indexes on a display. One of the values is referred to as $D_{L}$ and it is a relative quantification of the amount of large particles on the sample. The second index $D_{S}$ gives a relative quantification of the amount of small particles present on the oil sample.

The model DR-III-Direct Reading Ferrograph by Predict Technologies, (figure 7.3), was used to obtain the results for $D_{L}$ and $D_{S}$.

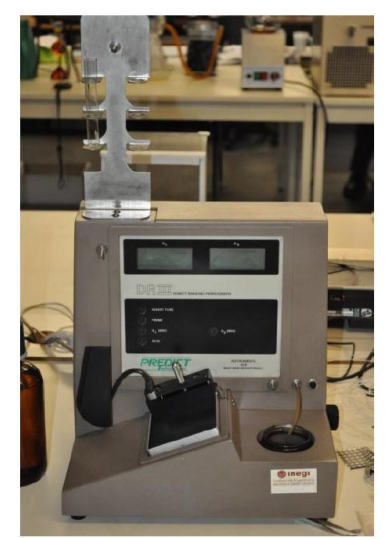

Figure 7.3.: Direct Reading Ferrography by Predict Technologies. 
With these values, $D_{L}$ and $D_{S}$, two wear indexes can be calculated:

$$
\begin{aligned}
& C P U C=\frac{D_{L}+D_{S}}{d} \\
& I S U C=\frac{D_{L}^{2}-D_{S}^{2}}{d^{2}}
\end{aligned}
$$

where

- $C P U C$ - Wear Particles concentration,

- ISUC - Wear Severity,

- $d$ is the dilution factor.

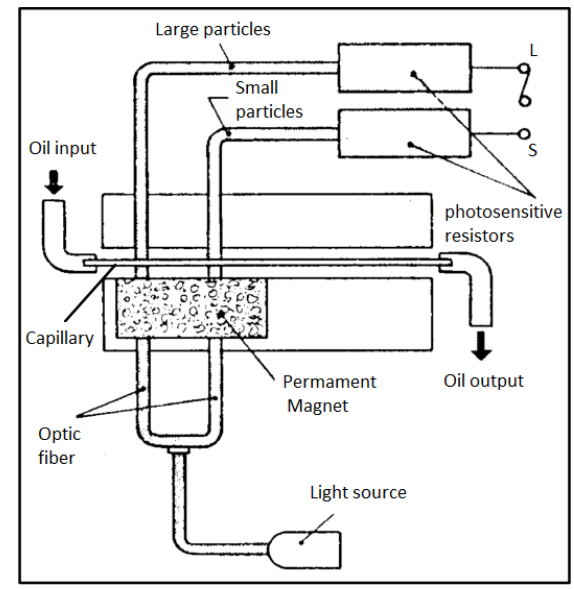

Figure 7.4.: Direct Reading Ferrography (DRIII).

\subsubsection{Analytic Ferrography (FMIII)}

\section{Ferrogram preparation}

The preparation of the ferrogram requires the preparation of a small volume of dissolved oil sample.

Afterwards the oil is forced to flow at a very low speed between two edges of a thin glass plate that functions as a flow channel. Below this thin glass plate there is a magnet. This way the particles will deposit on the glass plate according to its size and magnetic character. The larger ferromagnetic particles will deposit preferably at the beginning of the ferrogram, where the flow initiates. The size of the ferromagnetic particles decreases along the ferrogram. It should be mentioned that ferromagnetic particles stay perpendicularly aligned to the flow direction. 
Although this technique is more efficient on the detection of ferrous particles, nonferrous particles like aluminium and copper alloys can also deposit due to acquired magnetism due to contact with ferrous particles or be trapped between the ferrous filaments or simply by gravity deposition. The remaining types of particles like contaminants, products resulting from oil oxidation or fibbers will randomly deposit along the ferrogram.

When all of the oil sample makes its way through the thin glass plate, a quantity of solvent is made to flow over the deposits in order to fix the particles to the glass substrate.

These thin glass plates are made of a heat resistant glass. This has to do with the fact that the particles can be "heat treated" to evaluate its composition by colour changes.

To prepare the ferrograms the analytic ferrographer used was the model FM-IIIFerrograph by Predict Technologies, figure 7.5.

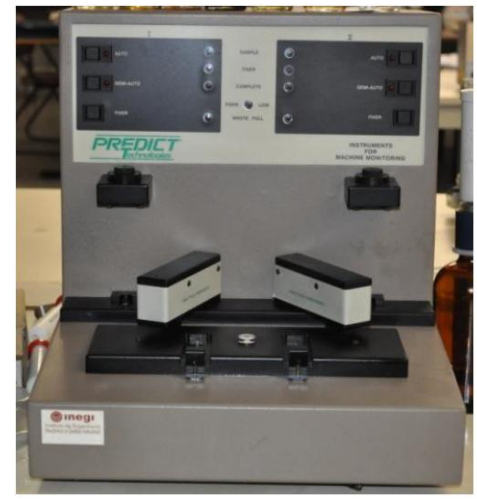

Figure 7.5.: Analytic Ferrography (FMIII) by Predict Technologies.

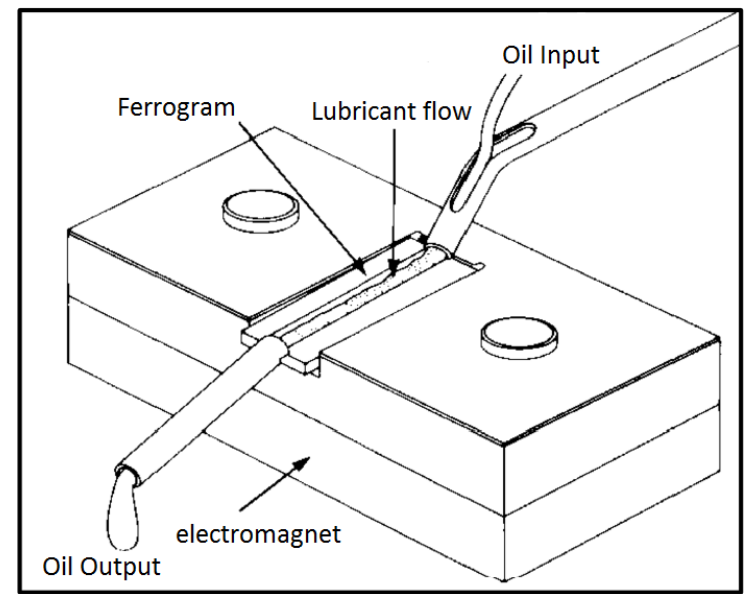

Figure 7.6.: Analytic Ferrography (FMIII). 
After preparation, the ferrogram is observed on a biological optical microscope the ferroscope.

The ferroscope used to evaluate the samples is the Ferroscope - IV by Predict Technologies, figure 7.7. By performing this evaluation the type of particles present on the oil sample can be evaluated and by comparison with characteristic particles one can have an idea on the type of and severity of the wear conditions.

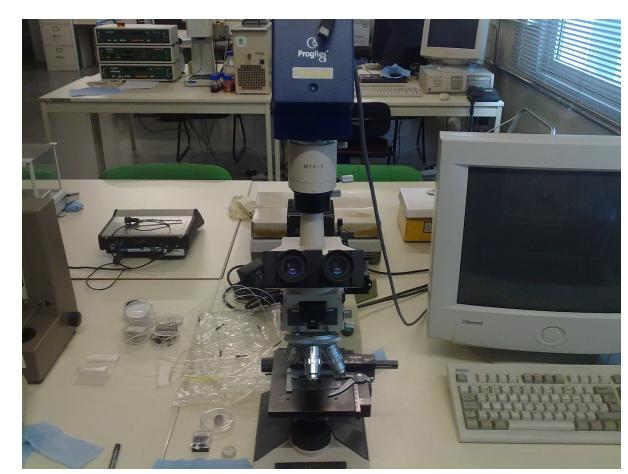

Figure 7.7.: Ferroscope - IV by Predict Technologies.

\subsubsection{Results from wear evaluation through lubricant analysis}

It should be noted that the MINE oil ran more cycles than the other gear oils, because this lubricant passed through four more tests that were used to perform the manual adjustment of the endscale values of the torque sensors. PAOR also passed through more cycles than expected because some problems arose on the slave gearbox and the entire set of tests at 400rpm had to be repeated.

On table 7.3 the wear indexes at the end of all testing for each wind turbine gear oil are presented.

Table 7.3.: Wear indexes at the end of all testing for each wind turbine gear oil. 1 - No dilution

\begin{tabular}{rcccccc}
\hline & & & \multicolumn{4}{c}{ Wear Indexes } \\
\cline { 4 - 7 } Oil & $\mathrm{d}$ & Cycles & $D_{L}$ & $D_{S}$ & CPUC & ISUC \\
\hline MINE & 0.1 & $12.47 \times 10^{5}$ & 48.3 & 15.2 & 635 & $2.10 \times 10^{5}$ \\
MINR & 0.1 & $9.68 \times 10^{5}$ & 55.6 & 17.5 & 731 & $2.79 \times 10^{5}$ \\
PAGD $^{1}$ & 1 & $10.16 \times 10^{5}$ & 47.8 & 23.6 & 71.4 & $1.73 \times 10^{3}$ \\
PAOR & 0.1 & $17.35 \times 10^{5}$ & 50.9 & 12.3 & 632 & $2.44 \times 10^{5}$ \\
\hline
\end{tabular}

Figure 7.9 shows the specific film thickness for the tests conducted. Comparing figure 7.8 to figure 7.9 it seems that no apparent relation between the specific film thickness and the CPUC index can be found. This may be due to the fact that specific film thickness is always $\Lambda<0.7$, which means boundary lubrication conditions. In 


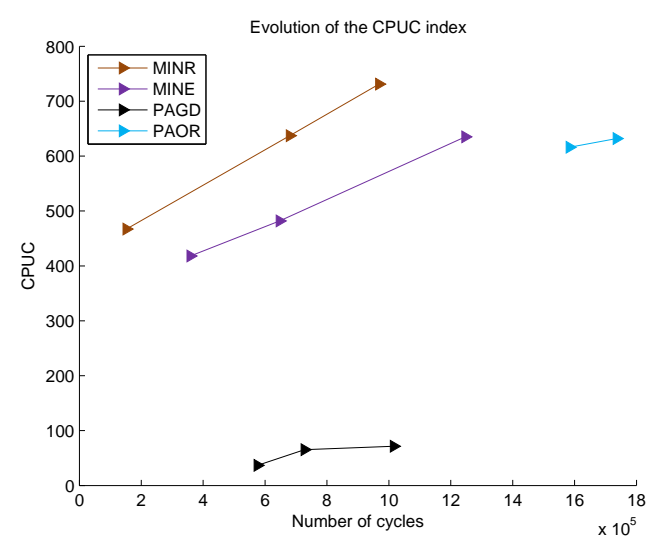

(a)

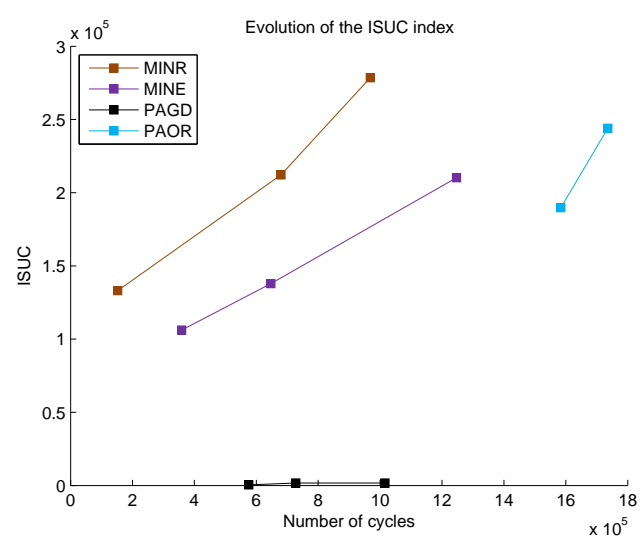

(b)

Figure 7.8.: Evolution of the wear indexes with the number of cycles: a) CPUC; b) ISUC;

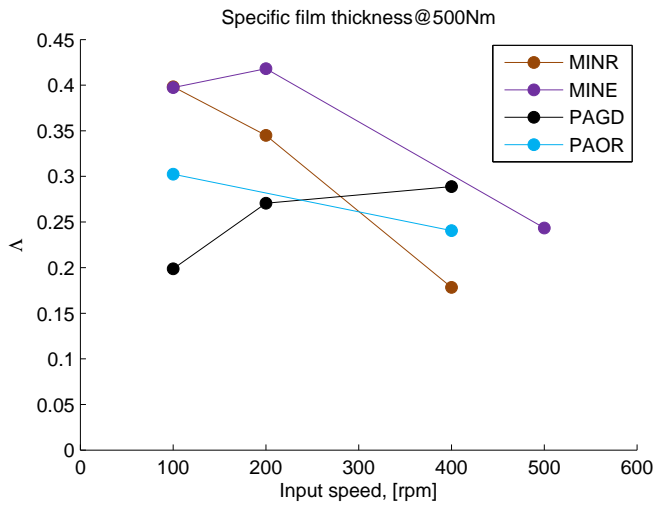

(a)

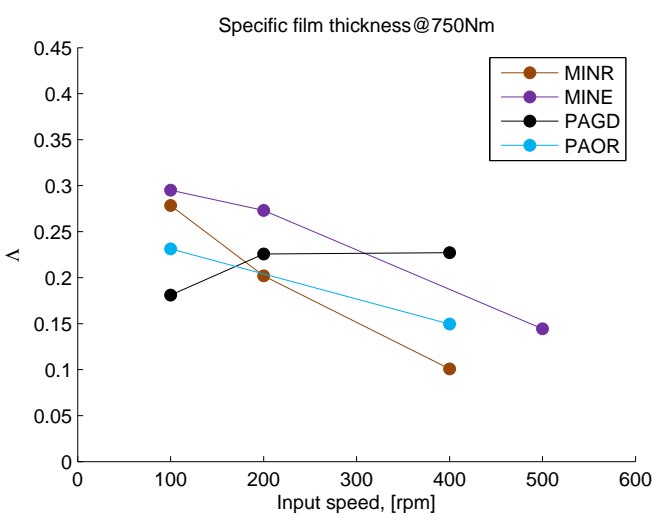

(b)

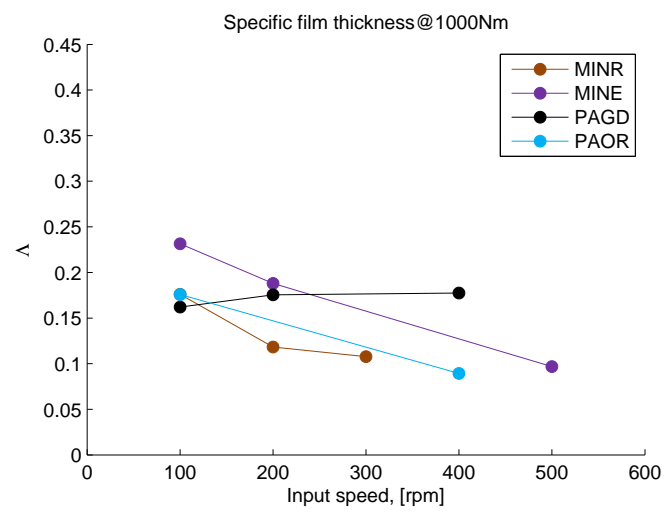

(c)

Figure 7.9.: Specific film thickness as a function of input speed: a) Test points @ $500 \mathrm{Nm}$; b) Test points @ 750Nm; c) Test points @ 1000Nm; 
these conditions the oil additives greatly influence the tribological behaviour on the contacts between gear teeth. Since all the wind turbine gear oils have such distinct additive packages (table 4.2), the wear results in such extreme conditions are deeply related with the effects of the different additive packages.

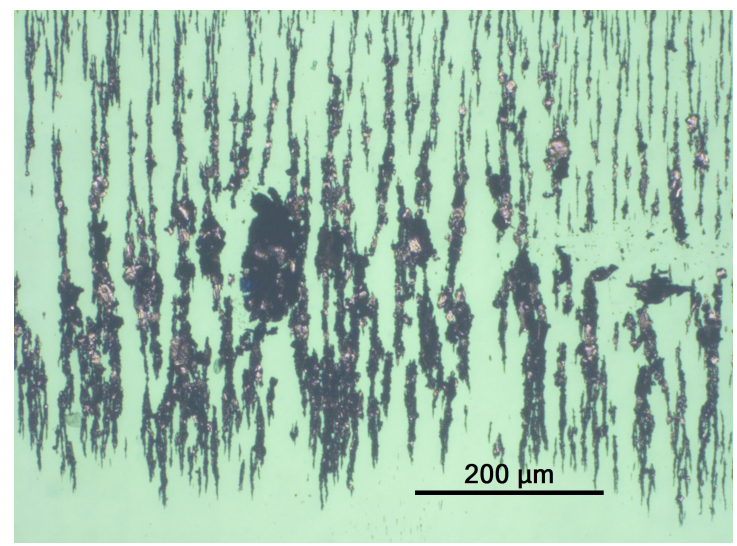

(a) MINE

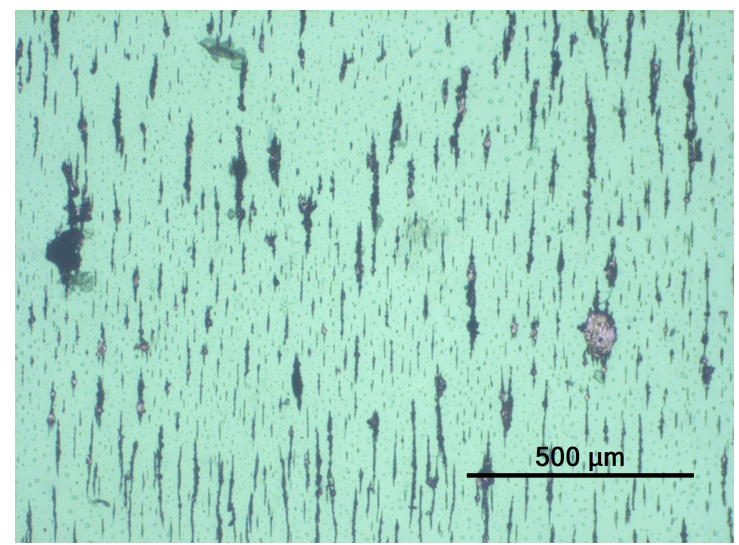

(c) PAGD

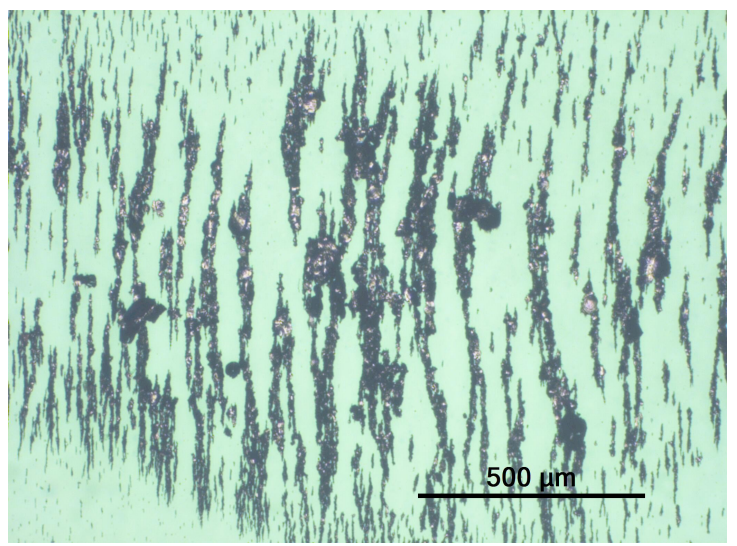

(b) MINR

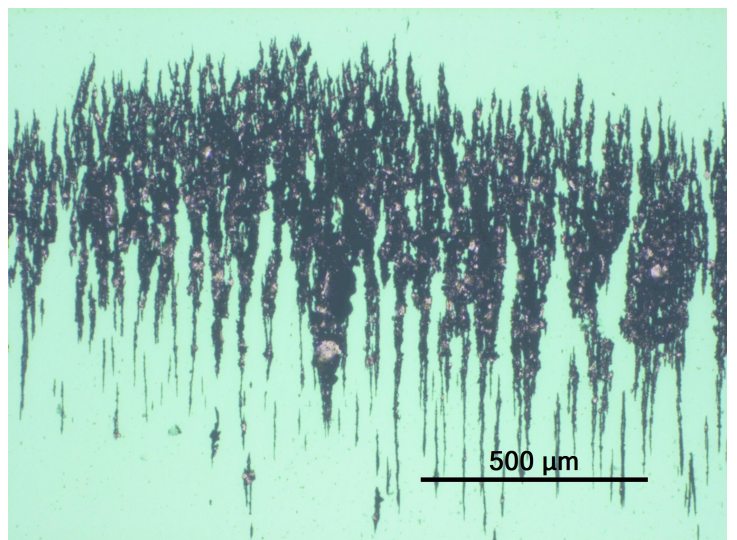

(d) PAOR

Figure 7.10.: Nucleus of the Ferroram, (third oil sample): a) MINE; b) MINR; c) PAGD; d) PAOR;

Magnification: $\times 100$

Dilution: a) 0.1 ; b) 0.1 ; c) 1 ; d) 0.1 ;

Looking at figure 7.8 it can clearly be seen that there is a very significant difference between the PAGD oil and the other wind turbine gear oils. The wear indexes of the PAGD oil are orders of magnitude lower than the other ones. This can be visually confirmed by looking at the ferrograms on figures 7.10(a) to 7.10(c). These results are in agreement with what is reported by D. Gonçalves on [12].

Comparing the ferrograms respecting to the mineral based gear oils, figures 7.10(a) and $7.10(\mathrm{~b})$, it can be noticed that they are quite similar despite the fact that the particles on the MINR ferrogram seem to be more evenly distributed than the ones 
on the MINE one. The ferrogram picture that respects to PAOR oil, figure 7.10(d), seems to show an higher particles concentration than what is verified for the other gear oils, which is countered by the wear indexes (table 7.3 and figures 7.8), this may have to do with the fact that the particles seem to be closer to each other than on the other ferrograms.

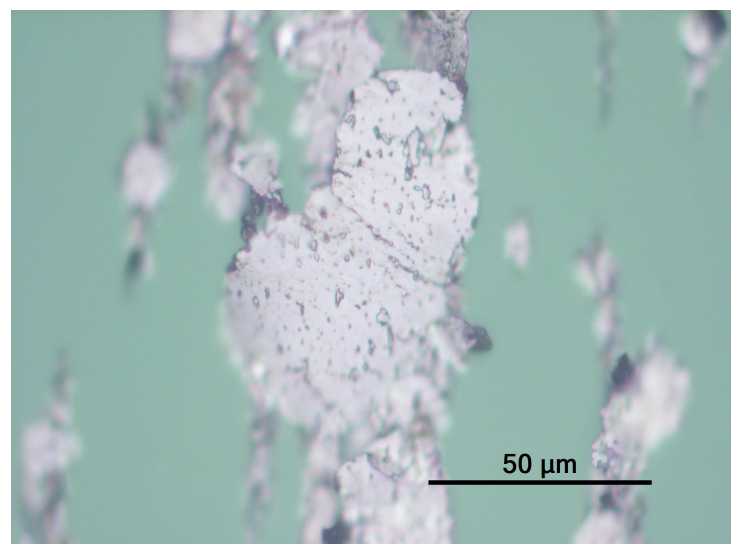

(a) MINE

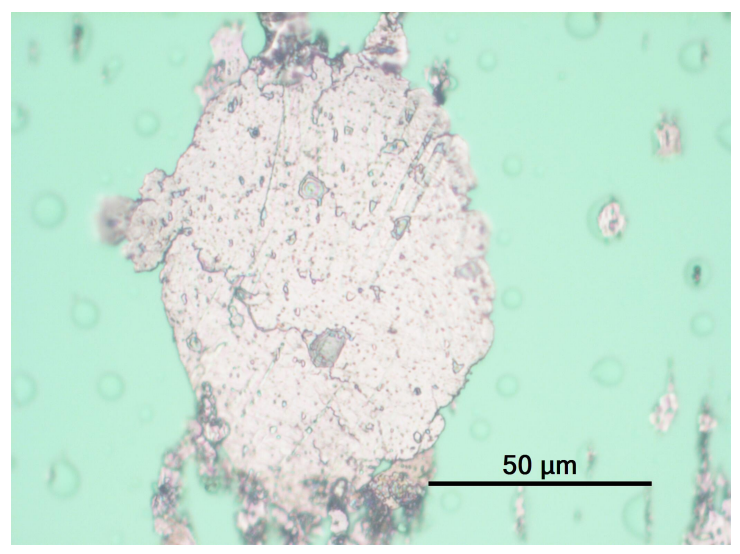

(c) PAGD

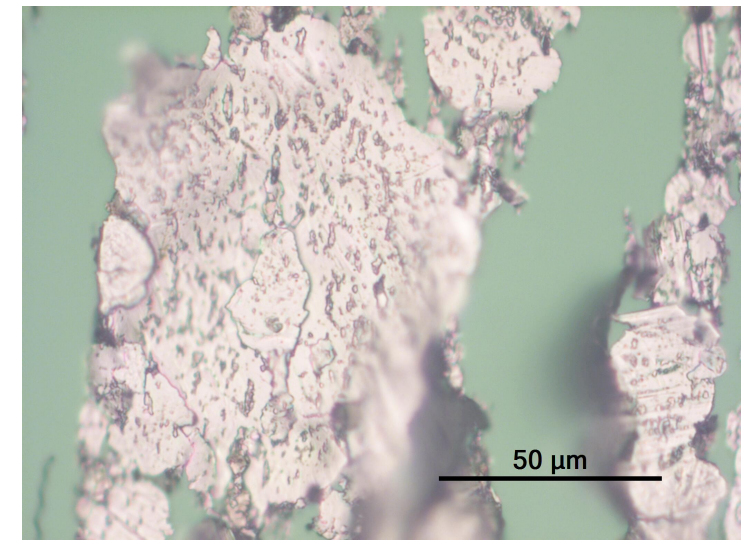

(b) MINR

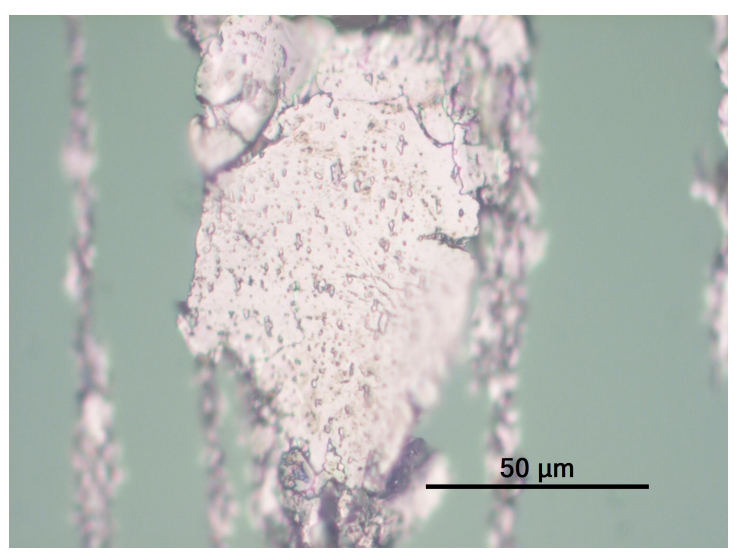

(d) PAOR

Figure 7.11.: Typical particles on the ferrogram nucleus, (third oil sample): a) MINE; b) MINR; c) PAGD; d) PAOR;

Magnification: $\times 1000$

Dilution: a) 0.1 ; b) 0.1 ; c) 1 ; d) 0.1 ;

On figures 7.11(a) to 7.11(d) typical particles of the nucleus of the ferrogram are shown.

With respect to the type of particles present on the ferrograms one can say that similar particles can be found all across of the samples of all wind turbine gear oils. These are usually quite large, very thin and reveal fractured edges which suggests typical gear fatigue wear. On some of these particles (refer to the reports on appendix B), parallel and straight lines are visible, that seem to evidence that some kind of sliding process was involved during their formation. Some evidence of oxidation can 
be found all across the samples.

Generally some kind of dotted marks, (figures 7.11) can be observed on the particles from all of the samples, varying its intensity and number of marks according to the oil. On one hand the PAGD shows the least and most lightly coloured marks across all gear oils. On the other hand the MINR oil shows the most and more strongly coloured marks, which suggests that more severe wear phenomena may have occurred. MINE and PAOR sat in between PAGD and MINR and were difficultly distinguishable.

Curiously both MINE and PAOR showed evidence of wear by corrosion, as it can be seen on figures 7.12 .

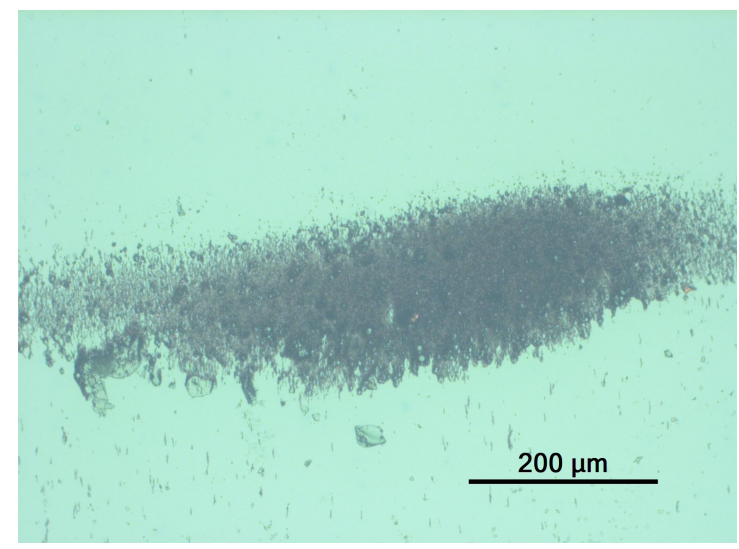

(a) MINE

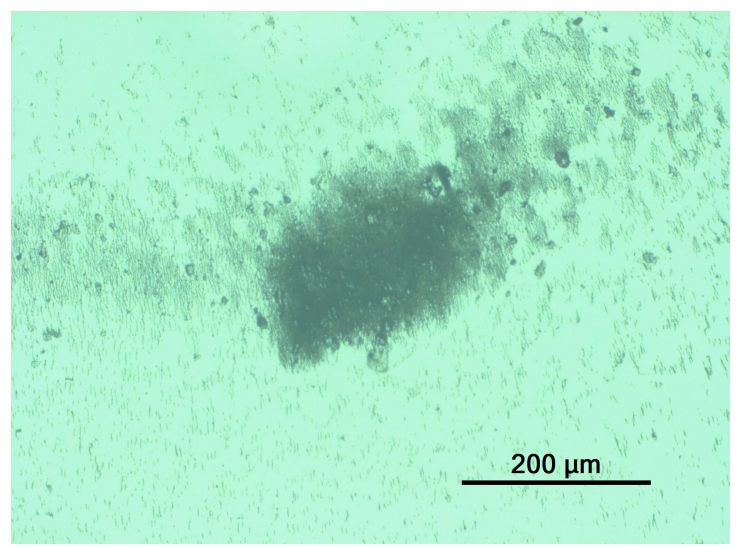

(b) PAOR

Figure 7.12.: Evidence of wear by corrosion on MINE and PAOR: a) MINE; b) PAOR; Magnification: $\times 200$

Dilution: a) 0.1 ; b) 0.1 ;

As it was explained after the test was complete for each wind turbine gear oil the transfer gearbox was filled with solvent in order to remove most of the lubricant residues and wear particles. With this method one can simply guarantee that the number of particles at the start of the testing procedures is low.

From the interpretation of the ferrograms and the wear indexes it can be assumed that the PAGD showed better wear performance than the other oils. It not only showed smaller wear indexes, but also also its particles showed less oxidation. MINR was the worst performer and PAOR and MINE sat in between PAGD and MINR with a slight advantage for the Poly- $\alpha$-olefin based lubricant.

For more detailed results on the $D_{L}$ and $D_{S}$ indexes and additional pictures of the wear particles and their distribution on the ferrograms, please refer to Appendix B. 


\subsection{Power loss results}

In order to calculate the experimental power loss on the transfer gearbox the readings from the torque sensors were used. Since the output speed follows the transmission ratio $\left(i_{c}\right)$ of the transfer gearbox, it can be stated that the power loss is given by

$$
\Delta P=\left(\frac{T Q_{\text {in }}}{i_{c}}-T Q_{\text {out }}\right) \cdot n_{\text {out }} \cdot \frac{\pi}{30}
$$

where:

- $T Q_{\text {out }}$ is the output torque of the transfer gearbox,

- $T Q_{i n}$ is the input torque of the transfer gearbox,

- $i_{c}$ is the trasmission ratio, $\left(i_{c}>1\right.$, speed multiplier $)$,

- $n_{\text {out }}$ is the output speed, $\left(n_{\text {out }}=I_{c} \cdot n_{\text {in }}\right)$.

When the tests started it was found that de measurements of the torque values were not tottaly reliable and that the calibration function implemented on the test rig needed adjustment. This meant that a manual adjustment of the calibration function had to be performed. This adjustment was made on the endscale value of the output torque transducer. Then a test was performed at $235 \mathrm{rpm}$ and $1000 \mathrm{Nm}$ and the results were then compared with previous results available from D. Gonçalves [12]. After this comparison the output torque transducer was calibrated to predict a pre-defined a certain value for the efficiency at the calibration test conditions. The results available from the torque reads, are valid for relative comparisons between the various tests, although their absolute value can't be assured.

\subsection{Stabilization temperature and measured torque loss}

In the tables 7.4 and 7.5 the experimental results in terms of stabilization temperature and calculated power loss from torque readings are presented. In tables 7.4 and 7.5 some results relating to PAOR oil are missing. The reason for this has to do with a critical failure on the gearbox test rig at the start of the 200/500 test point (on this oil the 200rpm speed was left to be the last one to be tested). 
Table 7.4.: Stabilization temperatures, $\left(T_{\text {oil }}-T_{\text {room }}\right)$, from the experimental testing. 1 - Test performed @500rpm; 2- Reference test point @300rpm/800 Nm;

\begin{tabular}{rccccccccc}
\hline & \multicolumn{7}{c}{ Test Points, $(\mathrm{rpm} / \mathrm{Nm})$} \\
\cline { 2 - 9 } Oil & $100 / 500$ & $100 / 750$ & $100 / 1000$ & $200 / 500$ & $200 / 750$ & $200 / 1000$ & $400 / 500$ & $400 / 750$ & $400 / 1000$ \\
\hline MINE & 18.244 & 25.360 & 32.862 & 31.772 & 42.343 & 53.100 & $66.589^{1}$ & $83.176^{1}$ & $103.535^{1}$ \\
MINR & 21.483 & 29.323 & 38.392 & 36.836 & 49.169 & 62.358 & 65.757 & 85.920 & $75.475^{2}$ \\
PAGD & 17.130 & 22.503 & 28.565 & 29.940 & 38.857 & 44.871 & 53.433 & 63.901 & 76.199 \\
PAOR & 18.440 & 25.398 & 33.305 & - & - & - & 55.399 & 70.870 & 87.642 \\
\hline
\end{tabular}

Table 7.5.: Power Loss results from torque sensors readings, [W].

1 - Test performed @500rpm; 2- Reference test point @300rpm/800 Nm;

\begin{tabular}{rccccccccc}
\hline & \multicolumn{7}{c}{ Test Points, $(\mathrm{rpm} / \mathrm{Nm})$} \\
\cline { 2 - 10 } Oil & $100 / 500$ & $100 / 750$ & $100 / 1000$ & $200 / 500$ & $200 / 750$ & $200 / 1000$ & $400 / 500$ & $400 / 750$ & $400 / 1000$ \\
\hline MINE & 153.3 & 229.8 & 358.1 & 288.4 & 550.8 & 738.1 & $938.4^{1}$ & $1510.4^{1}$ & $2140.5^{1}$ \\
MINR & 161.0 & 256.2 & 367.9 & 351.9 & 613.9 & 753.6 & 730.1 & 1257.1 & $980.4^{2}$ \\
PAGD & 210.3 & 332.9 & 454.1 & 404.0 & 662.9 & 910.4 & 839.0 & 1397.8 & 1978.9 \\
PAOR & 220.3 & 319.7 & 470.8 & - & - & - & 843.1 & 1427.8 & 1811.4 \\
\hline
\end{tabular}

The results available were analysed anyway because despite of having only two speeds, these are the extreme ones and it was verified that the evolution of the power loss with speed for the same load level was approximately linear between the three test points.

Despite showing the lowest operating $\Delta T$ for the same operating conditions PAGD wind turbine gear oil shows the highest power loss values. From thermodynamics basics, when the thermal equilibrium is reached the heat dissipation through the gearbox must be equal to the sum of the losses produced inside the gearbox. Since the only thing that was modified during the tests was the gear oil the difference between the wall temperature of the gearbox housing and the room temperature must be the same in order to have the same heat dissipation.

This analysis showed that the measurements of the torque sensors are not completely reliable.

The torque sensors used to perform the measurements during this work are quite old and their performance specifications are shown on table 7.6.

On table 7.6 it can be observed that the margins of error due to non-linearity, hysteresis and zero balance can introduce significant errors on the torque measurements, since the experimental $\Delta T_{Q}$ measurements range from $\approx 5$ to $\approx 20 \mathrm{Nm}$. The solution to this problems passes through using the global heat transfer coefficient derived from the results of all the experimental tests. 


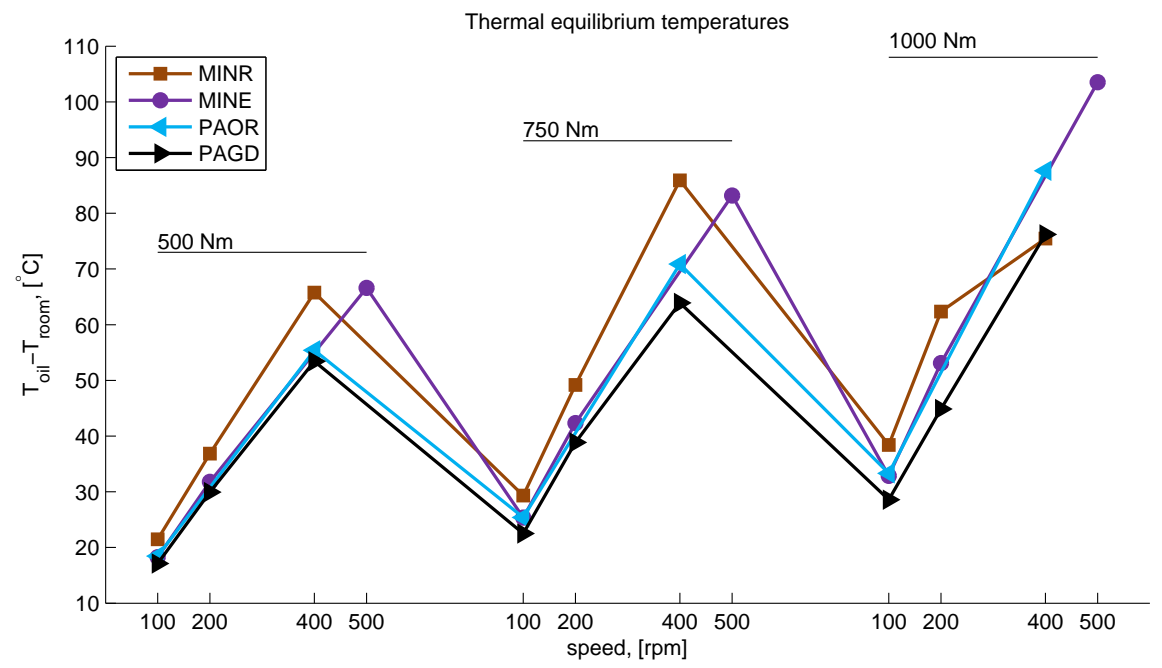

(a)

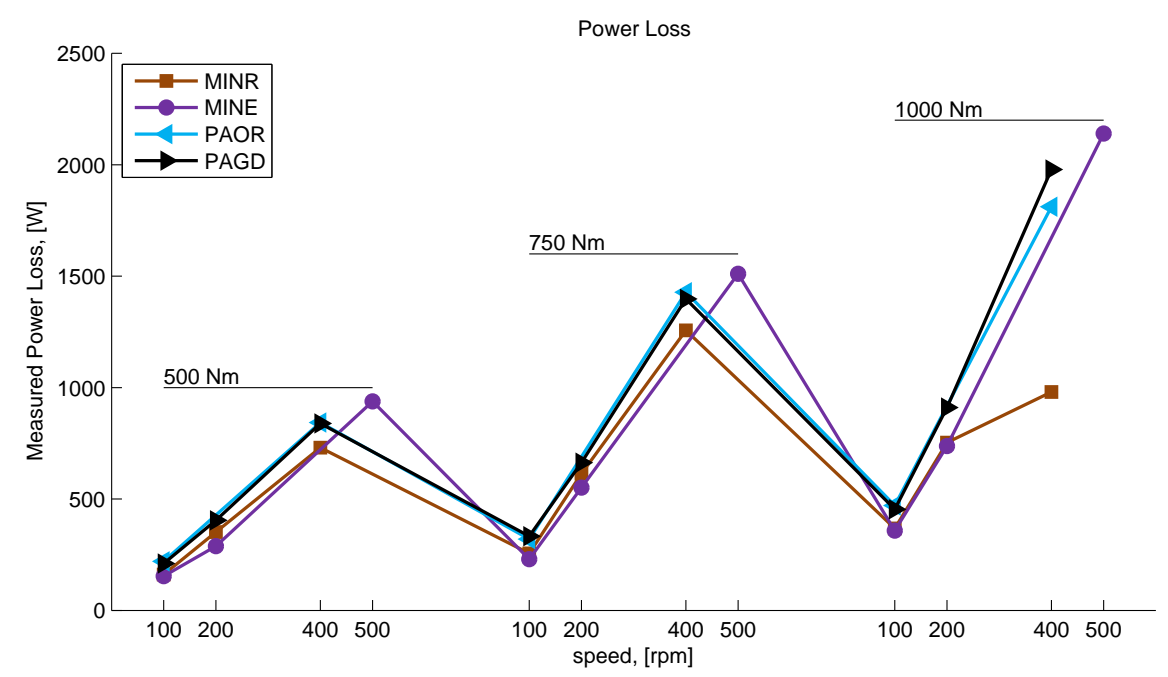

(b)

Figure 7.13.: Stabilization temperatures and power loss: a)Thermal equilibrium temperatures; b) Power loss derived from torque and speed measurements;

\section{Determination of the Global Heat Transfer coefficient}

Heat transfer analysis, can be used because when the thermal equilibrium is reached the heat loss will be equal to the power loss inside the transfer gearbox. This method is of a more complex nature since multiple factors must be taken into account when doing such analysis. All of these phenomena like convection radiation and conduction can be summarized on a global heat transfer coefficient that can be derived from experimental results greatly simplifying its calculation. This coefficient can be determined for various test conditions using all the available test points. It 
Table 7.6.: Torque sensors performance specifications (refer to Appendix C.3.) Rated output of the input torque sensor: $5650 \mathrm{Nm}$; Rated output of the output torque sensor: $2250 \mathrm{Nm}$.

1 - Percentage of rated output.

\begin{tabular}{rc}
\multicolumn{2}{c}{ Specifications } \\
\hline Non-Linearity (of rated output) & $\pm 0.1 \%^{1}$ \\
Hysteresis (of rated output) & $\pm 0.1 \%^{1}$ \\
Repeatability (of rated output) & $\pm 0.05 \%^{1}$ \\
Zero balance (of rated output) & $\pm 1 \%^{1}$ \\
\hline
\end{tabular}

was found that equation 7.4 gave a good correlation with the experimental data.

$$
\alpha \cdot A_{c a}=C_{1} \cdot \Delta T+C_{2}
$$

where:

- $\alpha$ is the heat transfer coefficient,

- $\Delta T$ is the difference between oil/wall temperature and room temperature,

- $C_{1}$ and $C_{2}$ are constants to be numerically determined.

As it is suggested on [15] the global power loss can be expressed as:

$$
Q_{c a}=\alpha \cdot A_{c a} \cdot \Delta T
$$

Constants $C_{1}$ and $C_{2}$ from equation 7.4 can be determined numerically fitting a first degree polynomial equation to the global heat transfer coefficient derived from the experimental results. However another path can be followed.

Substituting equation 7.4 on equation 7.5 , it can be obtained that:

$$
Q_{c a}=C_{1} \cdot \Delta T^{2}+C_{2} \cdot \Delta T
$$

Figure 7.14 shows a plot of the experimental power loss data against the temperature difference between the oil and room temperature.

As it can be seen on figure 7.14(a) the quadratic relation expressed on equation 7.6 satisfactorily correlates with the experimental data from all of the tests. The $C_{1}$ and $C_{2}$ coefficients can then substituted on equation 7.4. As it can be seen on figure 7.14(b) there is a satisfactory correlation between the experimental $\alpha \cdot A$ and the fitting coefficients from the experimental power loss. 


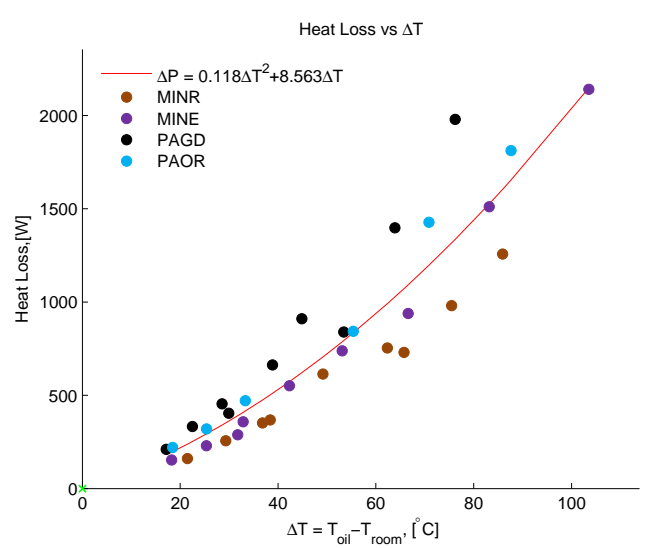

(a)

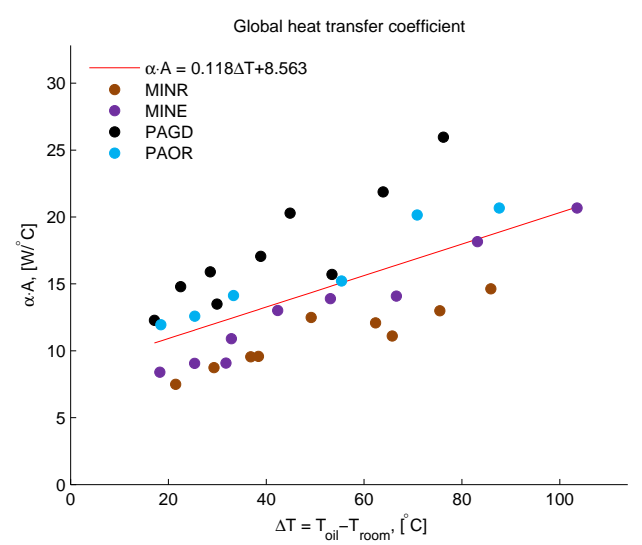

(b)

Figure 7.14.: Heat Loss and $\alpha \cdot A$ against $\Delta T=T_{\text {Oil }}-T_{\text {room }}$ : a) Heat loss; b) $\alpha \cdot A$

This same analysis was also performed taking into account the wall temperature instead of the oil sump temperature. For the results of this last approach refer to appendix B.6. These were not used because it resulted on a worst correlation.

Table 7.7.: Numerically adjusted coefficients for the prediction of the global heat transfer coefficient, $\left(\Delta T=T_{O i l}-T_{a m b}\right)$ and correlation factor $\left(R^{2}\right)$.

All Res. - Coefficients obtained from the results of all of the tests

\begin{tabular}{cccc}
\hline & $C_{1}$ & $C_{2}$ & $R^{2}$ \\
\hline All Res. & 0.1177 & 8.5628 & 0.846 \\
\hline
\end{tabular}

Using the global heat transfer coefficient the global power loss for each test was derived. These results are available on table 7.8 and figure 7.15 .

Table 7.8.: Power Loss results from the global heat transfer coefficient, [W].

1 - Test performed @500rpm; 2- Reference test point @300rpm/800 Nm;

\begin{tabular}{rccccccccc}
\hline & \multicolumn{7}{c}{ Test Points, $(\mathrm{rpm} / \mathrm{Nm})$} \\
\cline { 2 - 10 } Oil & $100 / 500$ & $100 / 750$ & $100 / 1000$ & $200 / 500$ & $200 / 750$ & $200 / 1000$ & $400 / 500$ & $400 / 750$ & $400 / 1000$ \\
\hline MINE & 195.4 & 292.8 & 408.5 & 390.9 & 573.6 & 786.6 & $1092.1^{1}$ & $1526.5^{1}$ & $2148.2^{1}$ \\
MINR & 238.3 & 352.3 & 502.2 & 475.1 & 705.6 & 991.6 & 1072.0 & 1604.6 & $1316.8^{2}$ \\
PAGD & 181.2 & 252.3 & 340.6 & 361.9 & 510.4 & 621.2 & 793.6 & 1027.8 & 1335.9 \\
PAOR & 197.9 & 293.4 & 415.7 & - & - & - & 835.6 & 1198.0 & 1654.5 \\
\hline
\end{tabular}

Judging from figure 7.15 and tables 7.4 and 7.8 it can be said that PAGD has shown the best power loss performance. MINR has proven to be the worst performer showing stabilization temperatures up to $22^{\circ} \mathrm{C}$ higher than PAGD for the second highest input power. MINE and PAOR seem to perform extremely close to each other and in between PAGD and MINR oils. 


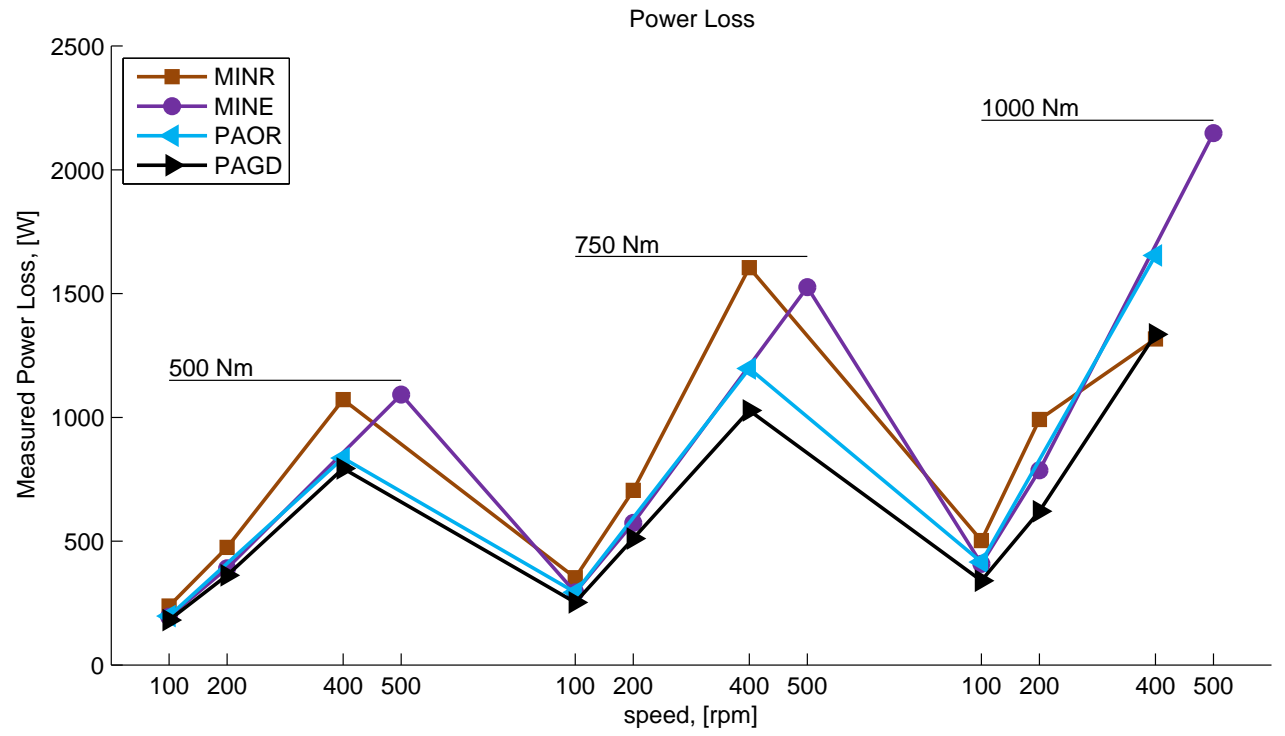

Figure 7.15.: Power Loss based on the global heat transfer coefficient. 



\section{Calibration of the power loss model and numerical results}

\subsection{Power loss model results and its optimization}

After the experimental results were available the power loss from the global heat transfer coefficient were with the predictions of the power model. Since its behaviour was similar across all wind turbine gear oils only results for MINE oil will be presented at this stage.

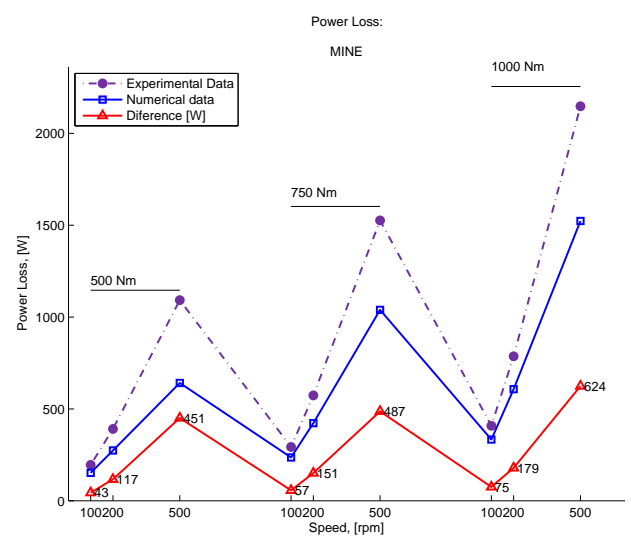

(a)

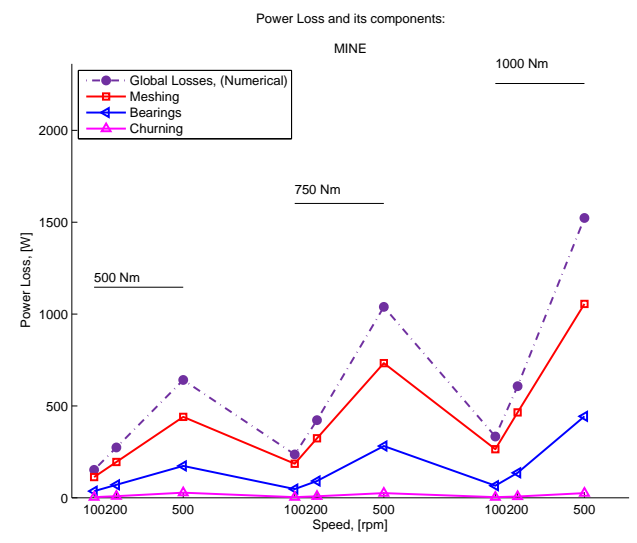

(b)

Figure 8.1.: Power loss prediction vs experimental results for MINE oil: a) Power Loss; b) Power loss prediction and its components;

Figure 8.1(a) shows that the power loss model underestimates power loss. From extensive testing and evaluation of the numerical results it was found that the main problems were on the prediction of churning power loss and on the prediction of the friction power loss at the gear mesh.

\subsubsection{Calibration of the gears churning power loss model}

Looking at the figure 8.1(b), where the various power loss components are presented, it seems that the churning power loss is clearly being underestimated, (about 
25W @ 500rpm input speed). Even if the model proposed by Changenet et al. [3, 4], demonstrates to give good correlations between the experimental data and numerical results it is not guaranteed that it will give good results on the present study. This has to do with some key differences between the experimental tests performed by $\mathrm{C}$. Changenet and the present work:

- The internal geometry of the transfer gearbox housing has great influence on the churning power loss [5]

- The presence of multiple pinions, wheels and other mechanical organs close to each other inside the transfer gearbox certainly create complex flow conditions, thus it is not guaranteed that the formulation described on section 6.2.1 for the prediction of the churning power loss still applies.

- The low speed and high viscosity conditions, probably weren't covered by Changenet et al. [3, 4].

After an extensive analysis of the experimental data available, from all tests, figure 8.2 was plotted. It displays the difference between oil sump and external wall temperature of the housing $\left(T_{\text {oil }}-T_{\text {wall }}\right)$ of the transfer gearbox against the difference between oil sump and room room temperatures $\left(T_{\text {oil }}-T_{\text {room }}\right)$.

Figure 8.2 indicates that the differences between the oil sump and the external wall of the housing of the test gearbox temperatures are lubricant independent.

This means that the oil's thermal properties have little influence on the overall stabilization temperatures, so the oil sump temperature should be approximately uniform.

Another interesting fact is that at least two regimes and a transition zone can be identified, it was then verified that these regimes are related to the input speed. Picking two points with similar $T_{\text {oil }}-T_{\text {wall }}$ for the same oil one can easily verify that the $T_{\text {oil }}-T_{\text {room }}$ can, in some cases almost double, which means that at higher speeds the internal heat transfer process seems to be more effective. This is probably related to the flow regimes inside the transfer gearbox.

The third zone has experimental points ranging from test at 300 to $500 \mathrm{rpm}$, this means that these zones are not characteristic of a certain speed, but that each zone corresponds to a range of speeds.

After this considerations it can be assumed that on the third zone the flow regime on the transfer gearbox might as well be a "turbulent flow". Since the second zone appears under the form of cloud of points it could be identified as a transition zone. The first zone is extremely well defined and it and it should be identified as the "laminar" flow zone. 


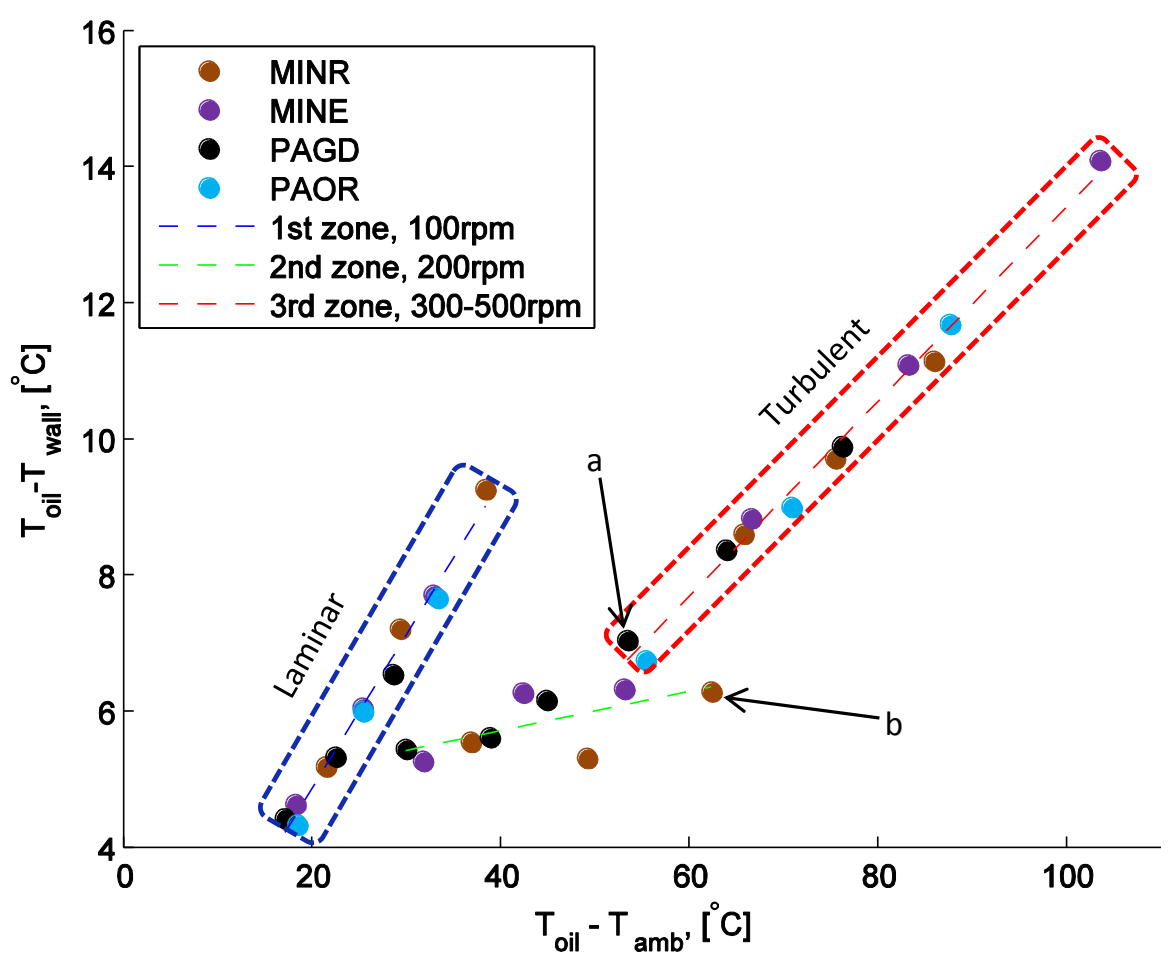

Figure 8.2.: Difference between oil sump and external wall temperature of the housing $\left(T_{\text {oil }}-T_{\text {wall }}\right)$ of the transfer gearbox against the difference between oil sump and room room temperatures $\left(T_{\text {oil }}-T_{\text {room }}\right)$ : a PAGD@400rpm/500Nm; b - MINR@200rpm/1000Nm;

On the implemented churning power loss model when critical Reynolds number (equation 6.15) is above 4000 the flow regime is considered turbulent. Since there are kinematic relations connecting the different pinions inside the testing gearbox the critical Reynolds number will be quite similar across all of them. Then the mean value of $R e_{c}$ for each test was calculated and plotted against $T_{o i l}-T_{a m b}$, which is presented on figure 8.3.

Analysing figure 8.3 it can be seen that only four of the twelve points that belong to the turbulent flow regime, identified on figure 8.2, are above 4000. This means, that possibly due to interactions between the flows caused by the different pinions and the particular internal geometry of the test gearbox housing, the transition Reynolds number $\left(R e_{c}=4000\right)$ is being overestimated.

On figures 8.2 and 8.3 two points are marked with an arrow. These points belong to two different zones, as marked on figure 8.2. The point marked as $b$ belongs to the transition zone and the point marked with $a$ to the turbulent flow zone.

Figure 8.3 shows that point $b$ despite belonging to the transition zone exhibits a critical Reynolds number, $\left(R e_{c}=1414\right)$, higher than the point $a,\left(R e_{c}=1211\right)$. This 


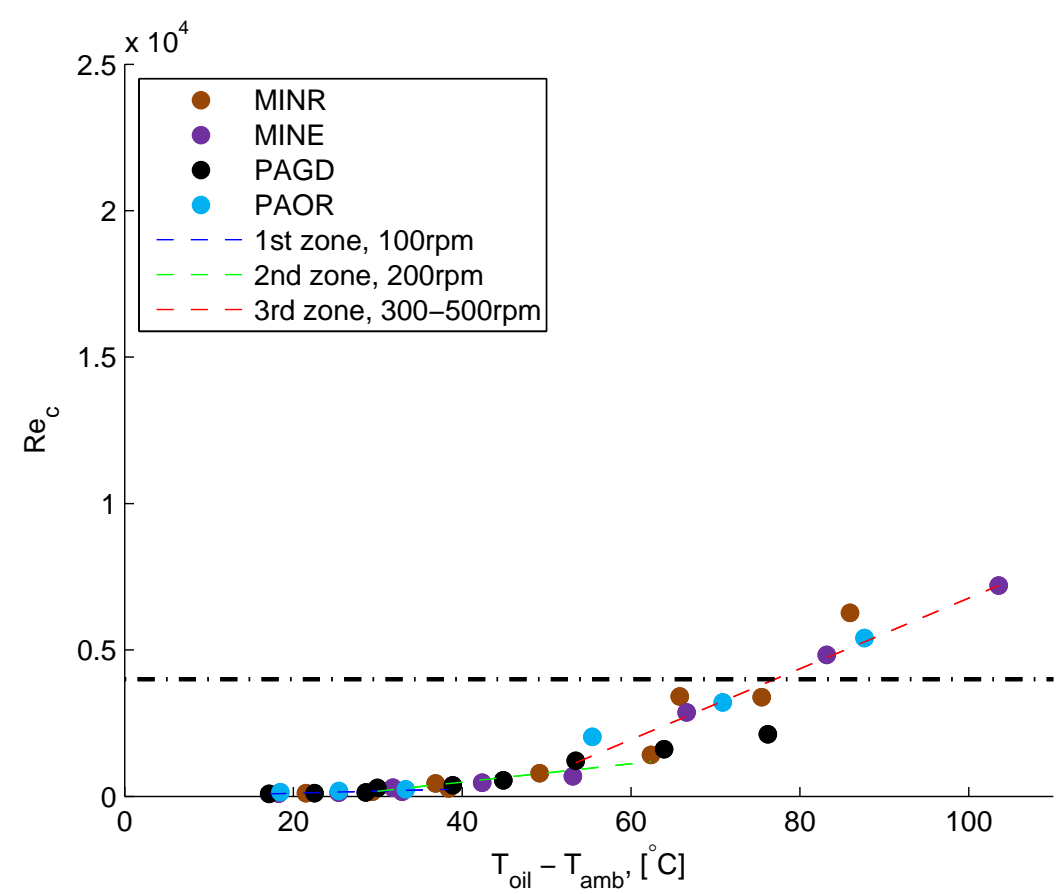

Figure 8.3.: Critical Reynolds number evaluation: a - PAGD@400rpm/500Nm $\Longrightarrow$ $R e_{c}=1211 ; \mathrm{b}-\mathrm{MINR} @ 200 \mathrm{rpm} / 1000 \mathrm{Nm} \Longrightarrow R e_{c}=1414$;

is an indication that the transition $R e_{c}$ is close to these points.

Figure 8.3 shows that the lines that fit the transition zone and turbulent zone intersect around $T_{o i l}-T_{\text {wall }}=50^{\circ} \mathrm{C}$. Analysing the position of these points it can seen that the point from the PAGD is much closer to $T_{\text {oil }}-T_{\text {wall }}=50^{\circ} \mathrm{C}$ than the point $b$, so, the critical Reynolds number chosen as the transition number is $R e_{c}=1211$. This point is marked as point $a$ on figures 8.2 and 8.3 .

The implemented gear churning power loss model [16,3], suggests a transition $R e_{c}$ of 4000. Since, this model is fully dependant on the critical Reynolds number and its parameters, the correction must be performed in a way that will not only affect this number but also the entire model. As an example the Froude number, equation 6.14, reveals a certain connection with $R e_{c}$ due to the fact that some key parameters are shared, both wheel radius $\left(R_{d}\right)$ and and angular speed $(\omega)$. If the correction is applied to the angular speed it will affect not only $R e_{c}$ but also the entire model.

If the theoretical transition $R e_{c}$ is divided by the chosen transition $R e_{c}$ it is obtained:

$$
c_{f}=\frac{4000}{1211}=3.3
$$


So, the correction of the entire model will be made multiplying the angular speed of the pinions by the correction factor factor $\left(c_{f}=3.3\right)$.

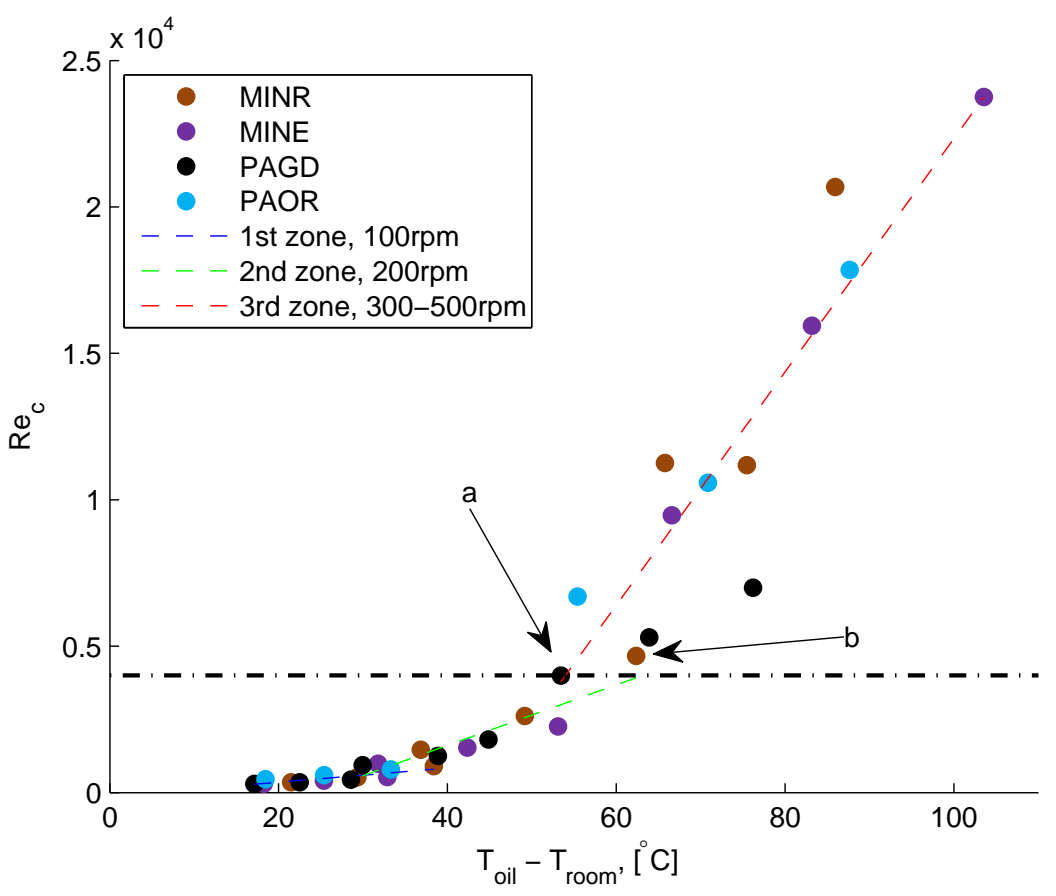

Figure 8.4.: Critical Reynolds number evaluation, considering the angular speed correction factor $\left(c_{f}=3.3\right)$ : a - PAGD@400rpm $/ 500 \mathrm{Nm} ; \mathrm{b}$ MINR@200rpm/1000Nm;

Figure 8.4 shows the critical Reynolds number $\left(R e_{c}\right)$ with the suggested correction factor applied, showing that all the points of the 300-500 rpm range have $R e_{c}>4000$ which is in agreement with the regimes identified on figure 8.2.

Figure 8.5 displays the power loss distributions inside the gearbox including the churning loss correction factor $\left(c_{f}=3.3\right)$.

Comparing figure 8.5 with 8.1 (b) it can be seen that the gear churning power loss component seems to have a much larger impact on the overall power loss. In fact the churning losses at the highest input speed are now about $250 \mathrm{~W}$, which seems to make more sense than the previous $25 \mathrm{~W}$ because there are 5 pinions on the test gearbox with speeds ranging from 500 to $1146 \mathrm{rpm}$. The adjusted model is also showing coherent results from the different load levels, for highest loads the churning power loss diminish which makes sense considering the higher oil sump temperature and therefore lower viscosity of the gear oil. 


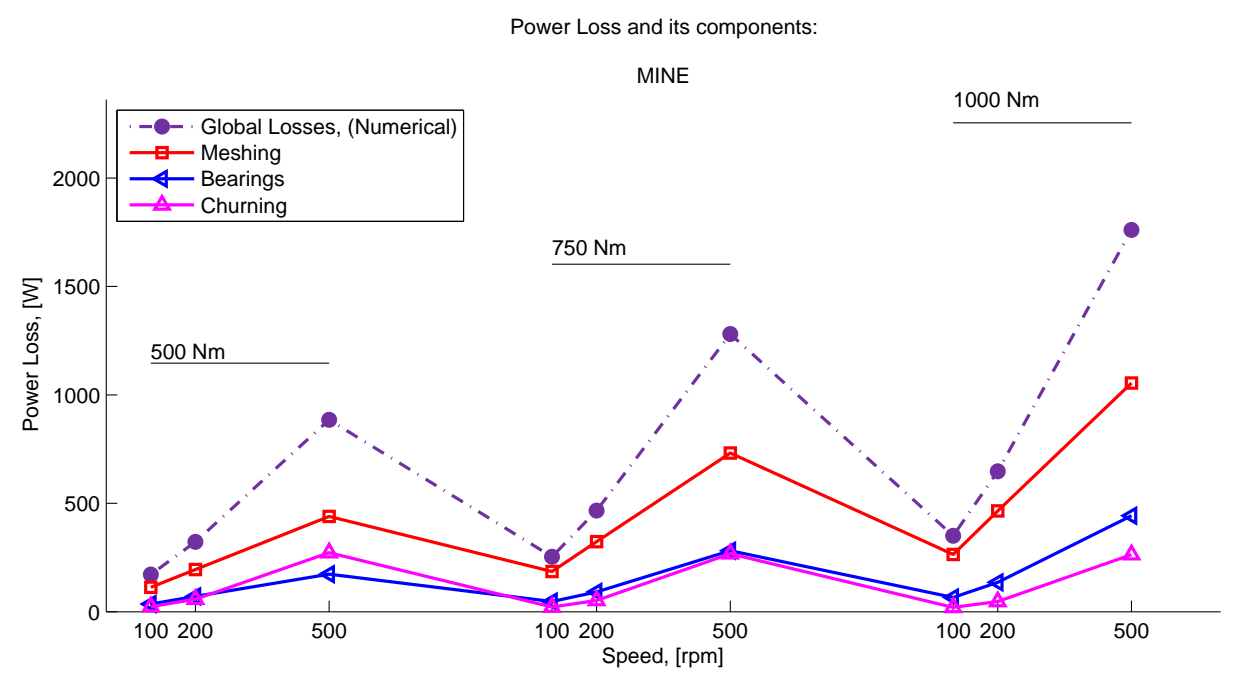

Figure 8.5.: Power loss model behaviour including the churning loss correction factor $\left(c_{f}=3.3\right)$.

\subsubsection{Calibration of the coefficient of friction on the gear mesh}

The results obtained with the power loss model are shown on the figures 8.6 to 8.9. On these figures one can clearly see that the implemented model when using the Michaelis [15] coefficient of friction, equation 6.26, fails to predict the correct power loss by underestimation. It showld be noted that figures 8.6 to 8.9 already include the churning loss correction factor $\left(c_{f}=3.3\right)$.

As it can been seen on the last figures, the friction coefficient clearly needs to be optimized for each wind turbine gear oil. In order to perform this task the power loss model exposed on section 6.2 was implemented in Matlab R2010a. Then the optimization was made using a non-linear least squares method with a custom objective function. This function was defined as the relative error between the experimental and the numerical power loss.

$$
\Delta E=\frac{\Delta P_{n u m}-\Delta P_{e x p}}{\Delta P_{\text {exp }}}
$$

In order to adjust the friction coefficient on the gear mesh a lubricant factor was defined. An appropriate lubricant factor for low speed and high torque working conditions, $X_{L}$, was already suggested by D. Gonçalves [12] which consists on equation 8.3 . 
8.1. Power loss model results and its optimization

(This page was intentionally left blank) 
8. Calibration of the power loss model and numerical results

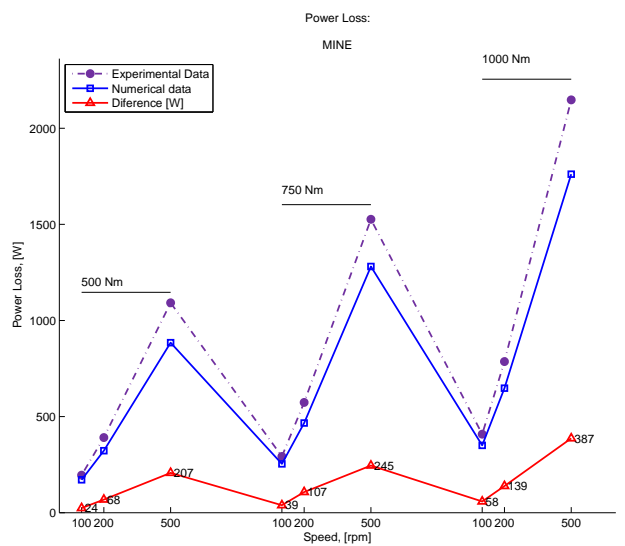

(a)

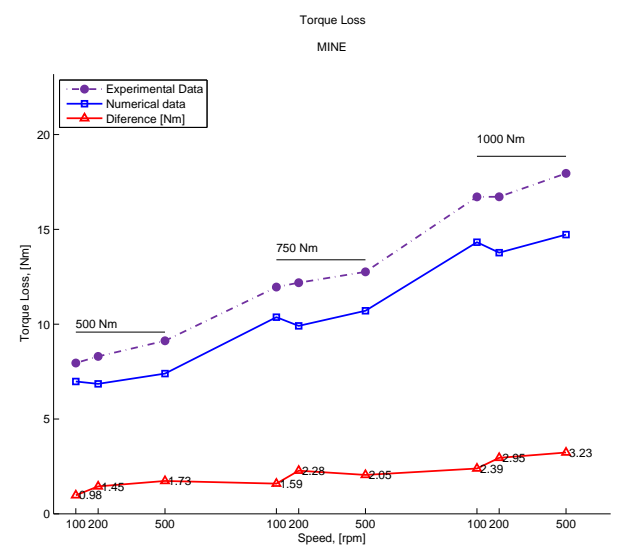

(b)

Figure 8.6.: Loss prediction vs experimental results for MINE oil: a) Power Loss; b) Torque Loss;

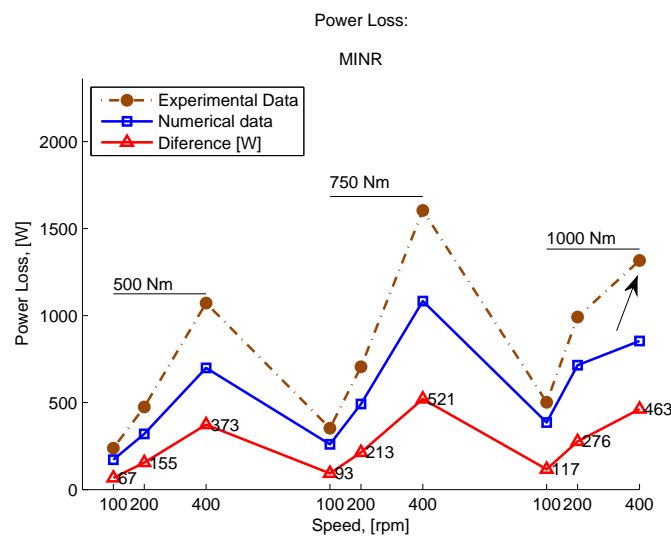

(a)

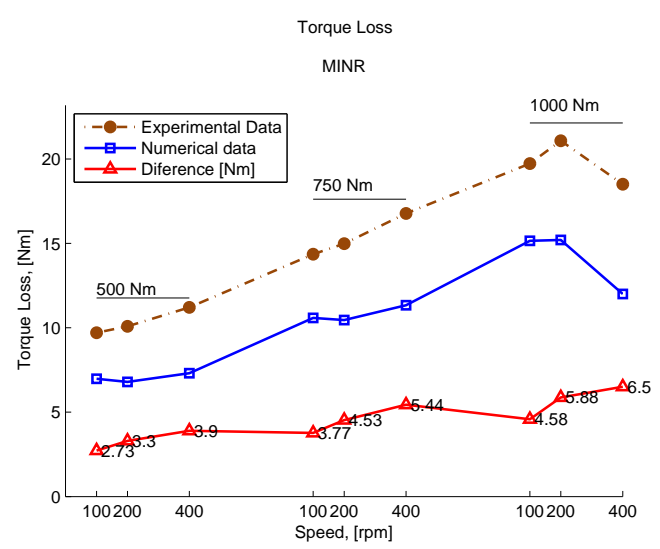

(b)

Figure 8.7.: Loss prediction vs experimental results for MINR oil: a) Power Loss; b) Torque Loss;

The arrow indicates experimental results for MINR@300 $\mathrm{rpm} / 800 \mathrm{Nm}$. MINR@300 rpm $/ 800 \mathrm{Nm}$ was performed instead of MINR@400 rpm $/ 1000 \mathrm{Nm}$ since the expected temperatures would be excessive for mineral based lubricants. 


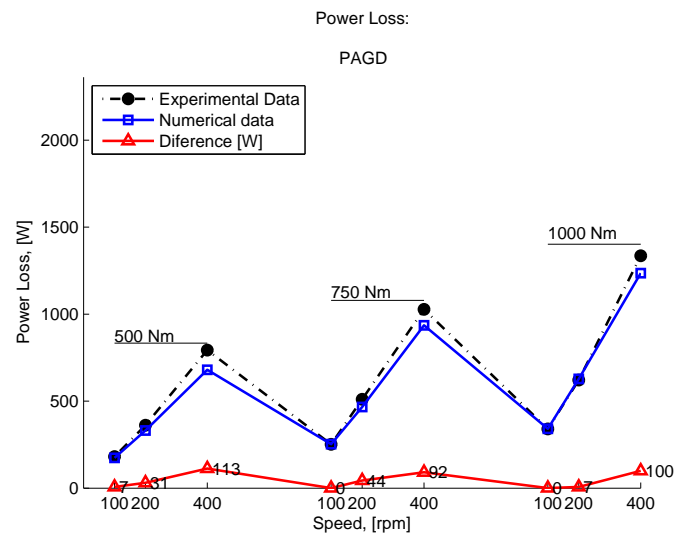

(a)

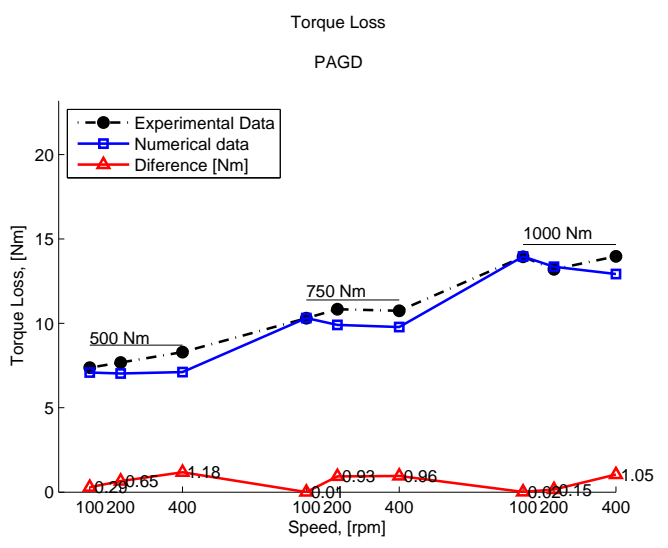

(b)

Figure 8.8.: Loss prediction vs experimental results for PAGD oil: a) Power Loss; b) Torque Loss;

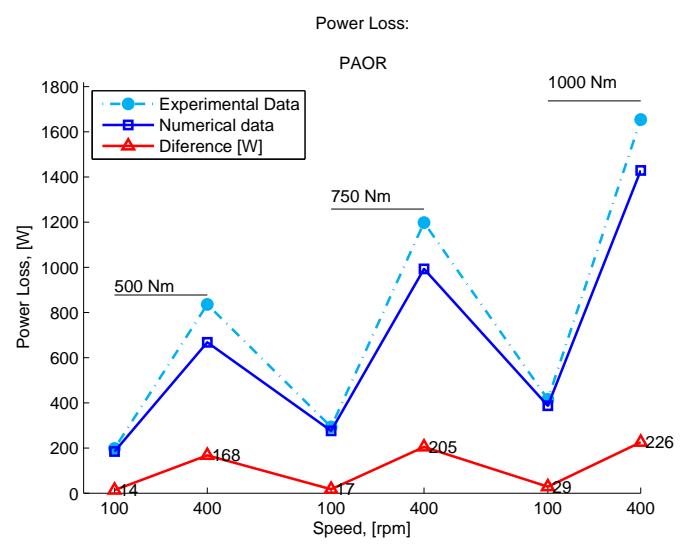

(a)

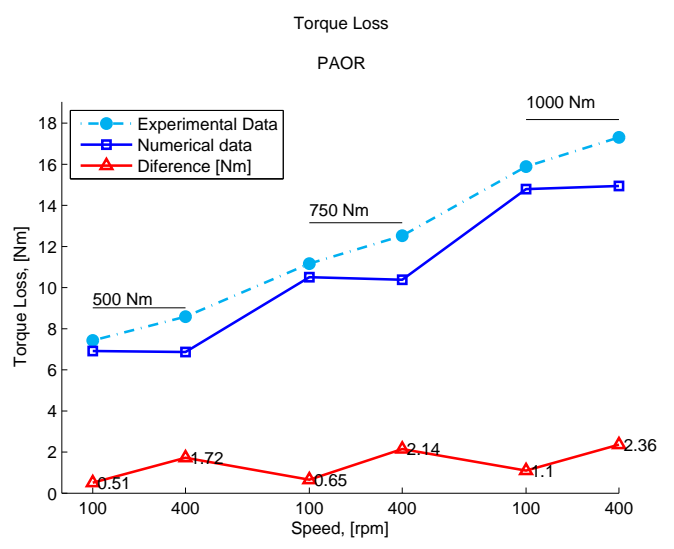

(b)

Figure 8.9.: Loss prediction vs experimental results for PAOR oil: a) Power Loss; b) Torque Loss; 


$$
X_{L}=a_{1} \cdot \frac{\left(\frac{F_{b t}}{l_{\min }}\right)^{-b_{1}}}{v_{\sum c}^{-b_{2}}}
$$

The $a 1, b 1$ and $b 2$ coefficients on equation 8.3 were numerically adjusted for each wind turbine gear oil in order to better predict the experimental results

\section{Numerical results after optimization of the coefficient of friction and process validation}

During the process of evaluating the optimized coefficients no matter how the upper and lower bounds of these coefficients were set, the multiplicative coefficient $a_{1}$ was always leaning towards its upper limit. The load dependant coefficient $b_{1}$ was positive which means that the load influence was being reduced. The speed coefficient was leaning towards 0.2 , resulting on an overall friction coefficient mostly independent of the speed and corrected through a multiplicative factor, $a_{1}$.

Despite resulting on a good correlation between experimental and numerical results these coefficients seem to not make that much sense, specially the $a_{1}$ coefficient that seems to be doing most of the "work" on the adjustment by removing the influence from the load coefficient. Since the equation 6.26 proposed by Hohn et al. [15] was derived from experimental results in mixed film conditions it seems reasonable to think that both load and speed would have a different influence on the friction coefficient, when compared with the mixed film conditions.

The optimization routine was then rerun but this time with the multiplicative coefficient $a_{1}$ forced to 1 . The boundaries of the coefficients for the optimization routine were set free and the results obtained are shown in table 8.1. The quality of the numerical fit remains the same when forcing the $a_{1}$ coefficient to 1 .

Table 8.1.: Optimized lubricant factor coefficients, ( $a_{1}$ forced to 1$)$.

\begin{tabular}{rccc}
\hline Oil & $a_{1}$ & $b_{1}$ & $b_{2}$ \\
\hline MINE & 1 & -0.046 & 0.081 \\
MINR & 1 & -0.092 & 0.199 \\
PAGD & 1 & -0.012 & 0.109 \\
PAOR & 1 & -0.031 & 0.154 \\
\hline
\end{tabular}




$$
\begin{aligned}
& \text { 1) } \mu_{m z}=0.048 \cdot \frac{\left(F_{b t} / l_{m i n}\right)^{0.2+0.046}}{v_{\sum C}^{0.2-0.081} \cdot \rho_{C}^{0.2}} \cdot \eta_{o i l}^{-0.05} \cdot R_{a}^{0.25} \quad(\text { MINE) } \\
& \text { 2) } \mu_{m z}=0.048 \cdot \frac{\left(F_{b t} / l_{m i n}\right)^{0.2+0.092}}{v_{\sum C}^{0.2-0.199} \cdot \rho_{C}^{0.2}} \cdot \eta_{o i l}^{-0.05} \cdot R_{a}^{0.25} \quad(M I N R) \\
& \text { 3) } \mu_{m z}=0.048 \cdot \frac{\left(F_{b t} / l_{m i n}\right)^{0.2+0.012}}{v_{\sum}^{0.2-0.109} \cdot \rho_{C}^{0.2}} \cdot \eta_{o i l}^{-0.05} \cdot R_{a}^{0.25} \quad(P A G D) \\
& \text { 4) } \mu_{m z}=0.048 \cdot \frac{\left(F_{b t} / l_{m i n}\right)^{0.2+0.031}}{v_{\sum}^{0.2-0.154} \cdot \rho_{C}^{0.2}} \cdot \eta_{o i l}^{-0.05} \cdot R_{a}^{0.25} \quad(P A O R)
\end{aligned}
$$

Table 8.2.: Correlation factors $\left(R^{2}\right)$ considering the optimized lubricant factor coefficients $\left(a_{1}, b_{1}\right.$, $b_{2}$ - table 8.1) and the churning loss correction factor, $\left(c_{f}=3.3\right)$.

\begin{tabular}{rc}
\hline Oil & $R^{2}$ \\
\hline MINE & 0.980 \\
MINR & 0.983 \\
PAGD & 0.967 \\
PAOR & 0.978 \\
\hline
\end{tabular}

The modifications introduced by the optimized lubricant factor coefficients (table 8.1) on the Michaelis average coefficient of friction [15] are presented on equations 8.4 to 8.7 .

Analysing these coefficients it can be noticed that the load dependant coefficient, $b_{1}$, has its highest value for the PAGD and lowest for the MINR oil with the MINE and PAOR sitting in between them. This means that the load dependent coefficient was being underestimated on the original equation (equation 6.26) for all wind turbine gear oils. Looking to the velocity coefficients, $b_{2}$, it can be seen that these have the effect of decreasing the effect of the speed on the mean coefficient of friction on the gear mesh.

A set of figures was plotted where the effects described above are put into evidence, figures $8.21(\mathrm{c})$ and $8.21(\mathrm{~d})$.

From now on the lubricant factor coefficients on table 8.1 will be used.

Figures 8.10 to 8.13 show the results of the power loss model after the friction coefficient optimization and churning loss model calibration.

Observing the graphics from the loss distribution (figures 8.14 to 8.17), it is clear that the load loss plays a fundamental role on the overall power loss. The churning loss is of the same order of magnitude as the rolling bearings loss. 
8. Calibration of the power loss model and numerical results

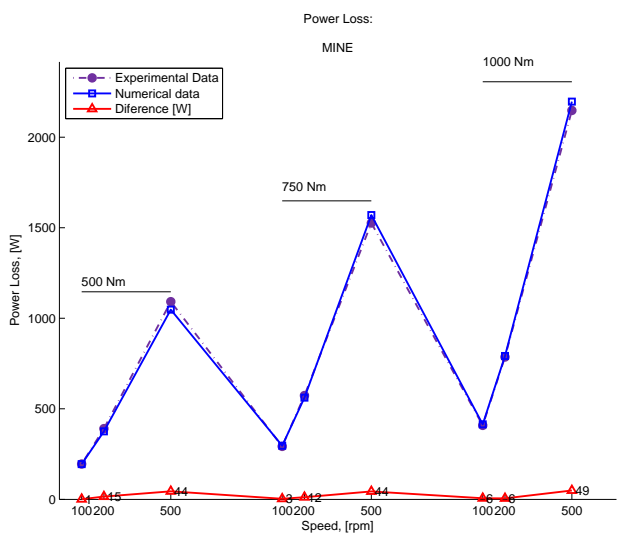

(a)

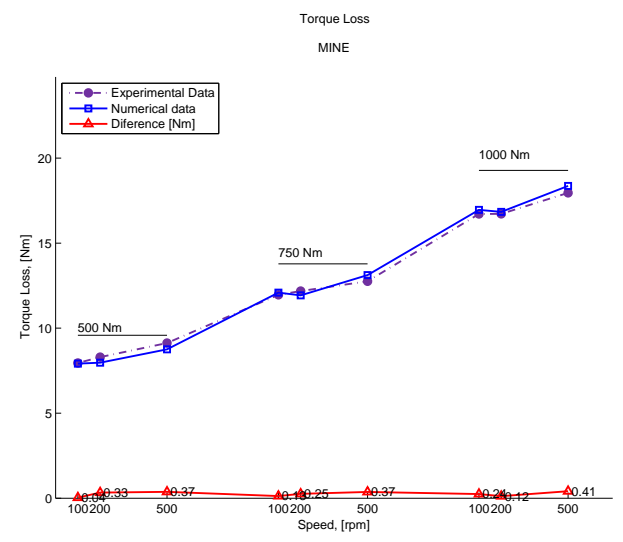

(b)

Figure 8.10.: Optimized loss prediction vs experimental results for MINE oil: a) Power Loss; b) Torque Loss;

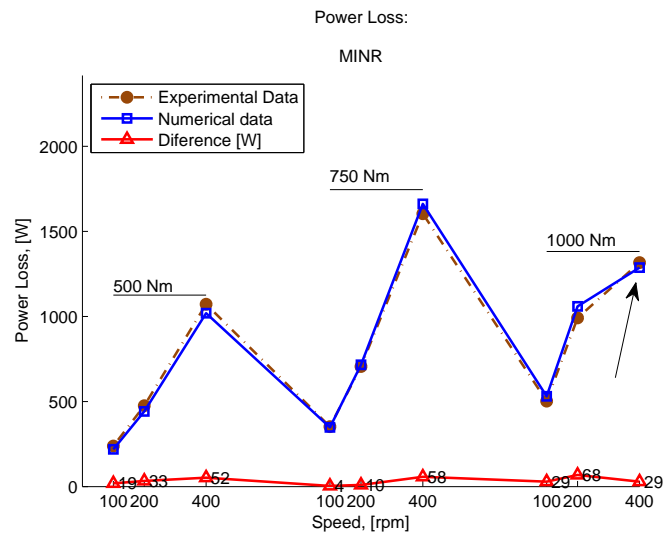

(a)

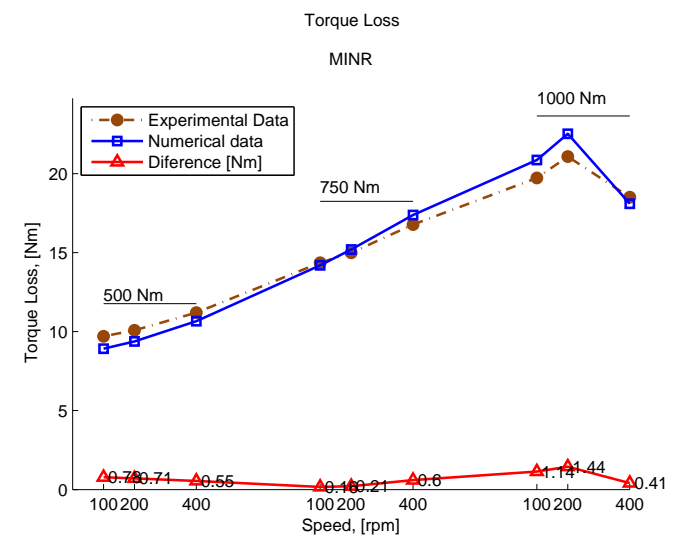

(b)

Figure 8.11.: Optimized power loss prediction vs experimental results for MINR oil: a) Power Loss; b) Torque Loss;

The arrow indicates results of MINR@300 $\mathrm{rpm} / 800 \mathrm{Nm}$, since the temperatures were well above $100^{\circ} \mathrm{C}$ on the MINR@400rpm/750Nm test point. 


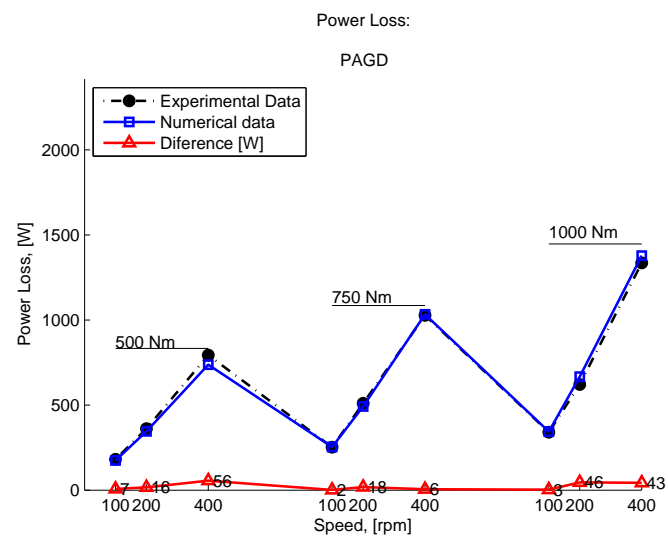

(a)

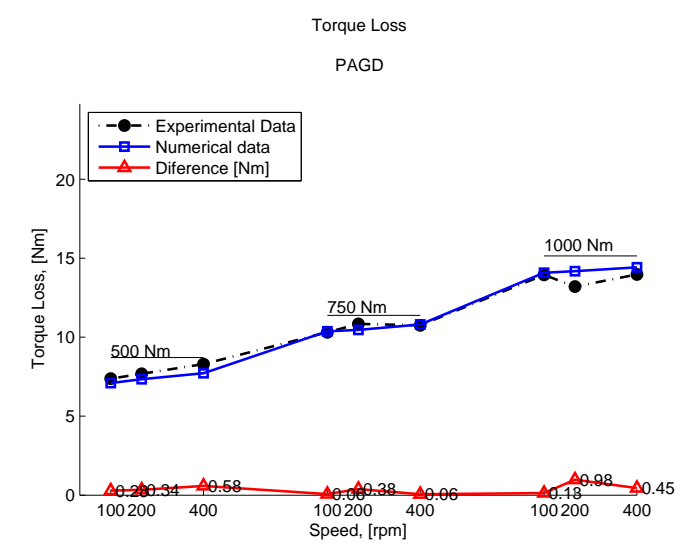

(b)

Figure 8.12.: Optimized loss prediction vs experimental results for PAGD oil: a) Power Loss; b) Torque Loss;

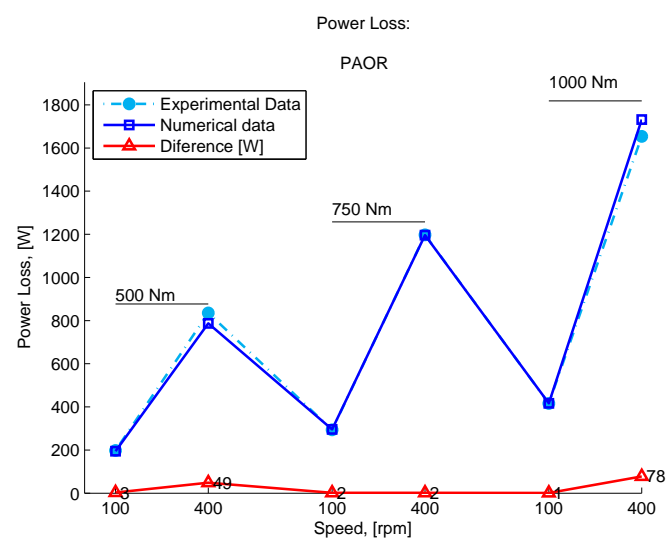

(a)

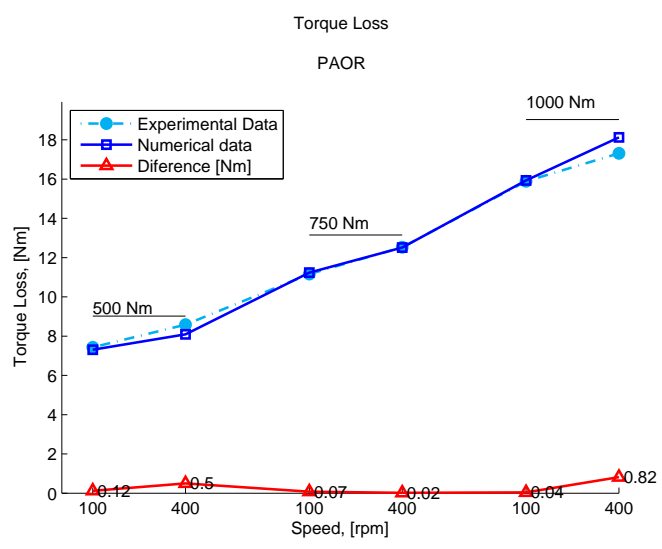

(b)

Figure 8.13.: Optimized loss prediction vs experimental results for PAOR oil: a) Power Loss; b) Torque Loss; 
8. Calibration of the power loss model and numerical results

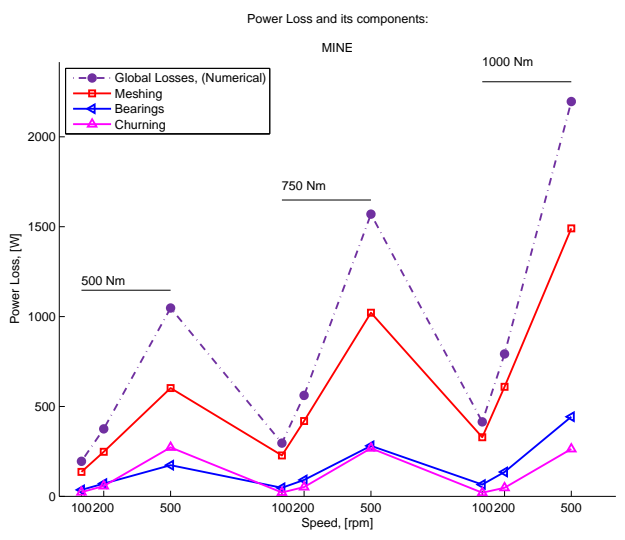

(a)

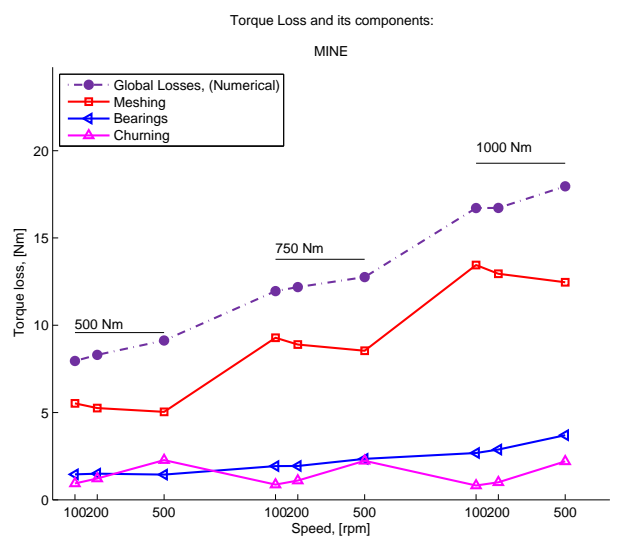

(b)

Figure 8.14.: Optimized loss prediction and its respective components for MINE oil: a) Power Loss; b) Torque Loss;

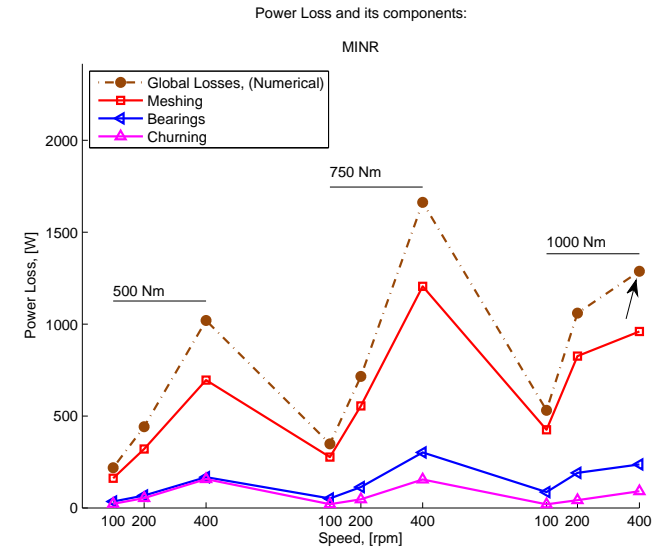

(a)

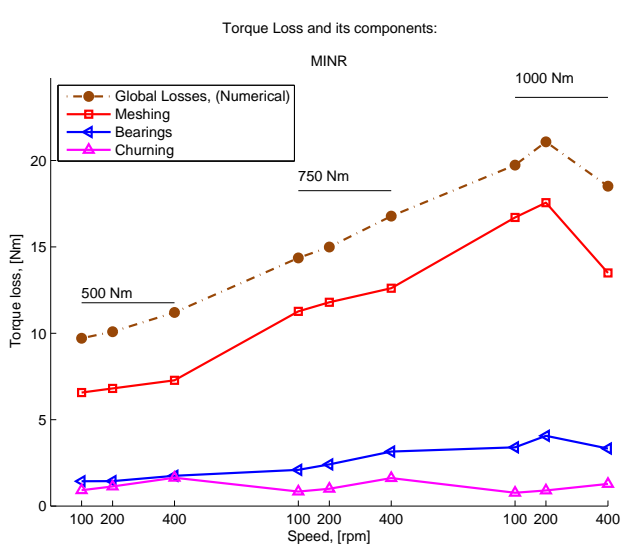

(b)

Figure 8.15.: Optimized loss prediction and its respective components for MINR oil: a) Power Loss; b) Torque Loss;

The arrow indicates results for MINR@300rpm/800 Nm. MINR@300rpm/800 Nm was performed instead of MINR@400 rpm/1000 $\mathrm{Nm}$ since the expected temperatures would be excessive for mineral based lubricants. 


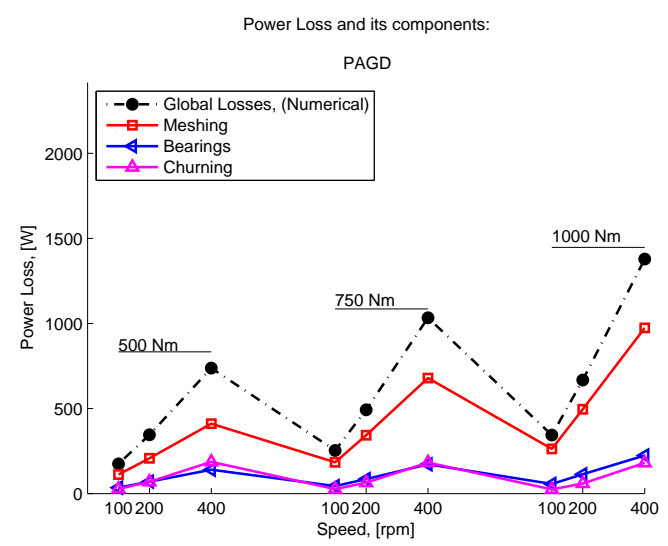

(a)

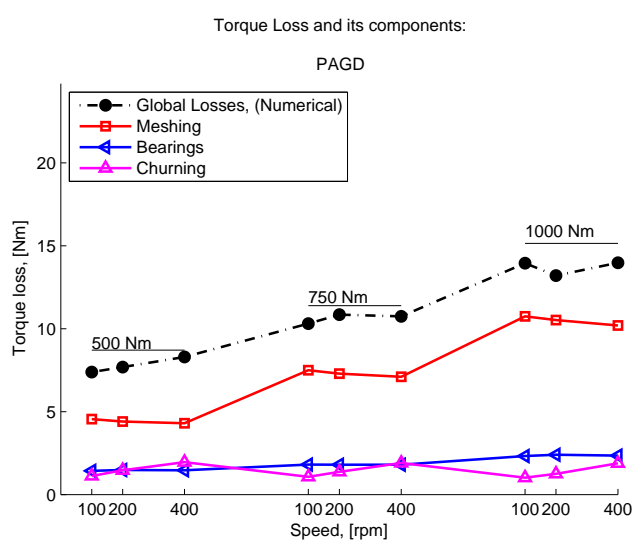

(b)

Figure 8.16.: Optimized loss prediction and its respective components for PAGD oil: a) Power Loss; b) Torque Loss;

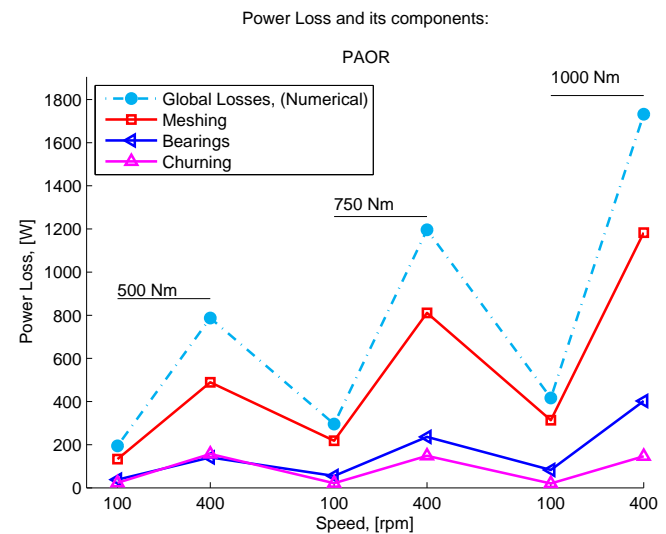

(a)

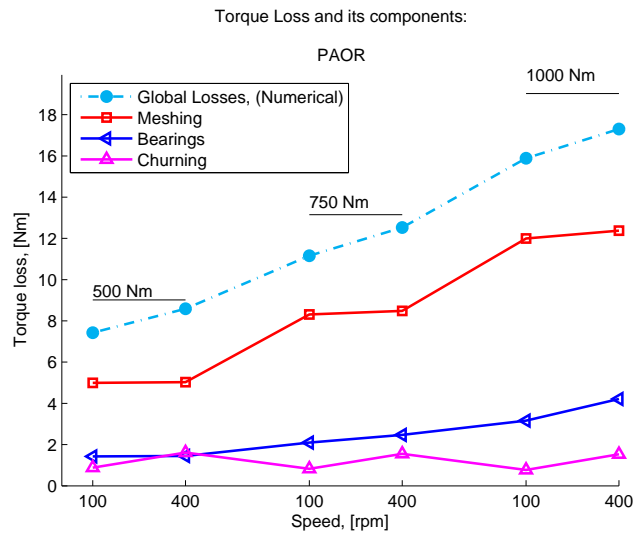

(b)

Figure 8.17.: Optimized loss prediction and its respective components for PAOR oil: a) Power Loss; b) Torque Loss; 
Figure 8.18 shows the relative weights of the different power loss components for the tested lubricants. As expected the losses on gear mesh have the highest contribution on the global power loss.

The churning loss has the highest impact on the overall power loss for the PAGD. This has to do, not only with the load losses being lower, but also due to its higher density and higher viscosity.

For the MINE, PAGD and PAOR the rolling bearings loss represent about $20 \%$ of the overall losses. Figure 8.18(b) also shows that for MINR oil the rolling bearings losses represent about $15 \%$ of the overall loss.

After optimizing the lubricant factor $X_{L}$, coefficients (table 8.1), some more efficiency tests were performed. The testing conditions for these additional tests were in between the test points of the initially defined "test matrix" (table 7.1).

A comparison between the power loss calculated with the optimized coefficient of friction and churning loss and the experimental results obtained using the global heat transfer coefficient was done, as represented in table 8.3. The power loss prediction correlates quite well with the experimental results.

Table 8.3.: Comparison between the experimental and predicted power loss for two experimental points in between the test matrix points.

Optimized lubricant factor coefficients (table 8.1) and churnig loss cortrection factor $\left(c_{f}=3.3\right)$ were used.

\begin{tabular}{ccccc}
\hline Oil & Test Point, $[\mathrm{rpm} / \mathrm{Nm}]$ & Heat loss, $[W]$ & Predicted, $[W]$ & Rel. Diff. [\%] \\
\hline MINE & $150 / 800$ & 427.864 & 448.719 & -4.9 \\
MINE & $300 / 600$ & 803.463 & 680.214 & 15.3 \\
PAOR & $300 / 800$ & 999.132 & 943.210 & 5.6 \\
\hline
\end{tabular}


8.1. Power loss model results and its optimization

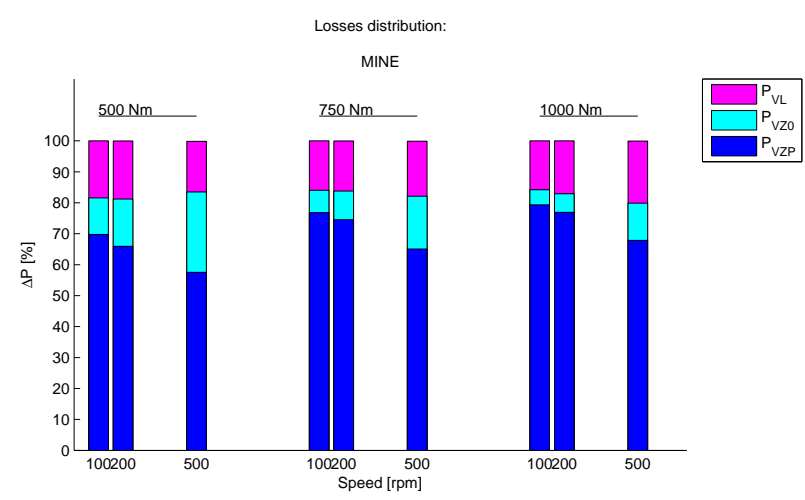

(a) MINE

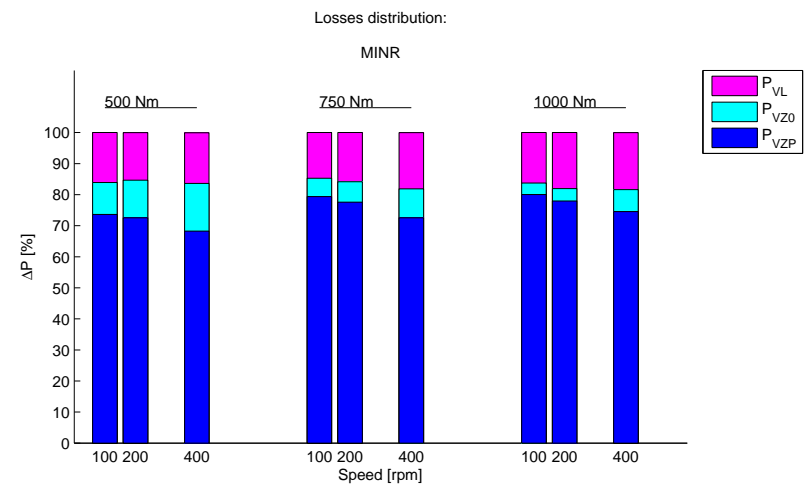

(b) MINR

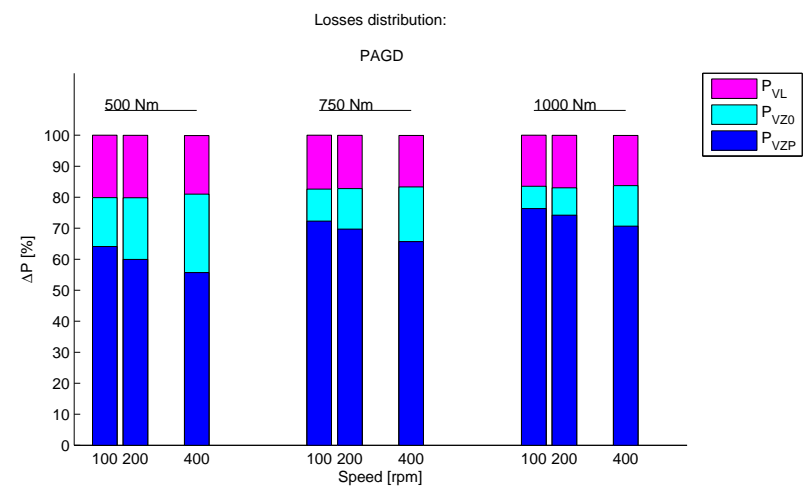

(c) PAGD

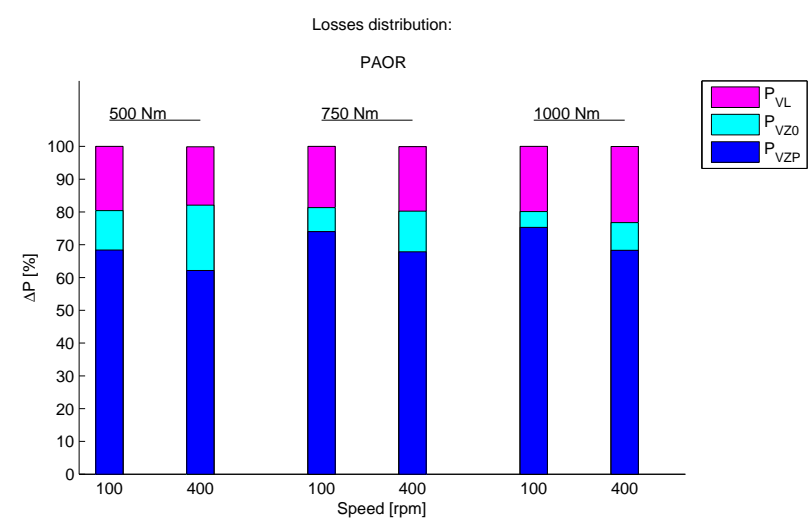

(d) PAOR

Figure 8.18.: Relative distribution of the loss components: a) MINE; b) MINR; c) PAGD; d) PAOR:

$P_{V L}$ - Rolling bearings loss; $P_{V Z 0}$ - Gears churning loss; $P_{V Z P}$ - Gears Load loss; 


\subsection{Power Loss dependence on input speed and input torque}

Using the numerical model implemented with optimizations performed at the churning loss model and friction coefficient it was possible to obtain numerical results for a wide range of working conditions. Only results on range of the tested conditions will be presented.

The power and torque losses were plotted against the input speed and the input torque. On figures 8.22 to 8.21 the efficiency, coefficient of friction, power and torque losses are plotted against the speed for a certain torque and against the torque for a certain speed. For these simulations, the room temperature was set at $25^{\circ} \mathrm{C}$.

\subsubsection{Prediction of the oil sump temperature based on the input power}

The oil sump temperature depends on the power loss and this fairly depends on the input power, a relation between the oil sump temperature and input power was sought.

A correlation of the form of equation 8.8 was tried.

$$
P_{I N}=m \cdot \Delta T^{2}+b \cdot \Delta T
$$

with $\Delta T$ defined as $T_{o i l}-T_{a m b}$ or $T_{w a l l}-T_{a m b}$.

Using the classic quadratic formula to solve it in order to $\Delta T$ one gets:

$$
\Delta T=\frac{\sqrt{4 \cdot m \cdot P_{I N}+b^{2}}-b}{2 \cdot m}
$$

Numerically adjusting the $m$ and $b$ coefficients one obtains the results on the table 8.4. Figure 8.19 shows the predicted $\Delta T$ and the experimental $\Delta T$ as function of the input power. This prediction of $\Delta T$ has an excellent correlation with the experimental results.

\subsubsection{Power loss predictions over a range of working conditions}

Figure 8.20 shows the efficiency as a function of the input torque or input speed. The power loss model with the proposed optimized coefficient of friction between gear theeth distinguishes the lubricants, while the other doesn't. 
8.2. Power Loss dependence on input speed and input torque

Table 8.4.: Optimized coefficients for the oil sump temperature prediction and correlation factor $\left(R^{2}\right)$.

\begin{tabular}{rccc}
\hline Oil & $m$ & $b$ & $R^{2}$ \\
\hline MINE & 2.5004 & 248.8511 & 0.998 \\
MINR & 1.6119 & 222.7312 & 0.997 \\
PAGD & 3.6753 & 256.2901 & 0.998 \\
PAOR & 2.2437 & 274.9222 & 0.988 \\
\hline
\end{tabular}

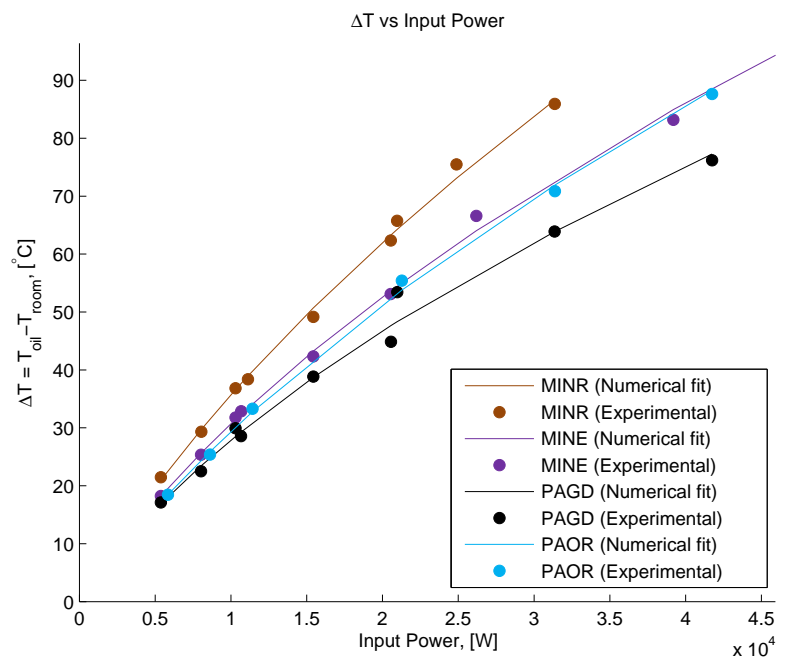

Figure 8.19.: Predicted and experimental oil sump temperature as a function of the input power for the wind turbine gear oils. 
Comparing the effects of speed and torque before and after the optimization of the coefficient of friction, some interesting conclusions can be withdrawn.

Since gear pair $1 / 2$ is subjected to the lowest speeds and highest loads the analysis of the coeffcient of friction behaviour will be made considering this gear pair.

Both models predict an increase of the coefficient of friction with the increase of the torque, as shown in figure 8.21(b). The power loss model considering only the optimized churning loss predicts a decreasing of the average coefficient of friction for all gear oils, with the increase of speed, figures 8.21(a) and 8.21(c).

Considering the optimized power loss model both PAGD and MINE show a small reduction of the coefficient of friction on the gear mesh with the increase of speed (figure 8.21(c)), which suggests that the effect of speed on the generation of the film thickness outweights the viscosity decrease with the increased oil sump temperature from the input power increase. PAOR seems to show a constant coefficient of friction over the same range of conditions. MINR shows increasing coefficient of friction with speed, probably due to its higher viscosity decrease with temperature, which outweights the benefit of increased speed on the generation of film thickness.

The oil that seems to show the best power loss performance is PAGD oil and the worst seems to be MINR. MINE and PAOR oils sitting in between them (figure 8.22). MINE shows such a distinct behaviour from MINR probably due to its high percentage of viscosity improving additives (figure 4.4(a)).

At the lowest speeds and highest torques the PAGD shows about $1.5 \%$ less power loss than MINR oil. The results presented on figures 8.20(d) and 8.23(d) show that the gap between the PAGD and the other oils increases as the load increases. In a real world application, on lets say, a wind turbine gearbox, where the forces are way higher than the ones verified on the test gearbox, it is expected that the gap between the PAGD and the other gear oils widens. It should be noted that the torque loss remains practically the same over the tested range of speeds at the same loading conditions for the PAGD and MINE oils. 


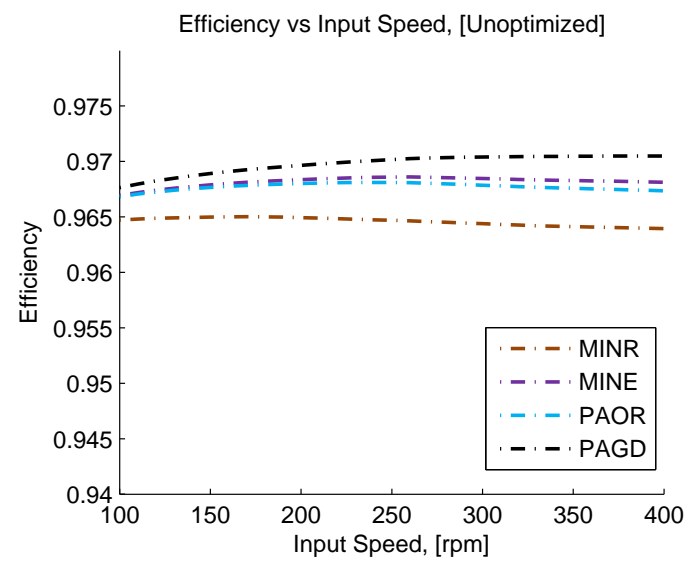

(a)

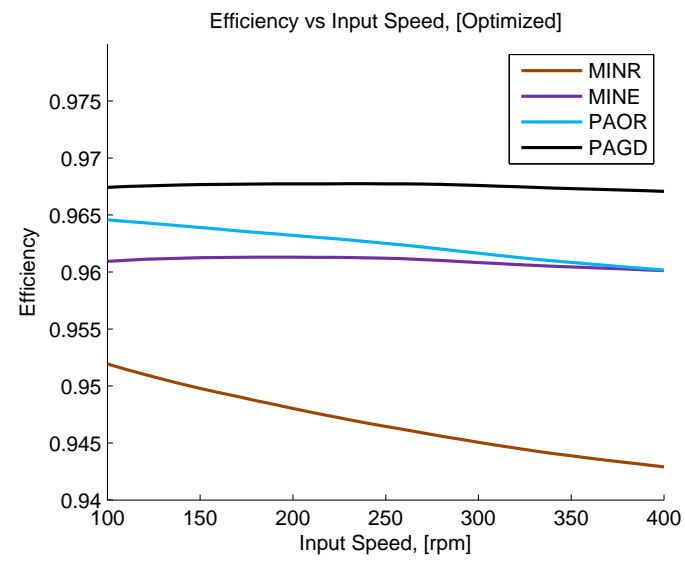

(c)

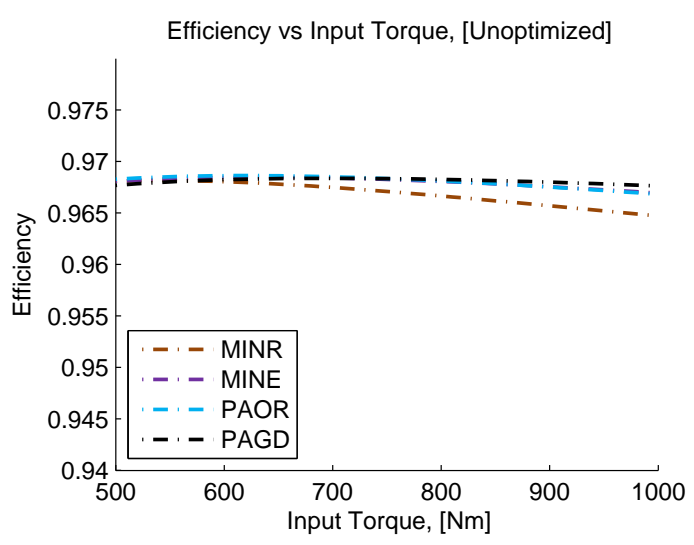

(b)

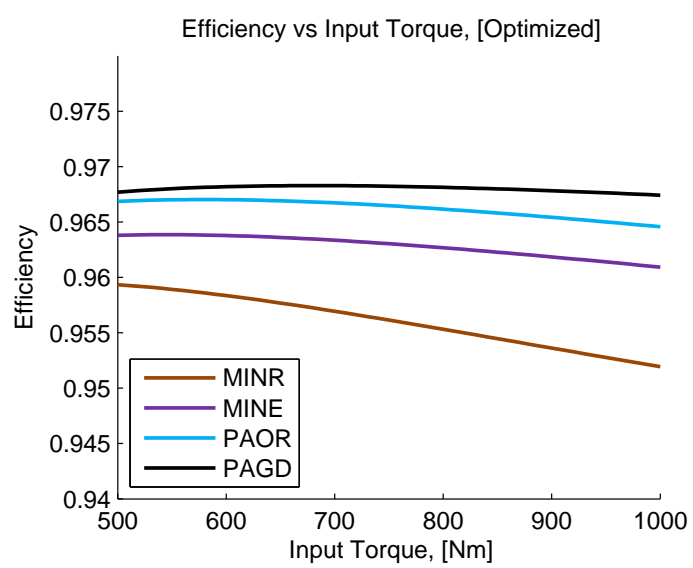

(d)

Figure 8.20.: Efficiency as a function of speed and torque:

a) input speed $\left(T Q_{I N}=1000 N m\right)^{1}$;

b) input torque $\left(n_{I N}=100 \mathrm{rpm}\right)^{1}$;

c)input speed $\left(T Q_{I N}=1000 \mathrm{Nm}\right)^{2}$;

d)input torque $\left(n_{I N}=100 \mathrm{rpm}\right)^{2}$;

1 - Power loss model considering the churning loss correction factor $\left(c_{f}=3.3\right)$;

2 - Power loss model considering the churning loss correction factor $\left(c_{f}=3.3\right)$ and optimized lubricant factor, $X_{L}$. 
8. Calibration of the power loss model and numerical results

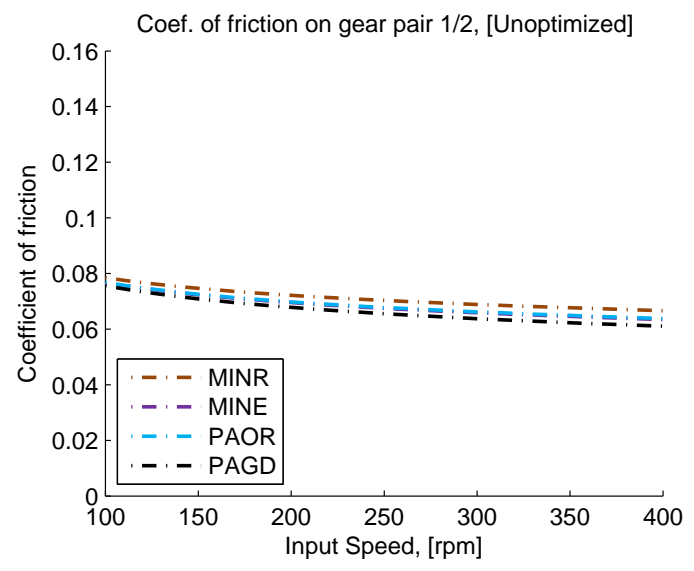

(a)

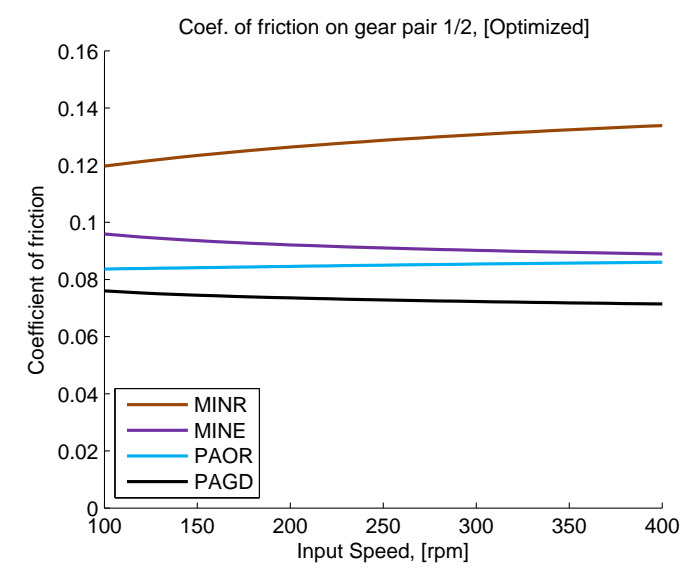

(c)

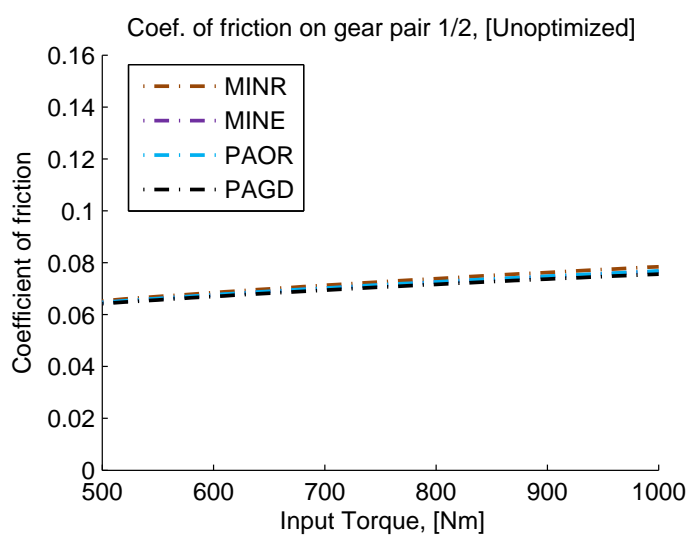

(b)

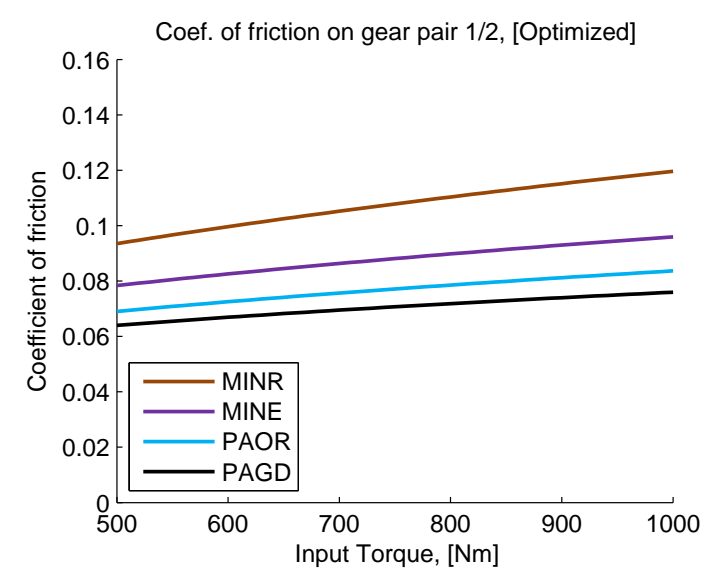

(d)

Figure 8.21.: Coefficient of friction on the gear pair $1 / 2$ as a function of speed and torque:
a) input speed $\left(T Q_{I N}=1000 N m\right)^{1}$;
b) input torque $\left(n_{I N}=100 \mathrm{rpm}\right)^{1}$;
c) input speed $\left(T Q_{I N}=1000 N m\right)^{2}$;
d) input torque $\left(n_{I N}=100 \mathrm{rpm}\right)^{2}$
1 - Base Michaelis [15], coefficient of friction;
2 - Considering the optimized lubricant factor, $X_{L}$. 


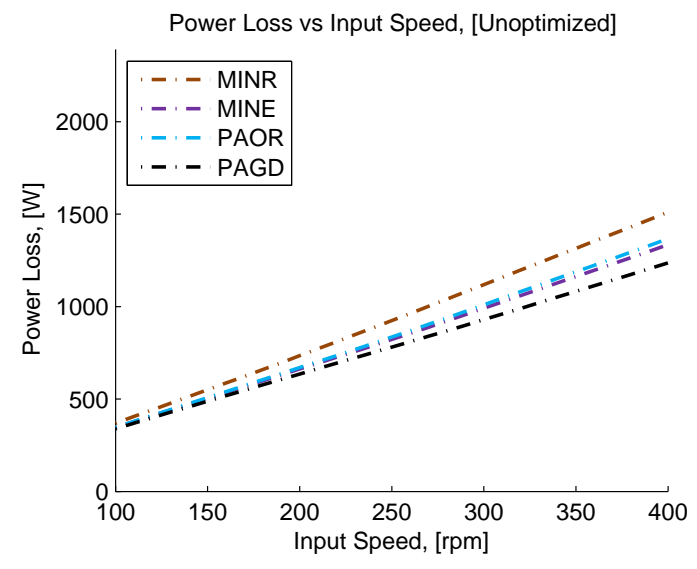

(a)

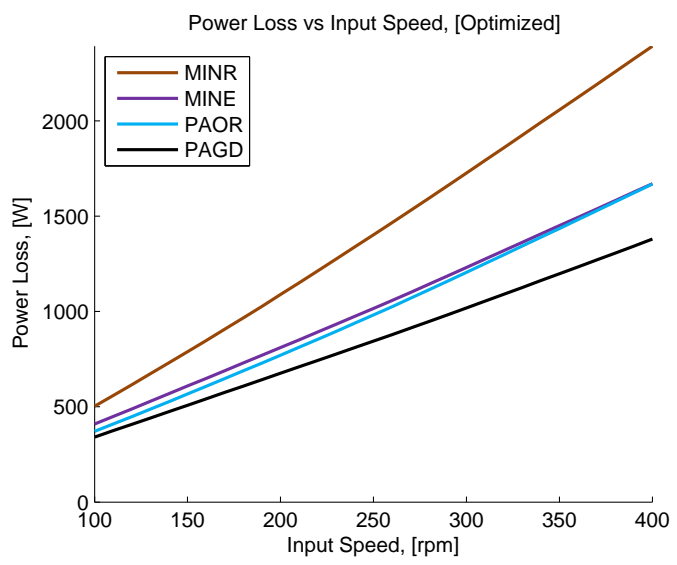

(c)

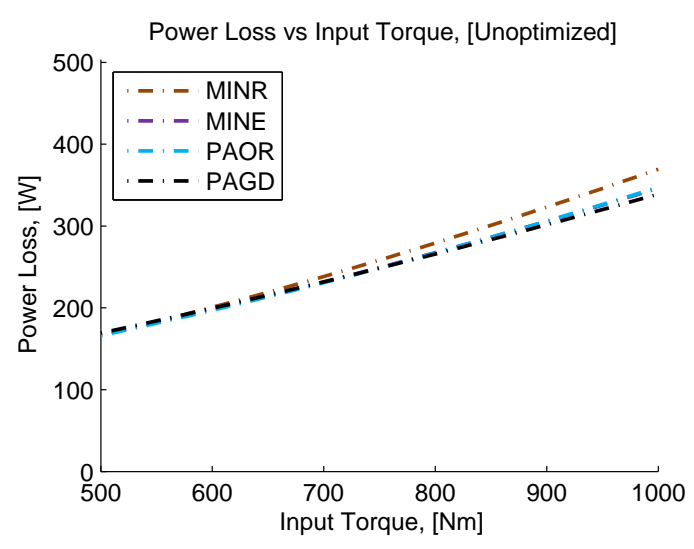

(b)

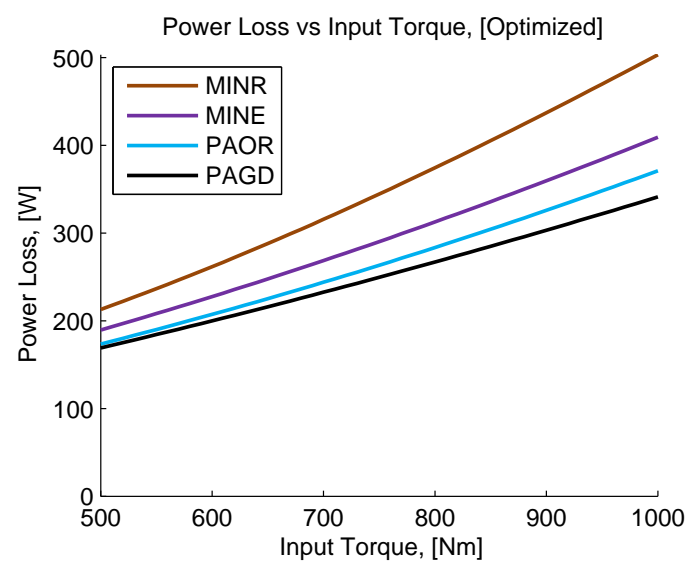

(d)

Figure 8.22.: Power loss prediction as a function of speed and torque:

a) input speed $\left(T Q_{I N}=1000 N m\right)^{1}$;

b) input torque $\left(n_{I N}=100 \mathrm{rpm}\right)^{1}$;

c) input speed $\left(T Q_{I N}=1000 N m\right)^{2}$;

d) input torque $\left.\left(n_{I N}=100 \mathrm{rpm}\right)^{2}\right)$

1 - Power loss model considering the churning loss correction factor $\left(c_{f}=3.3\right)$;

2 - Power loss model considering the churning loss correction factor $\left(c_{f}=3.3\right)$, and optimized lubricant factor, $X_{L}$. 
8. Calibration of the power loss model and numerical results

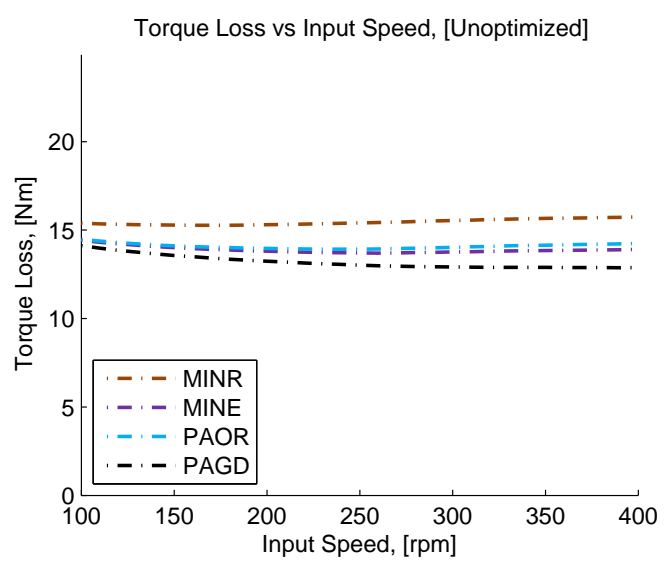

(a)

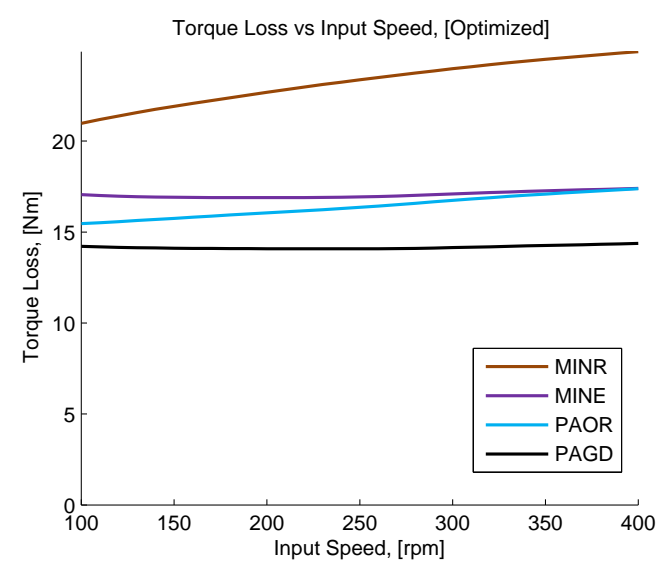

(c)

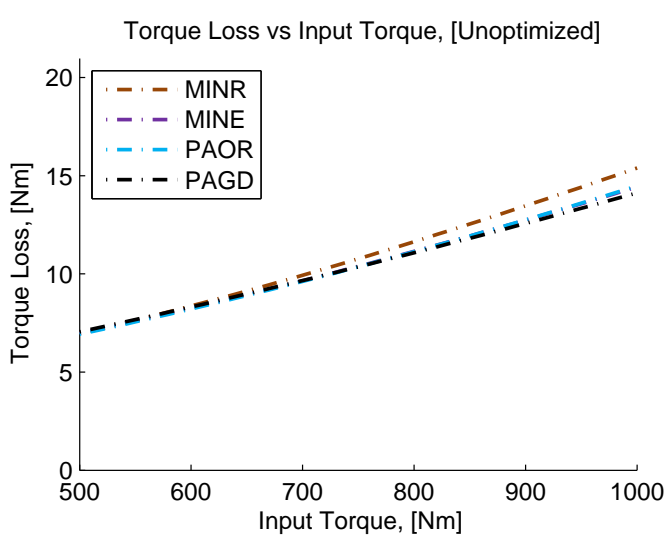

(b)

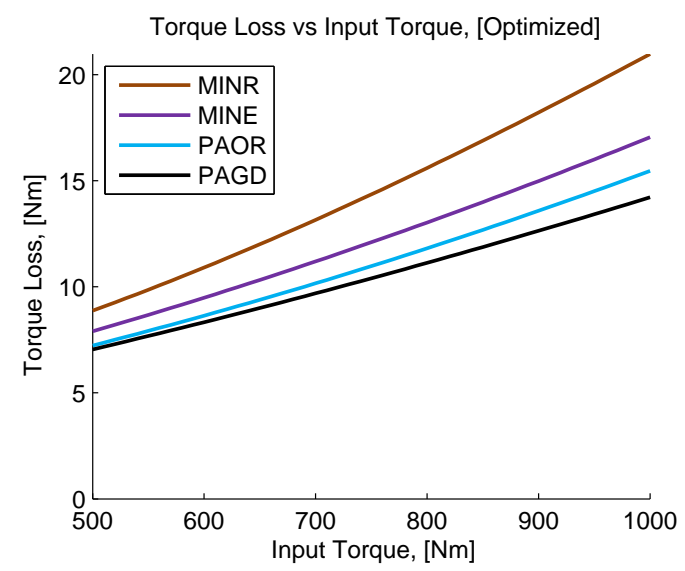

(d)

Figure 8.23.: Torque loss as a function of speed and torque:
a) input speed $\left(T Q_{I N}=1000 \mathrm{Nm}\right)^{1}$;
b) input torque $\left(n_{I N}=100 \mathrm{rpm}\right)^{1}$;
c) input speed $\left(T Q_{I N}=1000 \mathrm{Nm}\right)^{2}$;
d) input torque $\left(n_{I N}=100 \mathrm{rpm}\right)^{2}$

1 -Power loss model considering the churning loss correction factor $\left(c_{f}=3.3\right)$;

2 -Power loss model considering the churning loss correction factor $\left(c_{f}=3.3\right)$, and optimized lubricant factor, $X_{L}$. 
Analysing figures 8.24 some conclusions can be withdrawn. Figure 8.24(a) shows that the optimal operating conditions for the MINE oil regarding efficiency are at about $600 \mathrm{Nm}$ on input torque and input speeds on the range of $150-250 \mathrm{rpm}$. It seems that MINR, figure 8.24(b), optimal working conditions are the ones that provide the lowest input power. PAOR, figure 8.24(d), seems to perform best from 100 to $200 \mathrm{rpm}$ and up to $800 \mathrm{Nm}$. PAGD, figure 8.24 (c), seems to perform the best of the four, also it shows its highest efficiency level in the range of $550-900 \mathrm{Nm}$ and speeds up to $250 \mathrm{rpm}$.

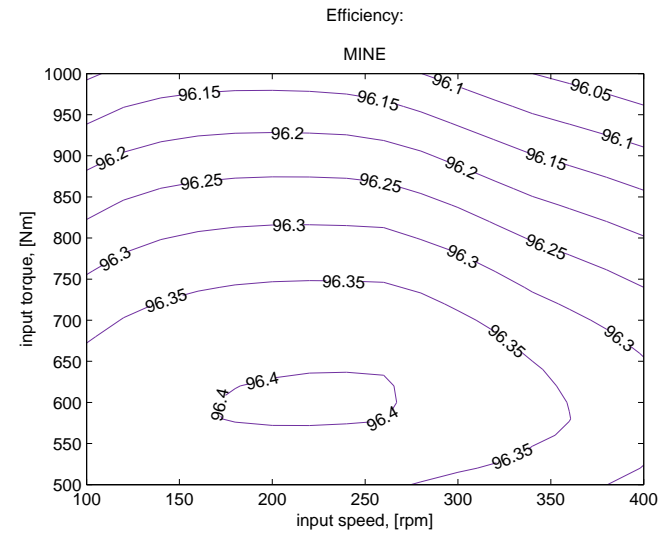

(a)

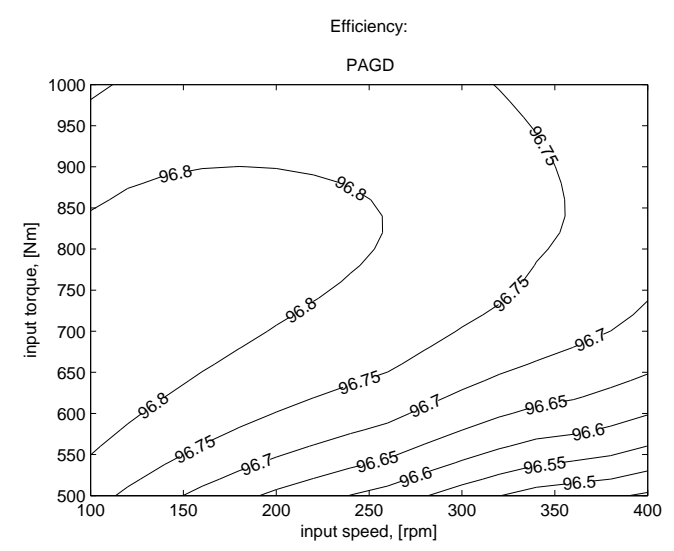

(c)

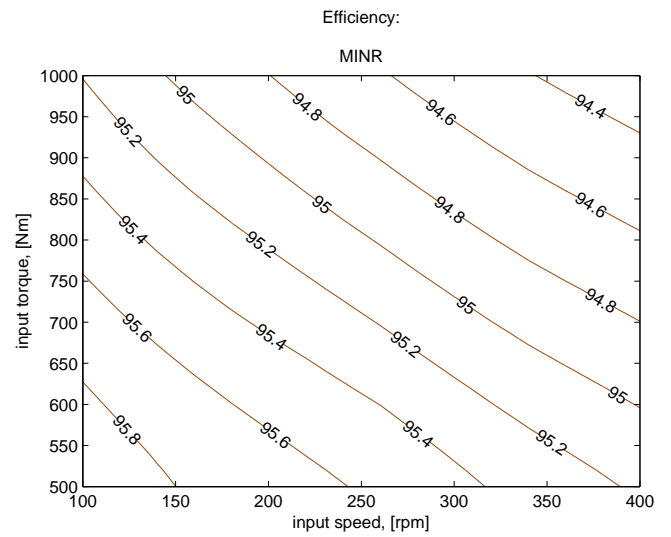

(b)

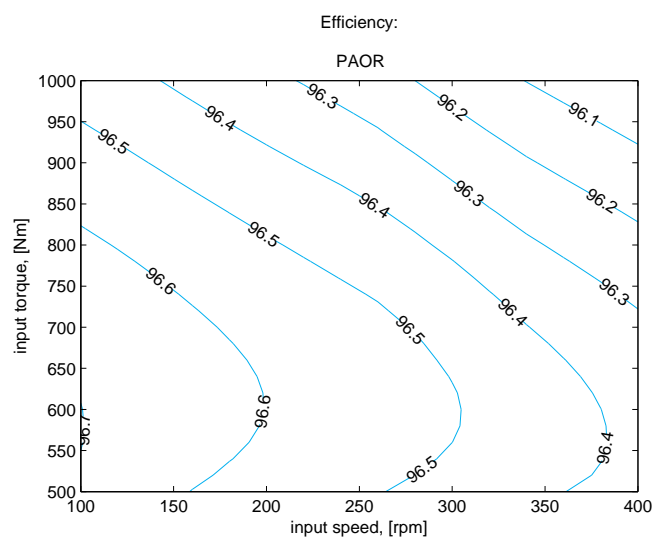

(d)

Figure 8.24.: Predicted efficiency maps over the range of tested conditions ${ }^{1}$ :

a) MINE; b) MINR; c) PAGD; d)PAOR;

1 - Power loss model considering the churning correction $\left(c_{f}=3.3\right)$ factor and optimized lubricant factor, $X_{L}$.

For further results including contour maps for all of the loss components in terms of both power and torque as well as the mean gear mesh friction coefficient as a function of both input power and input speed refer to appendix B.5. 



\section{Conclusions and Future work}

\subsection{Conclusions}

\subsubsection{Conclusions based on experimental evidence}

1. Analysing the stabilization temperatures it is verified that the PAGD oil generates temperatures up to $20^{\circ} \mathrm{C}$ lower than MINR oil for the most severe conditions. The difference on the stabilization temperatures to MINE and PAOR is about $10^{\circ} \mathrm{C}$ for the most severe conditions.

2. PAGD oil has shown the lowest power loss values on the tests performed. MINR had the highest and the MINE and PAOR oils sat in between them but closer to the PAGD with a slight advantage for the Poly- $\alpha$-olefin based lubricant.

3. When the thermal equilibrium is reached, the difference between oil sump temperature and housing external wall temperature of the transfer gearbox plotted as a function of the difference between oil sump temperature and room temperature, is lubricant independent. This suggests that the oil sump temperature should be practically uniform. Two speed dependant regimes and a transition zone were identified.

4. PAGD has shown orders of magnitude lower wear indexes and its wear particles seem to have less evidence of oxidation comparing with the other wind turbine gear oils. MINR had the worst performance and PAOR and MINE sat in between PAGD and MINR with a slight advantage for the Poly- $\alpha$-olefin based lubricant in terms of wear indexes, but with comparable wear particles.

5. The MINE oil has showed that its special formulation, with emphasis on viscosity improving additives, made a significant difference on its behaviour clearly distinguish from the MINR oil, despite both sharing a mineral basis.

6. MINE has been advertised to behave almost like an poly- $\alpha$-olefin, and it has proven to perform quite close to the PAOR oil. 


\subsubsection{Conclusions based on numerical results}

Concerning the numerical model, the optimized lubricant factor coefficients can adjust not only the average coefficient of friction between gear teeth, but can also be compensating possible power loss deviations on the gear churning and rolling bearing losses. There is no guarantee that the rolling bearings load loss and no-load loss on gears and other mechanical elements are being correctly evaluated. Therefore the calculated oil coefficients and gears churning correction through speed should only be used to perform calculations that relate to the evaluated gearbox and at conditions on the range of those of the performed testing.

1. A method was proposed to calibrate the churning power loss through the analysis of the balance temperatures and the critical Reynolds numbers. A multiplicative speed coefficient was used to calibrate the entire gear churning power loss model.

2. The numerical optimization of the lubricant factor was possible by adjusting just two parameters on the mean coefficient of friction formula, the speed and load exponents.

3. The power loss was predicted for three distinct points of two oils, (MINE and PAOR), that were not on the test matrix and the predictions were in fair agreement with the experimental results.

4. The friction loss at the gear mesh have the highest contribution for the global power loss across all four wind turbine gear oils. The churning power loss assumes the highest impact on the overall loss for the PAGD oil. This has to do, not only with the load losses being lower, but also due to its higher density and much higher viscosity at the same operating conditions. For the MINE, PAGD and PAOR the rolling bearings power loss represent about $20 \%$ of the overall loss. For MINR oil the bearings power loss represent about $15 \%$ of the overall loss.

5. PAGD and MINE oils have proven to be fairly insensitive to speed changes when considering the torque loss. MINR and PAOR have shown that its torque loss are fairly speed dependant. PAOR starts loosing its advantage to MINE as the speed increases.

6. Both PAGD and MINE show a small reduction on the coefficient of friction on the gear mesh with the increase of speed, which suggests that the effect of speed on the generation of the film thickness outweights the viscosity decrease 
with the increased oil sump temperature from the input power increase. PAOR seems to show a constant coefficient of friction over the same range of conditions. MINR shows increasing coefficient of friction with speed, probably due to its higher viscosity decrease with temperature, which outweights the benefit effect of increased speed on the generation of film thickness.

\subsection{Future work}

The tests with the PAOR oil should be finished to verify if it would have any effect on the correction coefficients. An ester based lubricant should be tested in order to compare it with the already tested gear oils.

In order to better assess the quality of the optimized coefficients and overall model performance, additional tests in between the performed test points, should be performed and compared with the predictions.

To improve the range of validity of the lubricant factor coefficients further experimental testing is required. Additional testing should also be performed on a single gear pair (FZG test rig), at low and high torques for a wide range of speeds. The torque loss should be monitored with torque load cells.

Tests at controlled temperature and very low loads could be conducted at various speeds in order to assess the effect of the churning losses. This procedure could help to validate the method used to calibrate the gears churning power loss.

In order to have a precise measurement of the torque loss, torque sensors for the torque supplied by the motor should be installed on the gearbox test rig.

If the gearbox test rig allowed for testing at controlled temperature and very low load torques the churning power loss could be estimated and compared with the ones predicted by the calibrated gear churning power loss. From the experimental results one could subtract the optimized friction power loss, (coefficients derived from the experimental results on the FZG test rig), and churning power loss. This procedure would allow for a possible optimization of the rolling bearings power loss. 



\section{Bibliography}

[1] SKF General Catalogue 6000 EN, SKF, November 2005.

[2] J A Brandão, M Meheux, J H O Seabra, F Ville, and M J D Castro, Traction curves and rheological parameters of fully formulated gear oils, Proceedings of the Institution of Mechanical Engineers, Part J: Journal of Engineering Tribology (2011).

[3] C. Changenet, G. Leprince, F. Ville, and P. Velex, A Note on Flow Regimes and Churning Loss Modeling, Journal of Mechanical Design 133 (2011), no. 12, 121009.

[4] C. Changenet and P. Velex, A model for the prediction of churning losses in geared transmissions - preliminary results, Journal of Mechanical Design 1 (2007), $128-133$.

[5] C. Changenet and P. Velex, Housing Influence on Churning Losses in Geared Transmissions, Journal of Mechanical Design 130 (2008), no. 6, 062603.

[6] Hanspeter Dinner, KISSsoft:- Wind Turbine Gearbox Calculation, April 2010.

[7] EU Ecolabel, Eu ecolabel, http://www.svanen.se/en/EU-Ecolabel/, $11 / 06 / 2012$.

[8] Ecolabel.se, White swan eco label, http://www.svanen.se/en/, 11/06/2012.

[9] Blauer Engel, Blauer engel, http://www.blauer-engel.de/, 11/06/2012.

[10] _ RAL-UZ 64, http://www.blauer-engel.de/en/products_brands/ vergabegrundlage.php?id=88, 19/06/2012.

[11] EWEA European Wind Energy Association, Wind energy factsheets, April 2010.

[12] D. Gonçalves, Efficiency of a Gearbox Lubricated with Wind Mill gear Oils, Master's dissertation, Faculdade de Engenharia da Universidade do Porto, 2011. 
[13] Greenseal, Green seal eco label, http://www.greenseal.org/Home.aspx, $11 / 06 / 2012$.

[14] B.-R. Höhn, K. Michaelis, and M. Hinterstoißer, Optimization of gearbox efficiency, goriva i maziva 48 (2009), no. 4, 462-480.

[15] B.-R. Höhn, K. Michaelis, and T. Vollmer, Thermal Rating of Gear Drives: Balance Between Power Loss and Heat Dissipation, AGMA Technical Paper (1996).

[16] G. Leprince, Pertes mécaniques par frottement et lubrification dans une boîte de vitesses, Ph.D. dissertation, L'Institut National des Sciences Appliquees de Lyon, 2011.

[17] Gauthier LePrince, Christophe Changenet, Fabrice Ville, Philippe Velex, Christophe Dufau, and Frédéric Jarnias, Influence of Aerated Lubricants on Gear Churning Losses - An Engineering model, Tribology Transactions 54 (2011), no. 6, 929-938.

[18] KLUBER Lubrication, Lubrication of gear systems - From large to small stationary gear sets, edition 11.03 ed., Kluber Lubrication Munchen KG.

[19] M. Maatar and P. Velex, An Analytical Expression for the Time-Varying Contact Length in Perfect Cylindrical Gears: Some Possible Applications in Gear Dnamics, Journal of Mechanical Design Vol. 118 (DECEMBER 1996), 586-589.

[20] Fausto Pedro García Márquez, Andrew Mark Tobias, Jesús María Pinar Pérez, and Mayorkinos Papaelias, Condition monitoring of wind turbines: Techniques and methods, Renewable Energy 46 (2012), no. 0, 169 - 178.

[21] R. Martins, Simulação e avaliação experimental do comportamento energético de uma caixa transfer para veículos de tracção integral, Master's dissertation, Faculdade de Engenharia da Universidade do Porto, 2002.

[22] Matweb, Mechanical properties of DIN 15CrNi6 steel, http://www . matweb.com/ search/QuickText. aspx?SearchText=15CrNi6, 06/06/2012.

[23] G. Mordukhovich and N. Anderson, Lubrication in helical gears, TriboTest 9 (2002), no. 1, 57-68, cited By (since 1996) 1.

[24] F. Roux, Notion de tribologie, em La Lubrification Industrielle - Tome 1 - Transmissions Compresseurs, Turbines, Publications de l'Institue Français du Pétrole, 1984. 
[25] Jorge Seabra, Armando Campos, and Alexandre Sottomayor, Lubrificação Elastohidrodinâmica, Departamento de Engenharia Mecânica e Gestão Industriual, Seç̧ão de Mecânica Aplicada, Porto, 2002. 

A. Appendix 
A. Appendix

A.1. Reports from the experimental tests 


\section{A.1.1. MINE Oil}


A. Appendix

\begin{tabular}{|c|c|c|c|}
\hline Test Number: 1 & Date: $14 / 03 / 2012$ & By: Pedro Marques & \\
\hline & & Oil Property & Units \\
\hline Oil Designation & & MINE & - \\
\hline Viscosity at $40^{\circ} \mathrm{C}$ & & 328.59 & $c S t$ \\
\hline Viscosity at $70^{\circ} \mathrm{C}$ & & 92.72 & $c S t$ \\
\hline Viscosity at $100^{\circ} \mathrm{C}$ & & 37.88 & $c S t$ \\
\hline Bulk Density at $25^{\circ} \mathrm{C}$ & & 886.74 & $\mathrm{Kg} / \mathrm{m}^{3}$ \\
\hline & & Imposed working conditions & Units \\
\hline $\mathrm{n}_{\text {in }}$ & & 100 & rpm \\
\hline $\mathrm{TQ}_{\mathrm{in}}$ & & 500 & $N m$ \\
\hline Warmup period & & 240 & $\min$ \\
\hline Test period & & 240 & $\min$ \\
\hline & & Actual working conditions & Units \\
\hline $\mathrm{n}_{\text {in }}$ & & 102.379 & rpm \\
\hline $\mathrm{n}_{\text {out }}$ & & 234.607 & rpm \\
\hline $\mathrm{TQ}_{\text {in }}$ & & 501.291 & $\mathrm{Nm}$ \\
\hline TQ out & & 212.462 & $N m$ \\
\hline TQout (theoretical) & & 218.755 & $\mathrm{Nm}$ \\
\hline Input Power & & 5374.39 & $W$ \\
\hline & & Temperature readings & Units \\
\hline $\mathrm{T}_{\text {oil }}$ & & 43.405 & ${ }^{\circ} \mathrm{C}$ \\
\hline $\mathrm{T}_{\text {wall }}$ & & 38.707 & ${ }^{\circ} \mathrm{C}$ \\
\hline $\mathrm{T}_{\text {wall }}$ (slave) & & 37.351 & ${ }^{\circ} \mathrm{C}$ \\
\hline \multirow[t]{2}{*}{$\mathrm{T}_{\mathrm{amb}}$} & & 24.966 & ${ }^{\circ} \mathrm{C}$ \\
\hline & & Additional information & Units \\
\hline$\Delta \mathrm{TQ}$ & & 6.300 & $N m$ \\
\hline $\mathrm{T}_{\mathrm{oil}}-\mathrm{T}_{\mathrm{amb}}$ & & 18.438 & ${ }^{\circ} \mathrm{C}$ \\
\hline $\mathrm{T}_{\mathrm{wall}}-\mathrm{T}_{\mathrm{amb}}$ & & 13.741 & ${ }^{\circ} \mathrm{C}$ \\
\hline
\end{tabular}

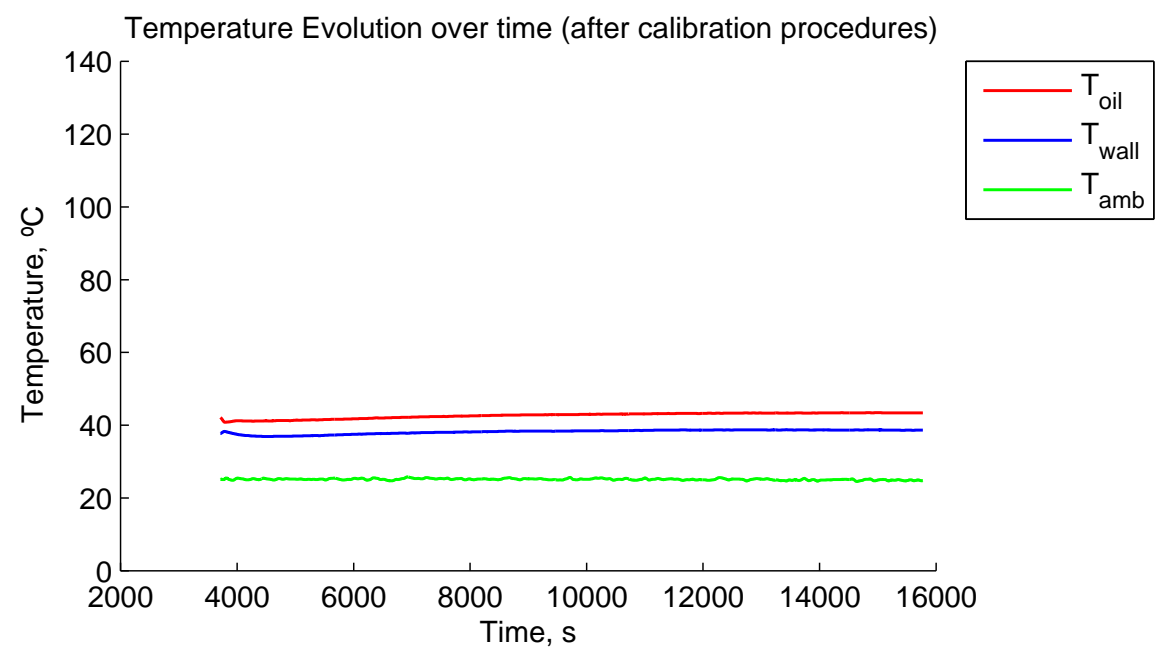


A.1. Reports from the experimental tests

\begin{tabular}{|c|c|c|c|c|}
\hline Test Number: 2 & Date: & $15 / 03 / 2012$ & By: Pedro Marques & \\
\hline & & & Oil Property & Units \\
\hline Oil Designation & & & MINE & - \\
\hline Viscosity at $40^{\circ} \mathrm{C}$ & & & 328.59 & $c S t$ \\
\hline Viscosity at $70^{\circ} \mathrm{C}$ & & & 92.72 & $c S t$ \\
\hline Viscosity at $100^{\circ} \mathrm{C}$ & & & 37.88 & $c S t$ \\
\hline Bulk Density at $25^{\circ} \mathrm{C}$ & & & 886.74 & $\mathrm{Kg} / \mathrm{m}^{3}$ \\
\hline & & & Imposed working conditions & Units \\
\hline $\mathrm{n}_{\text {in }}$ & & & 100 & rpm \\
\hline $\mathrm{TQ}_{\mathrm{in}}$ & & & 750 & $\mathrm{Nm}$ \\
\hline Warmup period & & & 240 & $\min$ \\
\hline Test period & & & 240 & $\min$ \\
\hline & & & Actual working conditions & Units \\
\hline $\mathrm{n}_{\text {in }}$ & & & 102.051 & rpm \\
\hline $\mathrm{n}_{\text {out }}$ & & & 233.855 & rpm \\
\hline $\mathrm{TQ}_{\mathrm{in}}$ & & & 750.995 & $\mathrm{Nm}$ \\
\hline TQout & & & 318.60 & $\mathrm{Nm}$ \\
\hline TQout (theoretical) & & & 327.722 & $N m$ \\
\hline Input Power & & & 8025.66 & $W$ \\
\hline & & & Temperature readings & Units \\
\hline $\mathrm{T}_{\text {oil }}$ & & & 50.036 & ${ }^{\circ} \mathrm{C}$ \\
\hline $\mathrm{T}_{\text {wall }}$ & & & 43.984 & ${ }^{\circ} \mathrm{C}$ \\
\hline $\mathrm{T}_{\text {wall }}$ (slave) & & & 43.108 & ${ }^{\circ} \mathrm{C}$ \\
\hline \multirow[t]{2}{*}{$\mathrm{T}_{\mathrm{amb}}$} & & & 24.666 & ${ }^{\circ} \mathrm{C}$ \\
\hline & & & Additional information & Units \\
\hline$\Delta \mathrm{TQ}$ & & & 9.362 & $N m$ \\
\hline $\mathrm{T}_{\mathrm{oil}}-\mathrm{T}_{\mathrm{amb}}$ & & & 25.370 & ${ }^{\circ} \mathrm{C}$ \\
\hline $\mathrm{T}_{\mathrm{wall}}-\mathrm{T}_{\mathrm{amb}}$ & & & 19.318 & ${ }^{\circ} \mathrm{C}$ \\
\hline
\end{tabular}

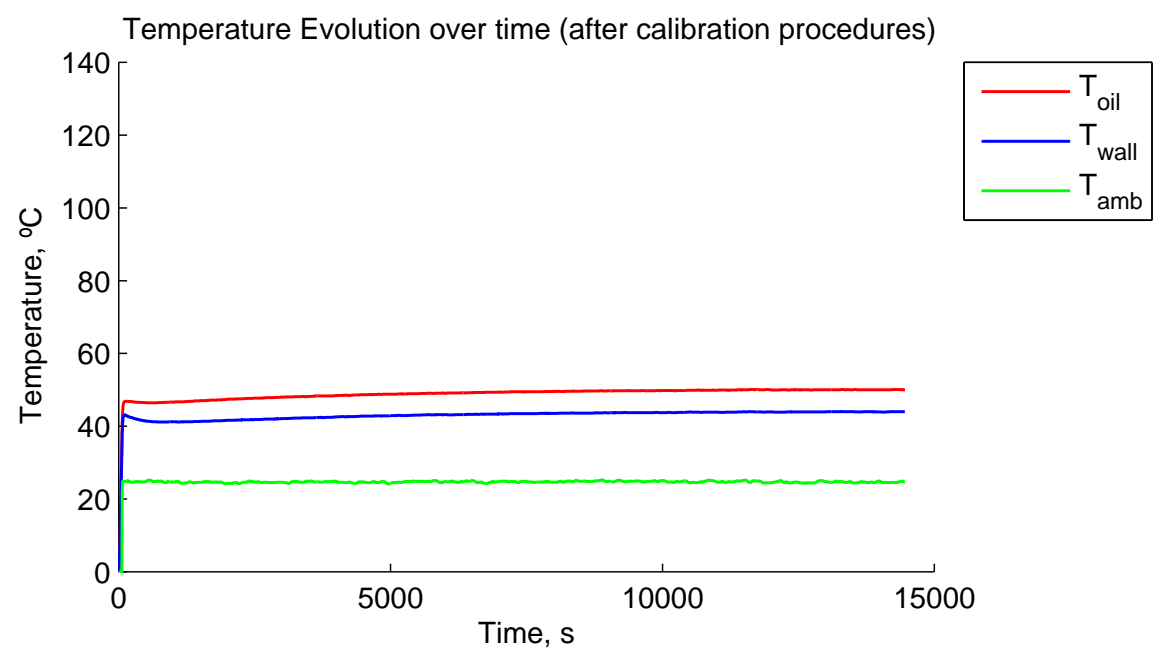


A. Appendix

\begin{tabular}{|c|c|c|c|c|}
\hline Test Number: 3 & Date: & $16 / 03 / 2012$ & By: Pedro Marques & \\
\hline & & & Oil Property & Units \\
\hline Oil Designation & & & MINE & - \\
\hline Viscosity at $40^{\circ} \mathrm{C}$ & & & 328.59 & $c S t$ \\
\hline Viscosity at $70^{\circ} \mathrm{C}$ & & & 92.72 & $c S t$ \\
\hline Viscosity at $100^{\circ} \mathrm{C}$ & & & 37.88 & $c S t$ \\
\hline Bulk Density at $25^{\circ} \mathrm{C}$ & & & 886.74 & $\mathrm{Kg} / \mathrm{m}^{3}$ \\
\hline & & & Imposed working conditions & Units \\
\hline $\mathrm{n}_{\text {in }}$ & & & 100 & rpm \\
\hline $\mathrm{TQ}_{\mathrm{in}}$ & & & 1000 & $\mathrm{Nm}$ \\
\hline Warmup period & & & 240 & $\min$ \\
\hline Test period & & & 240 & $\min$ \\
\hline & & & Actual working conditions & Units \\
\hline $\mathrm{n}_{\mathrm{in}}$ & & & 101.849 & rpm \\
\hline $\mathrm{n}_{\text {out }}$ & & & 233.392 & rpm \\
\hline $\mathrm{TQ}_{\mathrm{in}}$ & & & 1001.410 & $\mathrm{Nm}$ \\
\hline TQout & & & 422.317 & $N m$ \\
\hline TQout (theoretical) & & & 436.999 & $N m$ \\
\hline Input Power & & & 10680.61 & $W$ \\
\hline & & & Temperature readings & Units \\
\hline $\mathrm{T}_{\mathrm{oil}}$ & & & 55.943 & ${ }^{\circ} \mathrm{C}$ \\
\hline $\mathrm{T}_{\text {wall }}$ & & & 48.231 & ${ }^{\circ} \mathrm{C}$ \\
\hline $\mathrm{T}_{\text {wall }}$ (slave) & & & 47.565 & ${ }^{\circ} \mathrm{C}$ \\
\hline \multirow[t]{2}{*}{$\mathrm{T}_{\mathrm{amb}}$} & & & 23.065 & ${ }^{\circ} \mathrm{C}$ \\
\hline & & & Additional information & Units \\
\hline$\Delta \mathrm{TQ}$ & & & 14.682 & $N m$ \\
\hline $\mathrm{T}_{\mathrm{oil}}-\mathrm{T}_{\mathrm{amb}}$ & & & 32.878 & ${ }^{\circ} \mathrm{C}$ \\
\hline $\mathrm{T}_{\mathrm{wall}}-\mathrm{T}_{\mathrm{amb}}$ & & & 25.166 & ${ }^{\circ} \mathrm{C}$ \\
\hline
\end{tabular}

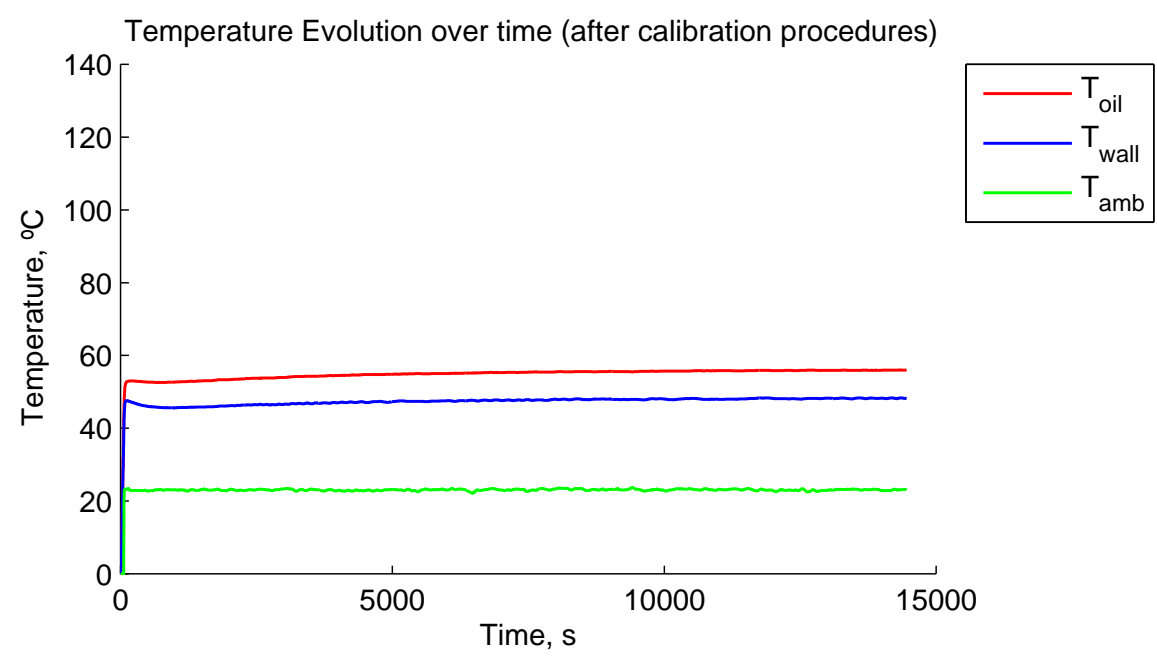


A.1. Reports from the experimental tests

\begin{tabular}{|c|c|c|c|c|}
\hline Test Number: 4 & Date: & $19 / 03 / 2012$ & By Pedro Marques & \\
\hline & & & Oil Property & Units \\
\hline Oil Designation & & & MINE & - \\
\hline Viscosity at $40^{\circ} \mathrm{C}$ & & & 328.59 & $c S t$ \\
\hline Viscosity at $70^{\circ} \mathrm{C}$ & & & 92.72 & $c S t$ \\
\hline Viscosity at $100^{\circ} \mathrm{C}$ & & & 37.88 & $c S t$ \\
\hline Bulk Density at $25^{\circ} \mathrm{C}$ & & & 886.74 & $K g / m^{3}$ \\
\hline & & & Imposed working conditions & Units \\
\hline $\mathrm{n}_{\text {in }}$ & & & 200 & rpm \\
\hline $\mathrm{TQ}_{\mathrm{in}}$ & & & 500 & $\mathrm{Nm}$ \\
\hline Warmup period & & & 240 & $\min$ \\
\hline Test period & & & 240 & $\min$ \\
\hline & & & Actual working conditions & Units \\
\hline $\mathrm{n}_{\text {in }}$ & & & 196.2479 & rpm \\
\hline $\mathrm{n}_{\text {out }}$ & & & 449.714 & rpm \\
\hline $\mathrm{TQ}_{\mathrm{in}}$ & & & 501.4967 & $\mathrm{Nm}$ \\
\hline TQout & & & 212.709 & $\mathrm{Nm}$ \\
\hline TQout (theoretical) & & & 218.845 & $\mathrm{Nm}$ \\
\hline Input Power & & & 10306.27 & $W$ \\
\hline & & & Temperature readings & Units \\
\hline $\mathrm{T}_{\text {oil }}$ & & & 55.02 & ${ }^{\circ} \mathrm{C}$ \\
\hline $\mathrm{T}_{\text {wall }}$ & & & 49.756 & ${ }^{\circ} \mathrm{C}$ \\
\hline $\mathrm{T}_{\text {wall }}$ (slave) & & & 48.325 & ${ }^{\circ} \mathrm{C}$ \\
\hline \multirow[t]{2}{*}{$\mathrm{T}_{\mathrm{amb}}$} & & & 23.254 & ${ }^{\circ} \mathrm{C}$ \\
\hline & & & Additional information & Units \\
\hline$\Delta \mathrm{TQ}$ & & & 6.137 & $N m$ \\
\hline $\mathrm{T}_{\mathrm{oil}}-\mathrm{T}_{\mathrm{amb}}$ & & & 31.766 & ${ }^{\circ} \mathrm{C}$ \\
\hline $\mathrm{T}_{\mathrm{wall}}-\mathrm{T}_{\mathrm{amb}}$ & & & 26.501 & ${ }^{\circ} \mathrm{C}$ \\
\hline
\end{tabular}

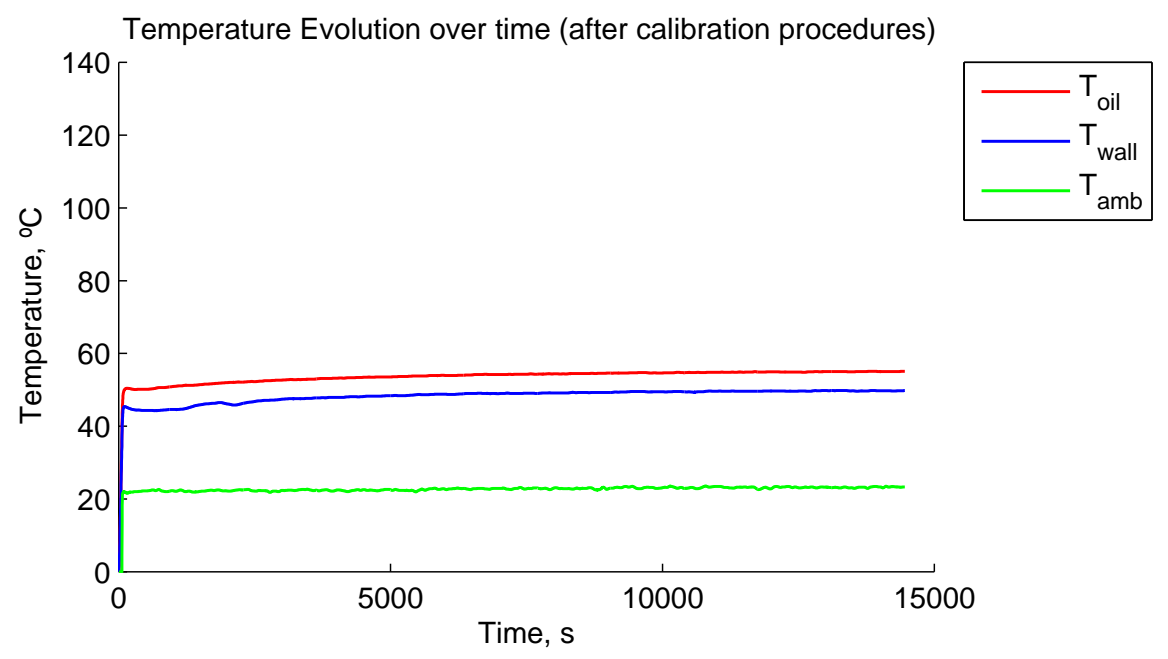


A. Appendix

\begin{tabular}{|c|c|c|c|c|}
\hline Test Number: 5 & Date: & $20 / 03 / 2012$ & By: Pedro Marques & \\
\hline & & & Oil Property & Units \\
\hline Oil Designation & & & MINE & - \\
\hline Viscosity at $40^{\circ} \mathrm{C}$ & & & 328.59 & $c S t$ \\
\hline Viscosity at $70^{\circ} \mathrm{C}$ & & & 92.72 & $c S t$ \\
\hline Viscosity at $100^{\circ} \mathrm{C}$ & & & 37.88 & $c S t$ \\
\hline \multirow[t]{2}{*}{ Bulk Density at $25^{\circ} \mathrm{C}$} & & & 886.74 & $\mathrm{Kg} / \mathrm{m}^{3}$ \\
\hline & & & Imposed working conditions & Units \\
\hline $\mathrm{n}_{\mathrm{in}}$ & & & 200 & rpm \\
\hline $\mathrm{TQ}_{\text {in }}$ & & & 750 & $N m$ \\
\hline Warmup period & & & 240 & $\min$ \\
\hline \multirow[t]{2}{*}{ Test period } & & & 240 & $\min$ \\
\hline & & & Actual working conditions & Units \\
\hline $\mathrm{n}_{\text {in }}$ & & & 196.151 & rpm \\
\hline $\mathrm{n}_{\text {out }}$ & & & 449.491 & rpm \\
\hline $\mathrm{TQ}_{\mathrm{in}}$ & & & 751.405 & $N m$ \\
\hline TQ out & & & 316.231 & $N m$ \\
\hline TQout (theoretical) & & & 327.9 & $N m$ \\
\hline \multirow[t]{2}{*}{ Input Power } & & & 15430.50 & $W$ \\
\hline & & & Temperature readings & Units \\
\hline $\mathrm{T}_{\text {oil }}$ & & & 66.464 & ${ }^{\circ} \mathrm{C}$ \\
\hline $\mathrm{T}_{\text {wall }}$ & & & 60.187 & ${ }^{\circ} \mathrm{C}$ \\
\hline $\mathrm{T}_{\text {wall }}$ (slave) & & & 58.381 & ${ }^{\circ} \mathrm{C}$ \\
\hline \multirow[t]{2}{*}{$\mathrm{T}_{\mathrm{amb}}$} & & & 24.131 & ${ }^{\circ} \mathrm{C}$ \\
\hline & & & Additional information & Units \\
\hline$\Delta \mathrm{TQ}$ & & & 11.670 & $N m$ \\
\hline $\mathrm{T}_{\mathrm{oil}}-\mathrm{T}_{\mathrm{amb}}$ & & & 42.333 & ${ }^{\circ} \mathrm{C}$ \\
\hline $\mathrm{T}_{\mathrm{wall}}-\mathrm{T}_{\mathrm{amb}}$ & & & 36.056 & ${ }^{\circ} \mathrm{C}$ \\
\hline
\end{tabular}

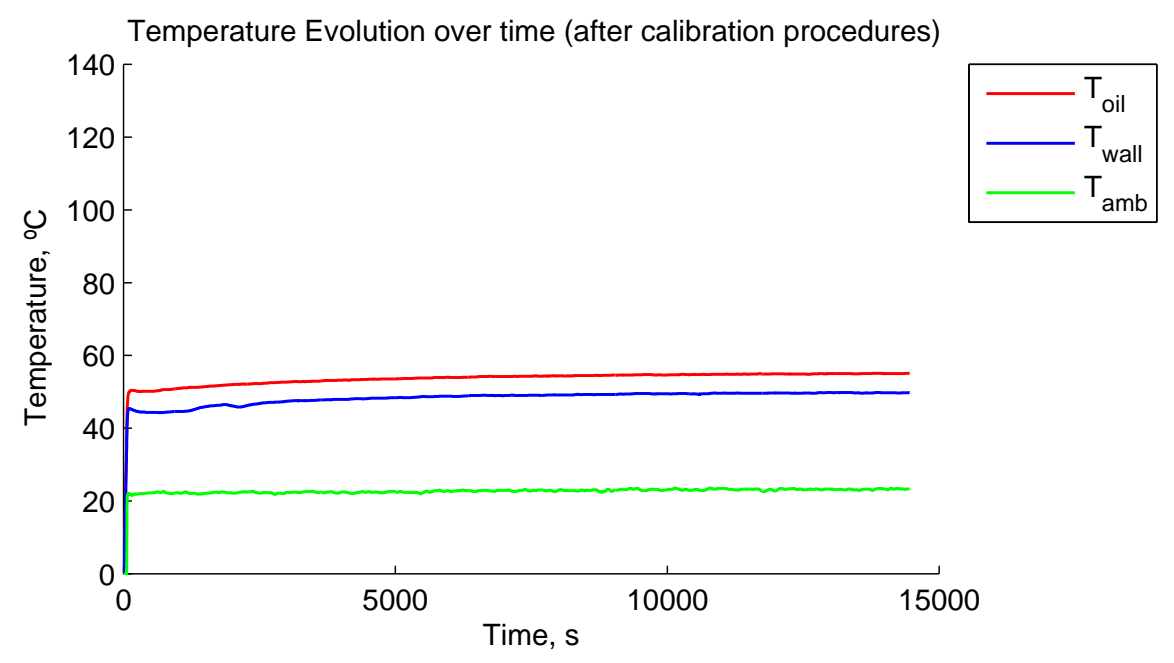


A.1. Reports from the experimental tests

\begin{tabular}{|c|c|c|c|c|}
\hline Test Number: 6 & Date: & $21 / 03 / 2012$ & By: Pedro Marques & \\
\hline & & & Oil Property & Units \\
\hline Oil Designation & & & MINE & - \\
\hline Viscosity at $40^{\circ} \mathrm{C}$ & & & 328.59 & $c S t$ \\
\hline Viscosity at $70^{\circ} \mathrm{C}$ & & & 92.72 & $c S t$ \\
\hline Viscosity at $100^{\circ} \mathrm{C}$ & & & 37.88 & $c S t$ \\
\hline Bulk Density at $25^{\circ} \mathrm{C}$ & & & 886.74 & $K g / m^{3}$ \\
\hline & & & Imposed working conditions & Units \\
\hline $\mathrm{n}_{\text {in }}$ & & & 200 & rpm \\
\hline $\mathrm{TQ}_{\mathrm{in}}$ & & & 1000 & $\mathrm{Nm}$ \\
\hline Warmup period & & & 240 & $\min$ \\
\hline Test period & & & 240 & $\min$ \\
\hline & & & Actual working conditions & Units \\
\hline $\mathrm{n}_{\text {in }}$ & & & 196.151 & rpm \\
\hline $\mathrm{n}_{\text {out }}$ & & & 449.164 & rpm \\
\hline $\mathrm{TQ}_{\mathrm{in}}$ & & & 1000.828 & $\mathrm{Nm}$ \\
\hline TQout & & & 421.031 & $\mathrm{Nm}$ \\
\hline TQout (theoretical) & & & 436.745 & $\mathrm{Nm}$ \\
\hline Input Power & & & 20542.89 & $W$ \\
\hline & & & Temperature readings & Units \\
\hline $\mathrm{T}_{\text {oil }}$ & & & 77.762 & ${ }^{\circ} \mathrm{C}$ \\
\hline $\mathrm{T}_{\text {wall }}$ & & & 71.439 & ${ }^{\circ} \mathrm{C}$ \\
\hline $\mathrm{T}_{\text {wall }}$ (slave) & & & 68.743 & ${ }^{\circ} \mathrm{C}$ \\
\hline \multirow[t]{2}{*}{$\mathrm{T}_{\mathrm{amb}}$} & & & 24.669 & ${ }^{\circ} \mathrm{C}$ \\
\hline & & & Additional information & Units \\
\hline$\Delta \mathrm{TQ}$ & & & 15.714 & $N m$ \\
\hline $\mathrm{T}_{\mathrm{oil}}-\mathrm{T}_{\mathrm{amb}}$ & & & 53.092 & ${ }^{\circ} \mathrm{C}$ \\
\hline $\mathrm{T}_{\mathrm{wall}}-\mathrm{T}_{\mathrm{amb}}$ & & & 46.770 & ${ }^{\circ} \mathrm{C}$ \\
\hline
\end{tabular}

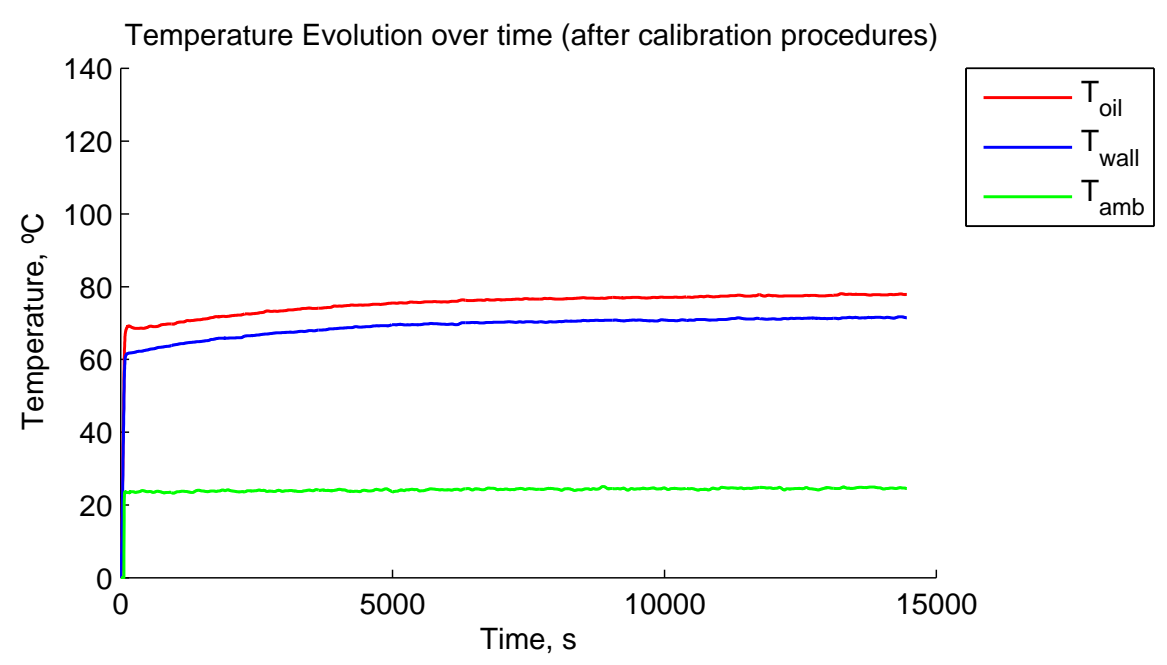


A. Appendix

\begin{tabular}{|c|c|c|c|c|}
\hline Test Number: 7 & Date: & $22 / 03 / 2012$ & By: Pedro Marques & \\
\hline & & & Oil Property & Units \\
\hline Oil Designation & & & MINE & - \\
\hline Viscosity at $40^{\circ} \mathrm{C}$ & & & 328.59 & $c S t$ \\
\hline Viscosity at $70^{\circ} \mathrm{C}$ & & & 92.72 & $c S t$ \\
\hline Viscosity at $100^{\circ} \mathrm{C}$ & & & 37.88 & $c S t$ \\
\hline \multirow[t]{2}{*}{ Bulk Density at $25^{\circ} \mathrm{C}$} & & & 886.74 & $\mathrm{Kg} / \mathrm{m}^{3}$ \\
\hline & & & Imposed working conditions & Units \\
\hline $\mathrm{n}_{\mathrm{in}}$ & & & 500 & rpm \\
\hline $\mathrm{TQ}_{\text {in }}$ & & & 500 & $N m$ \\
\hline Warmup period & & & 240 & $\min$ \\
\hline \multirow[t]{2}{*}{ Test period } & & & 240 & $\min$ \\
\hline & & & Actual working conditions & Units \\
\hline $\mathrm{n}_{\text {in }}$ & & & 498.599 & rpm \\
\hline $\mathrm{n}_{\text {out }}$ & & & 1142.435 & rpm \\
\hline $\mathrm{TQ}_{\mathrm{in}}$ & & & 501.543 & $N m$ \\
\hline TQ out & & & 211.052 & $N m$ \\
\hline TQout (theoretical) & & & 218.865 & $N m$ \\
\hline \multirow[t]{2}{*}{ Input Power } & & & 26187.14 & $W$ \\
\hline & & & Temperature readings & Units \\
\hline $\mathrm{T}_{\text {oil }}$ & & & 94.762 & ${ }^{\circ} \mathrm{C}$ \\
\hline $\mathrm{T}_{\text {wall }}$ & & & 85.925 & ${ }^{\circ} \mathrm{C}$ \\
\hline $\mathrm{T}_{\text {wall }}$ (slave) & & & 77.369 & ${ }^{\circ} \mathrm{C}$ \\
\hline \multirow[t]{2}{*}{$\mathrm{T}_{\mathrm{amb}}$} & & & 28.181 & ${ }^{\circ} \mathrm{C}$ \\
\hline & & & Additional information & Units \\
\hline$\Delta \mathrm{TQ}$ & & & 7.813 & $N m$ \\
\hline $\mathrm{T}_{\mathrm{oil}}-\mathrm{T}_{\mathrm{amb}}$ & & & 66.581 & ${ }^{\circ} \mathrm{C}$ \\
\hline $\mathrm{T}_{\text {wall }}-\mathrm{T}_{\mathrm{amb}}$ & & & 57.744 & ${ }^{\circ} \mathrm{C}$ \\
\hline
\end{tabular}

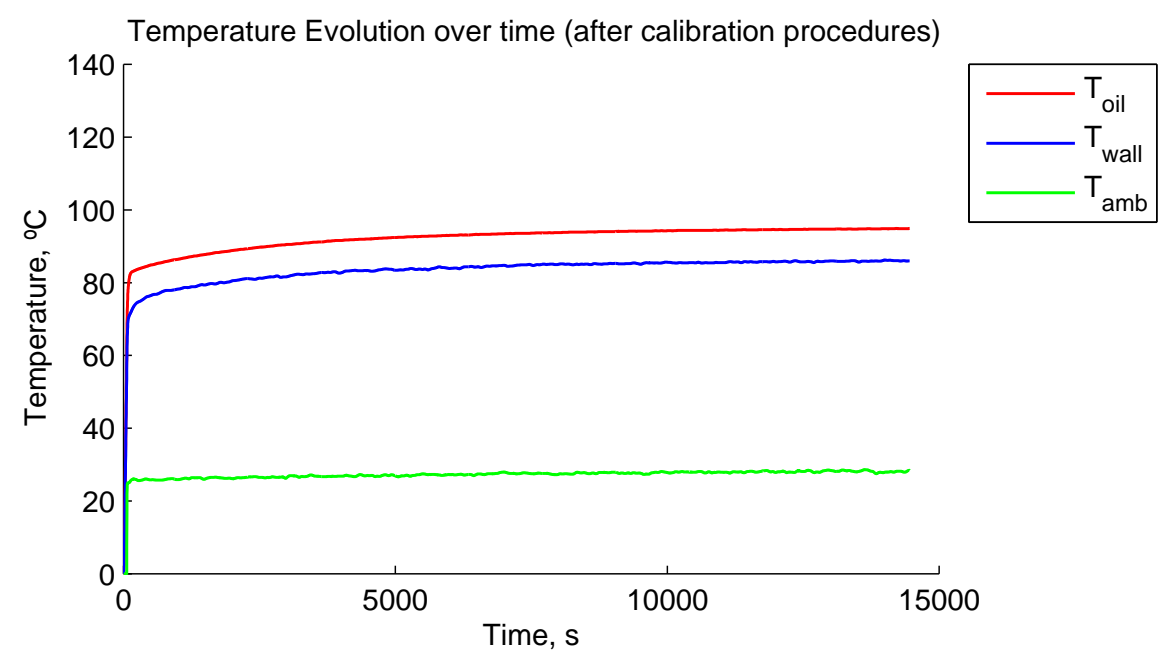


A.1. Reports from the experimental tests

\begin{tabular}{|c|c|c|c|c|}
\hline Test Number: 8 & Date: & $23 / 03 / 2012$ & By: Pedro Marques & \\
\hline & & & Oil Property & Units \\
\hline Oil Designation & & & MINE & - \\
\hline Viscosity at $40^{\circ} \mathrm{C}$ & & & 328.59 & $c S t$ \\
\hline Viscosity at $70^{\circ} \mathrm{C}$ & & & 92.72 & $c S t$ \\
\hline Viscosity at $100^{\circ} \mathrm{C}$ & & & 37.88 & $c S t$ \\
\hline Bulk Density at $25^{\circ} \mathrm{C}$ & & & 886.74 & $\mathrm{Kg} / \mathrm{m}^{3}$ \\
\hline & & & Imposed working conditions & Units \\
\hline $\mathrm{n}_{\text {in }}$ & & & 500 & rpm \\
\hline $\mathrm{TQ}_{\text {in }}$ & & & 750 & $\mathrm{Nm}$ \\
\hline Warmup period & & & 240 & $\min$ \\
\hline Test period & & & 240 & $\min$ \\
\hline & & & Actual working conditions & Units \\
\hline $\mathrm{n}_{\mathrm{in}}$ & & & 498.549 & rpm \\
\hline $\mathrm{n}_{\text {out }}$ & & & 1142.454 & rpm \\
\hline $\mathrm{TQ}_{\text {in }}$ & & & 750.585 & $\mathrm{Nm}$ \\
\hline TQout & & & 314.912 & $\mathrm{Nm}$ \\
\hline TQout (theoretical) & & & 327.543 & $N m$ \\
\hline Input Power & & & 39189.27 & $W$ \\
\hline & & & Temperature readings & Units \\
\hline $\mathrm{T}_{\mathrm{oil}}$ & & & 116.254 & ${ }^{\circ} \mathrm{C}$ \\
\hline $\mathrm{T}_{\text {wall }}$ & & & 105.160 & ${ }^{\circ} \mathrm{C}$ \\
\hline $\mathrm{T}_{\text {wall }}$ (slave) & & & 94.817 & ${ }^{\circ} \mathrm{C}$ \\
\hline \multirow{2}{*}{$\mathrm{T}_{\mathrm{amb}}$} & & & 33.078 & ${ }^{\circ} \mathrm{C}$ \\
\hline & & & Additional information & Units \\
\hline$\Delta \mathrm{TQ}$ & & & 12.631 & $N m$ \\
\hline $\mathrm{T}_{\mathrm{oil}}-\mathrm{T}_{\mathrm{amb}}$ & & & 83.177 & ${ }^{\circ} \mathrm{C}$ \\
\hline $\mathrm{T}_{\text {wall }}-\mathrm{T}_{\mathrm{amb}}$ & & & 72.083 & ${ }^{\circ} \mathrm{C}$ \\
\hline
\end{tabular}

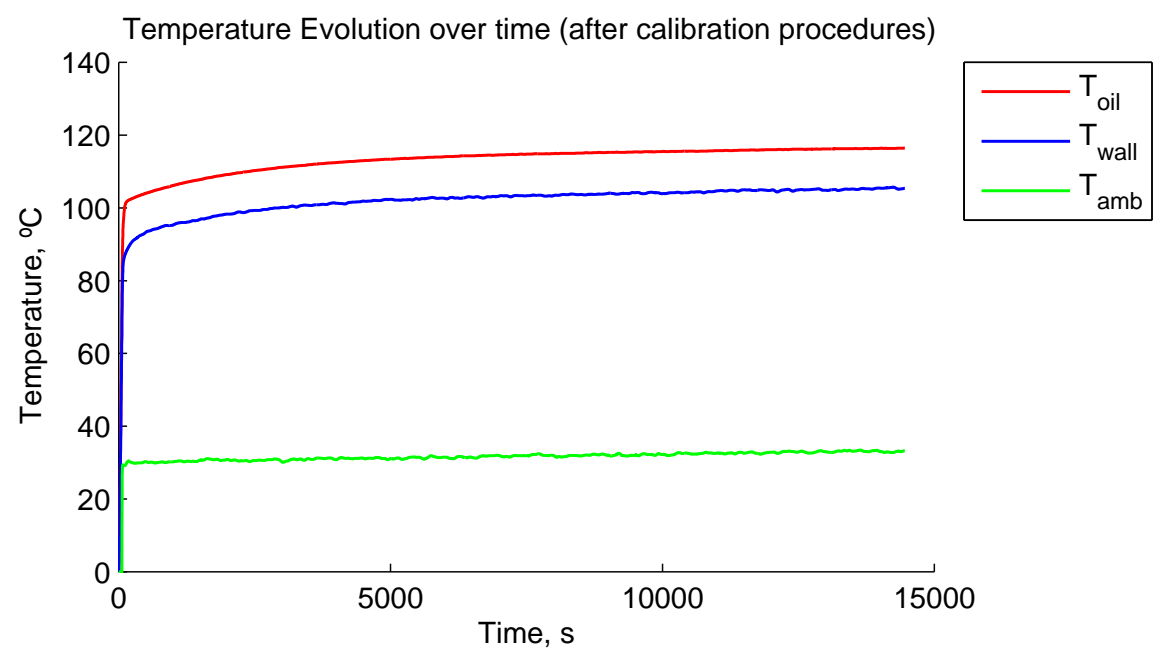


A. Appendix

\begin{tabular}{|c|c|c|c|}
\hline Test Number: 9 & Date: $26 / 03 / 2012$ & By: Pedro MArques & \\
\hline & & Oil Property & Units \\
\hline Oil Designation & & MINE & - \\
\hline Viscosity at $40^{\circ} \mathrm{C}$ & & 328.59 & $c S t$ \\
\hline Viscosity at $70^{\circ} \mathrm{C}$ & & 92.72 & $c S t$ \\
\hline Viscosity at $100^{\circ} \mathrm{C}$ & & 37.88 & $c S t$ \\
\hline Bulk Density at $25^{\circ} \mathrm{C}$ & & 886.74 & $\mathrm{Kg} / \mathrm{m}^{3}$ \\
\hline & & Imposed working conditions & Units \\
\hline $\mathrm{n}_{\text {in }}$ & & 500 & rpm \\
\hline $\mathrm{TQ}_{\mathrm{in}}$ & & 1000 & $N m$ \\
\hline Warmup period & & 240 & $\min$ \\
\hline Test period & & - & $\min$ \\
\hline & & Actual working conditions & Units \\
\hline $\mathrm{n}_{\text {in }}$ & & 498.493 & rpm \\
\hline $\mathrm{n}_{\text {out }}$ & & 1142.365 & rpm \\
\hline $\mathrm{TQ}_{\text {in }}$ & & 1000.560 & $\mathrm{Nm}$ \\
\hline TQ out & & 418.728 & $N m$ \\
\hline TQout (theoretical) & & 436.628 & $\mathrm{Nm}$ \\
\hline Input Power & & 52231.33 & $W$ \\
\hline & & Temperature readings & Units \\
\hline $\mathrm{T}_{\text {oil }}$ & & 136.130 & ${ }^{\circ} \mathrm{C}$ \\
\hline $\mathrm{T}_{\text {wall }}$ & & 122.036 & ${ }^{\circ} \mathrm{C}$ \\
\hline $\mathrm{T}_{\text {wall }}$ (slave) & & 108.46 & ${ }^{\circ} \mathrm{C}$ \\
\hline \multirow[t]{2}{*}{$\mathrm{T}_{\mathrm{amb}}$} & & 32.586 & ${ }^{\circ} \mathrm{C}$ \\
\hline & & Additional information & Units \\
\hline$\Delta \mathrm{TQ}$ & & 17.898 & $N m$ \\
\hline $\mathrm{T}_{\mathrm{oil}}-\mathrm{T}_{\mathrm{amb}}$ & & 103.544 & ${ }^{\circ} \mathrm{C}$ \\
\hline $\mathrm{T}_{\mathrm{wall}}-\mathrm{T}_{\mathrm{amb}}$ & & 89.450 & ${ }^{\circ} \mathrm{C}$ \\
\hline
\end{tabular}

Note: This test did not finish since a malfunction was detected on the gearbox test rig. Only the warmup results are available.

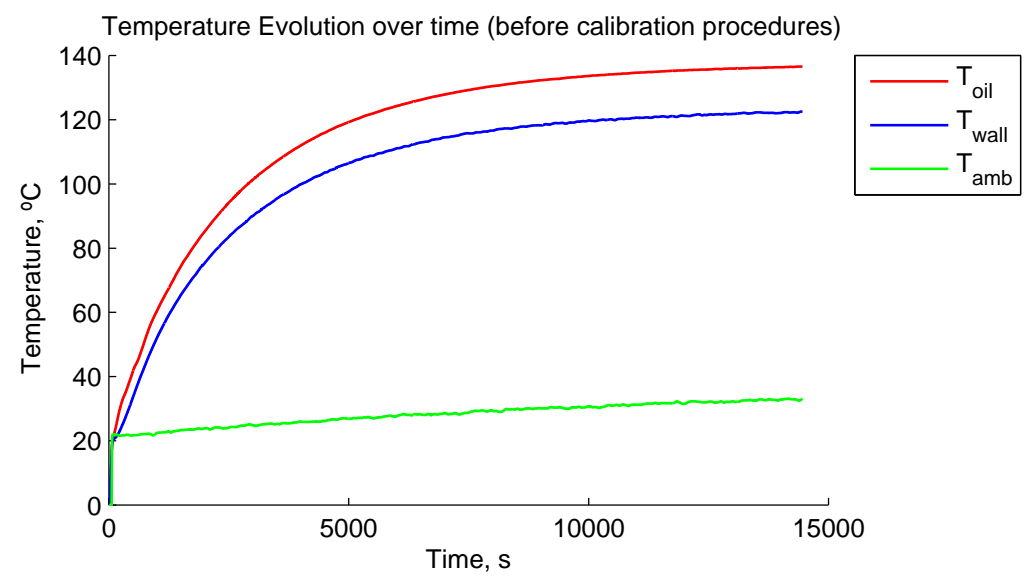


A.1. Reports from the experimental tests

\begin{tabular}{|c|c|c|c|c|}
\hline Test Number: 10 & Date: & $27 / 03 / 2012$ & By: Pedro Marques & \\
\hline & & & Oil Property & Units \\
\hline Oil Designation & & & MINE & - \\
\hline Viscosity at $40^{\circ} \mathrm{C}$ & & & 328.59 & $c S t$ \\
\hline Viscosity at $70^{\circ} \mathrm{C}$ & & & 92.72 & $c S t$ \\
\hline Viscosity at $100^{\circ} \mathrm{C}$ & & & 37.88 & $c S t$ \\
\hline \multirow[t]{2}{*}{ Bulk Density at $25^{\circ} \mathrm{C}$} & & & 886.74 & $\mathrm{Kg} / \mathrm{m}^{3}$ \\
\hline & & & Imposed working conditions & Units \\
\hline $\mathrm{n}_{\text {in }}$ & & & 150 & rpm \\
\hline $\mathrm{TQ}_{\mathrm{in}}$ & & & 800 & $\mathrm{Nm}$ \\
\hline Warmup period & & & 240 & $\min$ \\
\hline \multirow[t]{2}{*}{ Test period } & & & 240 & $\min$ \\
\hline & & & Actual working conditions & Units \\
\hline $\mathrm{n}_{\text {in }}$ & & & 145.618 & rpm \\
\hline $\mathrm{n}_{\text {out }}$ & & & 333.664 & rpm \\
\hline $\mathrm{TQ}_{\mathrm{in}}$ & & & 801.013 & $\mathrm{Nm}$ \\
\hline TQout & & & 336.850 & $\mathrm{Nm}$ \\
\hline TQout (theoretical) & & & 349.549 & $N m$ \\
\hline Input Power & & & 12214.67 & $W$ \\
\hline & & & Temperature readings & Units \\
\hline $\mathrm{T}_{\text {oil }}$ & & & 58.536 & ${ }^{\circ} \mathrm{C}$ \\
\hline $\mathrm{T}_{\text {wall }}$ & & & 50.617 & ${ }^{\circ} \mathrm{C}$ \\
\hline $\mathrm{T}_{\text {wall }}$ (slave) & & & 53.996 & ${ }^{\circ} \mathrm{C}$ \\
\hline \multirow[t]{2}{*}{$\mathrm{T}_{\mathrm{amb}}$} & & & 24.499 & ${ }^{\circ} \mathrm{C}$ \\
\hline & & & Additional information & Units \\
\hline$\Delta \mathrm{TQ}$ & & & 12.7 & $N m$ \\
\hline $\mathrm{T}_{\mathrm{oil}}-\mathrm{T}_{\mathrm{amb}}$ & & & 34.036 & ${ }^{\circ} \mathrm{C}$ \\
\hline $\mathrm{T}_{\mathrm{wall}}-\mathrm{T}_{\mathrm{amb}}$ & & & 26.117 & ${ }^{\circ} \mathrm{C}$ \\
\hline
\end{tabular}

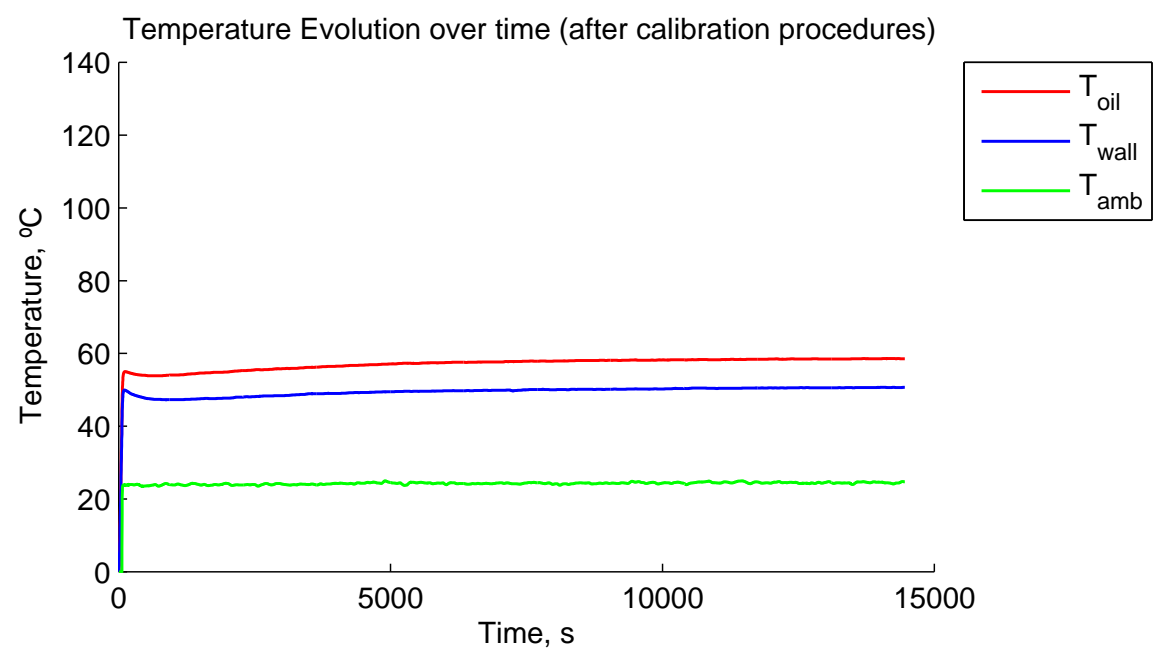


A. Appendix

\begin{tabular}{|c|c|c|c|c|}
\hline Test Number: 11 & Date: & $28 / 03 / 2012$ & By: Pedro Marques & \\
\hline & & & Oil Property & Units \\
\hline Oil Designation & & & MINE & - \\
\hline Viscosity at $40^{\circ} \mathrm{C}$ & & & 328.59 & $c S t$ \\
\hline Viscosity at $70^{\circ} \mathrm{C}$ & & & 92.72 & $c S t$ \\
\hline Viscosity at $100^{\circ} \mathrm{C}$ & & & 37.88 & $c S t$ \\
\hline Bulk Density at $25^{\circ} \mathrm{C}$ & & & 886.74 & $\mathrm{Kg} / \mathrm{m}^{3}$ \\
\hline & & & Imposed working conditions & Units \\
\hline $\mathrm{n}_{\text {in }}$ & & & 300 & rpm \\
\hline $\mathrm{TQ}_{\text {in }}$ & & & 600 & $N m$ \\
\hline Warmup period & & & 240 & $\min$ \\
\hline Test period & & & 240 & $\min$ \\
\hline & & & Actual working conditions & Units \\
\hline $\mathrm{n}_{\mathrm{in}}$ & & & 296.867 & rpm \\
\hline $\mathrm{n}_{\text {out }}$ & & & 680.361 & rpm \\
\hline $\mathrm{TQ}_{\mathrm{in}}$ & & & 602.205 & $\mathrm{Nm}$ \\
\hline TQout & & & 253.657 & $N m$ \\
\hline TQout (theoretical) & & & 262.792 & $N m$ \\
\hline Input Power & & & 18721.23 & $W$ \\
\hline & & & Temperature readings & Units \\
\hline $\mathrm{T}_{\mathrm{oil}}$ & & & 80.267 & ${ }^{\circ} \mathrm{C}$ \\
\hline $\mathrm{T}_{\text {wall }}$ & & & 73.552 & ${ }^{\circ} \mathrm{C}$ \\
\hline $\mathrm{T}_{\text {wall }}$ (slave) & & & 65.736 & ${ }^{\circ} \mathrm{C}$ \\
\hline \multirow[t]{2}{*}{$\mathrm{T}_{\mathrm{amb}}$} & & & 26.367 & ${ }^{\circ} \mathrm{C}$ \\
\hline & & & Additional information & Units \\
\hline$\Delta \mathrm{TQ}$ & & & 9.135 & $N m$ \\
\hline $\mathrm{T}_{\mathrm{oil}}-\mathrm{T}_{\mathrm{amb}}$ & & & 53.899 & ${ }^{\circ} \mathrm{C}$ \\
\hline $\mathrm{T}_{\mathrm{wall}}-\mathrm{T}_{\mathrm{amb}}$ & & & 47.185 & ${ }^{\circ} \mathrm{C}$ \\
\hline
\end{tabular}

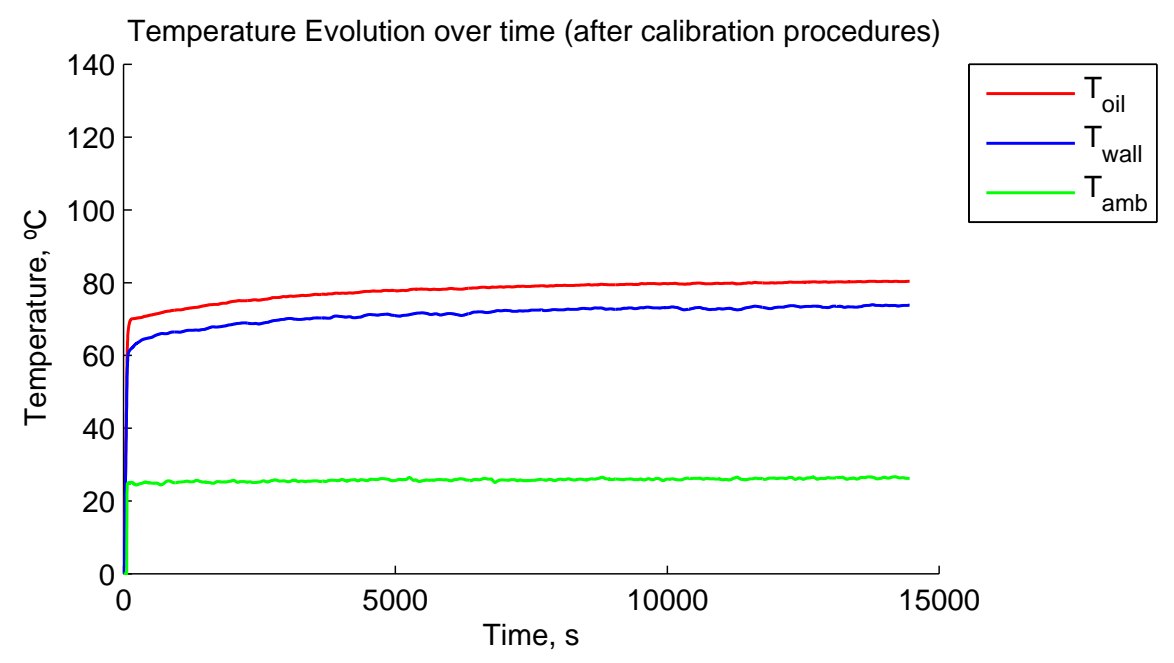


A.1. Reports from the experimental tests

\section{A.1.2. MINR Oil}


A. Appendix

\begin{tabular}{|c|c|c|c|c|}
\hline Test Number: 12 & Date: & $9 / 04 / 2012$ & By: Pedro Marques & \\
\hline & & & Oil Property & Units \\
\hline Oil Designation & & & MINR & - \\
\hline Viscosity at $40^{\circ} \mathrm{C}$ & & & 330.26 & $c S t$ \\
\hline Viscosity at $70^{\circ} \mathrm{C}$ & & & 68.06 & $c S t$ \\
\hline Viscosity at $100^{\circ} \mathrm{C}$ & & & 23.45 & $c S t$ \\
\hline Bulk Density at $25^{\circ} \mathrm{C}$ & & & 896.44 & $\mathrm{Kg} / \mathrm{m}^{3}$ \\
\hline & & & Imposed working conditions & Units \\
\hline $\mathrm{n}_{\text {in }}$ & & & 100 & rpm \\
\hline $\mathrm{TQ}_{\mathrm{in}}$ & & & 500 & $\mathrm{Nm}$ \\
\hline Warmup period & & & 240 & $\min$ \\
\hline Test period & & & 240 & $\min$ \\
\hline & & & Actual working conditions & Units \\
\hline $\mathrm{n}_{\text {in }}$ & & & 102.280 & rpm \\
\hline $\mathrm{n}_{\text {out }}$ & & & 234.381 & rpm \\
\hline $\mathrm{TQ}_{\mathrm{in}}$ & & & 502.266 & $N m$ \\
\hline TQout & & & 212.632 & $\mathrm{Nm}$ \\
\hline TQout (theoretical) & & & 219.181 & $\mathrm{Nm}$ \\
\hline Input Power & & & 5379.62 & $W$ \\
\hline & & & Temperature readings & Units \\
\hline $\mathrm{T}_{\text {oil }}$ & & & 44.713 & ${ }^{\circ} \mathrm{C}$ \\
\hline $\mathrm{T}_{\text {wall }}$ & & & 39.527 & ${ }^{\circ} \mathrm{C}$ \\
\hline $\mathrm{T}_{\text {wall }}$ (slave) & & & 37.163 & ${ }^{\circ} \mathrm{C}$ \\
\hline \multirow[t]{2}{*}{$\mathrm{T}_{\mathrm{amb}}$} & & & 23.238 & ${ }^{\circ} \mathrm{C}$ \\
\hline & & & Additional information & Units \\
\hline$\Delta \mathrm{TQ}$ & & & 6.549 & $N m$ \\
\hline $\mathrm{T}_{\mathrm{oil}}-\mathrm{T}_{\mathrm{amb}}$ & & & 21.475 & ${ }^{\circ} \mathrm{C}$ \\
\hline $\mathrm{T}_{\mathrm{wall}}-\mathrm{T}_{\mathrm{amb}}$ & & & 16.289 & ${ }^{\circ} \mathrm{C}$ \\
\hline
\end{tabular}

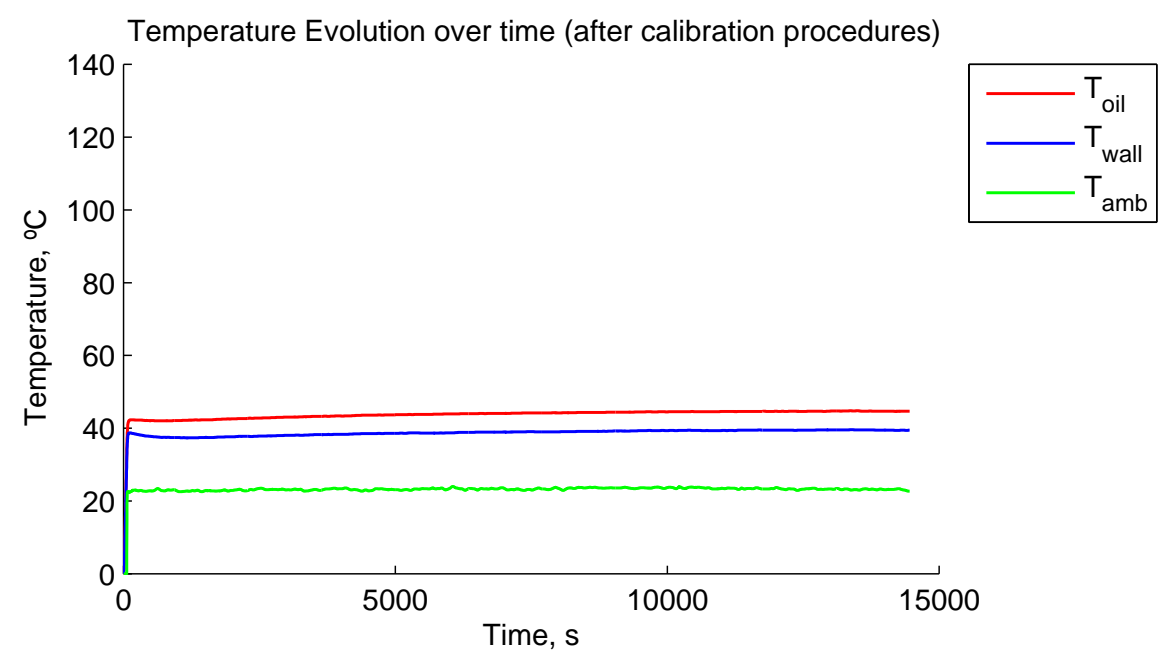


A.1. Reports from the experimental tests

\begin{tabular}{|c|c|c|c|c|}
\hline Test Number: 13 & Date: & $10 / 04 / 2012$ & By: Pedro Marques & \\
\hline & & & Oil Property & Units \\
\hline Oil Designation & & & MINR & - \\
\hline Viscosity at $40^{\circ} \mathrm{C}$ & & & 330.26 & $c S t$ \\
\hline Viscosity at $70^{\circ} \mathrm{C}$ & & & 68.06 & $c S t$ \\
\hline Viscosity at $100^{\circ} \mathrm{C}$ & & & 23.45 & $c S t$ \\
\hline Bulk Density at $25^{\circ} \mathrm{C}$ & & & 896.44 & $K g / m^{3}$ \\
\hline & & & Imposed working conditions & Units \\
\hline $\mathrm{n}_{\text {in }}$ & & & 100 & rpm \\
\hline $\mathrm{TQ}_{\mathrm{in}}$ & & & 750 & $\mathrm{Nm}$ \\
\hline Warmup period & & & 240 & $\min$ \\
\hline Test period & & & 240 & $\min$ \\
\hline & & & Actual working conditions & Units \\
\hline $\mathrm{n}_{\text {in }}$ & & & 102.198 & rpm \\
\hline $\mathrm{n}_{\text {out }}$ & & & 234.193 & rpm \\
\hline $\mathrm{TQ}_{\mathrm{in}}$ & & & 751.940 & $\mathrm{Nm}$ \\
\hline TQout & & & 317.667 & $\mathrm{Nm}$ \\
\hline TQout (theoretical) & & & 328.134 & $\mathrm{Nm}$ \\
\hline Input Power & & & 8047.39 & $W$ \\
\hline & & & Temperature readings & Units \\
\hline $\mathrm{T}_{\text {oil }}$ & & & 51.495 & ${ }^{\circ} \mathrm{C}$ \\
\hline $\mathrm{T}_{\text {wall }}$ & & & 44.285 & ${ }^{\circ} \mathrm{C}$ \\
\hline $\mathrm{T}_{\text {wall }}$ (slave) & & & 43.449 & ${ }^{\circ} \mathrm{C}$ \\
\hline \multirow[t]{2}{*}{$\mathrm{T}_{\mathrm{amb}}$} & & & 22.181 & ${ }^{\circ} \mathrm{C}$ \\
\hline & & & Additional information & Units \\
\hline$\Delta \mathrm{TQ}$ & & & 10.465 & $N m$ \\
\hline $\mathrm{T}_{\mathrm{oil}}-\mathrm{T}_{\mathrm{amb}}$ & & & 29.314 & ${ }^{\circ} \mathrm{C}$ \\
\hline $\mathrm{T}_{\mathrm{wall}}-\mathrm{T}_{\mathrm{amb}}$ & & & 42.103 & ${ }^{\circ} \mathrm{C}$ \\
\hline
\end{tabular}

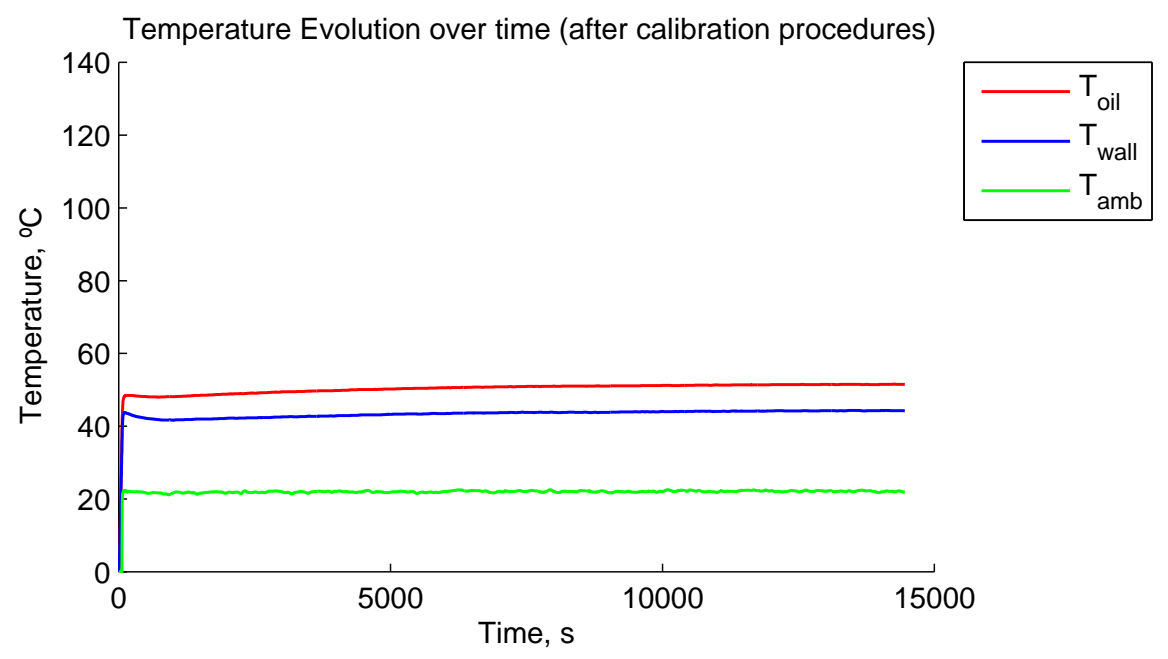


A. Appendix

\begin{tabular}{|c|c|c|c|c|}
\hline Test Number: 14 & Date: & $11 / 04 / 2012$ & By: Pedro Marques & \\
\hline & & & Oil Property & Units \\
\hline Oil Designation & & & MINR & - \\
\hline Viscosity at $40^{\circ} \mathrm{C}$ & & & 330.26 & $c S t$ \\
\hline Viscosity at $70^{\circ} \mathrm{C}$ & & & 68.06 & $c S t$ \\
\hline Viscosity at $100^{\circ} \mathrm{C}$ & & & 23.45 & $c S t$ \\
\hline Bulk Density at $25^{\circ} \mathrm{C}$ & & & 896.44 & $\mathrm{Kg} / \mathrm{m}^{3}$ \\
\hline & & & Imposed working conditions & Units \\
\hline $\mathrm{n}_{\text {in }}$ & & & 100 & rpm \\
\hline $\mathrm{TQ}_{\text {in }}$ & & & 1000 & $N m$ \\
\hline Warmup period & & & 240 & $\min$ \\
\hline Test period & & & 240 & $\min$ \\
\hline & & & Actual working conditions & Units \\
\hline $\mathrm{n}_{\mathrm{in}}$ & & & 106.050 & rpm \\
\hline $\mathrm{n}_{\text {out }}$ & & & 243.020 & rpm \\
\hline $\mathrm{TQ}_{\mathrm{in}}$ & & & 1001.079 & $\mathrm{Nm}$ \\
\hline TQout & & & 422.405 & $\mathrm{Nm}$ \\
\hline TQout (theoretical) & & & 436.854 & $N m$ \\
\hline Input Power & & & 11117.49 & $W$ \\
\hline & & & Temperature readings & Units \\
\hline $\mathrm{T}_{\mathrm{oil}}$ & & & 61.467 & ${ }^{\circ} \mathrm{C}$ \\
\hline $\mathrm{T}_{\text {wall }}$ & & & 52.208 & ${ }^{\circ} \mathrm{C}$ \\
\hline $\mathrm{T}_{\text {wall }}$ (slave) & & & 50.673 & ${ }^{\circ} \mathrm{C}$ \\
\hline \multirow[t]{2}{*}{$\mathrm{T}_{\mathrm{amb}}$} & & & 23.074 & ${ }^{\circ} \mathrm{C}$ \\
\hline & & & Additional information & Units \\
\hline$\Delta \mathrm{TQ}$ & & & 14.450 & $N m$ \\
\hline $\mathrm{T}_{\mathrm{oil}}-\mathrm{T}_{\mathrm{amb}}$ & & & 38.394 & ${ }^{\circ} \mathrm{C}$ \\
\hline $\mathrm{T}_{\mathrm{wall}}-\mathrm{T}_{\mathrm{amb}}$ & & & 29.134 & ${ }^{\circ} \mathrm{C}$ \\
\hline
\end{tabular}

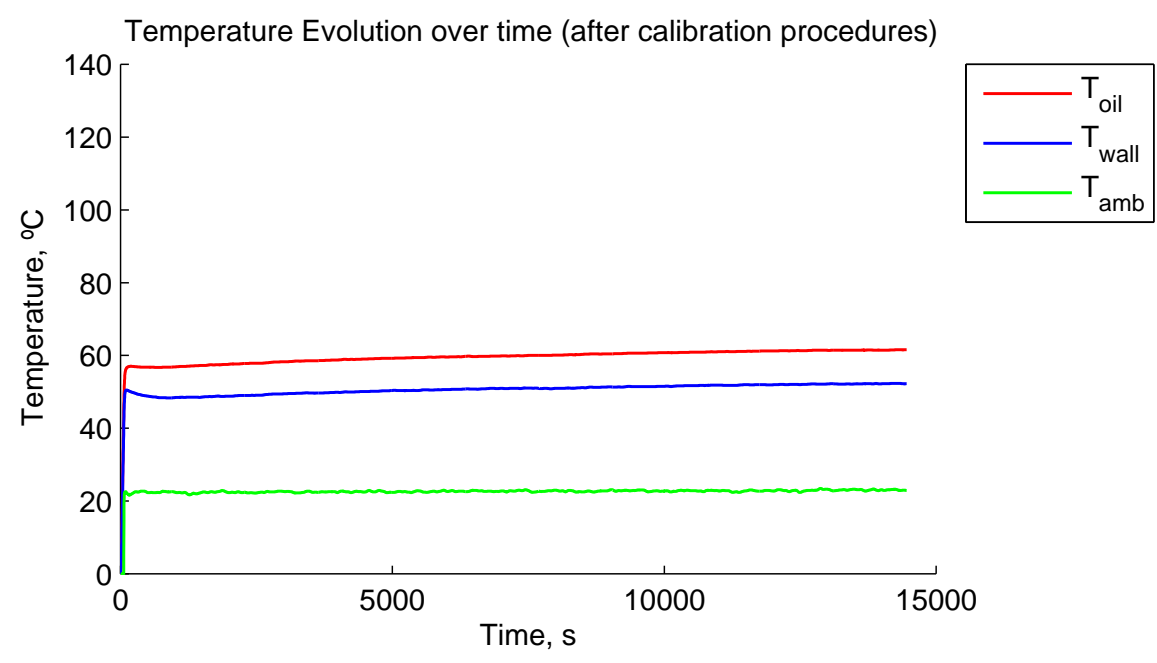


A.1. Reports from the experimental tests

\begin{tabular}{|c|c|c|c|c|}
\hline Test Number: 15 & Date: & $12 / 04 / 2012$ & By: Pedro Marques & \\
\hline & & & Oil Property & Units \\
\hline Oil Designation & & & MINR & - \\
\hline Viscosity at $40^{\circ} \mathrm{C}$ & & & 330.26 & $c S t$ \\
\hline Viscosity at $70^{\circ} \mathrm{C}$ & & & 68.06 & $c S t$ \\
\hline Viscosity at $100^{\circ} \mathrm{C}$ & & & 23.45 & $c S t$ \\
\hline Bulk Density at $25^{\circ} \mathrm{C}$ & & & 896.44 & $\mathrm{Kg} / \mathrm{m}^{3}$ \\
\hline & & & Imposed working conditions & Units \\
\hline $\mathrm{n}_{\text {in }}$ & & & 400 & rpm \\
\hline $\mathrm{TQ}_{\mathrm{in}}$ & & & 500 & $N m$ \\
\hline Warmup period & & & 240 & $\min$ \\
\hline Test period & & & 240 & $\min$ \\
\hline & & & Actual working conditions & Units \\
\hline $\mathrm{n}_{\mathrm{in}}$ & & & 398.544 & rpm \\
\hline $\mathrm{n}_{\text {out }}$ & & & 913.288 & rpm \\
\hline $\mathrm{TQ}_{\mathrm{in}}$ & & & 502.146 & $N m$ \\
\hline TQ out & & & 211.500 & $N m$ \\
\hline TQ out (theoretical) & & & 219.128 & $N m$ \\
\hline Input Power & & & 20957.23 & $W$ \\
\hline & & & Temperature readings & Units \\
\hline $\mathrm{T}_{\text {oil }}$ & & & 91.693 & ${ }^{\circ} \mathrm{C}$ \\
\hline $\mathrm{T}_{\text {wall }}$ & & & 83.099 & ${ }^{\circ} \mathrm{C}$ \\
\hline $\mathrm{T}_{\text {wall }}$ (slave) & & & 69.071 & ${ }^{\circ} \mathrm{C}$ \\
\hline \multirow[t]{2}{*}{$\mathrm{T}_{\mathrm{amb}}$} & & & 25.954 & ${ }^{\circ} \mathrm{C}$ \\
\hline & & & Additional information & Units \\
\hline$\Delta \mathrm{TQ}$ & & & 7.628 & $N m$ \\
\hline $\mathrm{T}_{\mathrm{oil}}-\mathrm{T}_{\mathrm{amb}}$ & & & 65.740 & ${ }^{\circ} \mathrm{C}$ \\
\hline $\mathrm{T}_{\mathrm{wall}}-\mathrm{T}_{\mathrm{amb}}$ & & & 57.146 & ${ }^{\circ} \mathrm{C}$ \\
\hline
\end{tabular}

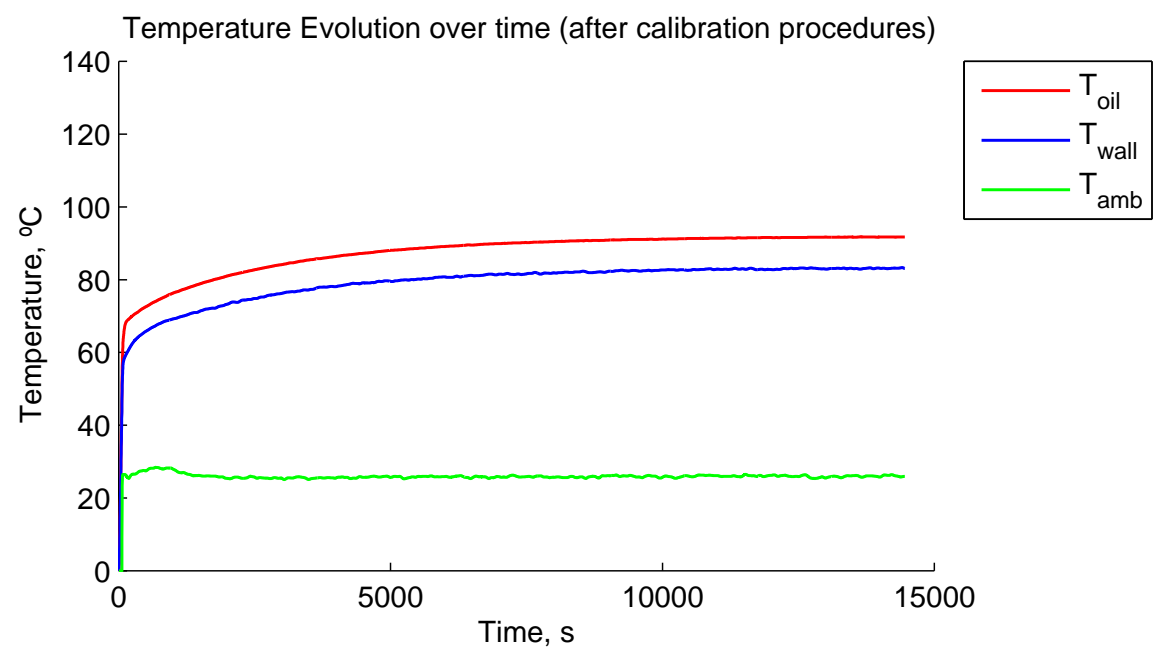


A. Appendix

\begin{tabular}{|c|c|c|c|c|c|}
\hline Test Number: & 16 & Date: & $13 / 04 / 2012$ & By: Pedro Marques & \\
\hline & & & & Oil Property & Units \\
\hline Oil Designation & & & & MINR & - \\
\hline Viscosity at $40^{\circ} \mathrm{C}$ & & & & 330.26 & $c S t$ \\
\hline Viscosity at $70^{\circ} \mathrm{C}$ & & & & 68.06 & $c S t$ \\
\hline Viscosity at $100^{\circ} \mathrm{C}$ & & & & 23.45 & $c S t$ \\
\hline Bulk Density at $25^{\circ} \mathrm{C}$ & & & & 896.44 & $K g / m^{3}$ \\
\hline & & & & Imposed working conditions & Units \\
\hline $\mathrm{n}_{\mathrm{in}}$ & & & & 400 & rpm \\
\hline $\mathrm{TQ}_{\mathrm{in}}$ & & & & 750 & $N m$ \\
\hline Warmup period & & & & 240 & $\min$ \\
\hline Test period & & & & 240 & $\min$ \\
\hline & & & & Actual working conditions & Units \\
\hline $\mathrm{n}_{\mathrm{in}}$ & & & & 398.434 & rpm \\
\hline $\mathrm{n}_{\text {out }}$ & & & & 913.035 & rpm \\
\hline $\mathrm{TQ}_{\mathrm{in}}$ & & & & 751.633 & $\mathrm{Nm}$ \\
\hline TQout & & & & 314.852 & $\mathrm{Nm}$ \\
\hline TQout (theoretical) & & & & 328.000 & $N m$ \\
\hline Input Power & & & & 31321.04 & $W$ \\
\hline & & & & Temperature readings & Units \\
\hline $\mathrm{T}_{\text {oil }}$ & & & & 112.332 & ${ }^{\circ} \mathrm{C}$ \\
\hline $\mathrm{T}_{\text {wall }}$ & & & & 101.177 & ${ }^{\circ} \mathrm{C}$ \\
\hline $\mathrm{T}_{\text {wall }}$ (slave) & & & & 81.847 & ${ }^{\circ} \mathrm{C}$ \\
\hline \multirow[t]{2}{*}{$\mathrm{T}_{\mathrm{amb}}$} & & & & 26.411 & ${ }^{\circ} \mathrm{C}$ \\
\hline & & & & Additional information & Units \\
\hline$\Delta \mathrm{TQ}$ & & & & 13.148 & $N m$ \\
\hline $\mathrm{T}_{\mathrm{oil}}-\mathrm{T}_{\mathrm{amb}}$ & & & & 85.921 & ${ }^{\circ} \mathrm{C}$ \\
\hline $\mathrm{T}_{\mathrm{wall}}-\mathrm{T}_{\mathrm{amb}}$ & & & & 59.436 & ${ }^{\circ} \mathrm{C}$ \\
\hline
\end{tabular}

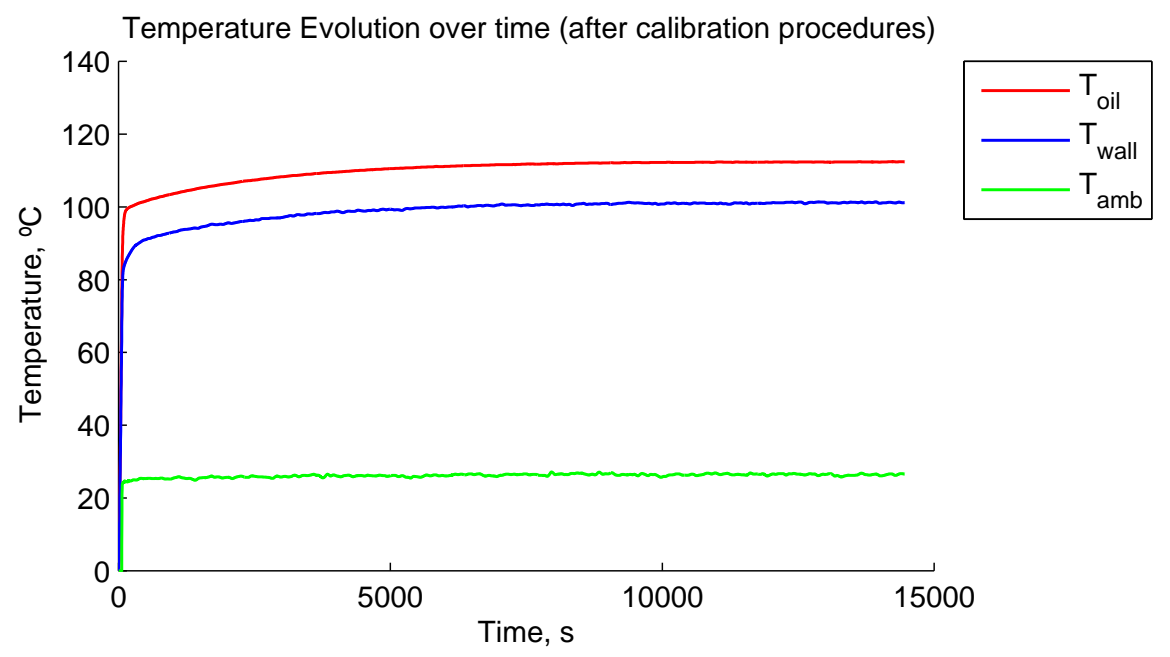


A.1. Reports from the experimental tests

\begin{tabular}{|c|c|c|c|c|}
\hline Test Number: 17 & Date: & $16 / 04 / 2012$ & By: Pedro Marques & \\
\hline & & & Oil Property & Units \\
\hline Oil Designation & & & MINR & - \\
\hline Viscosity at $40^{\circ} \mathrm{C}$ & & & 330.26 & $c S t$ \\
\hline Viscosity at $70^{\circ} \mathrm{C}$ & & & 68.06 & $c S t$ \\
\hline Viscosity at $100^{\circ} \mathrm{C}$ & & & 23.45 & $c S t$ \\
\hline Bulk Density at $25^{\circ} \mathrm{C}$ & & & 896.44 & $\mathrm{Kg} / \mathrm{m}^{3}$ \\
\hline & & & Imposed working conditions & Units \\
\hline $\mathrm{n}_{\text {in }}$ & & & 300 & rpm \\
\hline $\mathrm{TQ}_{\text {in }}$ & & & 800 & $N m$ \\
\hline Warmup period & & & 240 & $\min$ \\
\hline Test period & & & 240 & $\min$ \\
\hline & & & Actual working conditions & Units \\
\hline $\mathrm{n}_{\text {in }}$ & & & 296.394 & rpm \\
\hline $\mathrm{n}_{\text {out }}$ & & & 679.205 & rpm \\
\hline $\mathrm{TQ}_{\text {in }}$ & & & 801.901 & $N m$ \\
\hline TQ out & & & 336.076 & $N m$ \\
\hline TQout (theoretical) & & & 349.937 & $N m$ \\
\hline Input Power & & & 24889.64 & $W$ \\
\hline & & & Temperature readings & Units \\
\hline $\mathrm{T}_{\text {oil }}$ & & & 100.946 & ${ }^{\circ} \mathrm{C}$ \\
\hline $\mathrm{T}_{\text {wall }}$ & & & 91.232 & ${ }^{\circ} \mathrm{C}$ \\
\hline $\mathrm{T}_{\text {wall }}$ (slave) & & & 74.689 & ${ }^{\circ} \mathrm{C}$ \\
\hline \multirow[t]{2}{*}{$\mathrm{T}_{\mathrm{amb}}$} & & & 25.476 & ${ }^{\circ} \mathrm{C}$ \\
\hline & & & Additional information & Units \\
\hline$\Delta \mathrm{TQ}$ & & & 13.861 & $N m$ \\
\hline $\mathrm{T}_{\mathrm{oil}}-\mathrm{T}_{\mathrm{amb}}$ & & & 75.470 & ${ }^{\circ} \mathrm{C}$ \\
\hline $\mathrm{T}_{\text {wall }}-\mathrm{T}_{\mathrm{amb}}$ & & & 65.755 & ${ }^{\circ} \mathrm{C}$ \\
\hline
\end{tabular}

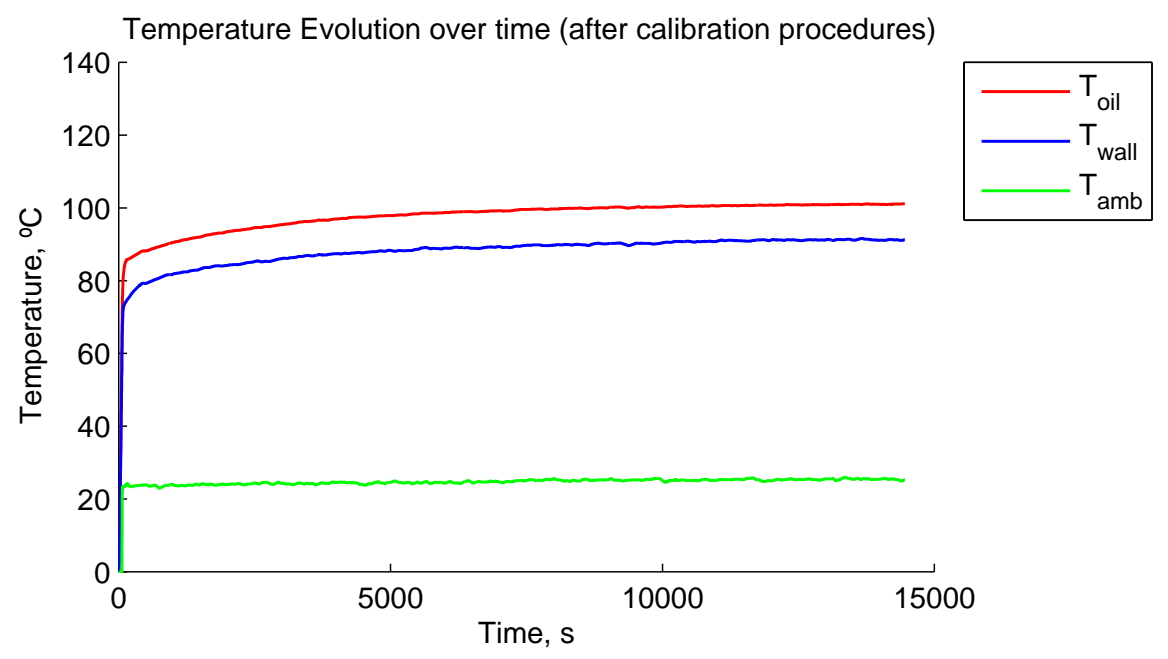


A. Appendix

\begin{tabular}{|c|c|c|c|c|}
\hline Test Number: 18 & Date: & $17 / 04 / 2012$ & By: Pedro Marques & \\
\hline & & & Oil Property & Units \\
\hline Oil Designation & & & MINR & - \\
\hline Viscosity at $40^{\circ} \mathrm{C}$ & & & 330.26 & $c S t$ \\
\hline Viscosity at $70^{\circ} \mathrm{C}$ & & & 68.06 & $c S t$ \\
\hline Viscosity at $100^{\circ} \mathrm{C}$ & & & 23.45 & $c S t$ \\
\hline Bulk Density at $25^{\circ} \mathrm{C}$ & & & 896.44 & $\mathrm{Kg} / \mathrm{m}^{3}$ \\
\hline & & & Imposed working conditions & Units \\
\hline $\mathrm{n}_{\text {in }}$ & & & 200 & rpm \\
\hline $\mathrm{TQ}_{\text {in }}$ & & & 500 & $N m$ \\
\hline Warmup period & & & 240 & $\min$ \\
\hline Test period & & & 240 & $\min$ \\
\hline & & & Actual working conditions & Units \\
\hline $\mathrm{n}_{\mathrm{in}}$ & & & 196.242 & rpm \\
\hline $\mathrm{n}_{\text {out }}$ & & & 449.700 & rpm \\
\hline $\mathrm{TQ}_{\mathrm{in}}$ & & & 501.465 & $\mathrm{Nm}$ \\
\hline TQout & & & 211.359 & $\mathrm{Nm}$ \\
\hline TQout (theoretical) & & & 218.831 & $\mathrm{Nm}$ \\
\hline Input Power & & & 10305.34 & $W$ \\
\hline & & & Temperature readings & Units \\
\hline $\mathrm{T}_{\mathrm{oil}}$ & & & 58.741 & ${ }^{\circ} \mathrm{C}$ \\
\hline $\mathrm{T}_{\text {wall }}$ & & & 53.193 & ${ }^{\circ} \mathrm{C}$ \\
\hline $\mathrm{T}_{\text {wall }}$ (slave) & & & 47.987 & ${ }^{\circ} \mathrm{C}$ \\
\hline \multirow[t]{2}{*}{$\mathrm{T}_{\mathrm{amb}}$} & & & 21.920 & ${ }^{\circ} \mathrm{C}$ \\
\hline & & & Additional information & Units \\
\hline$\Delta \mathrm{TQ}$ & & & 7.472 & $N m$ \\
\hline $\mathrm{T}_{\mathrm{oil}}-\mathrm{T}_{\mathrm{amb}}$ & & & 36.821 & ${ }^{\circ} \mathrm{C}$ \\
\hline $\mathrm{T}_{\mathrm{wall}}-\mathrm{T}_{\mathrm{amb}}$ & & & 31.273 & ${ }^{\circ} \mathrm{C}$ \\
\hline
\end{tabular}

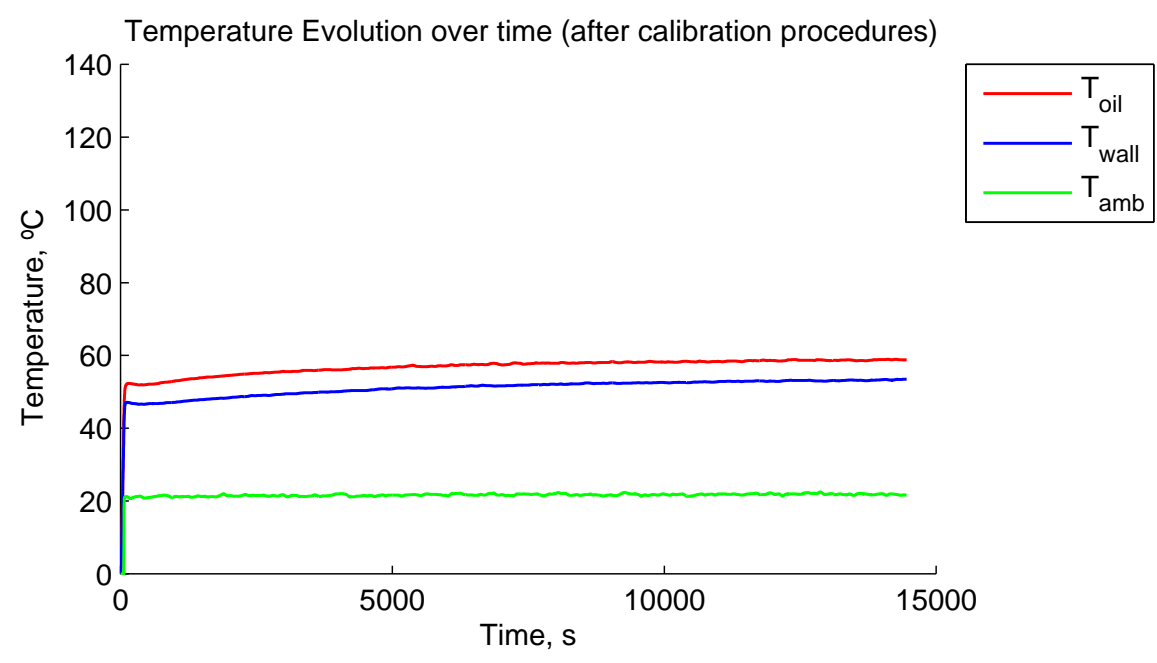


A.1. Reports from the experimental tests

\begin{tabular}{|c|c|c|c|c|}
\hline Test Number: 19 & Date: & $18 / 04 / 2012$ & By: Pedro Marques & \\
\hline & & & Oil Property & Units \\
\hline Oil Designation & & & MINR & - \\
\hline Viscosity at $40^{\circ} \mathrm{C}$ & & & 330.26 & $c S t$ \\
\hline Viscosity at $70^{\circ} \mathrm{C}$ & & & 68.06 & $c S t$ \\
\hline Viscosity at $100^{\circ} \mathrm{C}$ & & & 23.45 & $c S t$ \\
\hline Bulk Density at $25^{\circ} \mathrm{C}$ & & & 896.44 & $\mathrm{Kg} / \mathrm{m}^{3}$ \\
\hline & & & Imposed working conditions & Units \\
\hline $\mathrm{n}_{\text {in }}$ & & & 200 & rpm \\
\hline $\mathrm{TQ}_{\mathrm{in}}$ & & & 750 & $\mathrm{Nm}$ \\
\hline Warmup period & & & 240 & $\min$ \\
\hline Test period & & & 240 & $\min$ \\
\hline & & & Actual working conditions & Units \\
\hline $\mathrm{n}_{\text {in }}$ & & & 196.135 & rpm \\
\hline $\mathrm{n}_{\text {out }}$ & & & 449.455 & rpm \\
\hline $\mathrm{TQ}_{\mathrm{in}}$ & & & 751.429 & $\mathrm{Nm}$ \\
\hline TQout & & & 314.887 & $\mathrm{Nm}$ \\
\hline TQout (theoretical) & & & 327.910 & $N m$ \\
\hline Input Power & & & 15433.78 & $W$ \\
\hline & & & Temperature readings & Units \\
\hline $\mathrm{T}_{\text {oil }}$ & & & 71.479 & ${ }^{\circ} \mathrm{C}$ \\
\hline $\mathrm{T}_{\text {wall }}$ & & & 66.168 & ${ }^{\circ} \mathrm{C}$ \\
\hline $\mathrm{T}_{\text {wall }}$ (slave) & & & 61.512 & ${ }^{\circ} \mathrm{C}$ \\
\hline \multirow[t]{2}{*}{$\mathrm{T}_{\mathrm{amb}}$} & & & 22.319 & ${ }^{\circ} \mathrm{C}$ \\
\hline & & & Additional information & Units \\
\hline$\Delta \mathrm{TQ}$ & & & 13.025 & $N m$ \\
\hline $\mathrm{T}_{\mathrm{oil}}-\mathrm{T}_{\mathrm{amb}}$ & & & 49.160 & ${ }^{\circ} \mathrm{C}$ \\
\hline $\mathrm{T}_{\mathrm{wall}}-\mathrm{T}_{\mathrm{amb}}$ & & & 43.849 & ${ }^{\circ} \mathrm{C}$ \\
\hline
\end{tabular}

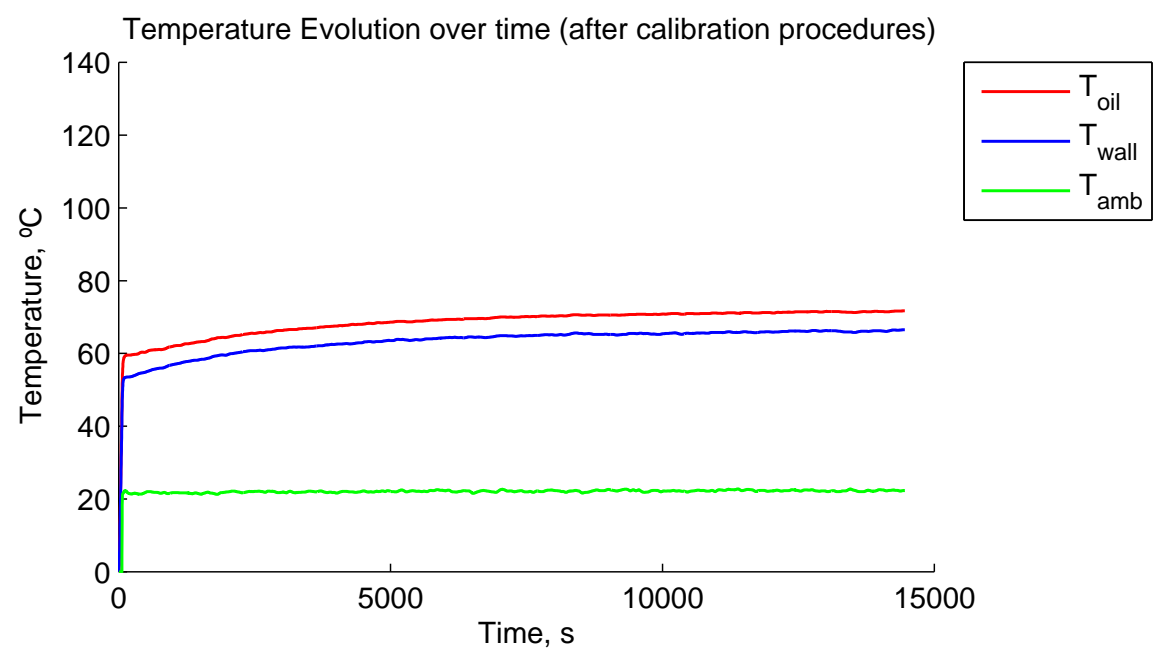


A. Appendix

\begin{tabular}{|c|c|c|c|c|}
\hline Test Number: 20 & Date: & $19 / 04 / 2012$ & By: Pedro Marques & \\
\hline & & & Oil Property & Units \\
\hline Oil Designation & & & MINR & - \\
\hline Viscosity at $40^{\circ} \mathrm{C}$ & & & 330.26 & $c S t$ \\
\hline Viscosity at $70^{\circ} \mathrm{C}$ & & & 68.06 & $c S t$ \\
\hline Viscosity at $100^{\circ} \mathrm{C}$ & & & 23.45 & $c S t$ \\
\hline Bulk Density at $25^{\circ} \mathrm{C}$ & & & 896.44 & $\mathrm{Kg} / \mathrm{m}^{3}$ \\
\hline & & & Imposed working conditions & Units \\
\hline $\mathrm{n}_{\text {in }}$ & & & 200 & rpm \\
\hline $\mathrm{TQ}$ in & & & 1000 & $\mathrm{Nm}$ \\
\hline Warmup period & & & 240 & $\min$ \\
\hline Test period & & & 240 & $\min$ \\
\hline & & & Actual working conditions & Units \\
\hline $\mathrm{n}_{\text {in }}$ & & & 195.983 & rpm \\
\hline $\mathrm{n}_{\text {out }}$ & & & 449.107 & rpm \\
\hline $\mathrm{TQ}_{\mathrm{in}}$ & & & 1001.014 & $\mathrm{Nm}$ \\
\hline TQout & & & 420.806 & $\mathrm{Nm}$ \\
\hline TQout (theoretical) & & & 436.827 & $N m$ \\
\hline Input Power & & & 15433.78 & $W$ \\
\hline & & & Temperature readings & Units \\
\hline $\mathrm{T}_{\text {oil }}$ & & & 86.661 & ${ }^{\circ} \mathrm{C}$ \\
\hline $\mathrm{T}_{\text {wall }}$ & & & 80.375 & ${ }^{\circ} \mathrm{C}$ \\
\hline $\mathrm{T}_{\text {wall }}$ (slave) & & & 72.842 & ${ }^{\circ} \mathrm{C}$ \\
\hline \multirow[t]{2}{*}{$\mathrm{T}_{\mathrm{amb}}$} & & & 24.306 & ${ }^{\circ} \mathrm{C}$ \\
\hline & & & Additional information & Units \\
\hline$\Delta \mathrm{TQ}$ & & & 16.020 & $N m$ \\
\hline $\mathrm{T}_{\mathrm{oil}}-\mathrm{T}_{\mathrm{amb}}$ & & & 62.357 & ${ }^{\circ} \mathrm{C}$ \\
\hline $\mathrm{T}_{\mathrm{wall}}-\mathrm{T}_{\mathrm{amb}}$ & & & 48.536 & ${ }^{\circ} \mathrm{C}$ \\
\hline
\end{tabular}

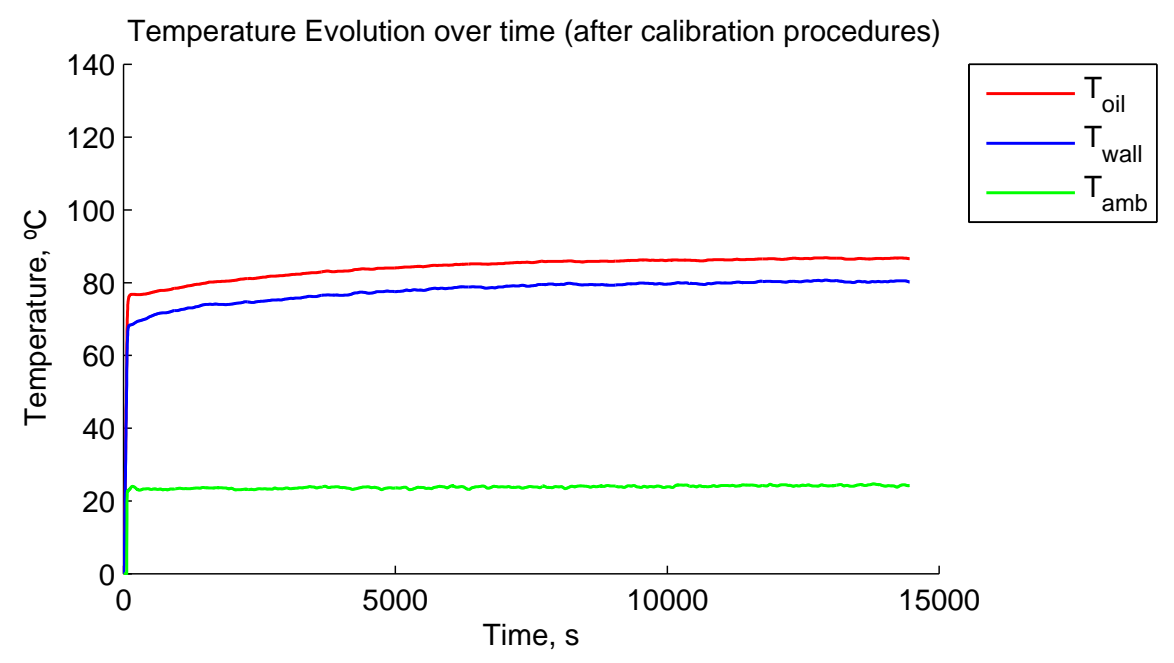




\section{A.1.3. PAGD Oil}


A. Appendix

\begin{tabular}{|c|c|c|c|c|}
\hline Test Number: 21 & Date: & $23 / 04 / 2012$ & By: Pedro Marques & \\
\hline & & & Oil Property & Units \\
\hline Oil Designation & & & PAGD & - \\
\hline Viscosity at $40^{\circ} \mathrm{C}$ & & & 300.69 & $c S t$ \\
\hline Viscosity at $70^{\circ} \mathrm{C}$ & & & 105.96 & $c S t$ \\
\hline Viscosity at $100^{\circ} \mathrm{C}$ & & & 52.76 & $c S t$ \\
\hline Bulk Density at $25^{\circ} \mathrm{C}$ & & & 1051.79 & $\mathrm{Kg} / \mathrm{m}^{3}$ \\
\hline & & & Imposed working conditions & Units \\
\hline $\mathrm{n}_{\mathrm{in}}$ & & & 400 & rpm \\
\hline $\mathrm{TQ}_{\text {in }}$ & & & 500 & $\mathrm{Nm}$ \\
\hline Warmup period & & & 240 & $\min$ \\
\hline Test period & & & 240 & $\min$ \\
\hline & & & Actual working conditions & Units \\
\hline $\mathrm{n}_{\mathrm{in}}$ & & & 398.531 & rpm \\
\hline $\mathrm{n}_{\text {out }}$ & & & 913.258 & rpm \\
\hline $\mathrm{TQ}_{\text {in }}$ & & & 502.403 & $\mathrm{Nm}$ \\
\hline TQout & & & 210.512 & $N m$ \\
\hline TQout (theoretical) & & & 219.240 & $N m$ \\
\hline Input Power & & & 20967.32 & $W$ \\
\hline & & & Temperature readings & Units \\
\hline $\mathrm{T}_{\mathrm{oil}}$ & & & 78.271 & ${ }^{\circ} \mathrm{C}$ \\
\hline $\mathrm{T}_{\text {wall }}$ & & & 71.225 & ${ }^{\circ} \mathrm{C}$ \\
\hline $\mathrm{T}_{\text {wall }}$ (slave) & & & 68.240 & ${ }^{\circ} \mathrm{C}$ \\
\hline \multirow[t]{2}{*}{$\mathrm{T}_{\mathrm{amb}}$} & & & 24.835 & ${ }^{\circ} \mathrm{C}$ \\
\hline & & & Additional information & Units \\
\hline$\Delta \mathrm{TQ}$ & & & 8.729 & $N m$ \\
\hline $\mathrm{T}_{\mathrm{oil}}-\mathrm{T}_{\mathrm{amb}}$ & & & 53.437 & ${ }^{\circ} \mathrm{C}$ \\
\hline $\mathrm{T}_{\text {wall }}-\mathrm{T}_{\mathrm{amb}}$ & & & 46.391 & ${ }^{\circ} \mathrm{C}$ \\
\hline
\end{tabular}

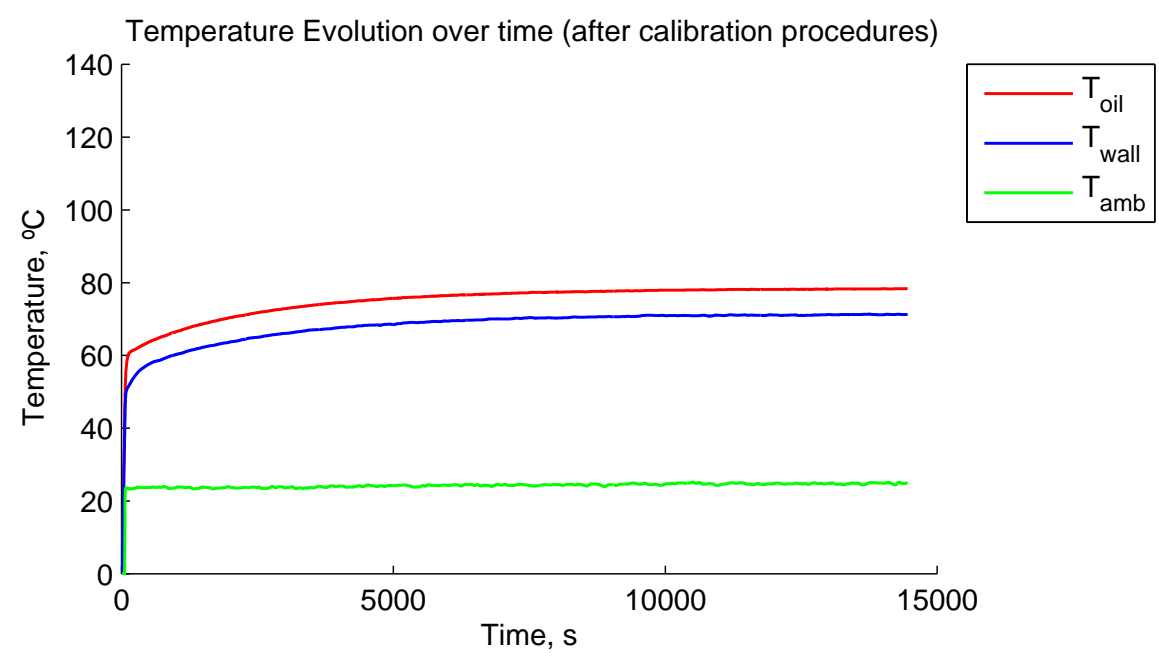


A.1. Reports from the experimental tests

\begin{tabular}{|c|c|c|c|c|}
\hline Test Number: 22 & Date: & $24 / 04 / 2012$ & By: Pedro Marques & \\
\hline & & & Oil Property & Units \\
\hline Oil Designation & & & PAGD & - \\
\hline Viscosity at $40^{\circ} \mathrm{C}$ & & & 300.69 & $c S t$ \\
\hline Viscosity at $70^{\circ} \mathrm{C}$ & & & 105.96 & $c S t$ \\
\hline Viscosity at $100^{\circ} \mathrm{C}$ & & & 52.76 & $c S t$ \\
\hline Bulk Density at $25^{\circ} \mathrm{C}$ & & & 1051.79 & $\mathrm{Kg} / \mathrm{m}^{3}$ \\
\hline & & & Imposed working conditions & Units \\
\hline $\mathrm{n}_{\text {in }}$ & & & 400 & \\
\hline $\mathrm{TQ}_{\mathrm{in}}$ & & & 750 & $N m$ \\
\hline Warmup period & & & 240 & $\min$ \\
\hline Test period & & & 240 & $\min$ \\
\hline & & & Actual working conditions & Units \\
\hline $\mathrm{n}_{\text {in }}$ & & & 398.450 & rpm \\
\hline $\mathrm{n}_{\text {out }}$ & & & 913.072 & rpm \\
\hline $\mathrm{TQ}_{\mathrm{in}}$ & & & 751.400 & $\mathrm{Nm}$ \\
\hline TQout & & & 313.301 & $\mathrm{Nm}$ \\
\hline TQout (theoretical) & & & 327.899 & $N m$ \\
\hline Input Power & & & 31352.62 & $W$ \\
\hline & & & Temperature readings & Units \\
\hline $\mathrm{T}_{\text {oil }}$ & & & 90.458 & ${ }^{\circ} \mathrm{C}$ \\
\hline $\mathrm{T}_{\text {wall }}$ & & & 82.089 & ${ }^{\circ} \mathrm{C}$ \\
\hline $\mathrm{T}_{\text {wall }}$ (slave) & & & 83.917 & ${ }^{\circ} \mathrm{C}$ \\
\hline \multirow{2}{*}{$\mathrm{T}_{\mathrm{amb}}$} & & & 26.552 & ${ }^{\circ} \mathrm{C}$ \\
\hline & & & Additional information & Units \\
\hline$\Delta \mathrm{TQ}$ & & & 14.598 & $N m$ \\
\hline $\mathrm{T}_{\mathrm{oil}}-\mathrm{T}_{\mathrm{amb}}$ & & & 63.906 & ${ }^{\circ} \mathrm{C}$ \\
\hline $\mathrm{T}_{\mathrm{wall}}-\mathrm{T}_{\mathrm{amb}}$ & & & 55.537 & ${ }^{\circ} \mathrm{C}$ \\
\hline
\end{tabular}

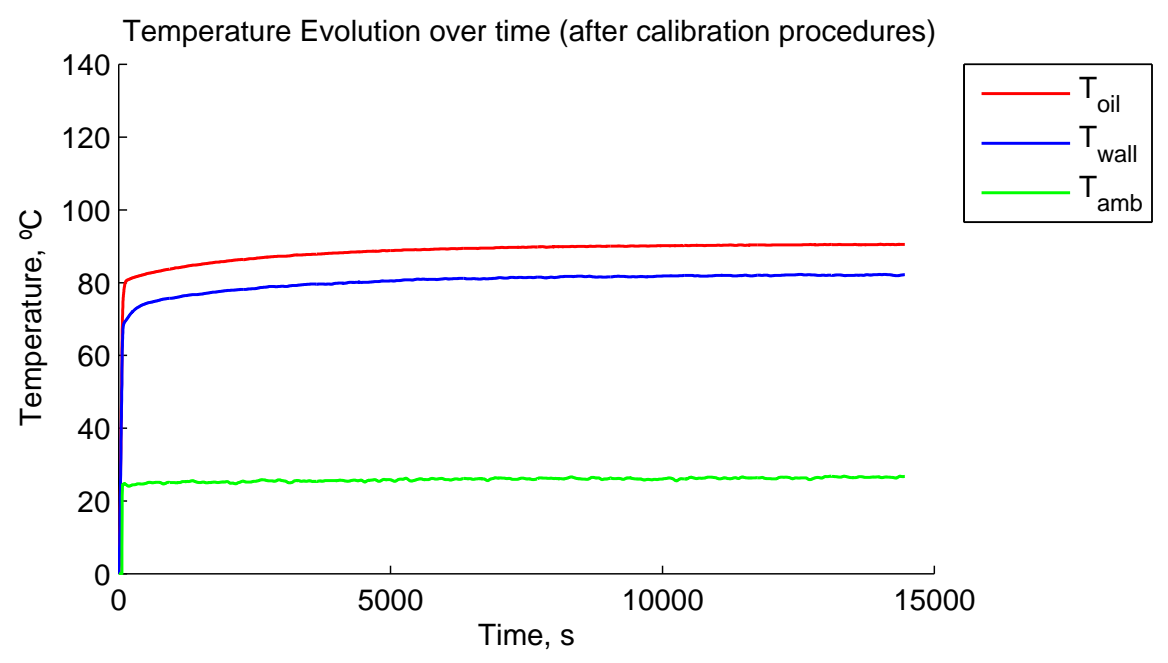


A. Appendix

\begin{tabular}{|c|c|c|c|c|}
\hline Test Number: 23 & Date: & $26 / 04 / 2012$ & By: Pedro Marques & \\
\hline & & & Oil Property & Units \\
\hline Oil Designation & & & PAGD & - \\
\hline Viscosity at $40^{\circ} \mathrm{C}$ & & & 300.69 & $c S t$ \\
\hline Viscosity at $70^{\circ} \mathrm{C}$ & & & 105.96 & $c S t$ \\
\hline Viscosity at $100^{\circ} \mathrm{C}$ & & & 52.76 & $c S t$ \\
\hline Bulk Density at $25^{\circ} \mathrm{C}$ & & & 1051.79 & $\mathrm{Kg} / \mathrm{m}^{3}$ \\
\hline & & & Imposed working conditions & Units \\
\hline $\mathrm{n}_{\text {in }}$ & & & 400 & rpm \\
\hline $\mathrm{TQ}_{\mathrm{in}}$ & & & 1000 & $N m$ \\
\hline Warmup period & & & 240 & $\min$ \\
\hline Test period & & & 240 & $\min$ \\
\hline & & & Actual working conditions & Units \\
\hline $\mathrm{n}_{\mathrm{in}}$ & & & 398.353 & rpm \\
\hline $\mathrm{n}_{\text {out }}$ & & & 912.850 & rpm \\
\hline $\mathrm{TQ}_{\text {in }}$ & & & 1000.617 & $N m$ \\
\hline TQout & & & 415.972 & $N m$ \\
\hline TQ out (theoretical) & & & 436.653 & $N m$ \\
\hline Input Power & & & 41741.11 & $W$ \\
\hline & & & Temperature readings & Units \\
\hline $\mathrm{T}_{\mathrm{oil}}$ & & & 104.314 & ${ }^{\circ} \mathrm{C}$ \\
\hline $\mathrm{T}_{\text {wall }}$ & & & 94.415 & ${ }^{\circ} \mathrm{C}$ \\
\hline $\mathrm{T}_{\text {wall }}$ (slave) & & & 101.291 & ${ }^{\circ} \mathrm{C}$ \\
\hline \multirow[t]{2}{*}{$\mathrm{T}_{\mathrm{amb}}$} & & & 28.119 & ${ }^{\circ} \mathrm{C}$ \\
\hline & & & Additional information & Units \\
\hline$\Delta \mathrm{TQ}$ & & & 20.681 & $N m$ \\
\hline $\mathrm{T}_{\mathrm{oil}}-\mathrm{T}_{\mathrm{amb}}$ & & & 76.196 & ${ }^{\circ} \mathrm{C}$ \\
\hline $\mathrm{T}_{\mathrm{wall}}-\mathrm{T}_{\mathrm{amb}}$ & & & 66.298 & ${ }^{\circ} \mathrm{C}$ \\
\hline
\end{tabular}

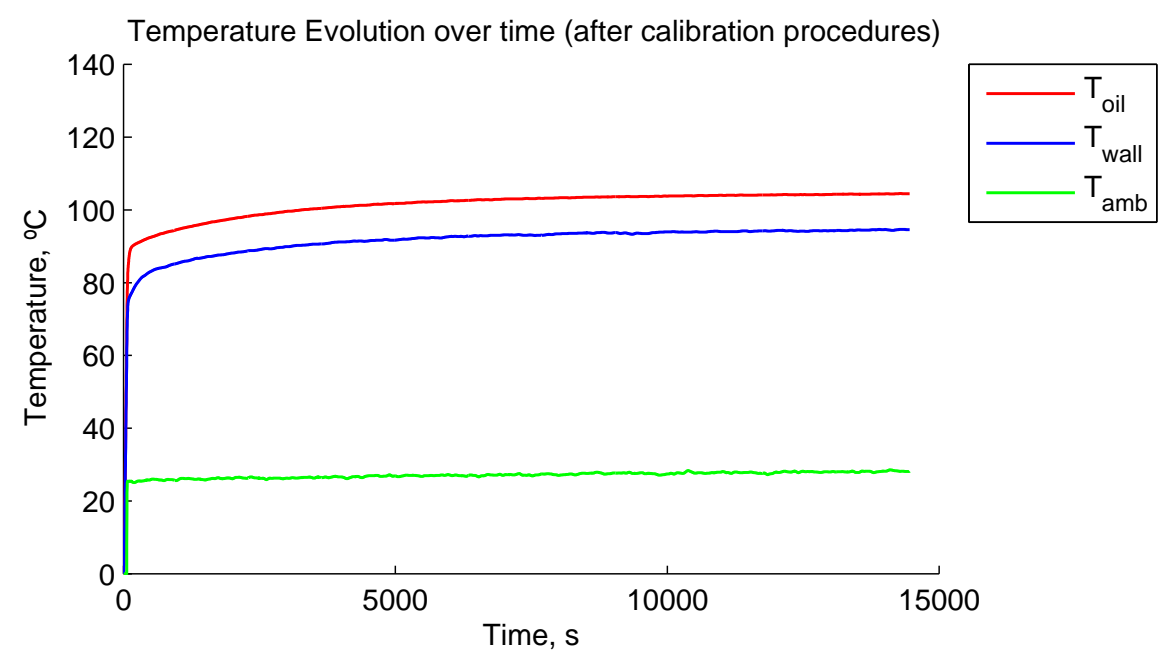


A.1. Reports from the experimental tests

\begin{tabular}{|c|c|c|c|c|}
\hline Test Number: 24 & Date: & $27 / 04 / 2012$ & By: Pedro Marques & \\
\hline & & & Oil Property & Units \\
\hline Oil Designation & & & PAGD & - \\
\hline Viscosity at $40^{\circ} \mathrm{C}$ & & & 300.69 & $c S t$ \\
\hline Viscosity at $70^{\circ} \mathrm{C}$ & & & 105.96 & $c S t$ \\
\hline Viscosity at $100^{\circ} \mathrm{C}$ & & & 52.76 & $c S t$ \\
\hline Bulk Density at $25^{\circ} \mathrm{C}$ & & & 1051.79 & $K g / m^{3}$ \\
\hline & & & Imposed working conditions & Units \\
\hline $\mathrm{n}_{\text {in }}$ & & & 100 & rpm \\
\hline $\mathrm{TQ}_{\mathrm{in}}$ & & & 500 & $\mathrm{Nm}$ \\
\hline Warmup period & & & 240 & $\min$ \\
\hline Test period & & & 240 & $\min$ \\
\hline & & & Actual working conditions & Units \\
\hline $\mathrm{n}_{\text {in }}$ & & & 102.309 & rpm \\
\hline $\mathrm{n}_{\text {out }}$ & & & 234.447 & rpm \\
\hline $\mathrm{TQ}_{\mathrm{in}}$ & & & 501.562 & $\mathrm{Nm}$ \\
\hline TQout & & & 210.295 & $\mathrm{Nm}$ \\
\hline TQout (theoretical) & & & 218.874 & $\mathrm{Nm}$ \\
\hline Input Power & & & 5373.64 & $W$ \\
\hline & & & Temperature readings & Units \\
\hline $\mathrm{T}_{\text {oil }}$ & & & 40.162 & ${ }^{\circ} \mathrm{C}$ \\
\hline $\mathrm{T}_{\text {wall }}$ & & & 35.742 & ${ }^{\circ} \mathrm{C}$ \\
\hline $\mathrm{T}_{\text {wall }}$ (slave) & & & 39.844 & ${ }^{\circ} \mathrm{C}$ \\
\hline \multirow[t]{2}{*}{$\mathrm{T}_{\mathrm{amb}}$} & & & 23.03 & ${ }^{\circ} \mathrm{C}$ \\
\hline & & & Additional information & Units \\
\hline$\Delta \mathrm{TQ}$ & & & 8.579 & $N m$ \\
\hline $\mathrm{T}_{\mathrm{oil}}-\mathrm{T}_{\mathrm{amb}}$ & & & 17.132 & ${ }^{\circ} \mathrm{C}$ \\
\hline $\mathrm{T}_{\mathrm{wall}}-\mathrm{T}_{\mathrm{amb}}$ & & & 12.712 & ${ }^{\circ} \mathrm{C}$ \\
\hline
\end{tabular}

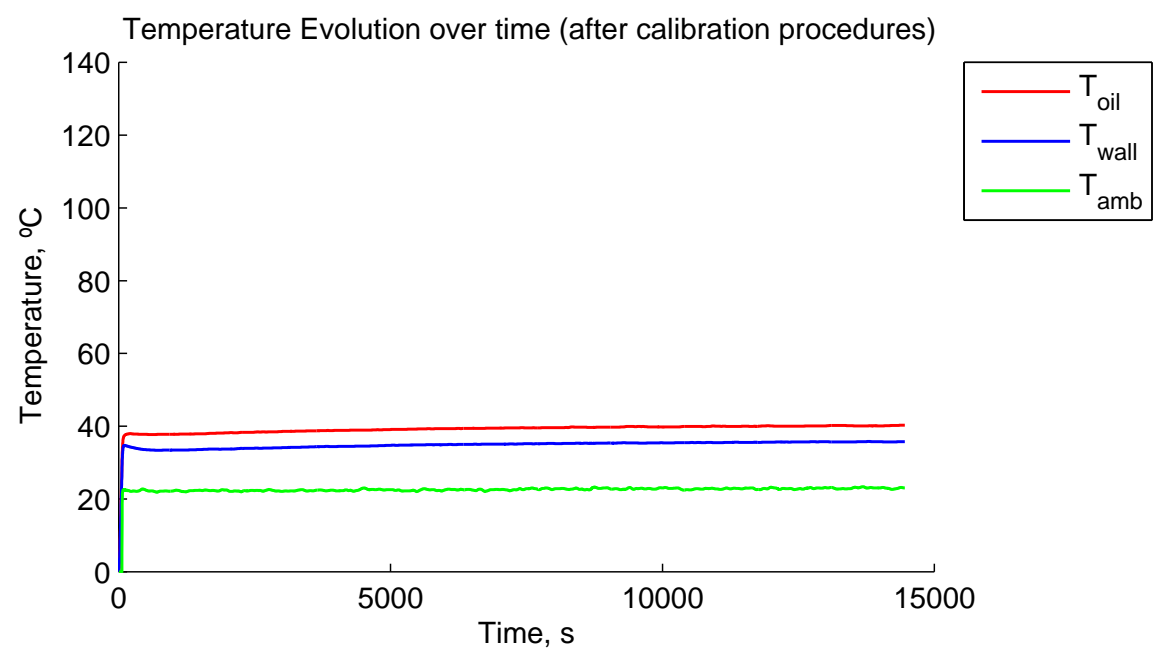


A. Appendix

\begin{tabular}{|c|c|c|c|c|}
\hline Test Number: 25 & Date: & $30 / 04 / 2012$ & By: Pedro Marques & \\
\hline & & & Oil Property & Units \\
\hline Oil Designation & & & PAGD & - \\
\hline Viscosity at $40^{\circ} \mathrm{C}$ & & & 300.69 & $c S t$ \\
\hline Viscosity at $70^{\circ} \mathrm{C}$ & & & 105.96 & $c S t$ \\
\hline Viscosity at $100^{\circ} \mathrm{C}$ & & & 52.76 & $c S t$ \\
\hline Bulk Density at $25^{\circ} \mathrm{C}$ & & & 1051.79 & $\mathrm{Kg} / \mathrm{m}^{3}$ \\
\hline & & & Imposed working conditions & Units \\
\hline $\mathrm{n}_{\text {in }}$ & & & 100 & rpm \\
\hline $\mathrm{TQ}_{\text {in }}$ & & & 750 & $\mathrm{Nm}$ \\
\hline Warmup period & & & 240 & $\min$ \\
\hline Test period & & & 240 & $\min$ \\
\hline & & & Actual working conditions & Units \\
\hline $\mathrm{n}_{\mathrm{in}}$ & & & 101.995 & rpm \\
\hline $\mathrm{n}_{\text {out }}$ & & & 233.728 & rpm \\
\hline $\mathrm{TQ}_{\mathrm{in}}$ & & & 751.200 & $\mathrm{Nm}$ \\
\hline TQout & & & 314.190 & $N m$ \\
\hline TQout (theoretical) & & & 327.812 & $\mathrm{Nm}$ \\
\hline Input Power & & & 8023.45 & $W$ \\
\hline & & & Temperature readings & Units \\
\hline $\mathrm{T}_{\mathrm{oil}}$ & & & 44.755 & ${ }^{\circ} \mathrm{C}$ \\
\hline $\mathrm{T}_{\text {wall }}$ & & & 39.426 & ${ }^{\circ} \mathrm{C}$ \\
\hline $\mathrm{T}_{\text {wall }}$ (slave) & & & 44.014 & ${ }^{\circ} \mathrm{C}$ \\
\hline \multirow[t]{2}{*}{$\mathrm{T}_{\mathrm{amb}}$} & & & 22.257 & ${ }^{\circ} \mathrm{C}$ \\
\hline & & & Additional information & Units \\
\hline$\Delta \mathrm{TQ}$ & & & 13.619 & $N m$ \\
\hline $\mathrm{T}_{\mathrm{oil}}-\mathrm{T}_{\mathrm{amb}}$ & & & 22.499 & ${ }^{\circ} \mathrm{C}$ \\
\hline $\mathrm{T}_{\mathrm{wall}}-\mathrm{T}_{\mathrm{amb}}$ & & & 17.169 & ${ }^{\circ} \mathrm{C}$ \\
\hline
\end{tabular}

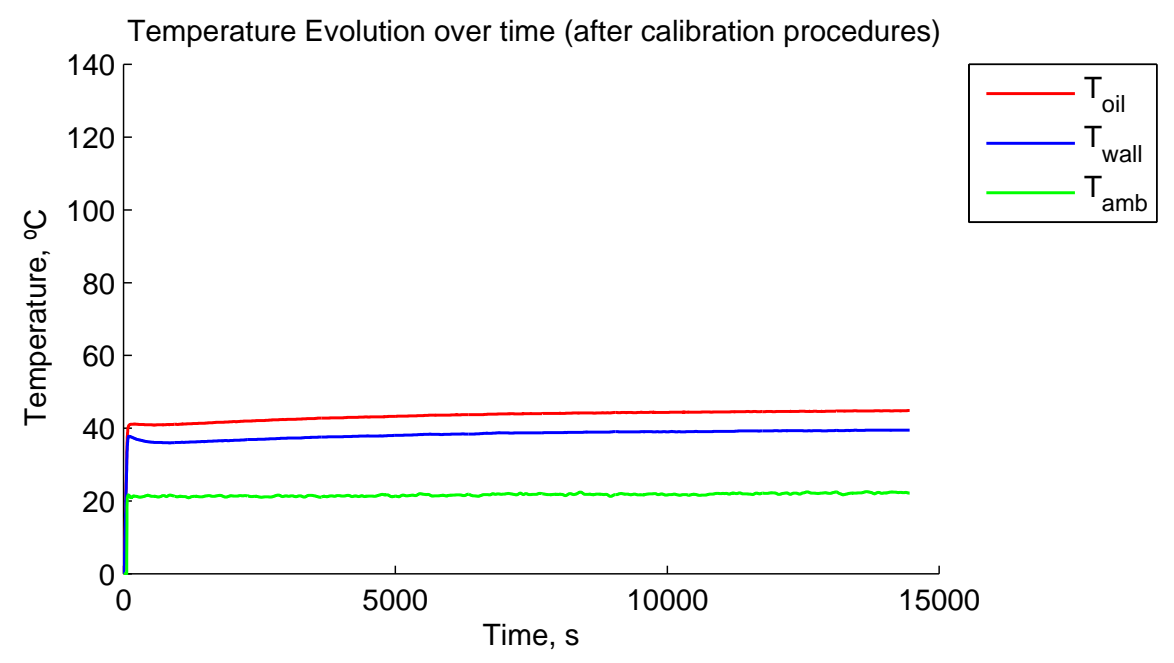


A.1. Reports from the experimental tests

\begin{tabular}{|c|c|c|c|c|}
\hline Test Number: 26 & Date: & $2 / 05 / 2012$ & By: Pedro Marques & \\
\hline & & & Oil & Units \\
\hline Designation (Internal) & & & PAGD & - \\
\hline Viscosity at $40^{\circ} \mathrm{C}$ & & & 300.69 & $c S t$ \\
\hline Viscosity at $70^{\circ} \mathrm{C}$ & & & 105.96 & $c S t$ \\
\hline Viscosity at $100^{\circ} \mathrm{C}$ & & & 52.76 & $c S t$ \\
\hline Bulk Density at $25^{\circ} \mathrm{C}$ & & & 1051.79 & $K g / m^{3}$ \\
\hline & & & Imposed working conditions & Units \\
\hline $\mathrm{n}_{\text {in }}$ & & & 100 & rpm \\
\hline $\mathrm{TQ}_{\mathrm{in}}$ & & & 1000 & $\mathrm{Nm}$ \\
\hline Warmup period & & & 240 & $\min$ \\
\hline Test period & & & 240 & $\min$ \\
\hline & & & Actual working conditions & Units \\
\hline $\mathrm{n}_{\text {in }}$ & & & 101.742 & $r p m$ \\
\hline $\mathrm{n}_{\text {out }}$ & & & 233.148 & rpm \\
\hline $\mathrm{TQ}_{\mathrm{in}}$ & & & 1001.474 & $\mathrm{Nm}$ \\
\hline TQout & & & 418.437 & $N m$ \\
\hline TQout (theoretical) & & & 437.027 & $N m$ \\
\hline Input Power & & & 10670.09 & $W$ \\
\hline & & & Temperature readings & Units \\
\hline $\mathrm{T}_{\mathrm{oil}}$ & & & 50.598 & ${ }^{\circ} \mathrm{C}$ \\
\hline $\mathrm{T}_{\text {wall }}$ & & & 44.056 & ${ }^{\circ} \mathrm{C}$ \\
\hline $\mathrm{T}_{\text {wall }}$ (slave) & & & 49.919 & ${ }^{\circ} \mathrm{C}$ \\
\hline \multirow[t]{2}{*}{$\mathrm{T}_{\mathrm{amb}}$} & & & 22.031 & ${ }^{\circ} \mathrm{C}$ \\
\hline & & & Additional information & Units \\
\hline$\Delta \mathrm{TQ}$ & & & 18.590 & $N m$ \\
\hline $\mathrm{T}_{\mathrm{oil}}-\mathrm{T}_{\mathrm{amb}}$ & & & 28.566 & ${ }^{\circ} \mathrm{C}$ \\
\hline $\mathrm{T}_{\mathrm{wall}}-\mathrm{T}_{\mathrm{amb}}$ & & & 22.024 & ${ }^{\circ} \mathrm{C}$ \\
\hline
\end{tabular}

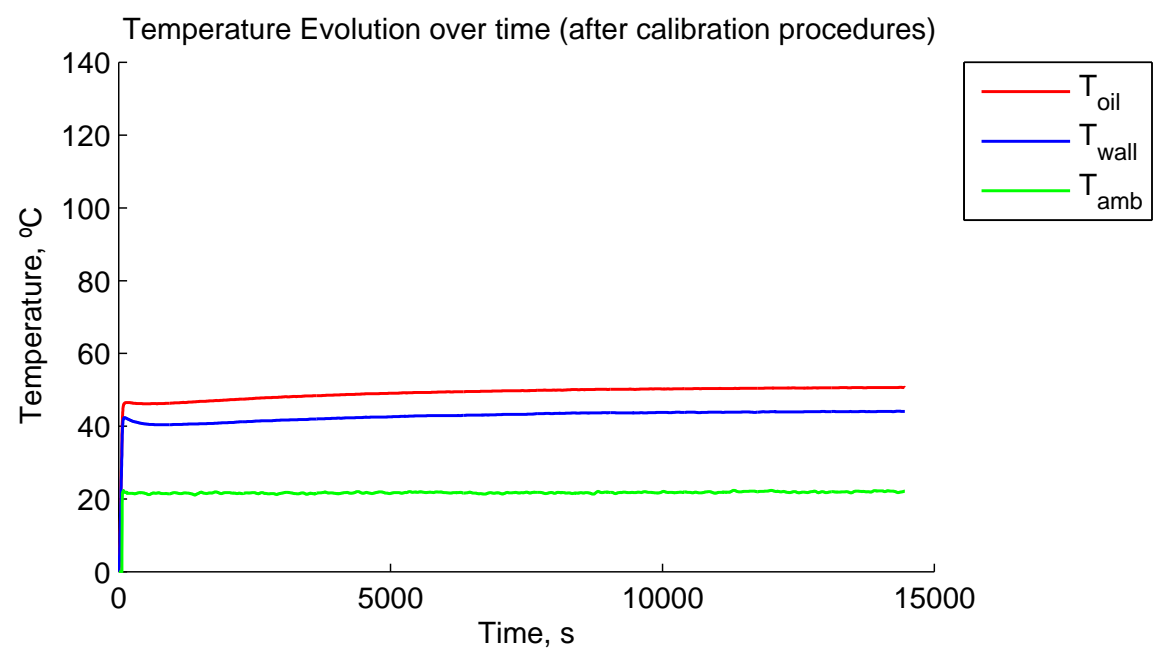


A. Appendix

\begin{tabular}{|c|c|c|c|c|}
\hline Test Number: 27 & Date: & $3 / 05 / 2012$ & By: Pedro Marques & \\
\hline & & & Oil Property & Units \\
\hline Oil Designation & & & PAGD & - \\
\hline Viscosity at $40^{\circ} \mathrm{C}$ & & & 300.69 & $c S t$ \\
\hline Viscosity at $70^{\circ} \mathrm{C}$ & & & 105.96 & $c S t$ \\
\hline Viscosity at $100^{\circ} \mathrm{C}$ & & & 52.76 & $c S t$ \\
\hline Bulk Density at $25^{\circ} \mathrm{C}$ & & & 1051.79 & $\mathrm{Kg} / \mathrm{m}^{3}$ \\
\hline & & & Imposed working conditions & Units \\
\hline $\mathrm{n}_{\text {in }}$ & & & 200 & rpm \\
\hline $\mathrm{TQ}_{\mathrm{in}}$ & & & 500 & $\mathrm{Nm}$ \\
\hline Warmup period & & & 240 & $\min$ \\
\hline Test period & & & 240 & $\min$ \\
\hline & & & Actual working conditions & Units \\
\hline $\mathrm{n}_{\text {in }}$ & & & 196.247 & rpm \\
\hline $\mathrm{n}_{\text {out }}$ & & & 449.712 & rpm \\
\hline $\mathrm{TQ}_{\mathrm{in}}$ & & & 501.507 & $N m$ \\
\hline TQout & & & 210.232 & $\mathrm{Nm}$ \\
\hline TQout (theoretical) & & & 218.85 & $\mathrm{Nm}$ \\
\hline Input Power & & & 10306.40 & $W$ \\
\hline & & & Temperature readings & Units \\
\hline $\mathrm{T}_{\text {oil }}$ & & & 53.352 & ${ }^{\circ} \mathrm{C}$ \\
\hline $\mathrm{T}_{\text {wall }}$ & & & 47.910 & ${ }^{\circ} \mathrm{C}$ \\
\hline $\mathrm{T}_{\text {wall }}$ (slave) & & & 55.327 & ${ }^{\circ} \mathrm{C}$ \\
\hline \multirow[t]{2}{*}{$\mathrm{T}_{\mathrm{amb}}$} & & & 23.414 & ${ }^{\circ} \mathrm{C}$ \\
\hline & & & Additional information & Units \\
\hline$\Delta \mathrm{TQ}$ & & & 8.618 & $N m$ \\
\hline $\mathrm{T}_{\mathrm{oil}}-\mathrm{T}_{\mathrm{amb}}$ & & & 29.938 & ${ }^{\circ} \mathrm{C}$ \\
\hline $\mathrm{T}_{\mathrm{wall}}-\mathrm{T}_{\mathrm{amb}}$ & & & 24.497 & ${ }^{\circ} \mathrm{C}$ \\
\hline
\end{tabular}

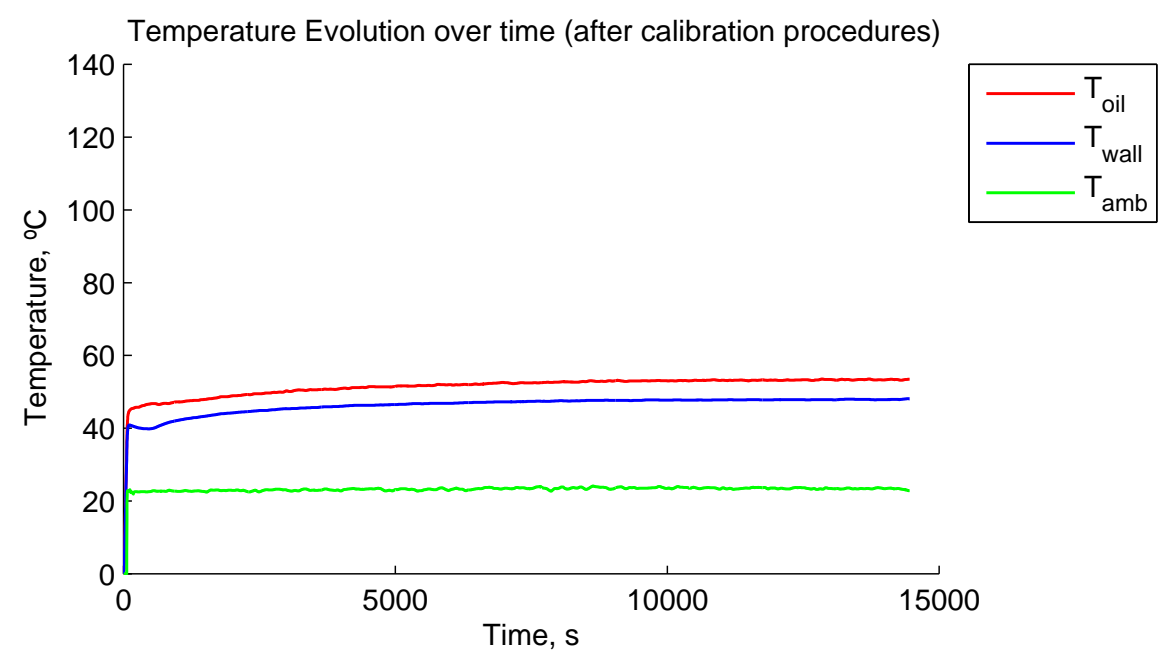


A.1. Reports from the experimental tests

\begin{tabular}{|c|c|c|c|c|}
\hline Test Number: 28 & Date: & $3 / 05 / 2012$ & By: Pedro Marques & \\
\hline & & & Oil Property & Units \\
\hline Oil Designation & & & PAGD & - \\
\hline Viscosity at $40^{\circ} \mathrm{C}$ & & & 300.69 & $c S t$ \\
\hline Viscosity at $70^{\circ} \mathrm{C}$ & & & 105.96 & $c S t$ \\
\hline Viscosity at $100^{\circ} \mathrm{C}$ & & & 52.76 & $c S t$ \\
\hline Bulk Density at $25^{\circ} \mathrm{C}$ & & & 1051.79 & $\mathrm{Kg} / \mathrm{m}^{3}$ \\
\hline & & & Imposed working conditions & Units \\
\hline $\mathrm{n}_{\text {in }}$ & & & 200 & rpm \\
\hline $\mathrm{TQ}_{\text {in }}$ & & & 750 & $\mathrm{Nm}$ \\
\hline Warmup period & & & 240 & $\min$ \\
\hline Test period & & & 240 & $\min$ \\
\hline & & & Actual working conditions & Units \\
\hline $\mathrm{n}_{\text {in }}$ & & & 196.152 & rpm \\
\hline $\mathrm{n}_{\text {out }}$ & & & 449.494 & rpm \\
\hline $\mathrm{TQ}_{\mathrm{in}}$ & & & 751.353 & $\mathrm{Nm}$ \\
\hline TQout & & & 313.778 & $\mathrm{Nm}$ \\
\hline TQout (theoretical) & & & 327.879 & $\mathrm{Nm}$ \\
\hline Input Power & & & 10306.40 & $W$ \\
\hline & & & Temperature readings & Units \\
\hline $\mathrm{T}_{\text {oil }}$ & & & 62.051 & ${ }^{\circ} \mathrm{C}$ \\
\hline $\mathrm{T}_{\text {wall }}$ & & & 56.437 & ${ }^{\circ} \mathrm{C}$ \\
\hline $\mathrm{T}_{\text {wall }}$ (slave) & & & 63.787 & ${ }^{\circ} \mathrm{C}$ \\
\hline \multirow[t]{2}{*}{$\mathrm{T}_{\mathrm{amb}}$} & & & 23.188 & ${ }^{\circ} \mathrm{C}$ \\
\hline & & & Additional information & Units \\
\hline$\Delta \mathrm{TQ}$ & & & 14.013 & $\mathrm{Nm}$ \\
\hline $\mathrm{T}_{\mathrm{oil}}-\mathrm{T}_{\mathrm{amb}}$ & & & 38.863 & ${ }^{\circ} \mathrm{C}$ \\
\hline $\mathrm{T}_{\mathrm{wall}}-\mathrm{T}_{\mathrm{amb}}$ & & & 33.249 & ${ }^{\circ} \mathrm{C}$ \\
\hline
\end{tabular}

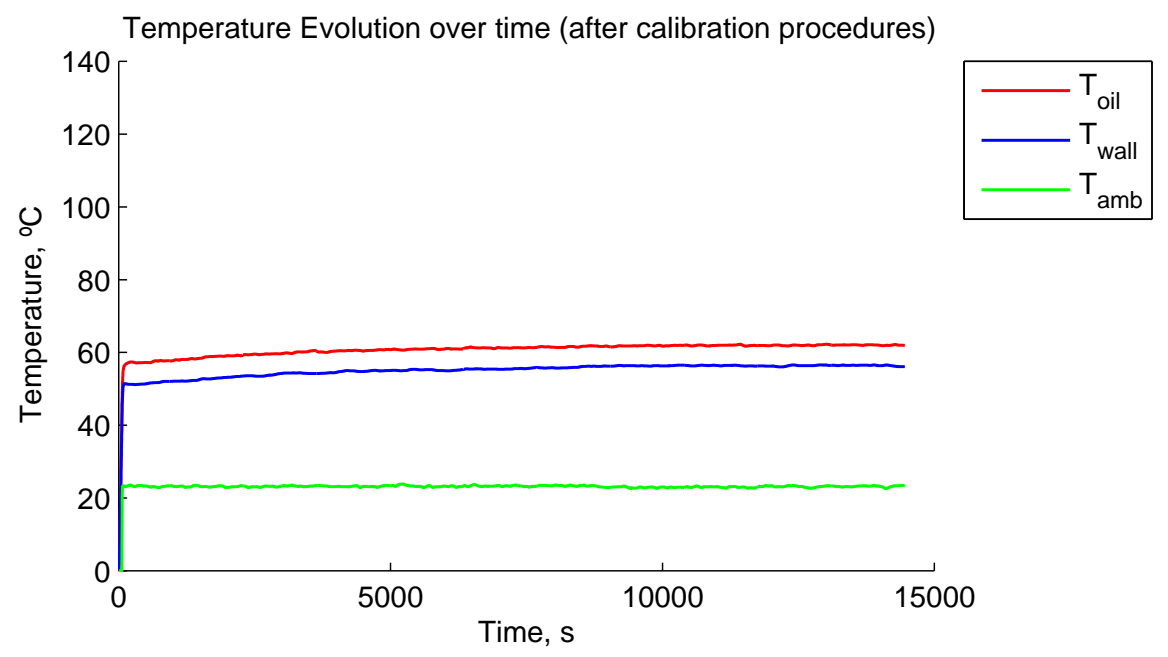


A. Appendix

\begin{tabular}{|c|c|c|c|}
\hline Test Number: 29 & Date: $15 / 05 / 2012$ & By: Pedro Marques & \\
\hline & & Oil Property & Units \\
\hline Oil Designation & & PAGD & - \\
\hline Viscosity at $40^{\circ} \mathrm{C}$ & & 300.69 & $c S t$ \\
\hline Viscosity at $70^{\circ} \mathrm{C}$ & & 105.96 & $c S t$ \\
\hline Viscosity at $100^{\circ} \mathrm{C}$ & & 52.76 & $c S t$ \\
\hline Bulk Density at $25^{\circ} \mathrm{C}$ & & 1051.79 & $\mathrm{Kg} / \mathrm{m}^{3}$ \\
\hline & & Imposed working conditions & Units \\
\hline $\mathrm{n}_{\text {in }}$ & & 200 & rpm \\
\hline $\mathrm{TQ}_{\mathrm{in}}$ & & 1000 & $N m$ \\
\hline Warmup period & & 240 & $\min$ \\
\hline Test period & & 240 & $\min$ \\
\hline & & Actual working conditions & Units \\
\hline $\mathrm{n}_{\text {in }}$ & & 196.048 & rpm \\
\hline $\mathrm{n}_{\text {out }}$ & & 449.256 & rpm \\
\hline $\mathrm{TQ}_{\text {in }}$ & & 1001.581 & $\mathrm{Nm}$ \\
\hline TQ out & & 417.708 & $N m$ \\
\hline TQout (theoretical) & & 437.074 & $\mathrm{Nm}$ \\
\hline Input Power & & 10306.40 & $W$ \\
\hline & & Temperature readings & Units \\
\hline $\mathrm{T}_{\text {oil }}$ & & 75.057 & ${ }^{\circ} \mathrm{C}$ \\
\hline $\mathrm{T}_{\text {wall }}$ & & 68.898 & ${ }^{\circ} \mathrm{C}$ \\
\hline $\mathrm{T}_{\text {wall }}$ (slave) & & 83.003 & ${ }^{\circ} \mathrm{C}$ \\
\hline \multirow[t]{2}{*}{$\mathrm{T}_{\mathrm{amb}}$} & & 30.198 & ${ }^{\circ} \mathrm{C}$ \\
\hline & & Additional information & Units \\
\hline$\Delta \mathrm{TQ}$ & & 19.366 & $N m$ \\
\hline $\mathrm{T}_{\mathrm{oil}}-\mathrm{T}_{\mathrm{amb}}$ & & 44.859 & ${ }^{\circ} \mathrm{C}$ \\
\hline $\mathrm{T}_{\mathrm{wall}}-\mathrm{T}_{\mathrm{amb}}$ & & 38.700 & ${ }^{\circ} \mathrm{C}$ \\
\hline
\end{tabular}

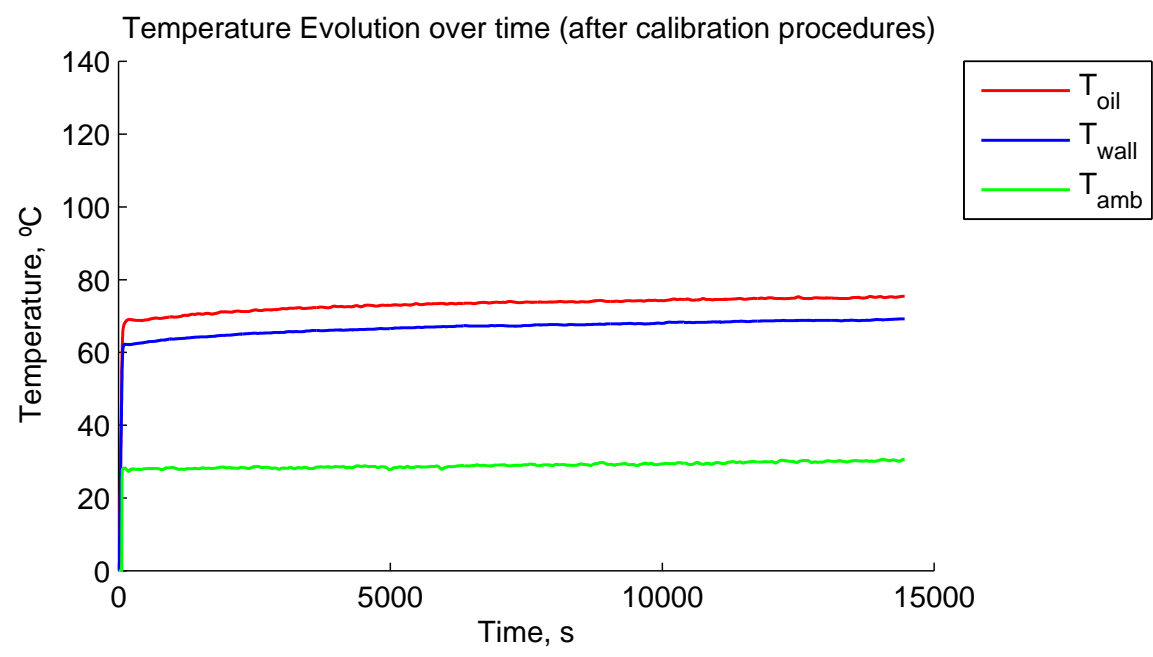




\section{A.1.4. PAOR Oil}


A. Appendix

\begin{tabular}{|c|c|c|c|c|}
\hline Test Number: 30 & Date: & $29 / 04 / 2012$ & By: Pedro Marques & \\
\hline & & & Oil Property & Units \\
\hline Oil Designation & & & PAOR & - \\
\hline Viscosity at $40^{\circ} \mathrm{C}$ & & & 324.37 & $c S t$ \\
\hline Viscosity at $70^{\circ} \mathrm{C}$ & & & 87.97 & $c S t$ \\
\hline Viscosity at $100^{\circ} \mathrm{C}$ & & & 35.27 & $c S t$ \\
\hline Bulk Density at $25^{\circ} \mathrm{C}$ & & & 854.937 & $\mathrm{Kg} / \mathrm{m}^{3}$ \\
\hline & & & Imposed working conditions & Units \\
\hline $\mathrm{n}_{\text {in }}$ & & & 400 & rpm \\
\hline $\mathrm{TQ}_{\text {in }}$ & & & 500 & $N m$ \\
\hline Warmup period & & & 240 & $\min$ \\
\hline Test period & & & 240 & $\min$ \\
\hline & & & Actual working conditions & Units \\
\hline $\mathrm{n}_{\mathrm{in}}$ & & & 405.406 & rpm \\
\hline $\mathrm{n}_{\text {out }}$ & & & 929.013 & rpm \\
\hline $\mathrm{TQ}_{\mathrm{in}}$ & & & 501.018 & $\mathrm{Nm}$ \\
\hline TQout & & & 209.988 & $\mathrm{Nm}$ \\
\hline TQout (theoretical) & & & 218.636 & $\mathrm{Nm}$ \\
\hline Input Power & & & 21270.25 & $W$ \\
\hline & & & Temperature readings & Units \\
\hline $\mathrm{T}_{\mathrm{oil}}$ & & & 86.243 & ${ }^{\circ} \mathrm{C}$ \\
\hline $\mathrm{T}_{\text {wall }}$ & & & 79.498 & ${ }^{\circ} \mathrm{C}$ \\
\hline $\mathrm{T}_{\text {wall }}$ (slave) & & & 76.991 & ${ }^{\circ} \mathrm{C}$ \\
\hline \multirow[t]{2}{*}{$\mathrm{T}_{\mathrm{amb}}$} & & & 30.845 & ${ }^{\circ} \mathrm{C}$ \\
\hline & & & Additional information & Units \\
\hline$\Delta \mathrm{TQ}$ & & & 8.649 & $N m$ \\
\hline $\mathrm{T}_{\mathrm{oil}}-\mathrm{T}_{\mathrm{amb}}$ & & & 55.398 & ${ }^{\circ} \mathrm{C}$ \\
\hline $\mathrm{T}_{\mathrm{wall}}-\mathrm{T}_{\mathrm{amb}}$ & & & 48.652 & ${ }^{\circ} \mathrm{C}$ \\
\hline
\end{tabular}

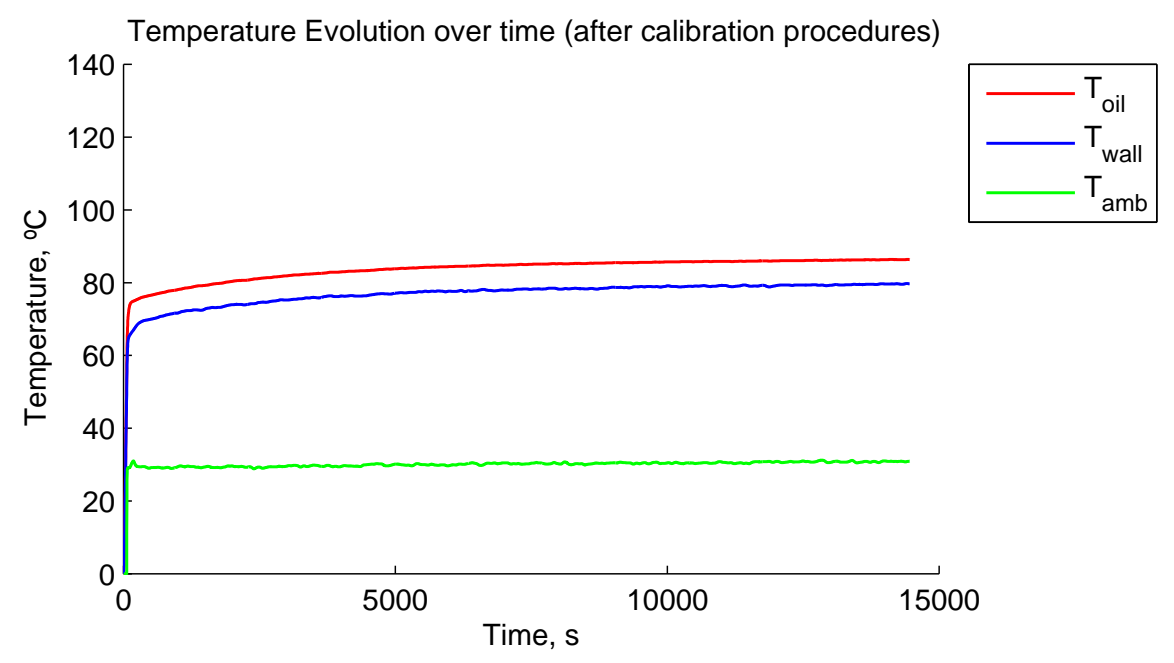


A.1. Reports from the experimental tests

\begin{tabular}{|c|c|c|c|c|}
\hline Test Number: 31 & Date: & $30 / 04 / 2012$ & By: Pedro Marques & \\
\hline & & & Oil Property & Units \\
\hline Oil Designation & & & PAOR & - \\
\hline Viscosity at $40^{\circ} \mathrm{C}$ & & & 324.37 & $c S t$ \\
\hline Viscosity at $70^{\circ} \mathrm{C}$ & & & 87.97 & $c S t$ \\
\hline Viscosity at $100^{\circ} \mathrm{C}$ & & & 35.27 & $c S t$ \\
\hline Bulk Density at $25^{\circ} \mathrm{C}$ & & & 854.937 & $K g / m^{3}$ \\
\hline & & & Imposed working conditions & Units \\
\hline $\mathrm{n}_{\text {in }}$ & & & 400 & rpm \\
\hline $\mathrm{TQ}_{\mathrm{in}}$ & & & 750 & $N m$ \\
\hline Warmup period & & & 240 & $\min$ \\
\hline Test period & & & 240 & $\min$ \\
\hline & & & Actual working conditions & Units \\
\hline $\mathrm{n}_{\mathrm{in}}$ & & & 398.452 & rpm \\
\hline $\mathrm{n}_{\text {out }}$ & & & 913.076 & rpm \\
\hline $\mathrm{TQ}_{\text {in }}$ & & & 751.960 & $N m$ \\
\hline TQ out & & & 323.181 & $N m$ \\
\hline TQ out (theoretical) & & & 328.143 & $N m$ \\
\hline Input Power & & & 31376.10 & $W$ \\
\hline & & & Temperature readings & Units \\
\hline $\mathrm{T}_{\text {oil }}$ & & & 103.588 & ${ }^{\circ} \mathrm{C}$ \\
\hline $\mathrm{T}_{\text {wall }}$ & & & 94.593 & ${ }^{\circ} \mathrm{C}$ \\
\hline $\mathrm{T}_{\text {wall }}$ (slave) & & & 97.593 & ${ }^{\circ} \mathrm{C}$ \\
\hline \multirow[t]{2}{*}{$\mathrm{T}_{\mathrm{amb}}$} & & & 32.712 & ${ }^{\circ} \mathrm{C}$ \\
\hline & & & Additional information & Units \\
\hline$\Delta \mathrm{TQ}$ & & & 14.963 & $N m$ \\
\hline $\mathrm{T}_{\mathrm{oil}}-\mathrm{T}_{\mathrm{amb}}$ & & & 70.876 & ${ }^{\circ} \mathrm{C}$ \\
\hline $\mathrm{T}_{\mathrm{wall}}-\mathrm{T}_{\mathrm{amb}}$ & & & 61.881 & ${ }^{\circ} \mathrm{C}$ \\
\hline
\end{tabular}

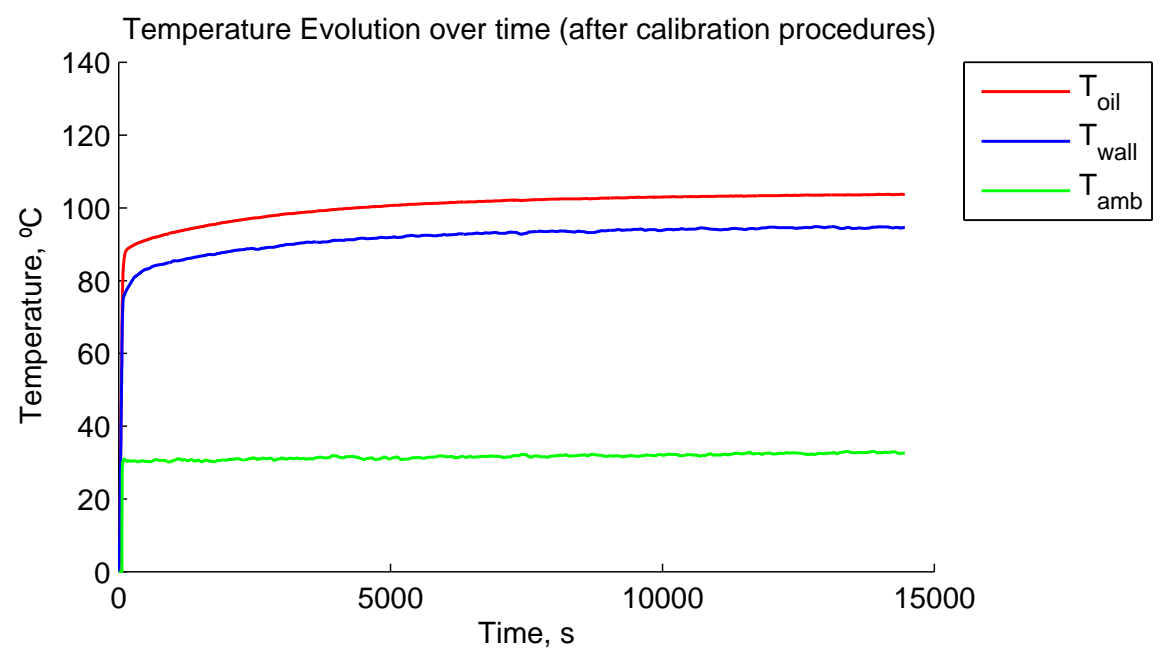


A. Appendix

\begin{tabular}{|c|c|c|c|c|}
\hline Test Number: 32 & Date: & $31 / 04 / 2012$ & By: Pedro Marques & \\
\hline & & & Oil Property & Units \\
\hline Oil Designation & & & PAOR & - \\
\hline Viscosity at $40^{\circ} \mathrm{C}$ & & & 324.37 & $c S t$ \\
\hline Viscosity at $70^{\circ} \mathrm{C}$ & & & 87.97 & $c S t$ \\
\hline Viscosity at $100^{\circ} \mathrm{C}$ & & & 35.27 & $c S t$ \\
\hline Bulk Density at $25^{\circ} \mathrm{C}$ & & & 854.937 & $\mathrm{Kg} / \mathrm{m}^{3}$ \\
\hline & & & Imposed working conditions & Units \\
\hline $\mathrm{n}_{\mathrm{in}}$ & & & 400 & rpm \\
\hline $\mathrm{TQ}_{\text {in }}$ & & & 1000 & $N m$ \\
\hline Warmup period & & & 240 & $\min$ \\
\hline Test period & & & 240 & $\min$ \\
\hline & & & Actual working conditions & Units \\
\hline $\mathrm{n}_{\mathrm{in}}$ & & & 398.308 & rpm \\
\hline $\mathrm{n}_{\text {out }}$ & & & 912.746 & rpm \\
\hline $\mathrm{TQ}_{\text {in }}$ & & & 1000.913 & $\mathrm{Nm}$ \\
\hline TQout & & & 417.781 & $N m$ \\
\hline TQout (theoretical) & & & 436.782 & $N m$ \\
\hline Input Power & & & 41748.72 & $W$ \\
\hline & & & Temperature readings & Units \\
\hline $\mathrm{T}_{\mathrm{oil}}$ & & & 126.881 & ${ }^{\circ} \mathrm{C}$ \\
\hline $\mathrm{T}_{\text {wall }}$ & & & 115.191 & ${ }^{\circ} \mathrm{C}$ \\
\hline $\mathrm{T}_{\text {wall }}$ (slave) & & & 125.443 & ${ }^{\circ} \mathrm{C}$ \\
\hline \multirow[t]{2}{*}{$\mathrm{T}_{\mathrm{amb}}$} & & & 39.242 & ${ }^{\circ} \mathrm{C}$ \\
\hline & & & Additional information & Units \\
\hline$\Delta \mathrm{TQ}$ & & & 19.002 & $N m$ \\
\hline $\mathrm{T}_{\mathrm{oil}}-\mathrm{T}_{\mathrm{amb}}$ & & & 87.639 & ${ }^{\circ} \mathrm{C}$ \\
\hline $\mathrm{T}_{\text {wall }}-\mathrm{T}_{\mathrm{amb}}$ & & & 75.949 & ${ }^{\circ} \mathrm{C}$ \\
\hline
\end{tabular}

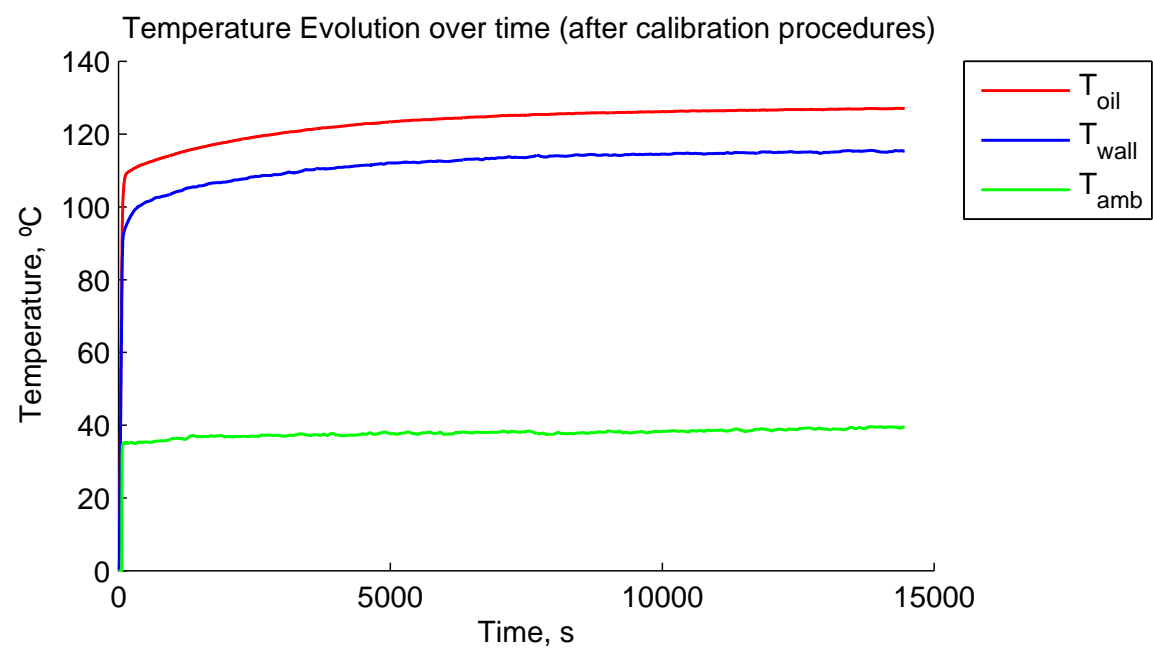


A.1. Reports from the experimental tests

\begin{tabular}{|c|c|c|c|c|}
\hline Test Number: 33 & Date: & $01 / 05 / 2012$ & By: Pedro Marques & \\
\hline & & & Oil Property & Units \\
\hline Oil Designation & & & PAOR & - \\
\hline Viscosity at $40^{\circ} \mathrm{C}$ & & & 324.37 & $c S t$ \\
\hline Viscosity at $70^{\circ} \mathrm{C}$ & & & 87.97 & $c S t$ \\
\hline Viscosity at $100^{\circ} \mathrm{C}$ & & & 35.27 & $c S t$ \\
\hline Bulk Density at $25^{\circ} \mathrm{C}$ & & & 854.937 & $\mathrm{Kg} / \mathrm{m}^{3}$ \\
\hline & & & Imposed working conditions & Units \\
\hline $\mathrm{n}_{\text {in }}$ & & & 100 & rpm \\
\hline $\mathrm{TQ}_{\mathrm{in}}$ & & & 500 & $\mathrm{Nm}$ \\
\hline Warmup period & & & 240 & $\min$ \\
\hline Test period & & & 240 & $\min$ \\
\hline & & & Actual working conditions & Units \\
\hline $\mathrm{n}_{\text {in }}$ & & & 111.031 & rpm \\
\hline $\mathrm{n}_{\text {out }}$ & & & 254.435 & rpm \\
\hline $\mathrm{TQ}_{\mathrm{in}}$ & & & 502.495 & $\mathrm{Nm}$ \\
\hline TQout & & & 211.024 & $\mathrm{Nm}$ \\
\hline TQout (theoretical) & & & 219.281 & $N m$ \\
\hline Input Power & & & 5842.59 & $W$ \\
\hline & & & Temperature readings & Units \\
\hline $\mathrm{T}_{\text {oil }}$ & & & 49.098 & ${ }^{\circ} \mathrm{C}$ \\
\hline $\mathrm{T}_{\text {wall }}$ & & & 44.765 & ${ }^{\circ} \mathrm{C}$ \\
\hline $\mathrm{T}_{\text {wall }}$ (slave) & & & 47.331 & ${ }^{\circ} \mathrm{C}$ \\
\hline \multirow[t]{2}{*}{$\mathrm{T}_{\mathrm{amb}}$} & & & 30.652 & ${ }^{\circ} \mathrm{C}$ \\
\hline & & & Additional information & Units \\
\hline$\Delta \mathrm{TQ}$ & & & 8.257 & $N m$ \\
\hline $\mathrm{T}_{\mathrm{oil}}-\mathrm{T}_{\mathrm{amb}}$ & & & 18.446 & ${ }^{\circ} \mathrm{C}$ \\
\hline $\mathrm{T}_{\mathrm{wall}}-\mathrm{T}_{\mathrm{amb}}$ & & & 14.113 & ${ }^{\circ} \mathrm{C}$ \\
\hline
\end{tabular}

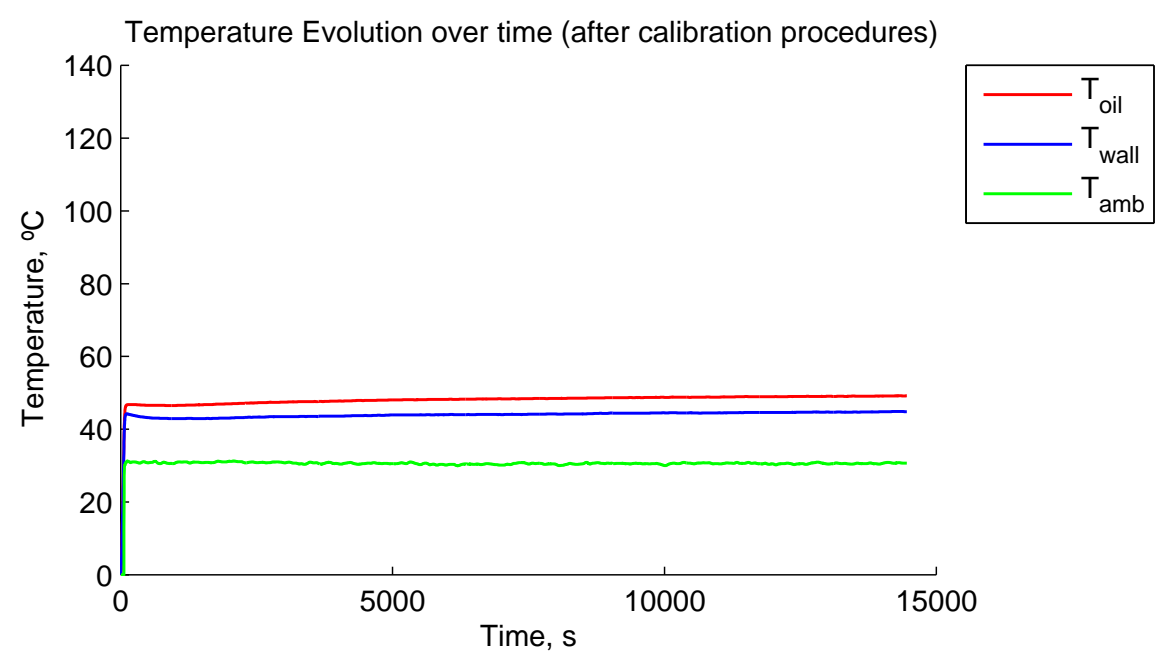


A. Appendix

\begin{tabular}{|c|c|c|c|c|}
\hline Test Number: 34 & Date: & $04 / 05 / 2012$ & By: Pedro Marques & \\
\hline & & & Oil Property & Units \\
\hline Oil Designation & & & PAOR & - \\
\hline Viscosity at $40^{\circ} \mathrm{C}$ & & & 324.37 & $c S t$ \\
\hline Viscosity at $70^{\circ} \mathrm{C}$ & & & 87.97 & $c S t$ \\
\hline Viscosity at $100^{\circ} \mathrm{C}$ & & & 35.27 & $c S t$ \\
\hline Bulk Density at $25^{\circ} \mathrm{C}$ & & & 854.937 & $\mathrm{Kg} / \mathrm{m}^{3}$ \\
\hline & & & Imposed working conditions & Units \\
\hline $\mathrm{n}_{\text {in }}$ & & & 100 & rpm \\
\hline $\mathrm{TQ}_{\mathrm{in}}$ & & & 750 & $\mathrm{Nm}$ \\
\hline Warmup period & & & 240 & $\min$ \\
\hline Test period & & & 240 & $\min$ \\
\hline & & & Actual working conditions & Units \\
\hline $\mathrm{n}_{\mathrm{in}}$ & & & 109.525 & rpm \\
\hline $\mathrm{n}_{\text {out }}$ & & & 250.982 & rpm \\
\hline $\mathrm{TQ}_{\mathrm{in}}$ & & & 751.680 & $\mathrm{Nm}$ \\
\hline TQout & & & 315.866 & $N m$ \\
\hline TQout (theoretical) & & & 328.021 & $\mathrm{Nm}$ \\
\hline Input Power & & & 8621.31 & $W$ \\
\hline & & & Temperature readings & Units \\
\hline $\mathrm{T}_{\mathrm{oil}}$ & & & 55.210 & ${ }^{\circ} \mathrm{C}$ \\
\hline $\mathrm{T}_{\text {wall }}$ & & & 49.212 & ${ }^{\circ} \mathrm{C}$ \\
\hline $\mathrm{T}_{\text {wall }}$ (slave) & & & 54.908 & ${ }^{\circ} \mathrm{C}$ \\
\hline \multirow[t]{2}{*}{$\mathrm{T}_{\mathrm{amb}}$} & & & 29.813 & ${ }^{\circ} \mathrm{C}$ \\
\hline & & & Additional information & Units \\
\hline$\Delta \mathrm{TQ}$ & & & 12.155 & $N m$ \\
\hline $\mathrm{T}_{\mathrm{oil}}-\mathrm{T}_{\mathrm{amb}}$ & & & 25.397 & ${ }^{\circ} \mathrm{C}$ \\
\hline $\mathrm{T}_{\mathrm{wall}}-\mathrm{T}_{\mathrm{amb}}$ & & & 19.400 & ${ }^{\circ} \mathrm{C}$ \\
\hline
\end{tabular}

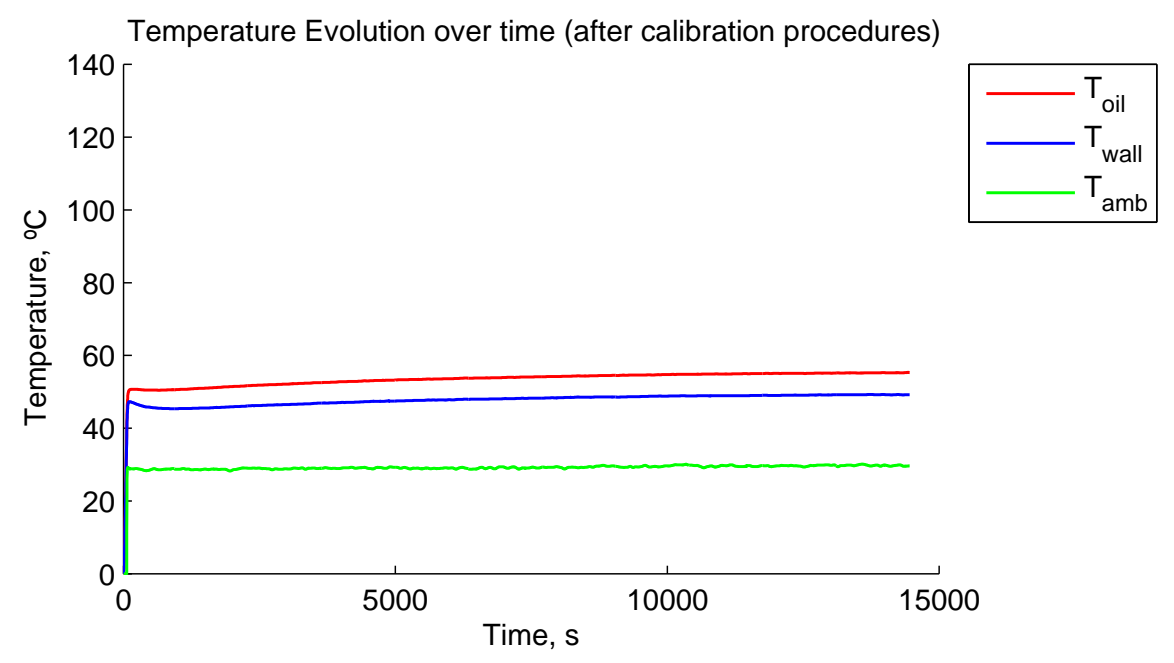


A.1. Reports from the experimental tests

\begin{tabular}{|c|c|c|c|c|}
\hline Test Number: 35 & Date: & $05 / 05 / 2012$ & By: Pedro Marques & \\
\hline & & & Oil Property & Units \\
\hline Oil Designation & & & PAOR & - \\
\hline Viscosity at $40^{\circ} \mathrm{C}$ & & & 324.37 & $c S t$ \\
\hline Viscosity at $70^{\circ} \mathrm{C}$ & & & 87.97 & $c S t$ \\
\hline Viscosity at $100^{\circ} \mathrm{C}$ & & & 35.27 & $c S t$ \\
\hline Bulk Density at $25^{\circ} \mathrm{C}$ & & & 854.937 & $\mathrm{Kg} / \mathrm{m}^{3}$ \\
\hline & & & Imposed working conditions & Units \\
\hline $\mathrm{n}_{\text {in }}$ & & & 100 & rpm \\
\hline $\mathrm{TQ}_{\text {in }}$ & & & 1000 & $\mathrm{Nm}$ \\
\hline Warmup period & & & 240 & $\min$ \\
\hline Test period & & & 240 & $\min$ \\
\hline & & & Actual working conditions & Units \\
\hline $\mathrm{n}_{\mathrm{in}}$ & & & 109.020 & rpm \\
\hline $\mathrm{n}_{\text {out }}$ & & & 249.825 & rpm \\
\hline $\mathrm{TQ}_{\text {in }}$ & & & 1001.099 & $\mathrm{Nm}$ \\
\hline TQout & & & 418.869 & $\mathrm{Nm}$ \\
\hline TQout (theoretical) & & & 436.863 & $N m$ \\
\hline Input Power & & & 11429.07 & $W$ \\
\hline & & & Temperature readings & Units \\
\hline $\mathrm{T}_{\mathrm{oil}}$ & & & 62.142 & ${ }^{\circ} \mathrm{C}$ \\
\hline $\mathrm{T}_{\text {wall }}$ & & & 54.481 & ${ }^{\circ} \mathrm{C}$ \\
\hline $\mathrm{T}_{\text {wall }}$ (slave) & & & 64.125 & ${ }^{\circ} \mathrm{C}$ \\
\hline \multirow[t]{2}{*}{$\mathrm{T}_{\mathrm{amb}}$} & & & 28.840 & ${ }^{\circ} \mathrm{C}$ \\
\hline & & & Additional information & Units \\
\hline$\Delta \mathrm{TQ}$ & & & 17.995 & $N m$ \\
\hline $\mathrm{T}_{\mathrm{oil}}-\mathrm{T}_{\mathrm{amb}}$ & & & 33.302 & ${ }^{\circ} \mathrm{C}$ \\
\hline $\mathrm{T}_{\text {wall }}-\mathrm{T}_{\mathrm{amb}}$ & & & 25.641 & ${ }^{\circ} \mathrm{C}$ \\
\hline
\end{tabular}

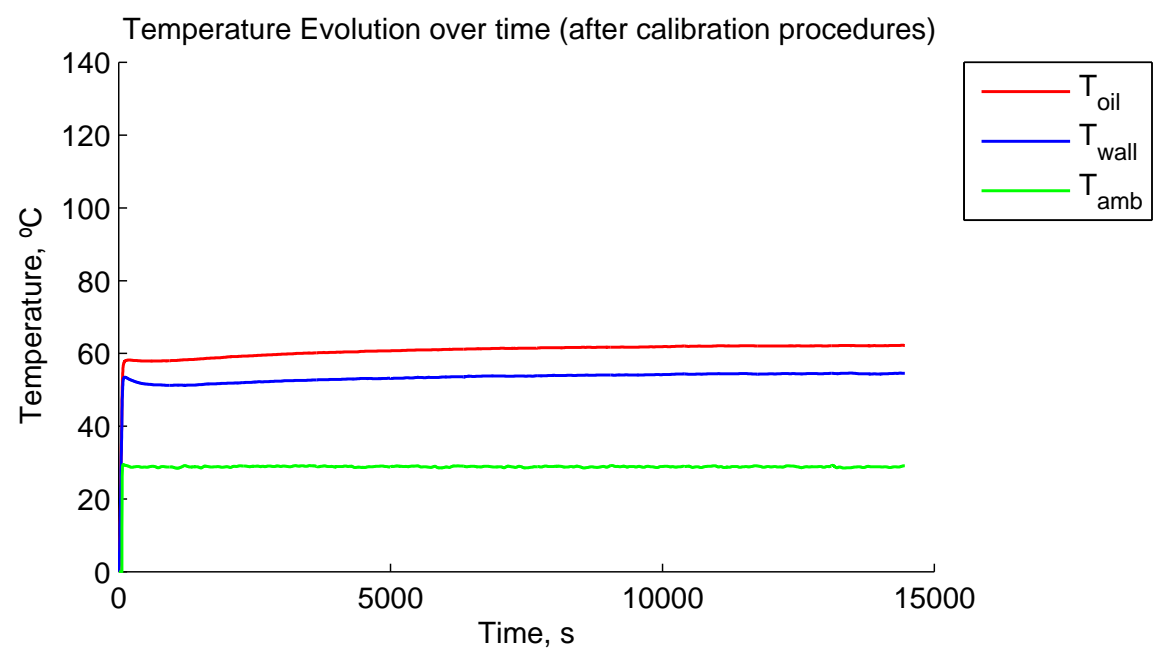


A. Appendix

\begin{tabular}{|c|c|c|c|c|}
\hline Test Number: 36 & Date: & $28 / 04 / 2012$ & By: Pedro Marques & \\
\hline & & & Oil Property & Units \\
\hline Oil Designation & & & PAOR & - \\
\hline Viscosity at $40^{\circ} \mathrm{C}$ & & & 324.37 & $c S t$ \\
\hline Viscosity at $70^{\circ} \mathrm{C}$ & & & 87.97 & $c S t$ \\
\hline Viscosity at $100^{\circ} \mathrm{C}$ & & & 35.27 & $c S t$ \\
\hline Bulk Density at $25^{\circ} \mathrm{C}$ & & & 854.937 & $\mathrm{Kg} / \mathrm{m}^{3}$ \\
\hline & & & Imposed working conditions & Units \\
\hline $\mathrm{n}_{\text {in }}$ & & & 300 & rpm \\
\hline $\mathrm{TQ}_{\text {in }}$ & & & 800 & $N m$ \\
\hline Warmup period & & & 240 & $\min$ \\
\hline Test period & & & 240 & $\min$ \\
\hline & & & Actual working conditions & Units \\
\hline $\mathrm{n}_{\mathrm{in}}$ & & & 302.187 & rpm \\
\hline $\mathrm{n}_{\text {out }}$ & & & 692.479 & rpm \\
\hline $\mathrm{TQ}_{\mathrm{in}}$ & & & 801.980 & $\mathrm{Nm}$ \\
\hline TQout & & & 335.031 & $\mathrm{Nm}$ \\
\hline TQout (theoretical) & & & 349.971 & $\mathrm{Nm}$ \\
\hline Input Power & & & 25378.62 & $W$ \\
\hline & & & Temperature readings & Units \\
\hline $\mathrm{T}_{\mathrm{oil}}$ & & & 92.613 & ${ }^{\circ} \mathrm{C}$ \\
\hline $\mathrm{T}_{\text {wall }}$ & & & 84.929 & ${ }^{\circ} \mathrm{C}$ \\
\hline $\mathrm{T}_{\text {wall }}$ (slave) & & & 94.485 & ${ }^{\circ} \mathrm{C}$ \\
\hline \multirow[t]{2}{*}{$\mathrm{T}_{\mathrm{amb}}$} & & & 29.933 & ${ }^{\circ} \mathrm{C}$ \\
\hline & & & Additional information & Units \\
\hline$\Delta \mathrm{TQ}$ & & & 14.9409 & $N m$ \\
\hline $\mathrm{T}_{\mathrm{oil}}-\mathrm{T}_{\mathrm{amb}}$ & & & 62.680 & ${ }^{\circ} \mathrm{C}$ \\
\hline $\mathrm{T}_{\mathrm{wall}}-\mathrm{T}_{\mathrm{amb}}$ & & & 55.006 & ${ }^{\circ} \mathrm{C}$ \\
\hline
\end{tabular}

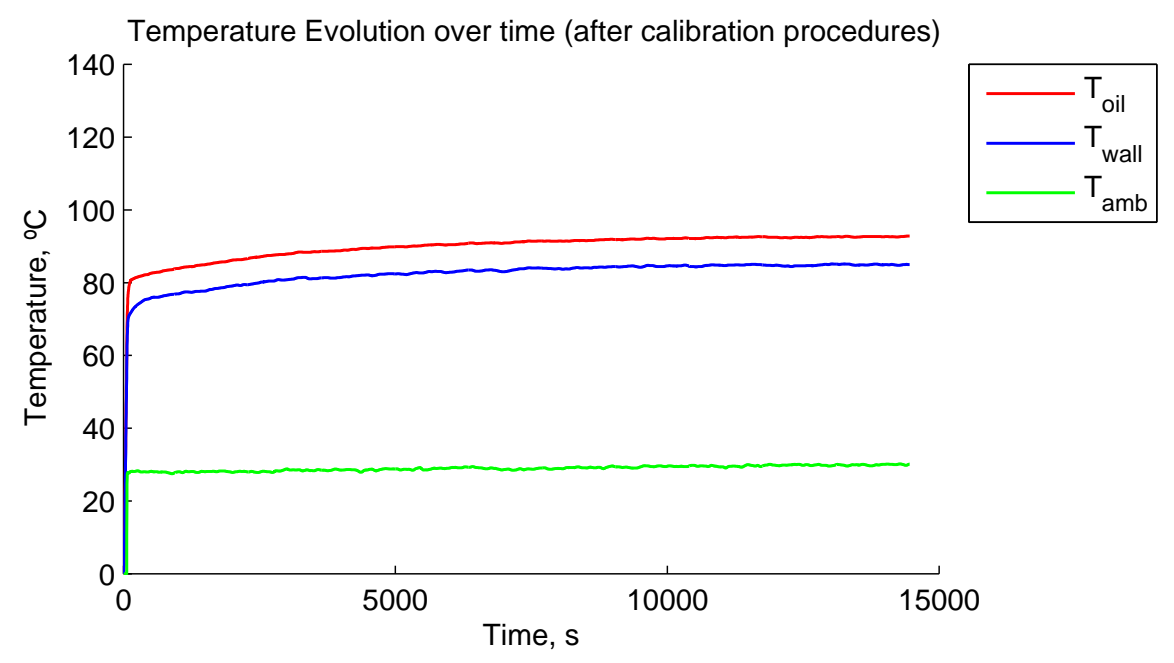




\title{
B. Lubricant Analysis Reports
}

\author{
B.1. MINE Oil
}




\section{Relatório}

de

\section{Análise de Lubrificantes}

\begin{tabular}{|c|c|}
\hline $\begin{array}{l}\text { Análise } \mathrm{n}^{\mathrm{o}} \text { : } \\
\text { Tipo de análise: } \\
\text { Confidencialidade: }\end{array}$ & $\begin{array}{l}12,24 \text { e } 25 \text { / } 12 \\
\text { Ferrometria e Ferrografia Analítica } \\
1\end{array}$ \\
\hline $\begin{array}{l}\text { Cliente: } \\
\text { Morada: } \\
\text { Telefone / Fax: }\end{array}$ & $\begin{array}{l}\text { INEGI - Cetrib } \\
\text { Porto }\end{array}$ \\
\hline $\begin{array}{l}\text { Equipamento: } \\
\text { Lubrificante: } \\
\text { Dossier: }\end{array}$ & $\begin{array}{l}\text { BANCO - Ensaios de Eficiência } \\
\text { Mineral E } \\
\text { / }\end{array}$ \\
\hline $\begin{array}{l}\mathrm{N}^{\circ} \text { de páginas: } \\
\text { Data: }\end{array}$ & $\begin{array}{l}6 \\
30 / 04 / 12\end{array}$ \\
\hline $\begin{array}{l}\text { Responsável: } \\
\text { Rúbrica: }\end{array}$ & Beatriz Graça - Jorge Seabra \\
\hline
\end{tabular}




\section{OBJECTIVO}

Análise de três amostras de óleo lubrificante MINE, resultantes de Ensaios de Eficiência no Banco de Ensaios para avaliação do desgaste presente.

As amostras analisadas foram as seguintes:

\begin{tabular}{|c|c|c|}
\hline \multirow{2}{*}{$\begin{array}{c}\text { Amostra } \\
(\mathrm{rpm})\end{array}$} & \multicolumn{2}{|c|}{ Análises efectuadas } \\
\cline { 2 - 3 } & Ferrometria & Ferrografia Analítica \\
\hline 100 & $\mathrm{X}$ & $\mathrm{X}$ \\
\hline 200 & $\mathrm{X}$ & $\mathrm{X}$ \\
\hline 500 & $\mathrm{X}$ & $\mathrm{X}$ \\
\hline
\end{tabular}

\section{RESULTADOS DAS ANÁLISES}

Nas páginas seguintes são apresentados os resultados referentes às análises de Ferrometria (DR III) e Ferrografia Analítica (FM III). 


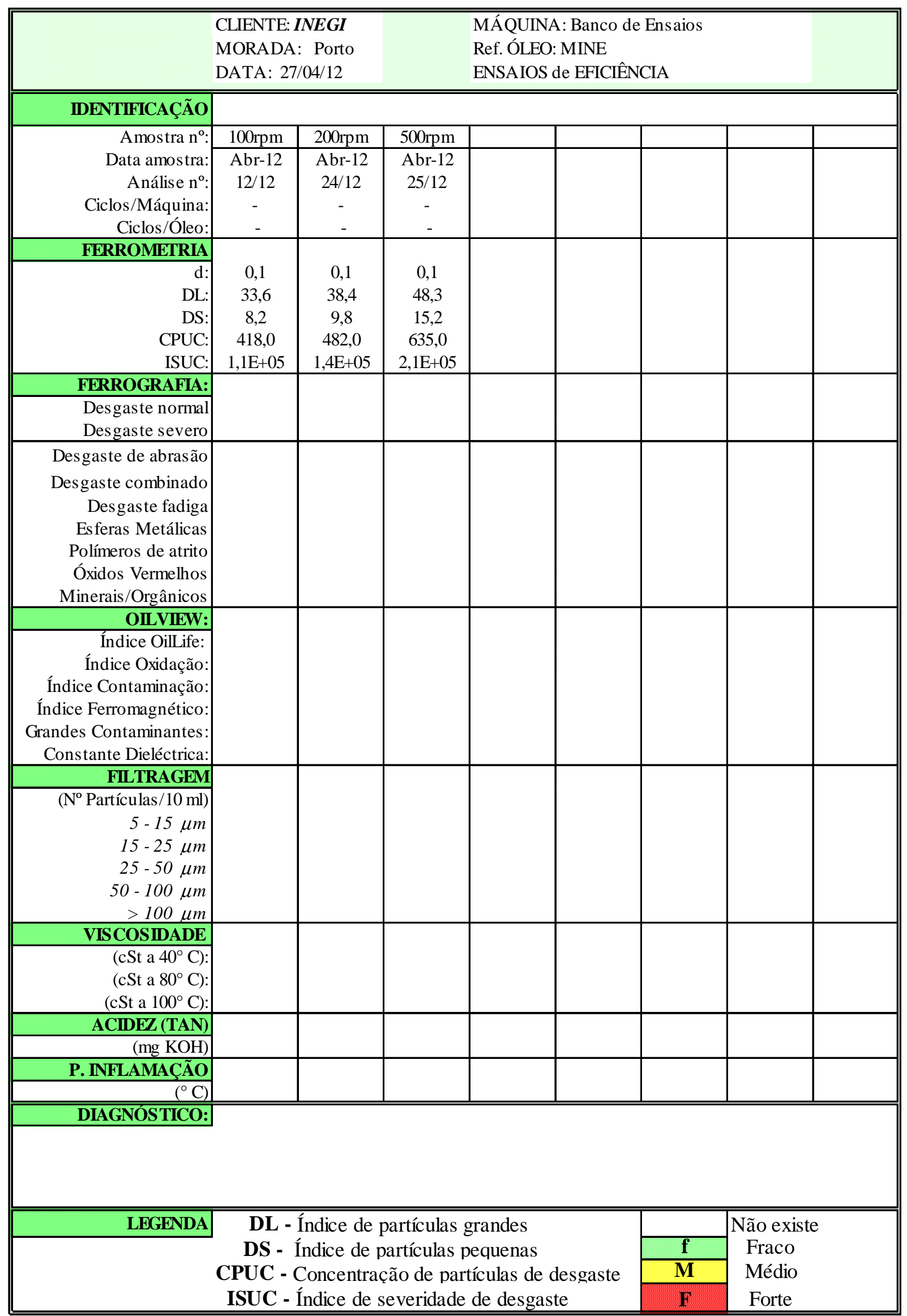




\begin{tabular}{|ll||}
\hline CLIENTE: INEGI & MÁQUINA: Banco de Ensaios \\
MORADA: Porto & Ref. ÓLEO: MINE 100RPM \\
DATA: $27 / 04 / 12$ & ENSAIOS de EFICIÊNCIA \\
\hline
\end{tabular}

\section{Fotografia 1}

1

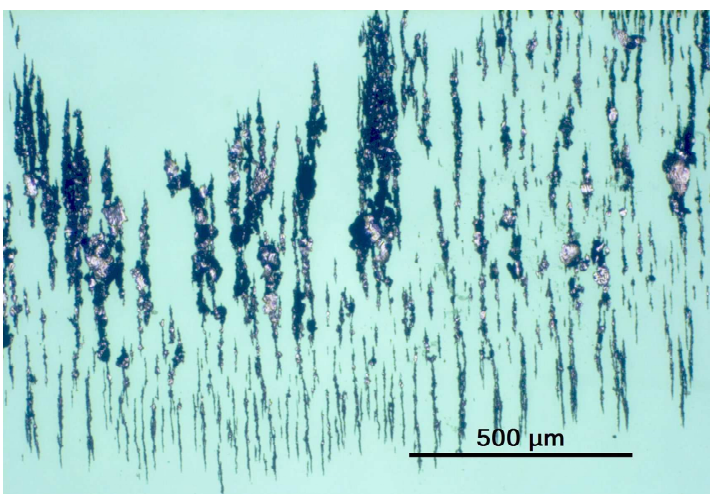

Fotografia 2

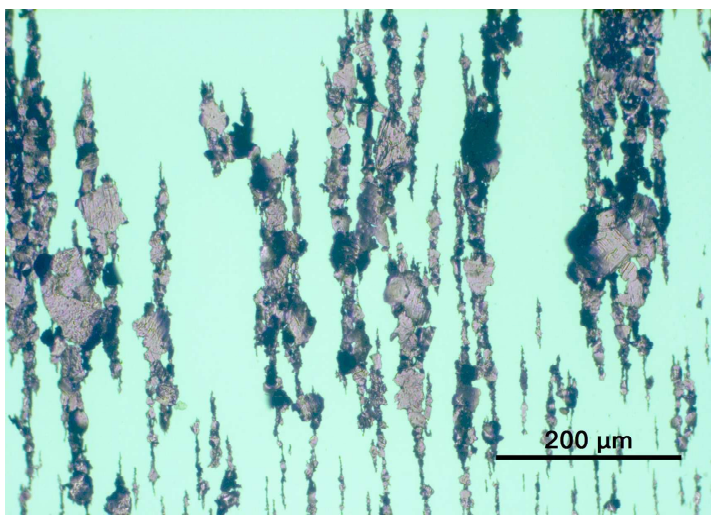

Ampliação: x 100 / x $200 \quad$ Diluíção: $0.1 \quad$ Luz: Branca / Verde

Observações: Presença de partículas ferrosas, algumas de grandes dimensões. Presença de alguns óxidos de ferro.

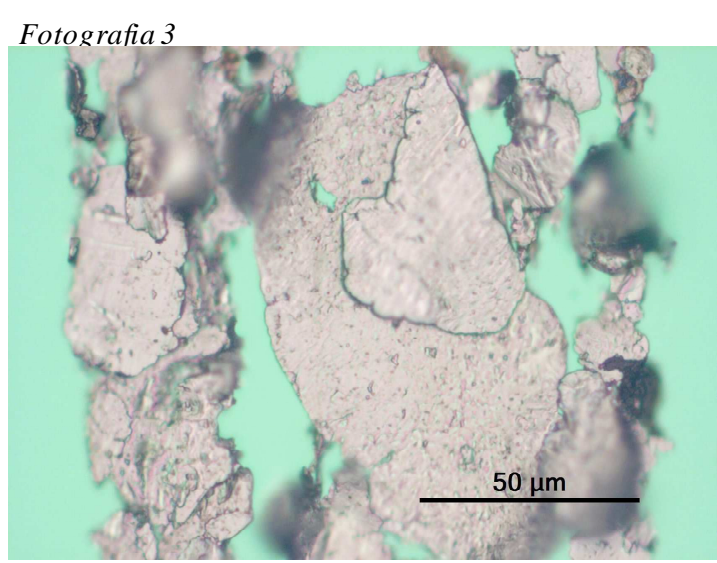

Fotografia 4

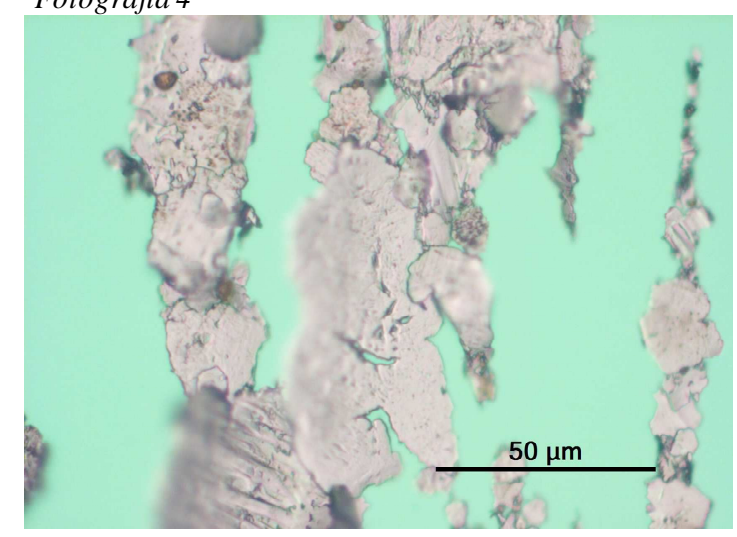

Ampliação: x 1000

Diluíção: 0.1

Luz: Branca / Verde

Observações: Ampliação da Fotografia 2. Partículas ferrosas, de grandes dimensões, típicas de desgaste de fadiga.

Fotografia 5

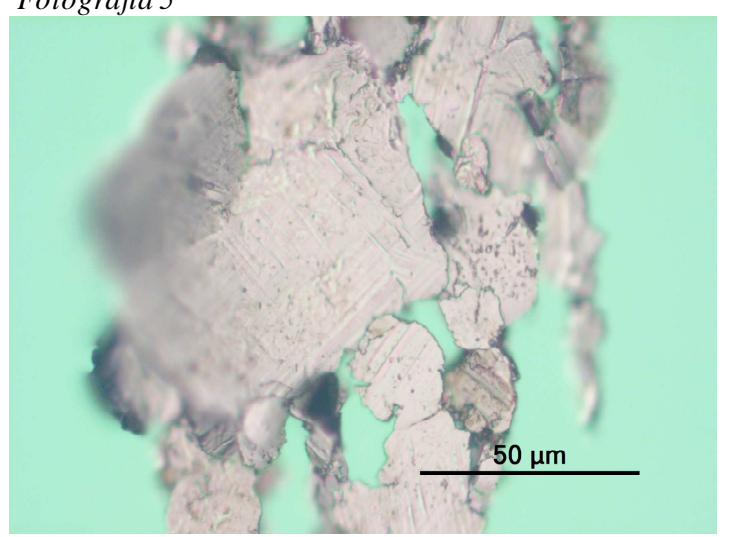

Ampliação: x 1000

Diluíção: 0.1

\section{Fotografia 6}

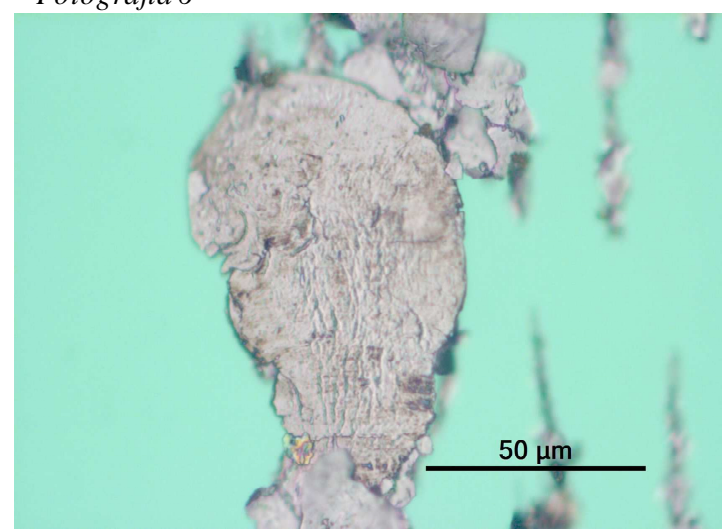

Observações: Ampliação da Fotografia 2. Partículas ferrosas, de grandes dimensões, típicas de desgaste de fadiga. 


\begin{tabular}{|ll|}
\hline CLIENTE: INEGI & MÁQUINA: Banco de Ensaios \\
MORADA: Porto & Ref. ÓLEO: MINE 200RPM \\
DATA: $27 / 04 / 12$ & ENSAIOS de EFICIËNCIA \\
\hline
\end{tabular}

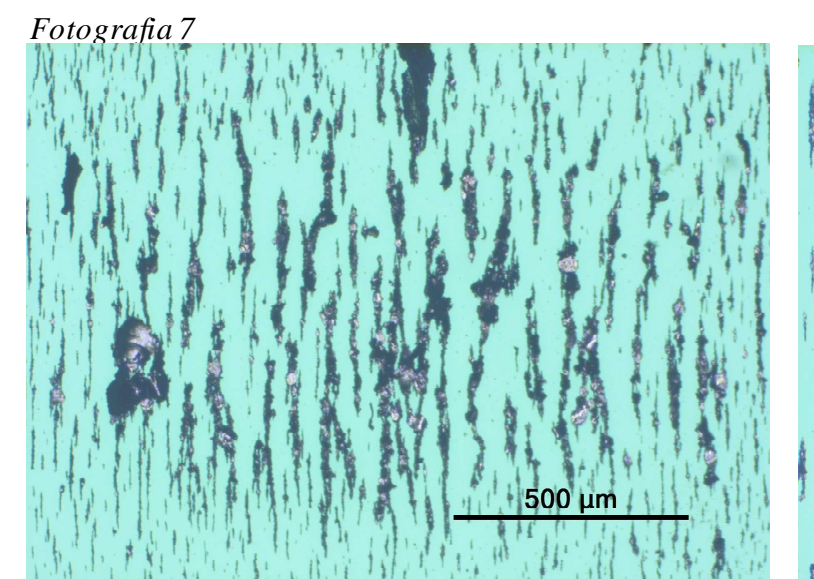

\begin{tabular}{|lcc|}
\hline Ampliação: x 100 / x 200 & Diluíção: 0.1 & Luz: Branca / Verde \\
Observações: Presença de partículas ferrosas, algumas de grandes dimensões. Presença de alguns óxidos de ferro.
\end{tabular}

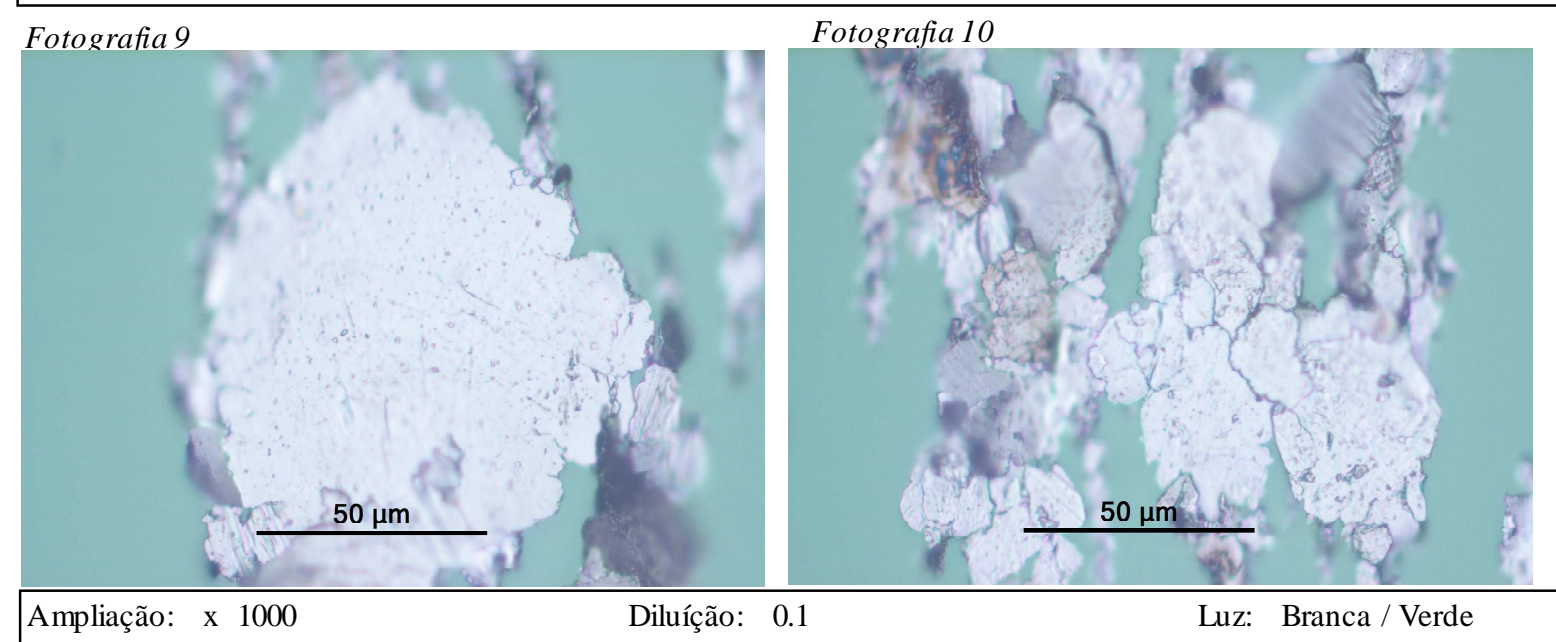

Observações: Ampliação da Fotografia 8. Partículas ferrosas, de grandes dimensões ,típicas de desgaste de fadiga.
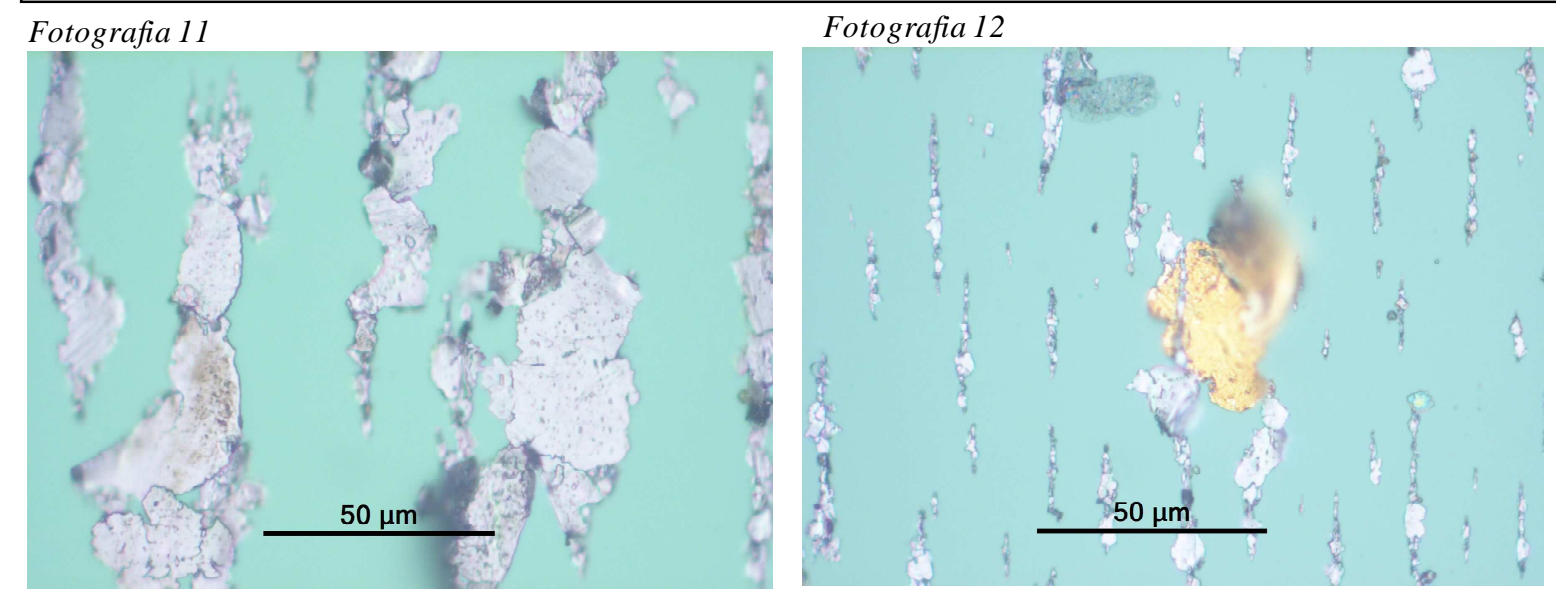

Ampliação: x 1000

Diluíção: 0.1

Luz: Branca / Verde

Observações: Fotografia 11: Partículas ferrosas de grandes dimensões típicas de desgaste de fadiga.

Fotografia 12: Partícula não ferrosa (liga de cobre). 


\begin{tabular}{||ll||}
\hline \hline CLIENTE: INEGI & MÁQUINA: Banco de Ensaios \\
MORADA: Porto & Ref. ÓLEO: MINE 500RPM \\
DATA: $27 / 04 / 12$ & ENSAIOS de EFICIÊNCIA \\
\hline
\end{tabular}
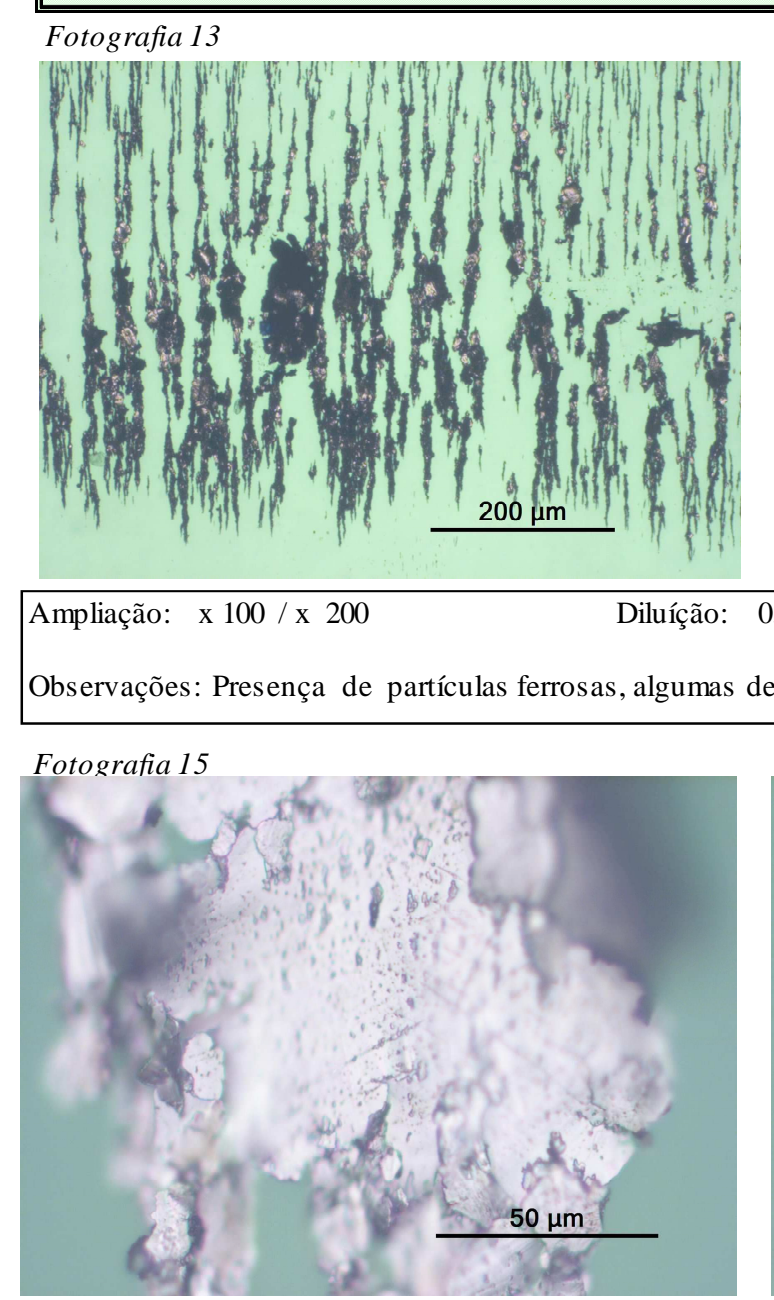

Fotografia 14

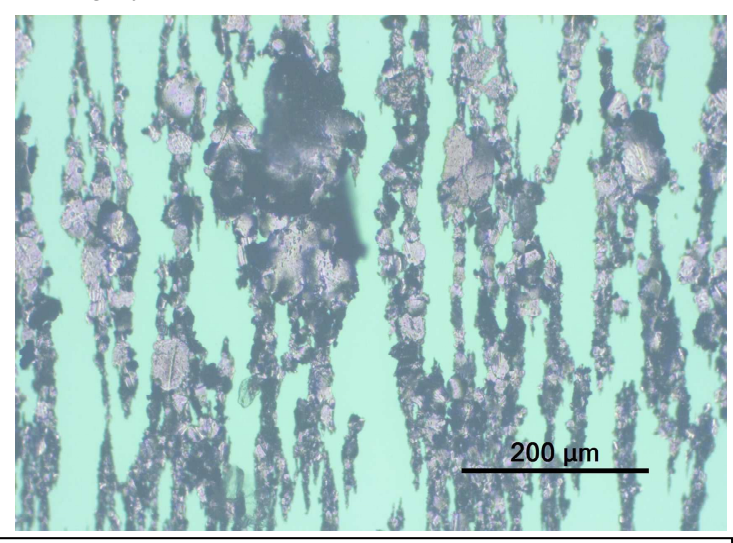

0.1

Luz: Branca / Verde

Observações: Presença de partículas ferrosas, algumas de grandes dimensões. Presença de alguns óxidos de ferro.

\section{Fotografia 16}

Ampliação: $\mathrm{x} 1000$

Diluíção: 0.1

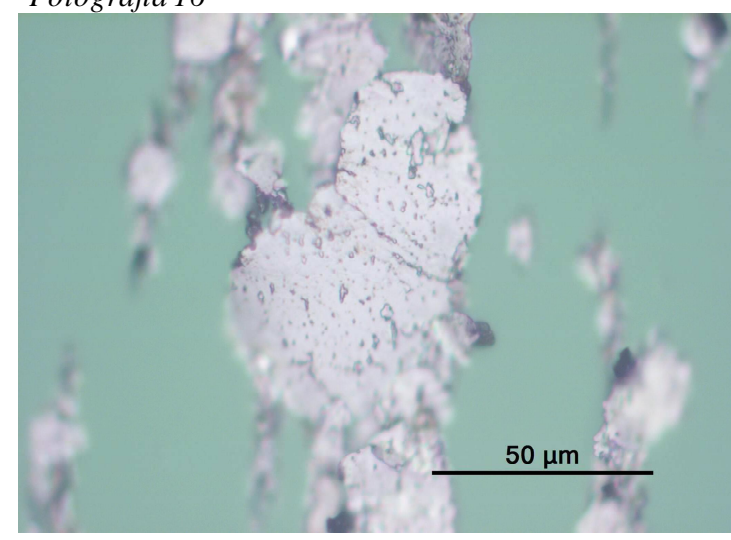

Observações: Ampliação da Fotografia 14. Partículas ferrosas, de grandes dimensões , típicas de desgaste de fadiga.

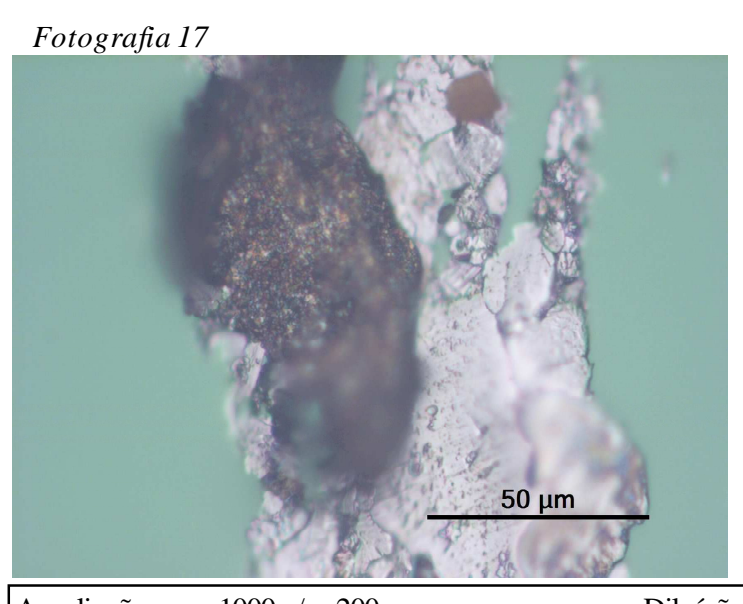

Fotografia 18

Ampliação: x 1000 / x 200

Diluíção: 0.1

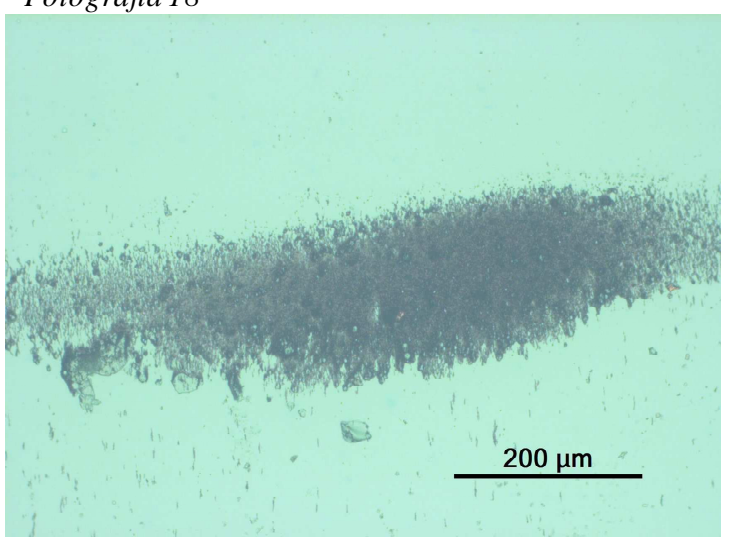

Observações: Fotografia 17: Óxido de ferro e particulass ferrosas de garndes dimensões;

Fotografia 18: Partículas de pequenas dimensões típicas de desgaste de corrosão. 
B. Lubricant Analysis Reports

\section{B.2. MINR Oil}




\section{Relatório}

de

\section{Análise de Lubrificantes}

\begin{tabular}{|l|l||}
\hline $\begin{array}{l}\text { Análise } \mathrm{n}^{\mathrm{o}}: \\
\text { Tipo de análise: } \\
\text { Confidencialidade: }\end{array}$ & $\begin{array}{l}21 \text { - } 23 / 12 \\
\text { Ferrometria e Ferrografia Analítica } \\
1\end{array}$ \\
\hline $\begin{array}{l}\text { Cliente: } \\
\text { Morada: } \\
\text { Telefone / Fax: }\end{array}$ & $\begin{array}{l}\text { INEGI - Cetrib } \\
\text { Porto }\end{array}$ \\
\hline $\begin{array}{l}\text { Equipamento: } \\
\text { Lubrificante: } \\
\text { Dossier: }\end{array}$ & $\begin{array}{l}\text { BANCO - Ensaios de Eficiência } \\
\text { Mineral R }\end{array}$ \\
\hline $\begin{array}{l}\text { No de páginas: } \\
\text { Data: }\end{array}$ & $\begin{array}{l}6 \\
30 / 04 / 12\end{array}$ \\
\hline $\begin{array}{l}\text { Responsável: } \\
\text { Rúbrica: }\end{array}$ & $\begin{array}{l}\text { Beatriz Graça - Jorge Seabra } \\
\text { Beangcis }\end{array}$ \\
\hline
\end{tabular}




\section{OBJECTIVO}

Análise de três amostras de óleo lubrificante MINR, resultantes de Ensaios de Eficiência no Banco de Ensaios para avaliação do desgaste presente.

As amostras analisadas foram as seguintes:

\begin{tabular}{|c|c|c|}
\hline \multirow{2}{*}{$\begin{array}{c}\text { Amostra } \\
(\mathrm{rpm})\end{array}$} & \multicolumn{2}{|c|}{ Análises efectuadas } \\
\cline { 2 - 3 } & Ferrometria & Ferrografia Analítica \\
\hline 100 & $\mathrm{X}$ & $\mathrm{X}$ \\
\hline 200 & $\mathrm{X}$ & $\mathrm{X}$ \\
\hline 400 & $\mathrm{X}$ & $\mathrm{X}$ \\
\hline
\end{tabular}

\section{RESULTADOS DAS ANÁLISES}

Nas páginas seguintes são apresentados os resultados referentes às análises de Ferrometria (DR III) e Ferrografia Analítica (FM III). 


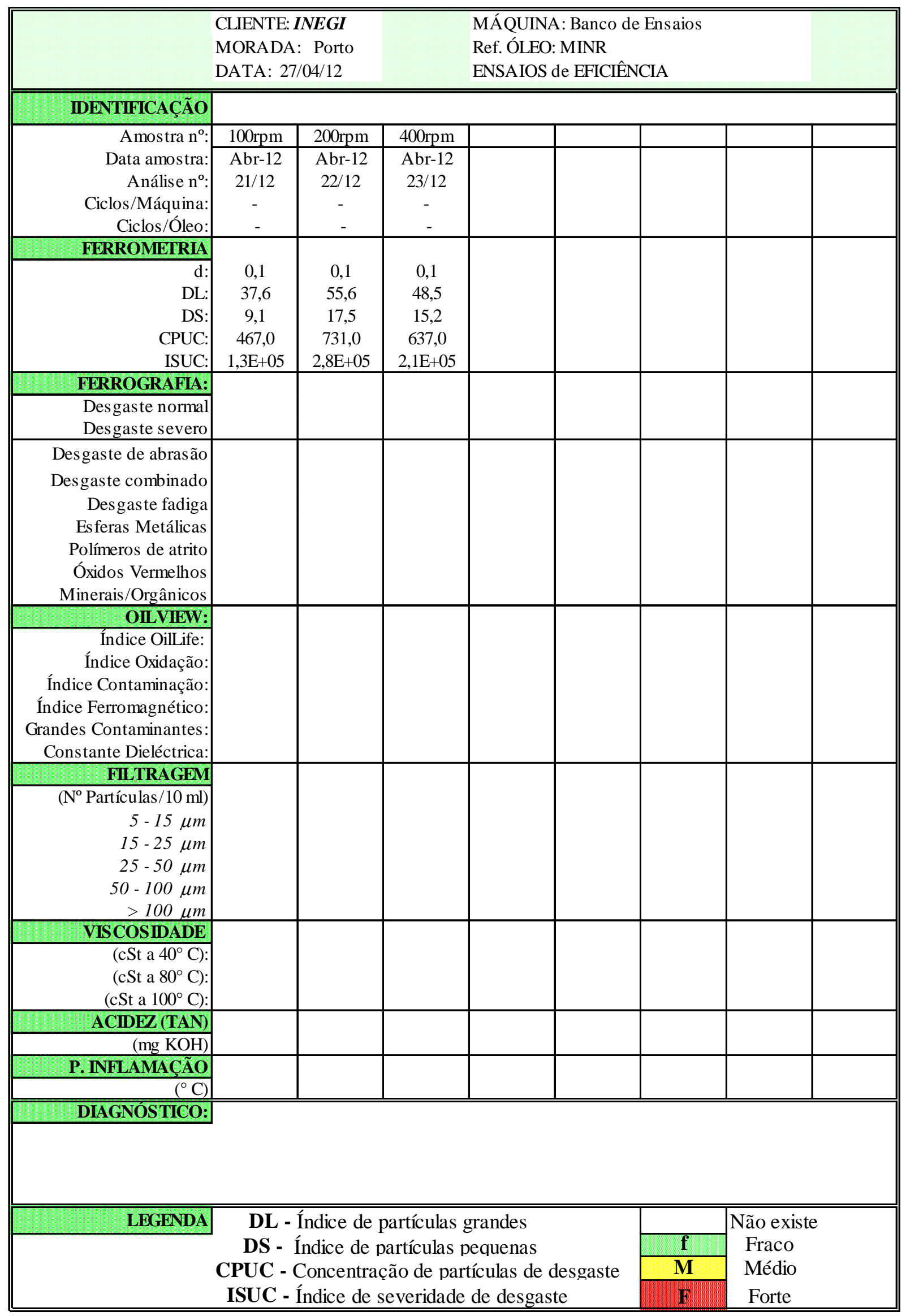


Inspect OIL

Inegl

\begin{tabular}{|ll||}
\hline CLIENTE: INEGI & MÁQUINA: Banco de Ensaios \\
MORADA: Porto & Ref. ÓLEO: MINR 100RPM \\
DATA: $27 / 04 / 12$ & ENSAIOS de EFICIÊNCIA \\
\hline
\end{tabular}
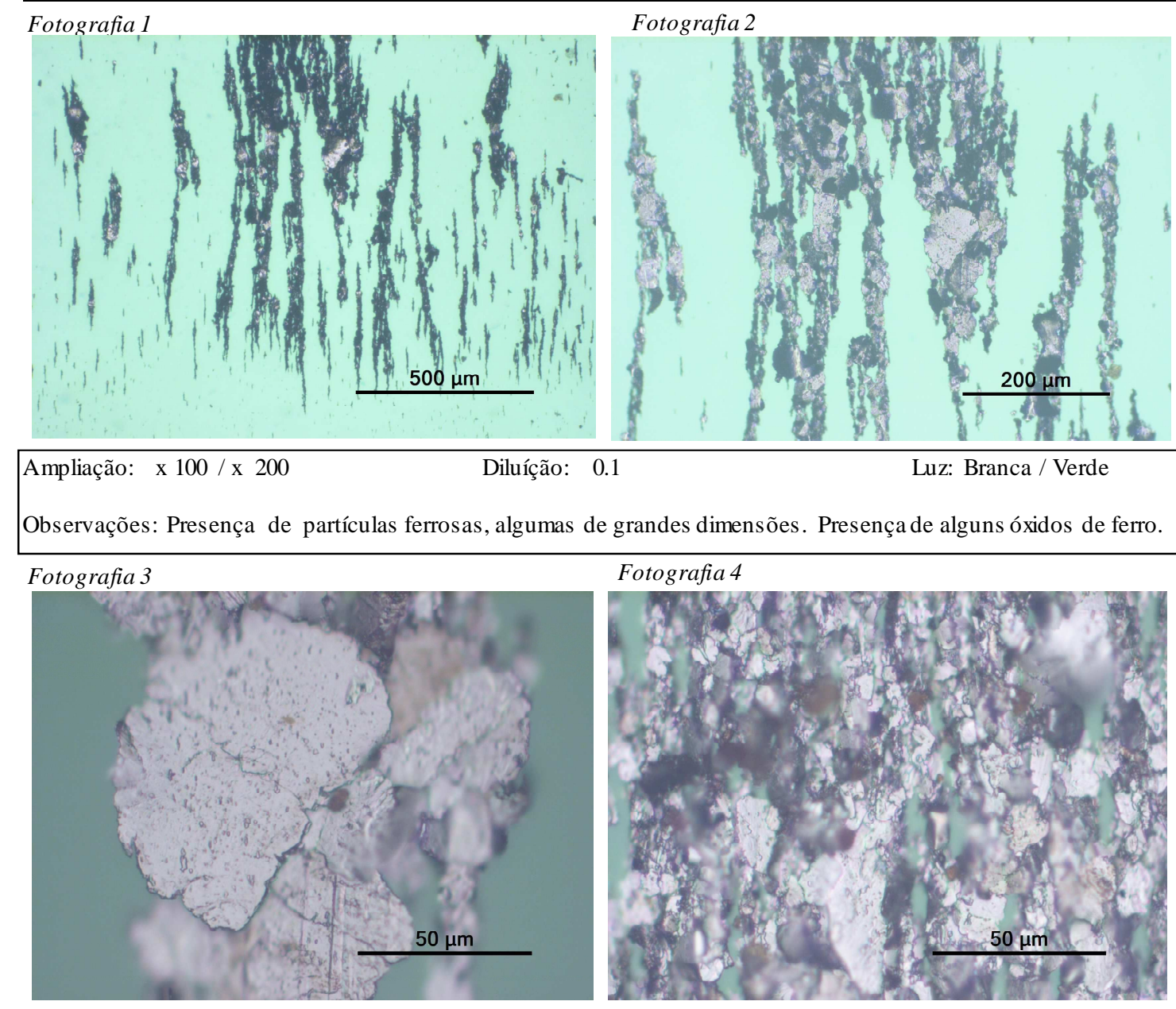

Luz: Branca / Verde

\begin{tabular}{llcc}
\hline Ampliação: & x 1000 & Diluíção: 0.1 & Luz: Branc \\
Observações: Fotografia & 3. Partículas ferrosas, de grandes dimensões, típicas de desgaste de fadiga.
\end{tabular}

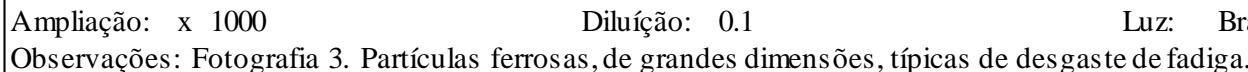

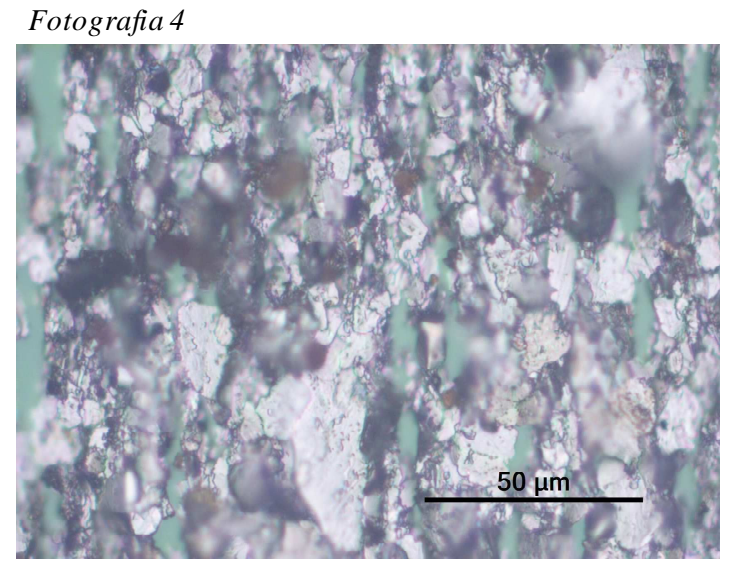

Fotografia 4: Partículas de pequenas e médias dimensões e óxidos de ferro vermelhos.

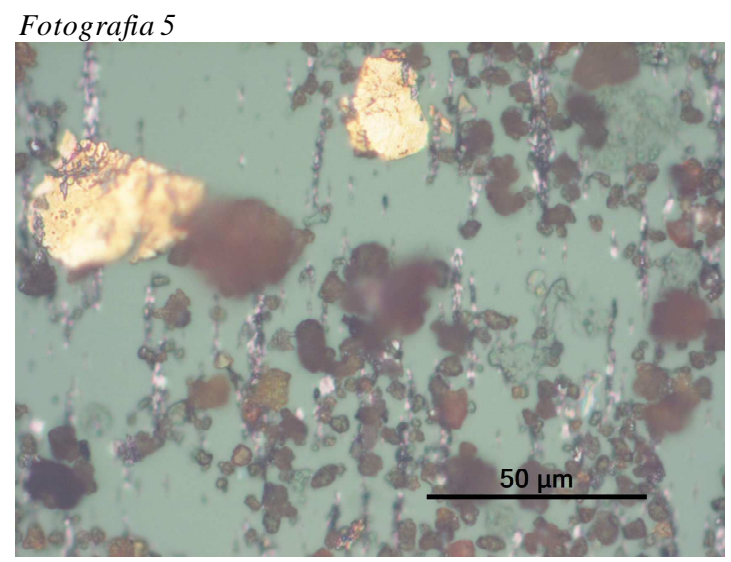

Fotografia 6

Ampliação: x 1000

Diluíção: 0.1

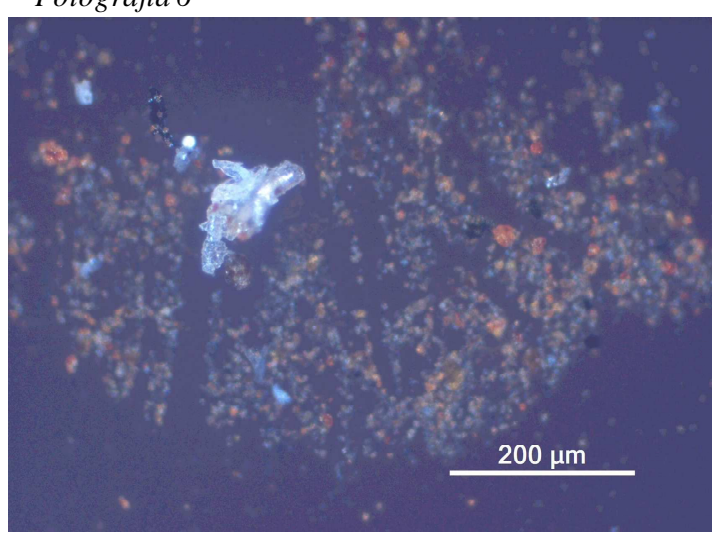

Observações: Fotografia 5: Presença significativa de óxidos de ferro vermelhos (presença de água?)

Fotografia 6: Partículas de óxidos vermelhos e de contaminantes observadas com luz polarizada. 


\begin{tabular}{|ll||}
\hline CLIENTE: INEGI & MÁQUINA: Banco de Ensaios \\
MORADA: Porto & Ref. ÓLEO: MINE 200RPM \\
DATA: $27 / 04 / 12$ & ENSAIOS de EFICIËNCIA \\
\hline
\end{tabular}
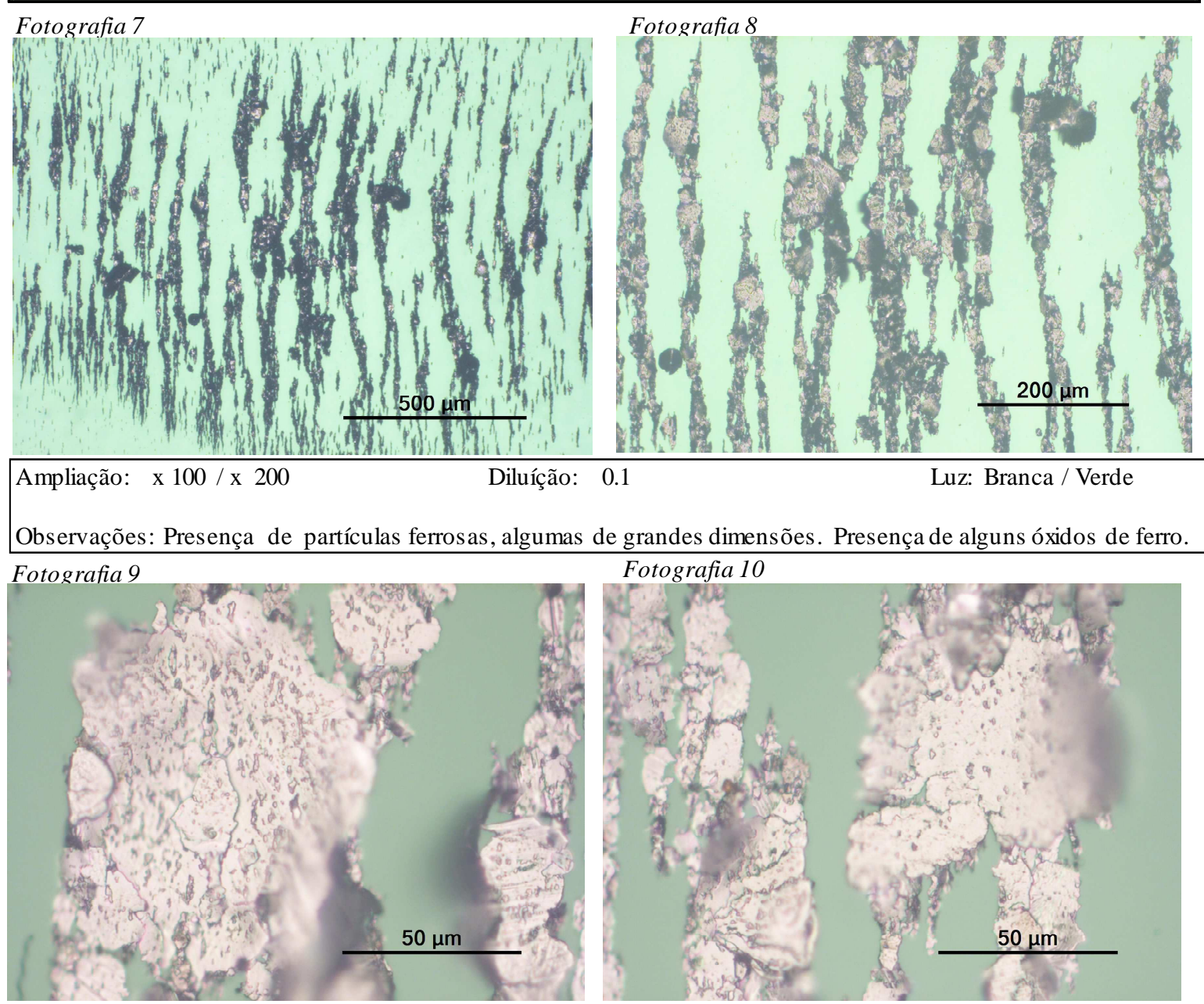

0.1

Luz: Branca / Verde

Ampliação: x $1000 \quad$ Diluíção: 0.1 Fotografia 10

Observações: Ampliação da Fotografia 8. Partículas ferrosas, de grandes dimensões ,típicas de desgaste de fadiga.

\section{Fotografia 11}
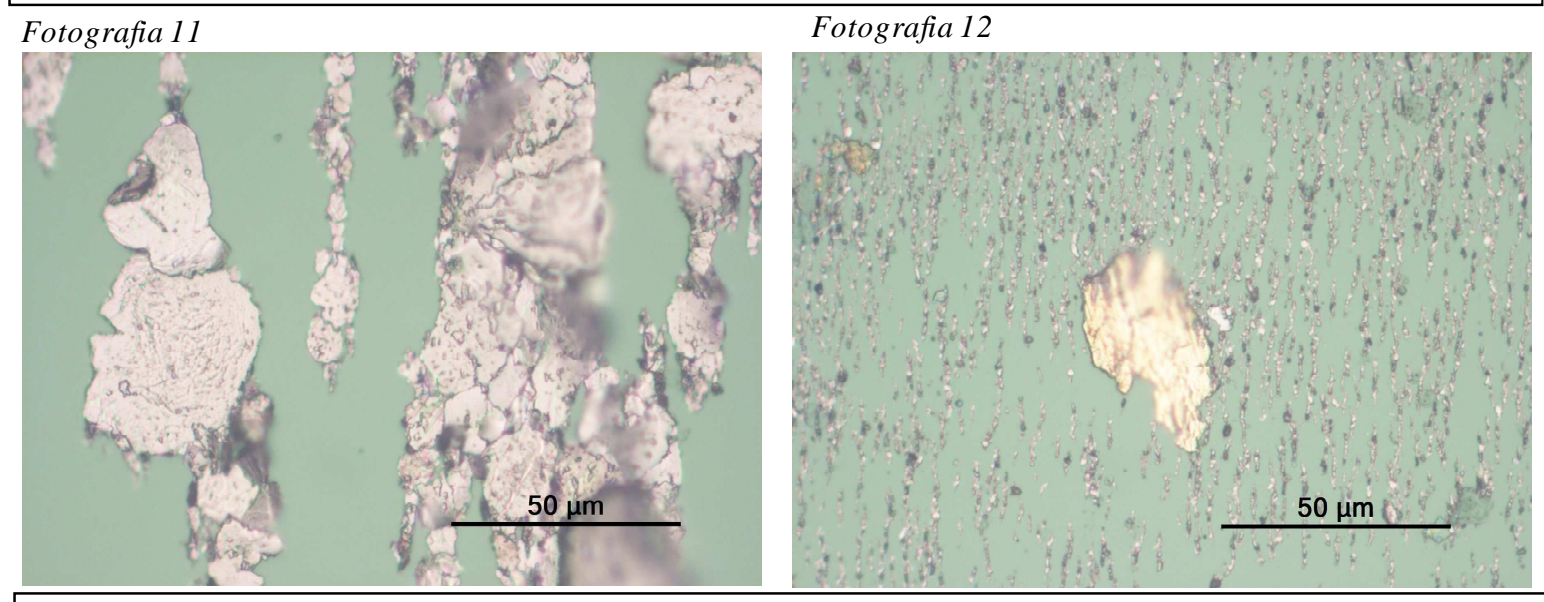

Ampliação: x 1000

Diluíção: 0.1

Luz: Branca / Verde

Observações: Fotografia 11: Partículas ferrosas de grandes dimensões típicas de desgaste de fadiga.

Fotografia 12: Partícula não ferrosa e partículas ferrosas de pequenas dimensões. 


\begin{tabular}{|ll|}
\hline CLIENTE: INEGI & MÁQUINA: Banco de Ensaios \\
MORADA: Porto & Ref. ÓLEO: MINE 500RPM \\
DATA: $27 / 04 / 12$ & ENSAIOS de EFICIÊNCIA \\
\hline
\end{tabular}
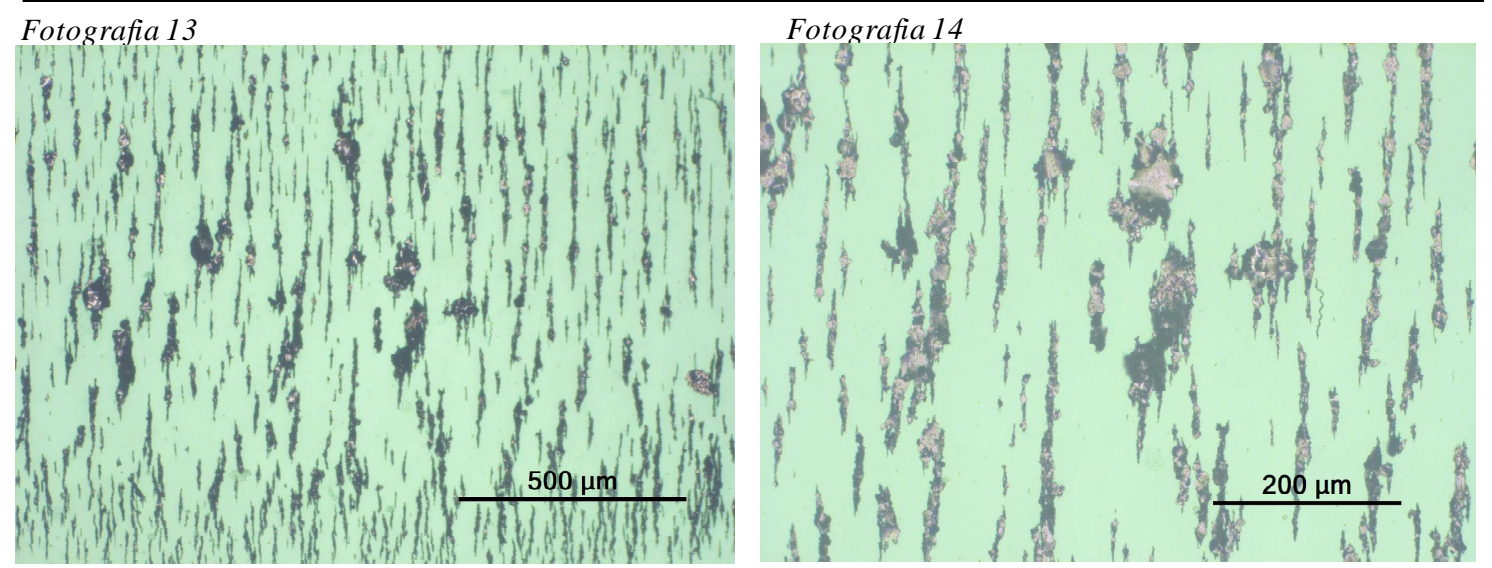

Ampliação: x 100 / x 200

Diluíção: 0.1

Luz: Branca / Verde

Observações: Presença de partículas ferrosas, algumas de grandes dimensões. Presença de alguns óxidos de ferro.

\section{Fotografia 15}

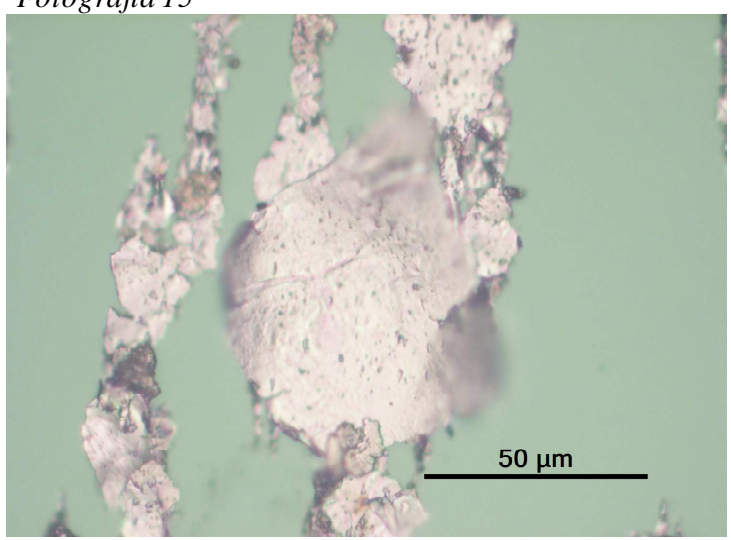

\section{Fotografia 16}
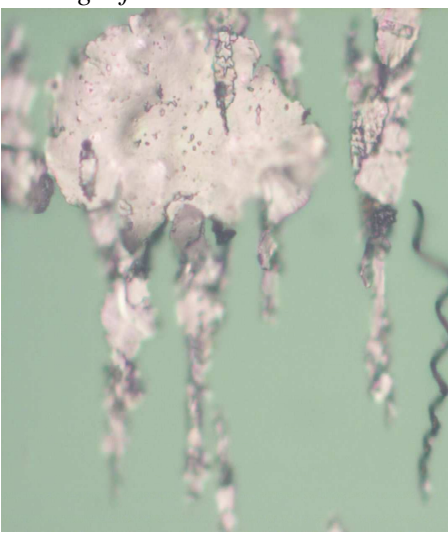

(1)

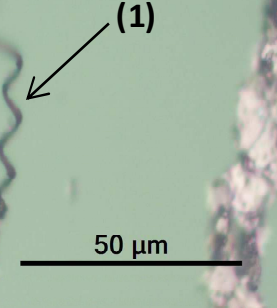

Ampliação: x 1000

Diluíção: 0.1

Luz: Branca / Verde

Observações: Ampliação da Fotografia 14. Partículas ferrosas, de grandes dimensões ,típicas de desgaste de fadiga. (1) - partícula ferrosa de desgaste de corte.
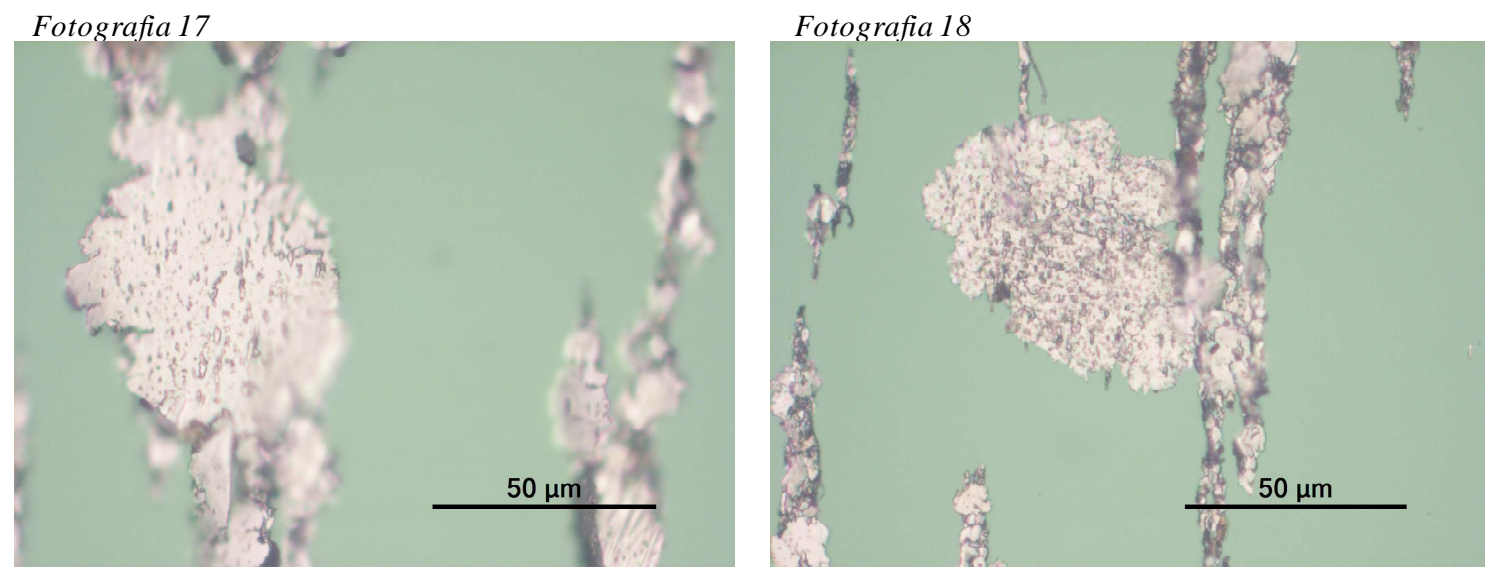

Ampliação: x 1000

Diluíção: 0.1

Luz: Branca / Verde

Observações: Ampliação da Fotografia 14. Partículas ferrosas, de grandes dimensões ,típicas de desgaste de fadiga. 
B.3. PAGD Oil 


\section{Relatório}

de

\section{Análise de Lubrificantes}

\begin{tabular}{|c|c|}
\hline $\begin{array}{l}\text { Análise } \mathrm{n}^{\mathrm{o}} \text { : } \\
\text { Tipo de análise: } \\
\text { Confidencialidade: }\end{array}$ & $\begin{array}{l}33,34 \text { e } 35 \text { / } 12 \\
\text { Ferrometria e Ferrografia Analítica } \\
1\end{array}$ \\
\hline $\begin{array}{l}\text { Cliente: } \\
\text { Morada: } \\
\text { Telefone / Fax: }\end{array}$ & $\begin{array}{l}\text { INEGI - Cetrib } \\
\text { Porto }\end{array}$ \\
\hline $\begin{array}{l}\text { Equipamento: } \\
\text { Lubrificante: } \\
\text { Dossier: }\end{array}$ & $\begin{array}{l}\text { BANCO - Ensaios de Eficiência } \\
\text { PAGD } \\
\text { / }\end{array}$ \\
\hline $\begin{array}{l}\text { No de páginas: } \\
\text { Data: }\end{array}$ & $\begin{array}{l}6 \\
30 / 05 / 12\end{array}$ \\
\hline $\begin{array}{l}\text { Responsável: } \\
\text { Rúbrica: }\end{array}$ & Beatriz Graça - Jorge Seabra \\
\hline
\end{tabular}




\section{OBJECTIVO}

Análise de três amostras de óleo lubrificante PAGD, resultantes de Ensaios de Eficiência no Banco de Ensaios para avaliação do desgaste presente.

As amostras analisadas foram as seguintes:

\begin{tabular}{|c|c|c|}
\hline \multirow{2}{*}{$\begin{array}{c}\text { Amostra } \\
(\mathrm{rpm})\end{array}$} & \multicolumn{2}{|c|}{ Análises efectuadas } \\
\cline { 2 - 3 } & Ferrometria & Ferrografia Analítica \\
\hline 100 & $\mathrm{X}$ & $\mathrm{X}$ \\
\hline 200 & $\mathrm{X}$ & $\mathrm{X}$ \\
\hline 400 & $\mathrm{X}$ & $\mathrm{X}$ \\
\hline
\end{tabular}

\section{RESULTADOS DAS ANÁLISES}

Nas páginas seguintes são apresentados os resultados referentes às análises de Ferrometria (DR III) e Ferrografia Analítica (FM III). 


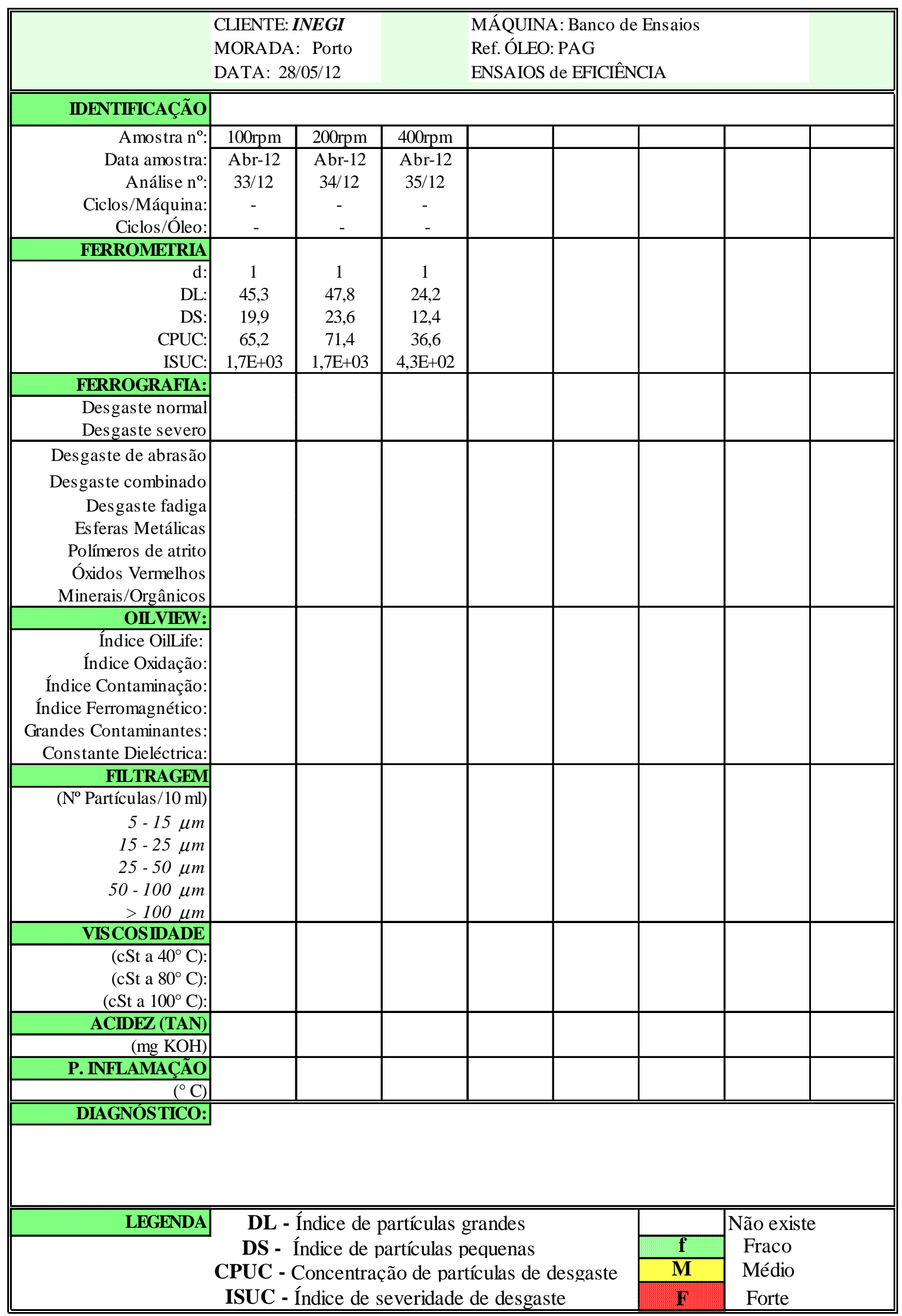




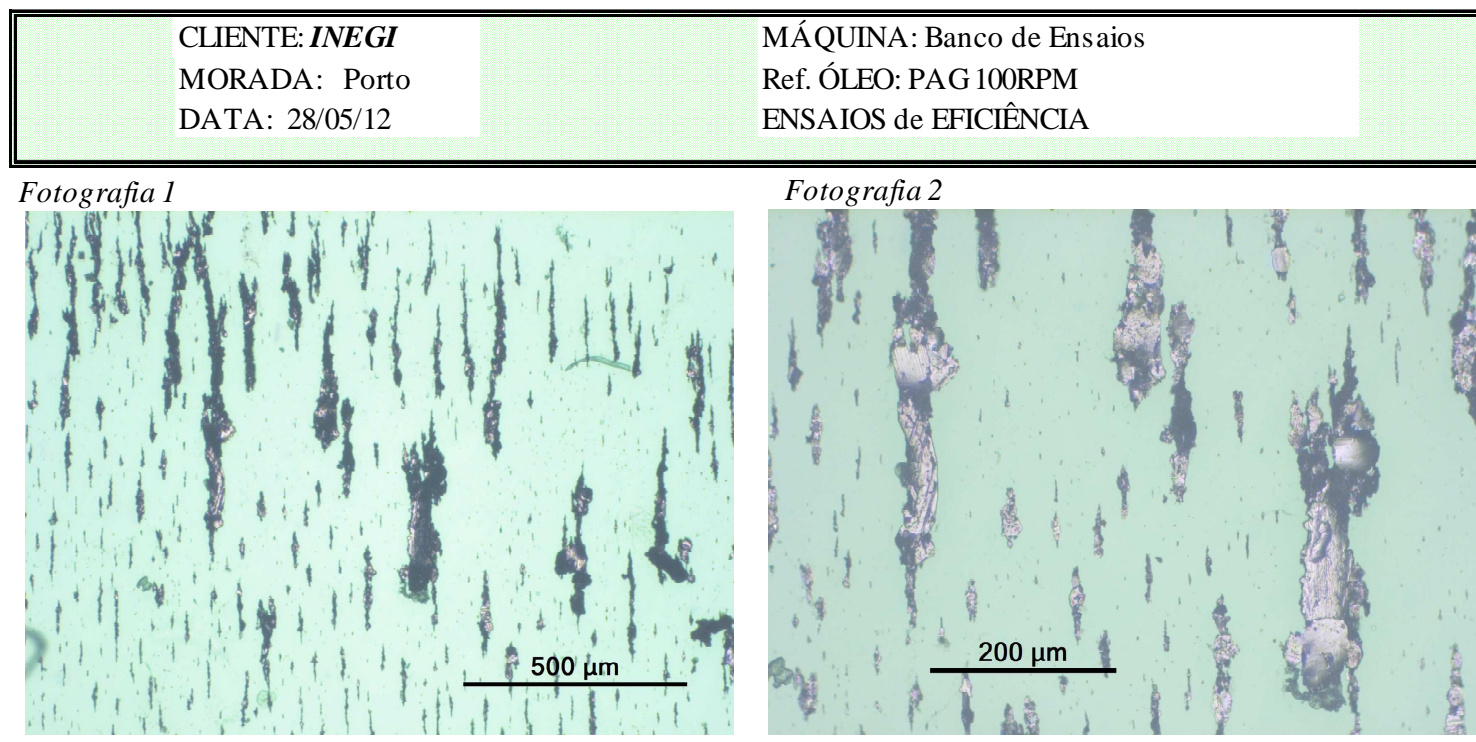

Ampliação: x $100 /$ x 200

Diluíção: 1

Luz: Branca / Verde

Observações: Presença de partículas ferrosas, algumas de grandes dimensões. Presença de alguns óxidos de ferro.

\section{Fotografia 3}

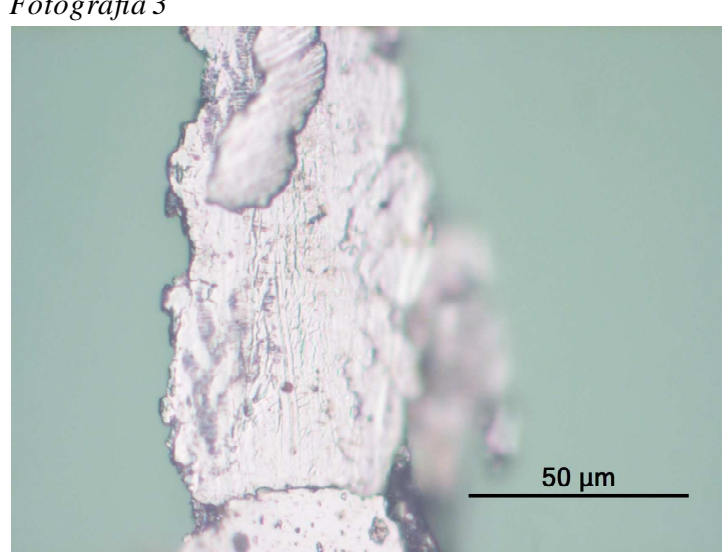

Ampliação: x 1000

\section{Fotografia 4 \\ Fotografia 4}

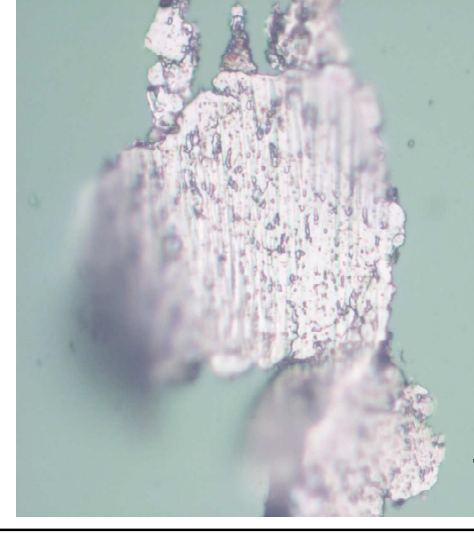

$50 \mu \mathrm{m}$

Observações: Ampliação da Fotografia 2. Partículas ferrosas, de grandes dimensões, típicas de desgaste de fadiga.

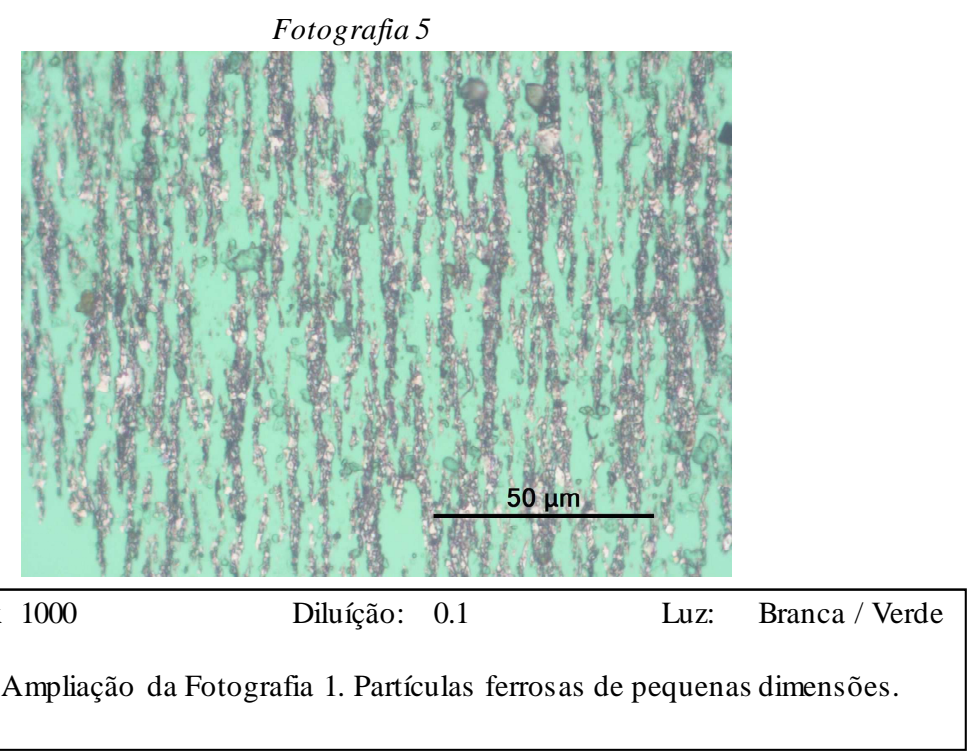




\begin{tabular}{|ll||}
\hline CLIENTE: $\boldsymbol{I N E G I}$ & MÁQUINA: Banco de Ensaios \\
MORADA: Porto & Ref. ÓLEO: PAG 100RPM \\
DATA: $28 / 05 / 12$ & ENSAIOS de EFICIËNCIA \\
\hline
\end{tabular}

Fotografia 6

Fotografia 7
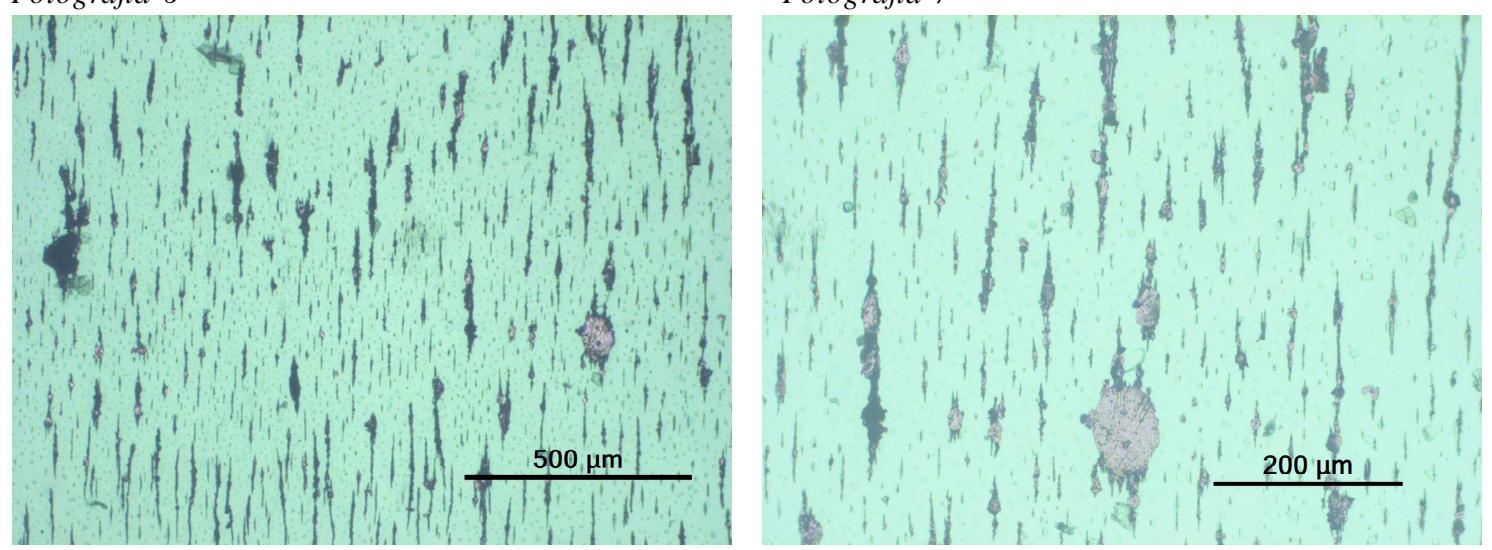

Ampliação: x 100 / x 200

Diluíção: 1

Luz: Branca / Verde

Observações: Presença de partículas ferrosas, algumas de grandes dimensões. Presença de alguns óxidos de ferro.
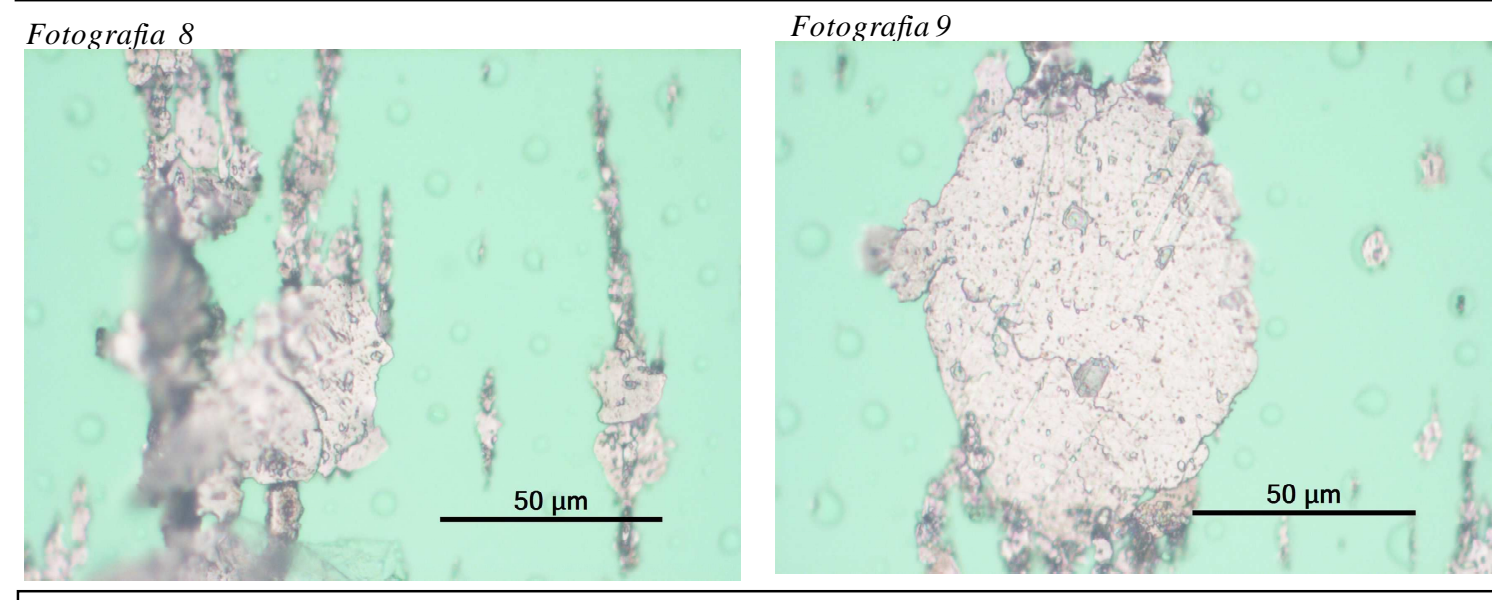

Ampliação: x 1000

Diluíção: 1

Luz: Branca / Verde

Observações: Ampliação da Fotografia 7. Partículas ferrosas, de grandes dimensões ,típicas de desgaste de fadiga.

\section{Fotografia 10}

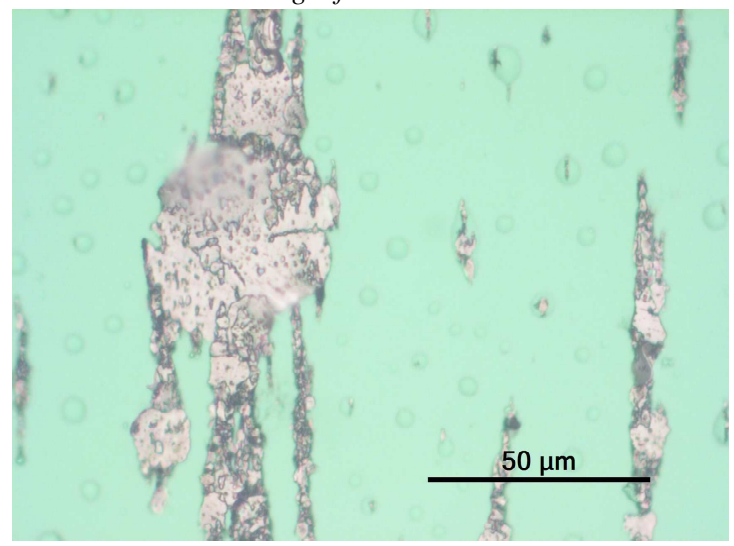

Ampliação: x $1000 \quad$ Diluíção: $1 \quad$ Luz: Branca / Verde
Observações: Partícula ferrosa de grandes dimensões típica de des gas te de fadiga.




\begin{tabular}{|ll|}
\hline CLIENTE: INEGI & MÁQUINA: Banco de Ensaios \\
MORADA: Porto & Ref. ÓLEO: MINE 500RPM \\
DATA: $27 / 04 / 12$ & ENSAIOS de EFICIÊNCIA \\
\hline
\end{tabular}
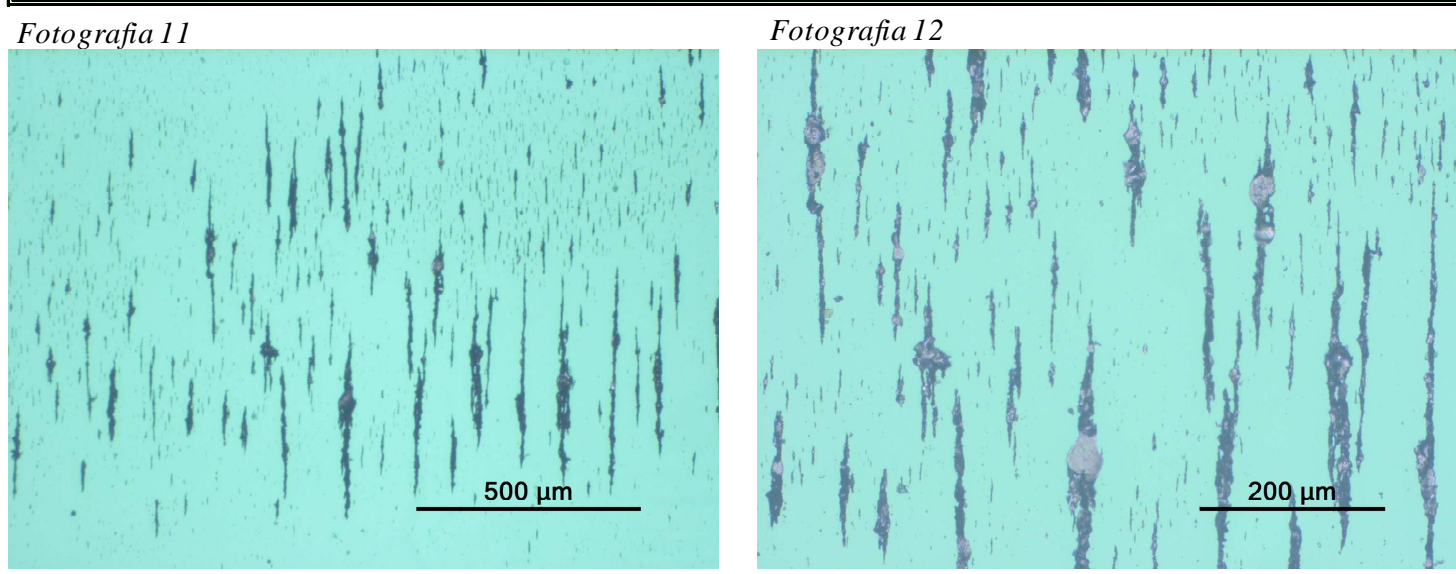

Ampliação: x $100 /$ x 200

Diluíção: 1

Luz: Branca / Verde

Observações: Presença de partículas ferrosas, poucas de grandes dimensões. Presença de alguns óxidos de ferro.

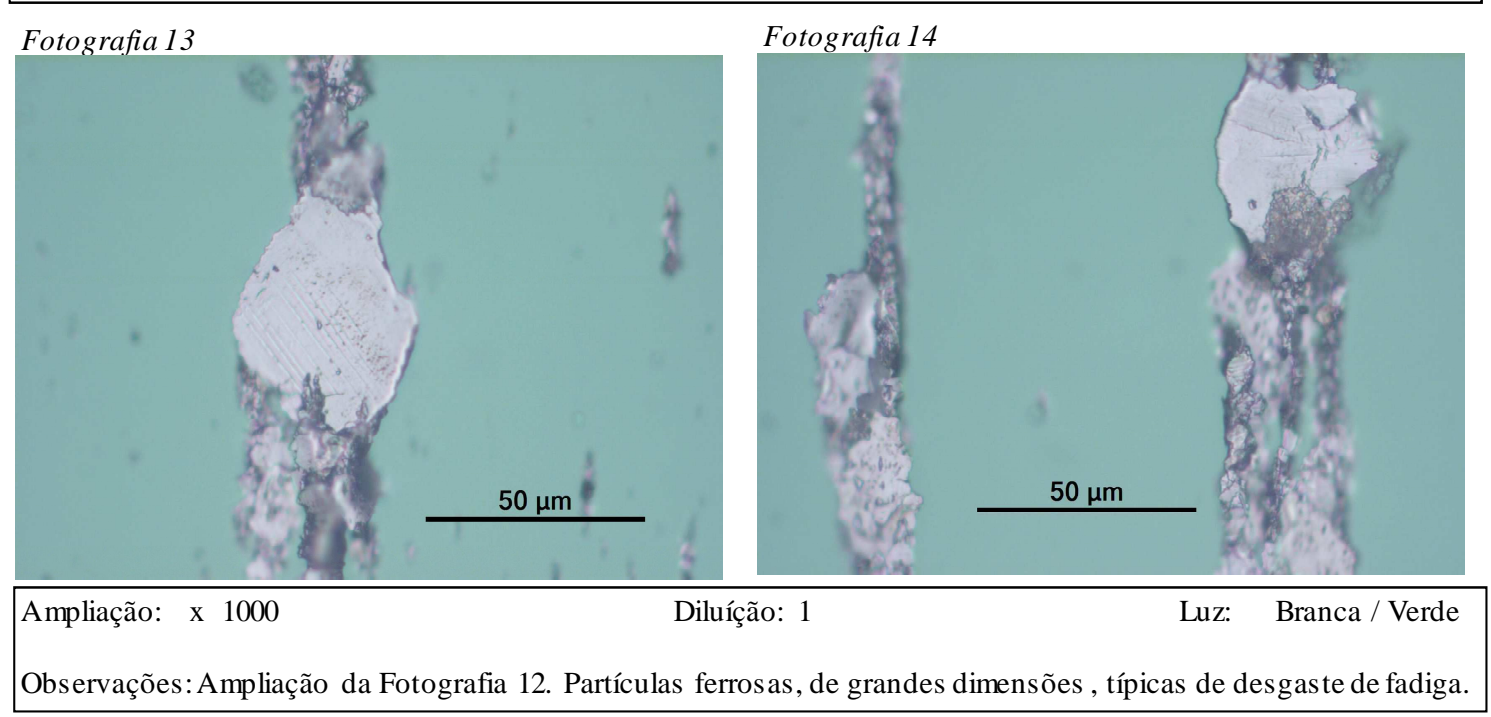

Fotografia 15

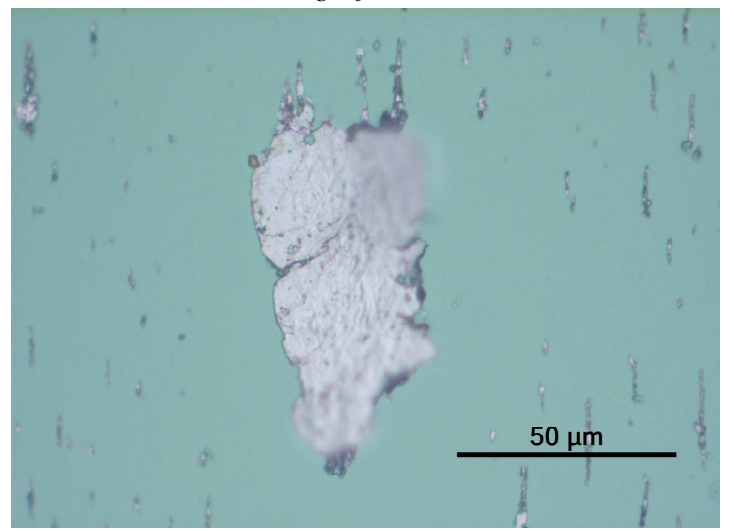

Ampliação: $\mathrm{x} 1000$

Diluíção: 1

Luz: Branca / Verde

Observações: Partícula ferrosa de grandes dimensões típica de desgaste de fadiga. 
B. Lubricant Analysis Reports

\section{B.4. PAOR Oil}




\section{Relatório}

de

\section{Análise de Lubrificantes}

\begin{tabular}{|c|c|}
\hline $\begin{array}{l}\text { Análise } \mathrm{n}^{\mathrm{o}} \text { : } \\
\text { Tipo de análise: } \\
\text { Confidencialidade: }\end{array}$ & $\begin{array}{l}42,43 \text { / } 12 \\
\text { Ferrometria e Ferrografia Analítica } \\
1\end{array}$ \\
\hline $\begin{array}{l}\text { Cliente: } \\
\text { Morada: } \\
\text { Telefone / Fax: }\end{array}$ & $\begin{array}{l}\text { INEGI - Cetrib } \\
\text { Porto }\end{array}$ \\
\hline $\begin{array}{l}\text { Equipamento: } \\
\text { Lubrificante: } \\
\text { Dossier: }\end{array}$ & $\begin{array}{l}\text { BANCO - Ensaios de Eficiência } \\
\text { PAO } \\
\quad /\end{array}$ \\
\hline $\begin{array}{l}\mathrm{N}^{\circ} \text { de páginas: } \\
\text { Data: }\end{array}$ & $\begin{array}{l}6 \\
12 / 06 / 12\end{array}$ \\
\hline $\begin{array}{l}\text { Responsável: } \\
\text { Rúbrica: }\end{array}$ & Beatriz Graça - Jorge Seabra \\
\hline
\end{tabular}




\section{OBJECTIVO}

Análise de três amostras de óleo lubrificante PAO, resultantes de Ensaios de Eficiência no Banco de Ensaios para avaliação do desgaste presente.

As amostras analisadas foram as seguintes:

\begin{tabular}{|c|c|c|}
\hline \multirow{2}{*}{$\begin{array}{c}\text { Amostra } \\
(\mathrm{rpm})\end{array}$} & \multicolumn{2}{|c|}{ Análises efectuadas } \\
\cline { 2 - 3 } & Ferrometria & Ferrografia Analítica \\
\hline 100 & $\mathrm{X}$ & $\mathrm{X}$ \\
\hline 400 & $\mathrm{X}$ & $\mathrm{X}$ \\
\hline
\end{tabular}

\section{RESULTADOS DAS ANÁLISES}

Nas páginas seguintes são apresentados os resultados referentes às análises de Ferrometria (DR III) e Ferrografia Analítica (FM III). 


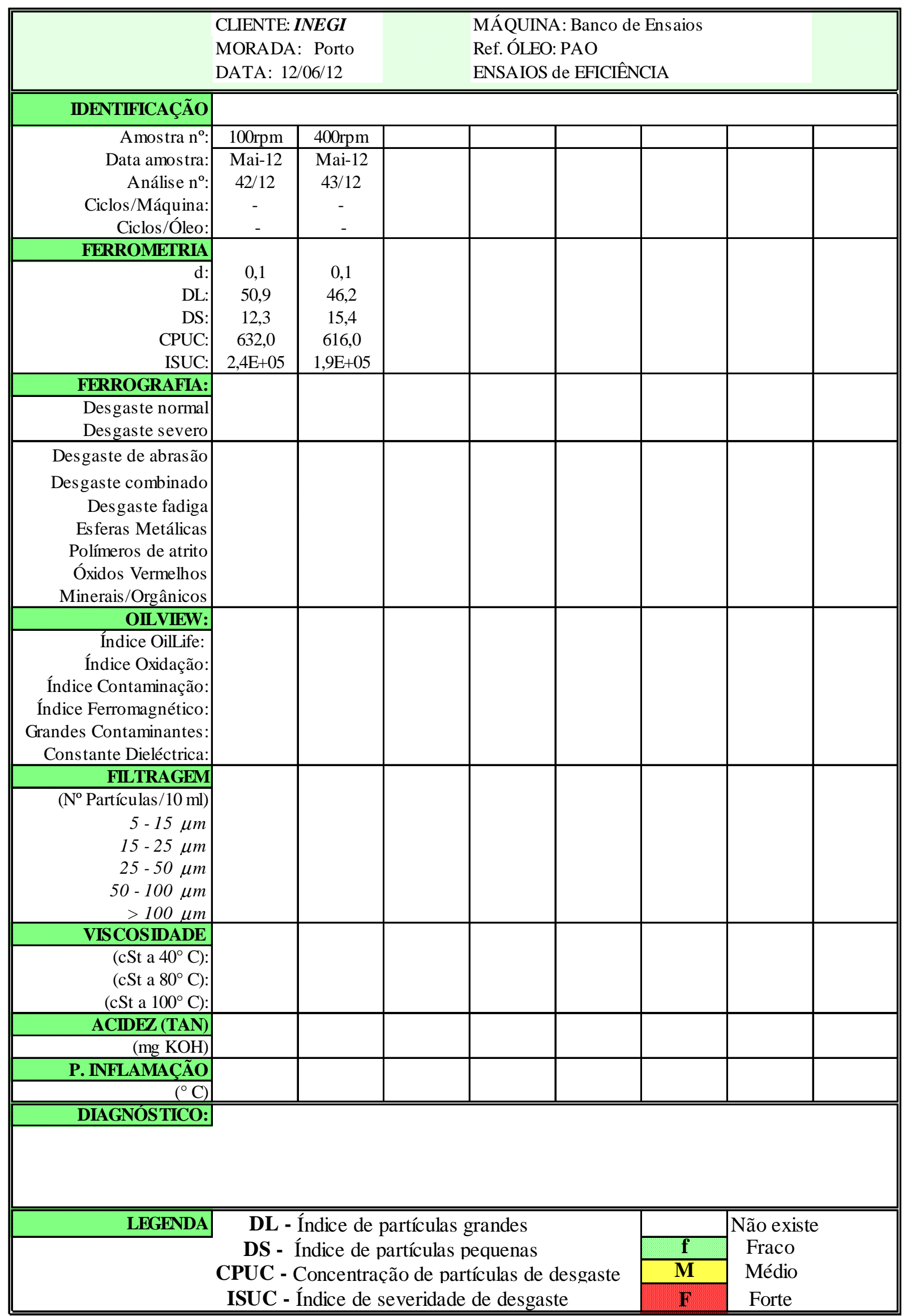



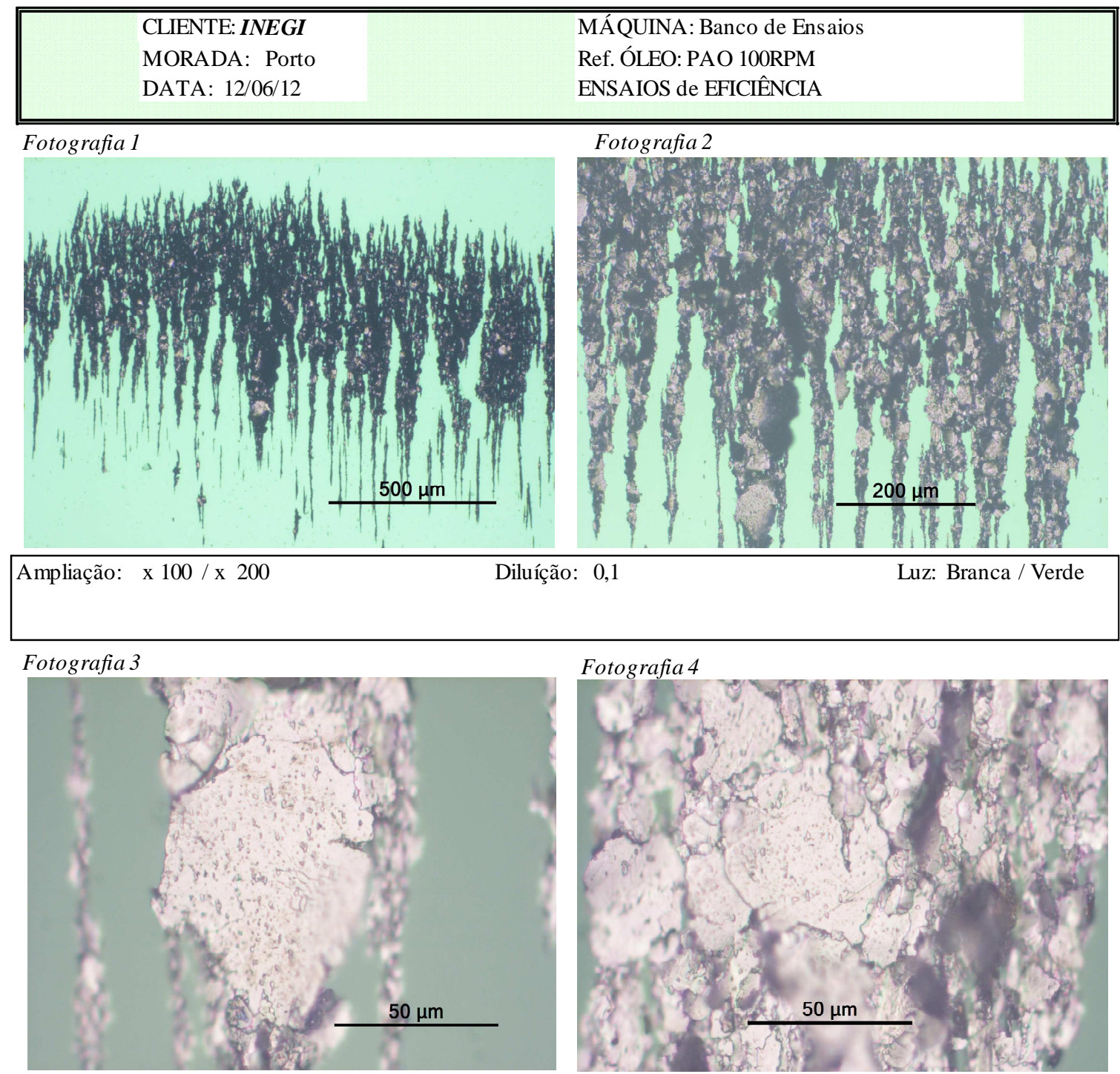

Ampliação: $\mathrm{x} 1000$

Diluíção: 0,1

Luz: Branca / Verde

Observações: Ampliação da Fotografia 1. Partículas ferrosas, de grandes dimensões, típicas de desgaste de fadiga.

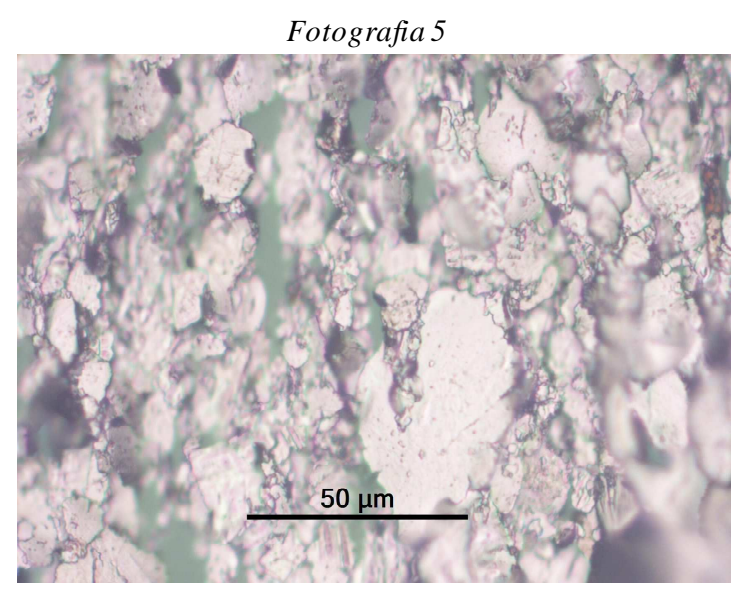

Ampliação: x $1000 \quad$ Diluíção: $0,1 \quad$ Luz:
Observações: Ampliação da Fotografia 1. Partículas ferrosas de pequenas dimensões.




\begin{tabular}{|ll|}
\hline CLIENTE: $I N E G I$ & MÁQUINA: Banco de Ensaios \\
MORADA: Porto & Ref. ÓLEO: PAO 400RPM \\
DATA: $12 / 06 / 12$ & ENSAIOS de EFICIËNCIA \\
\hline
\end{tabular}

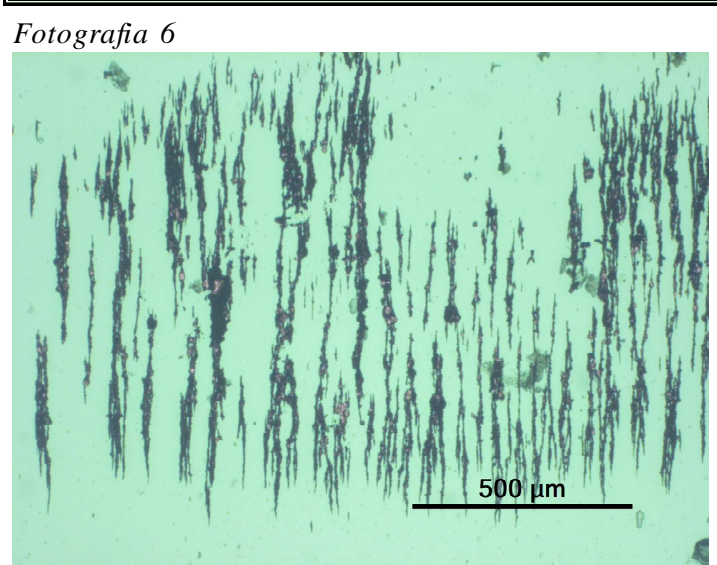

Fotografia 7

Ampliação: x 100 / x 200

Diluíção: 0,1

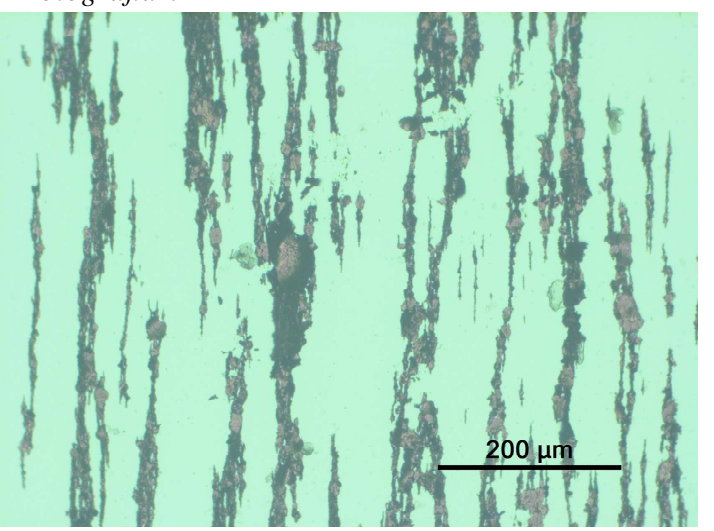

Observações: Presença de partículas ferrosas, algumas de grandes dimensões. Presença de alguns óxidos de ferro.

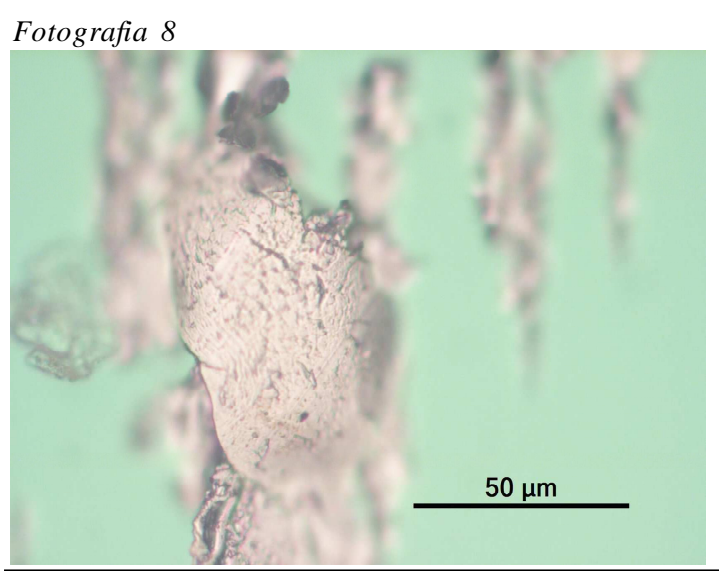

Fotografia 9

Ampliação: x 1000

Diluíção: 0,1
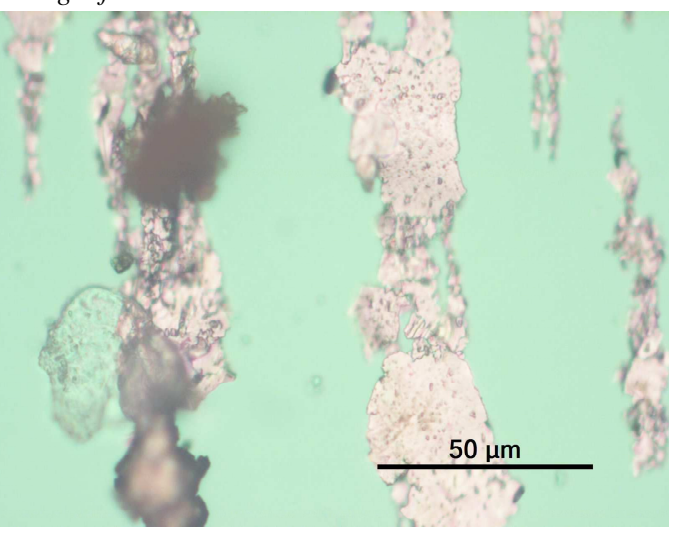

Observações: Ampliação da Fotografia 7. Partículas ferrosas, de grandes dimensões ,típicas de desgaste de fadiga.

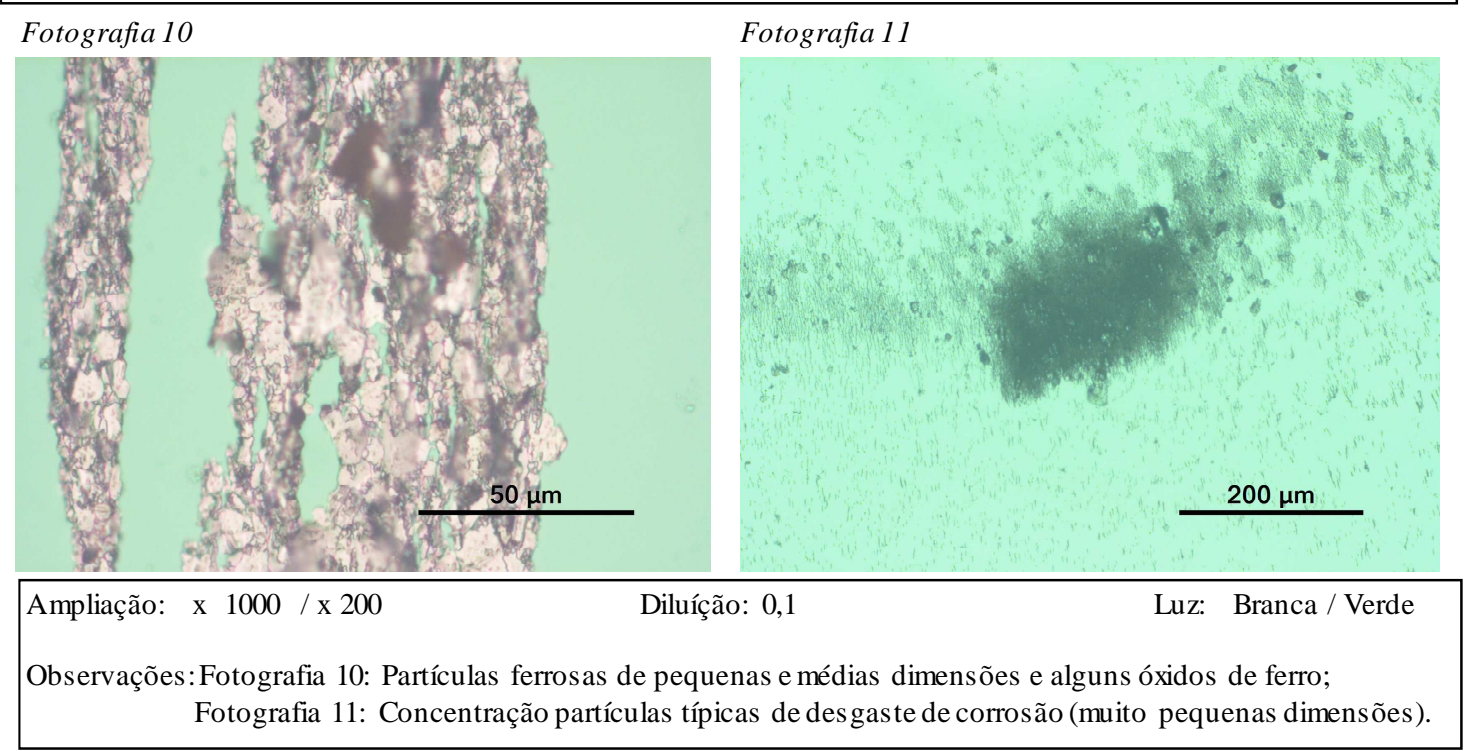


B. Lubricant Analysis Reports

\section{B.5. Power Loss dependence on Input Speed and Input Torque, (Extended plotting)}




\section{B.5.1. MINE Oil}

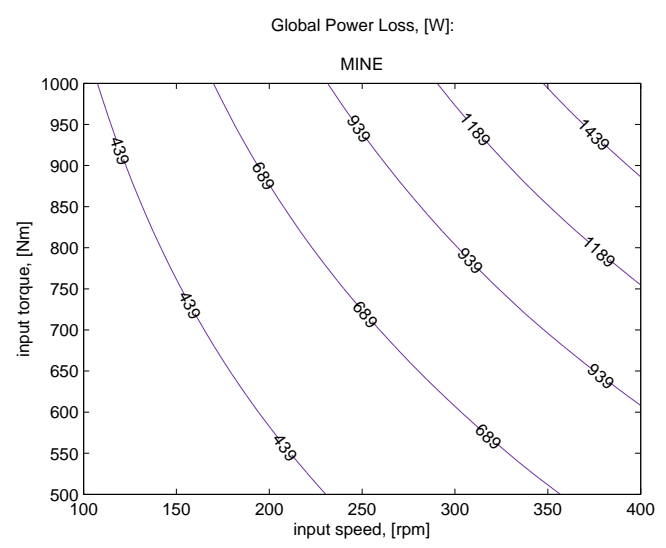

(a)

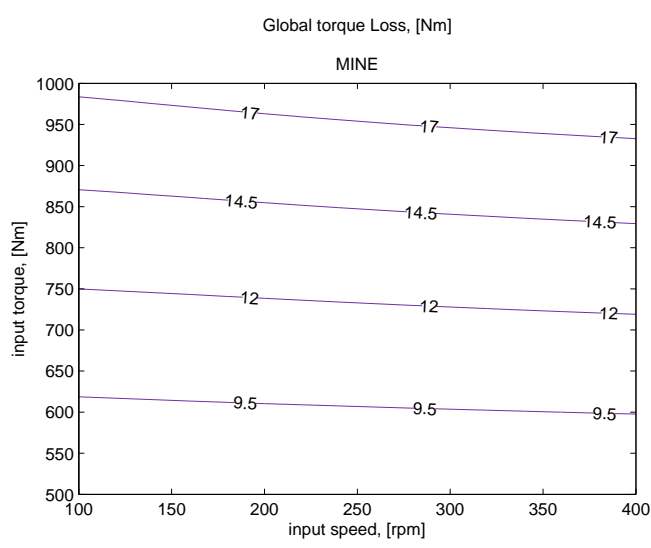

(b)

Figure B.1.: Global losses depending on both input speed and input torque: a) Power loss; b) Torque loss

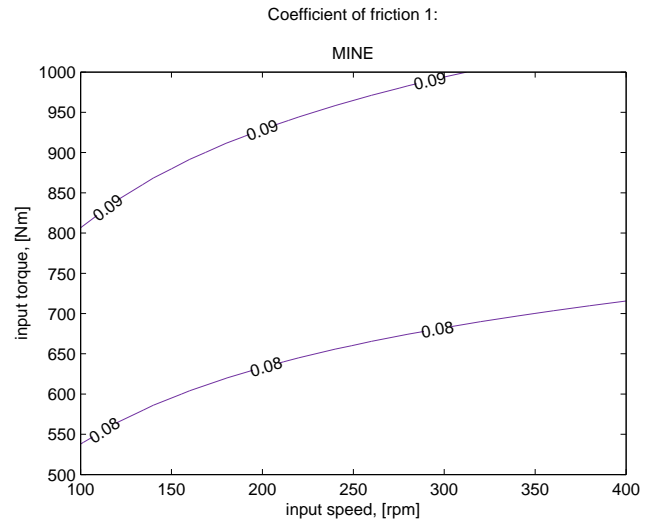

(a)

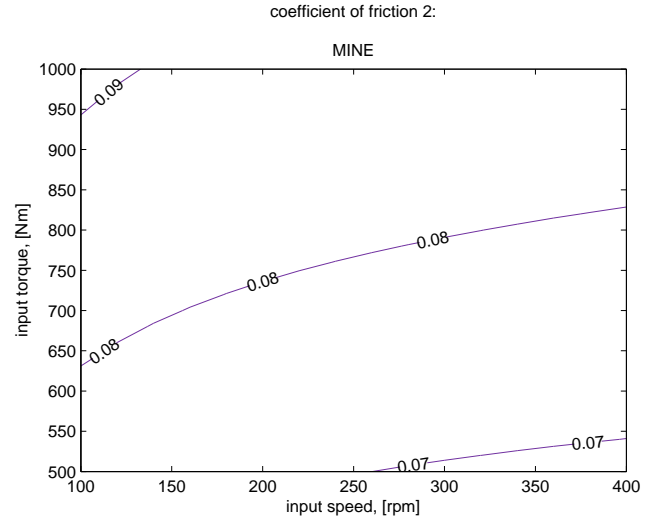

(b)

Figure B.2.: Mean coefficient of friction on both geared pairs: a) Meshing $1 / 2$; b Meshing 3/5 


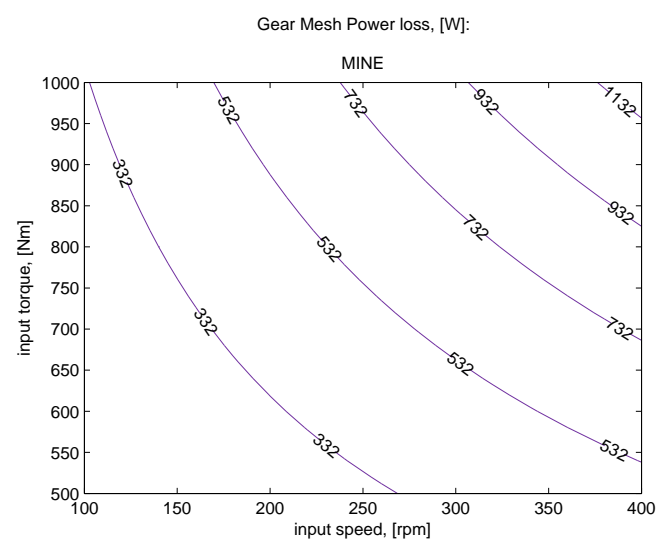

(a)

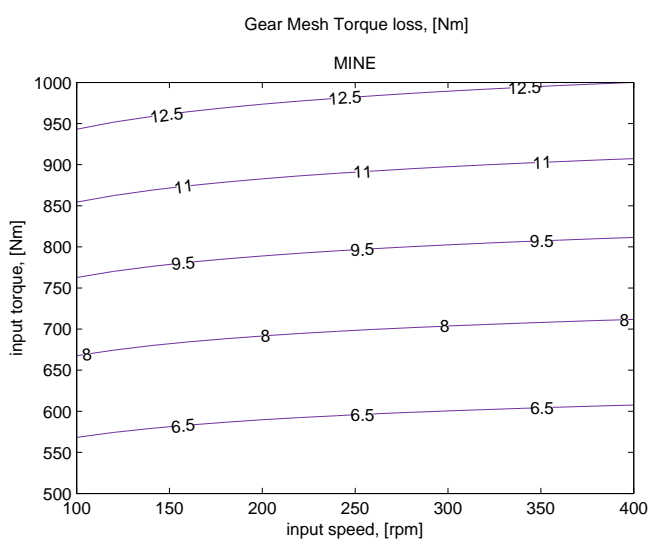

(b)

Figure B.3.: Gear Mesh losses depending on both input speed and input torque: a) Power loss; b) Torque loss

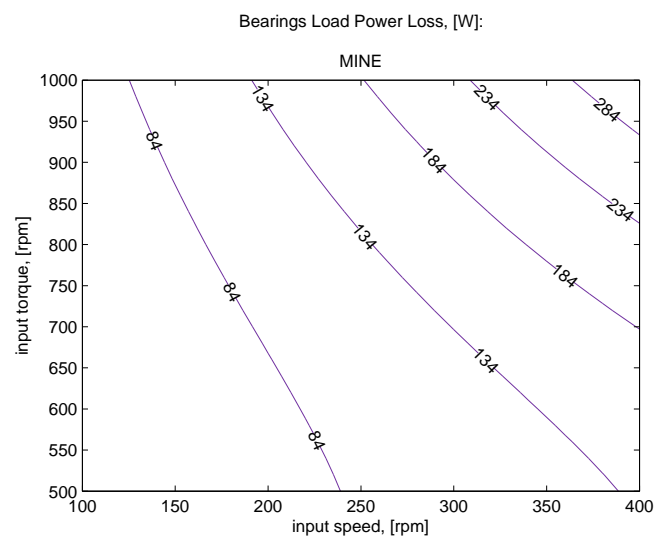

(a)

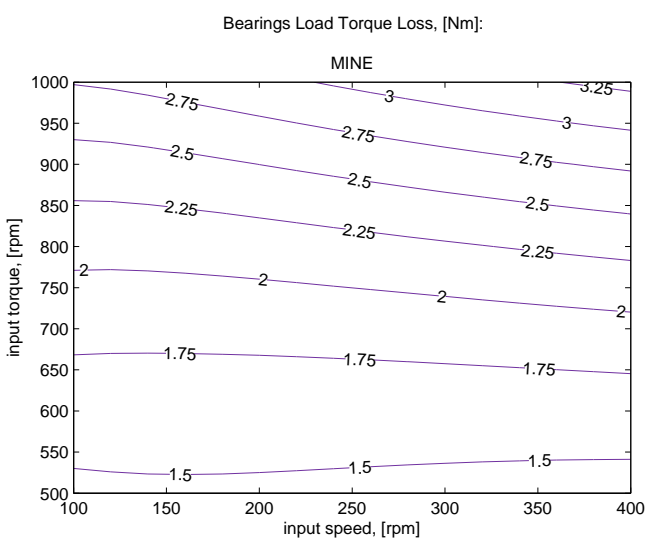

(b)

Figure B.4.: Bearing load losses depending on both input speed and input torque: a) Power loss; b) Torque loss

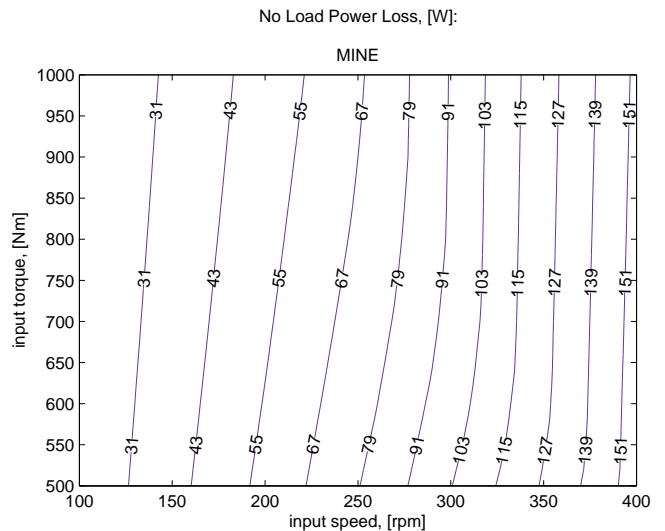

(a)

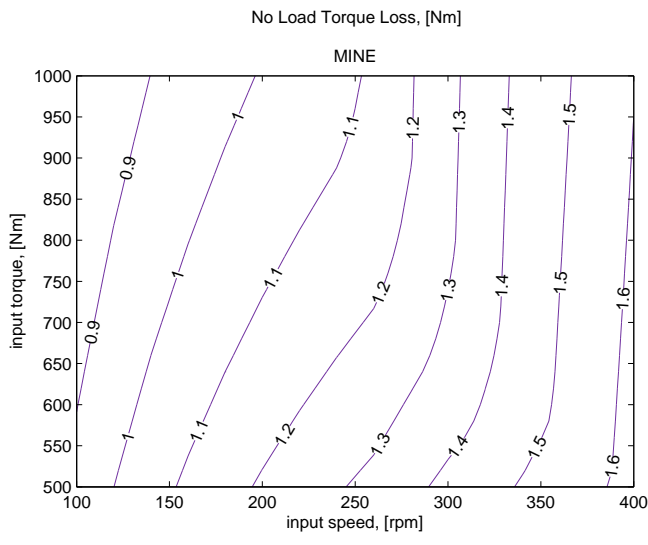

(b)

Figure B.5.: No-load losses depending on both input speed and input torque: a) Power loss; b) Torque loss 


\section{B.5.2. MINR Oil}

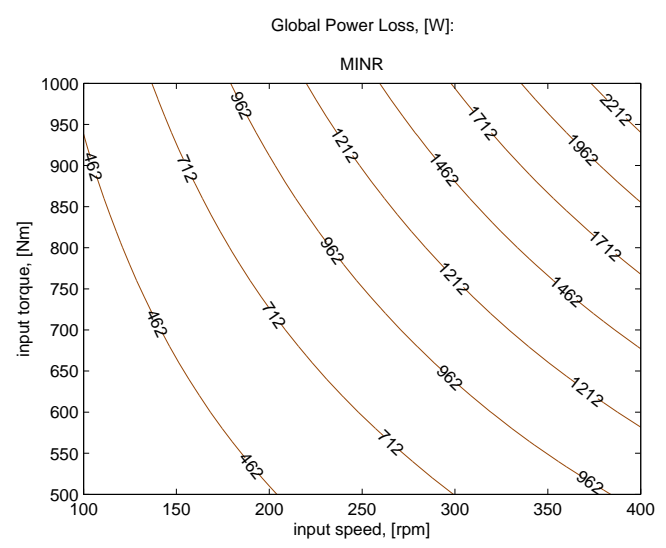

(a)

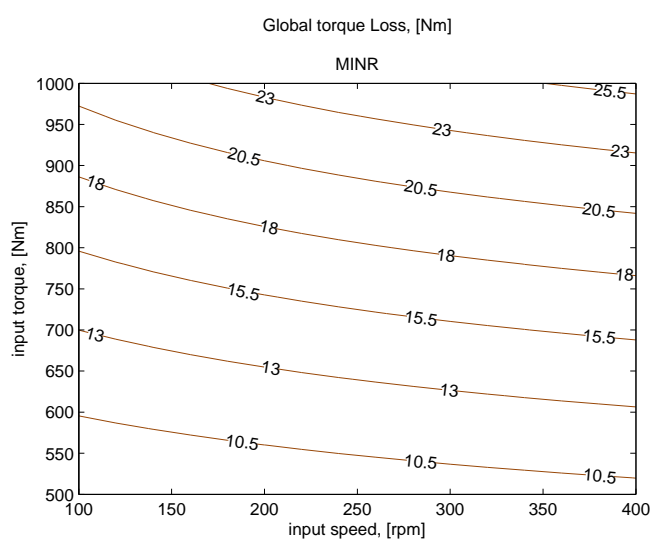

(b)

Figure B.6.: Global losses depending on both input speed and input torque: a) Power loss; b) Torque loss

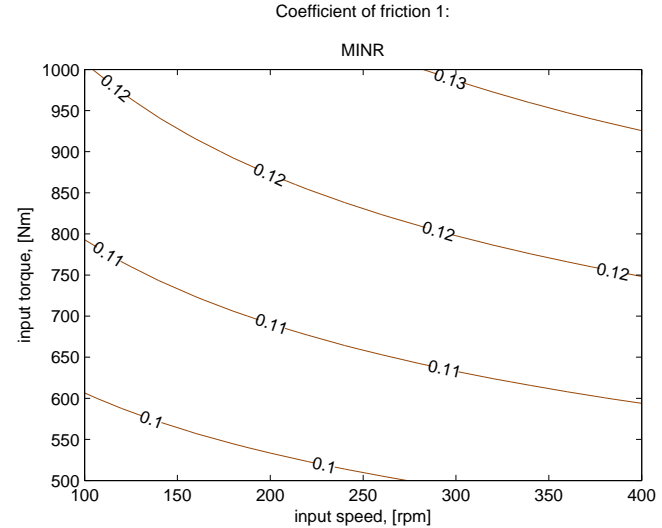

(a)

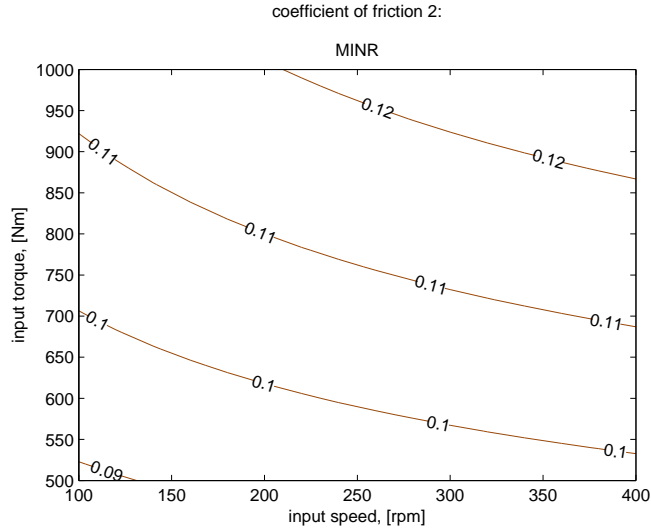

(b)

Figure B.7.: Mean coefficient of friction on both geared pairs: a) Meshing 1/2; b Meshing 3/5 


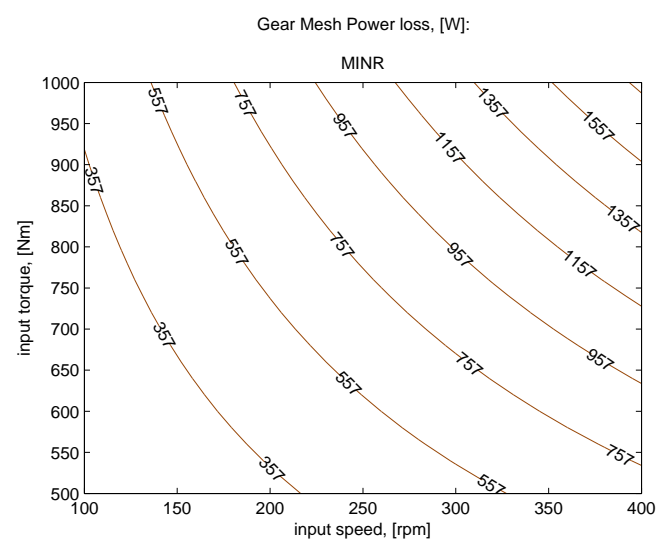

(a)

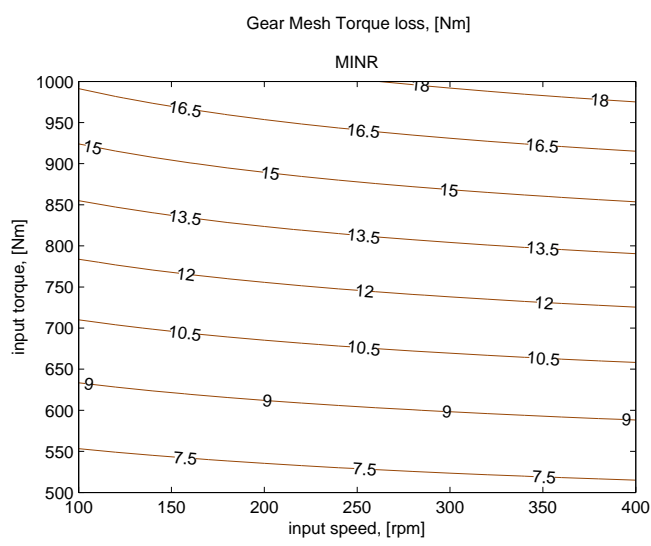

(b)

Figure B.8.: Gear Mesh losses depending on both input speed and input torque: a) Power loss; b) Torque loss

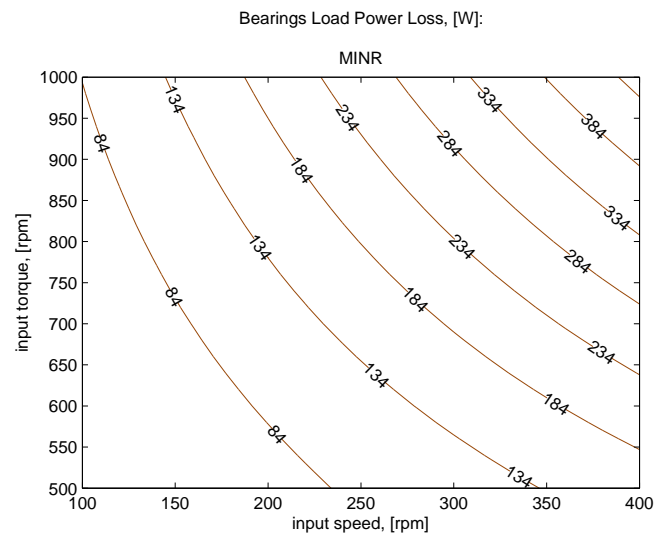

(a)

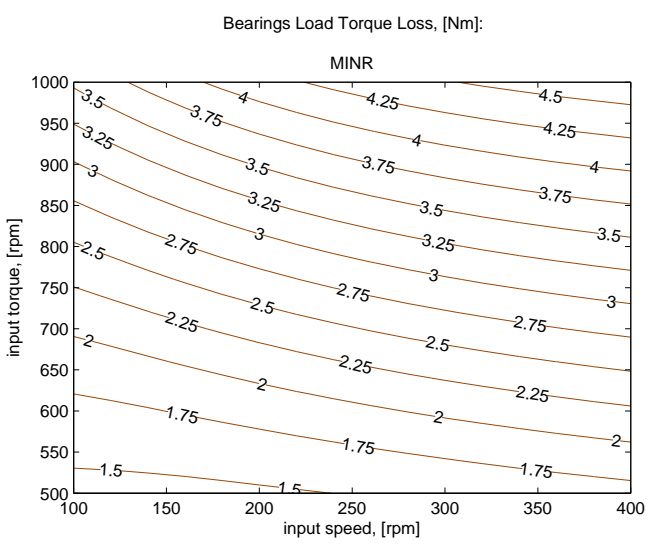

(b)

Figure B.9.: Bearing load losses depending on both input speed and input torque: a) Power loss; b) Torque loss

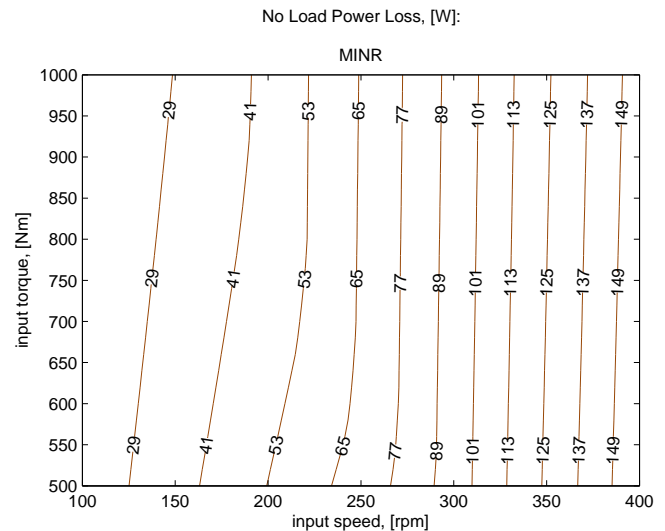

(a)

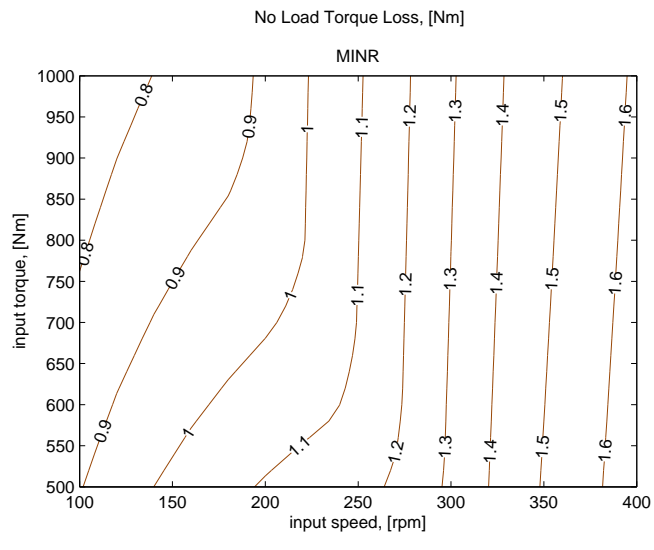

(b)

Figure B.10.: No-load losses depending on both input speed and input torque: a) Power loss; b) Torque loss 


\section{B.5.3. PAGD Oil}

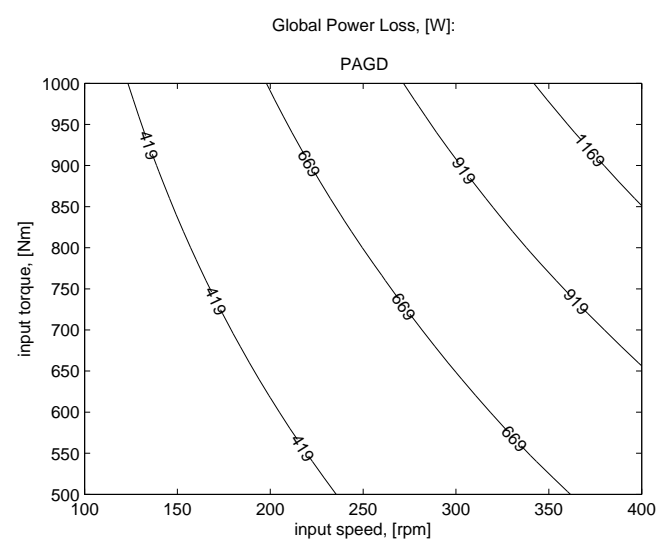

(a)

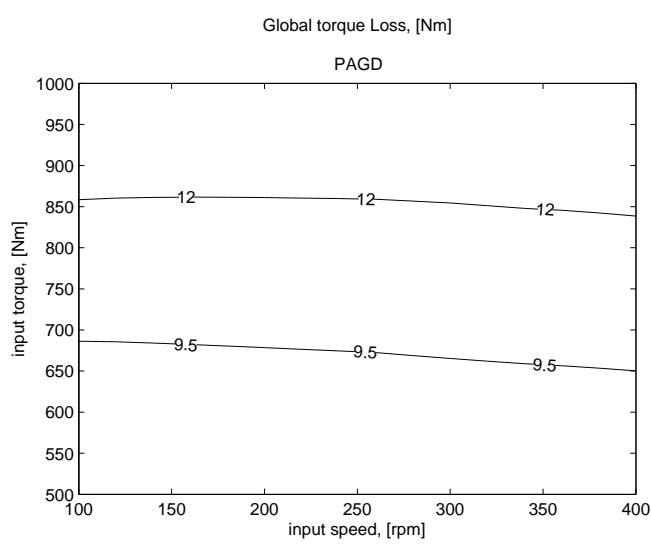

(b)

Figure B.11.: Global losses depending on both input speed and input torque: a) Power loss; b) Torque loss

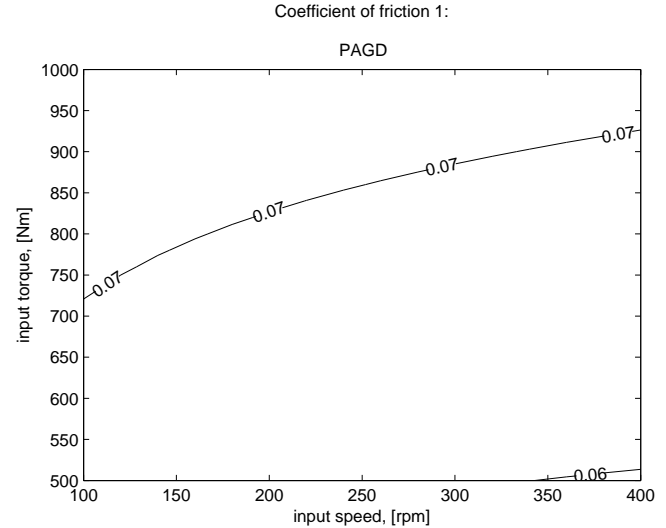

(a)

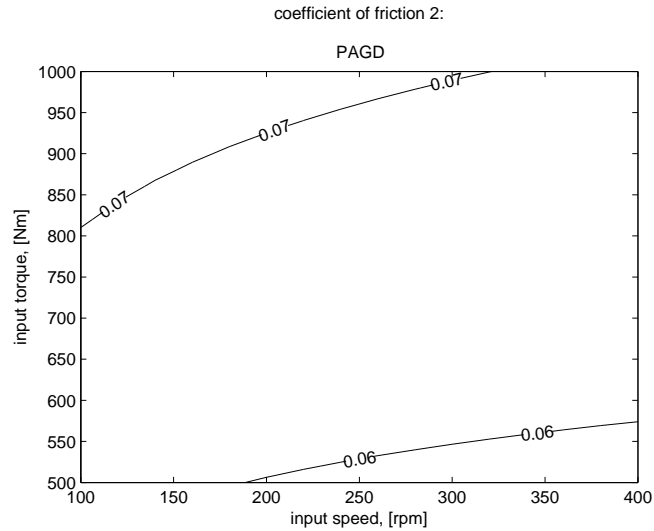

(b)

Figure B.12.: Mean coefficient of friction on both geared pairs: a) Meshing 1/2; b Meshing 3/5 


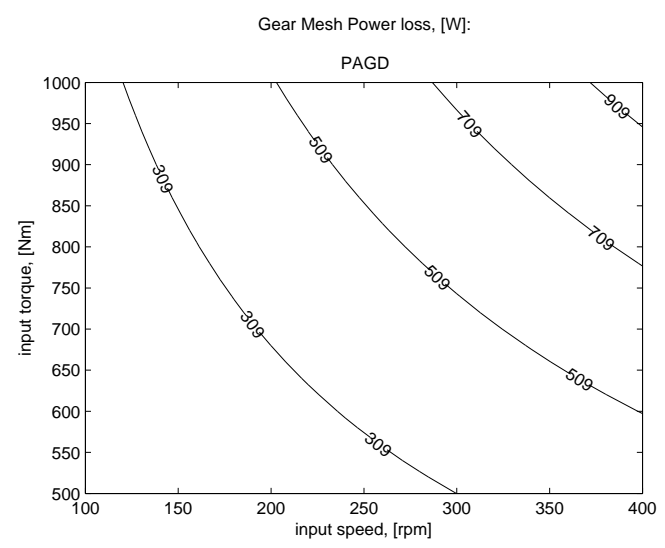

(a)

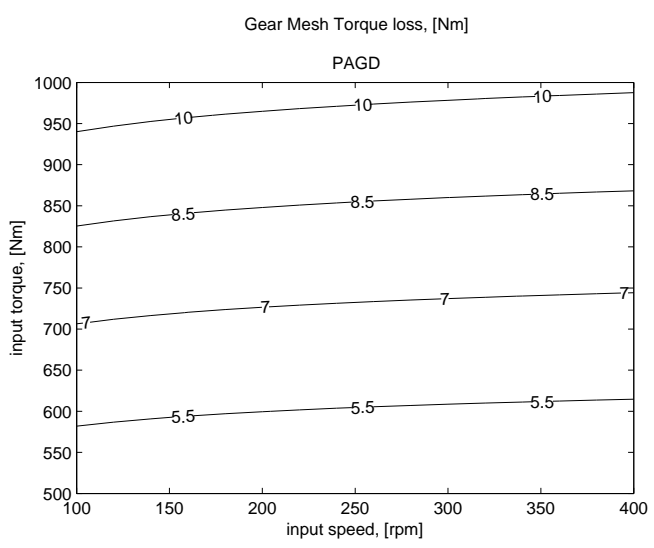

(b)

Figure B.13.: Gear Mesh losses depending on both input speed and input torque: a) Power loss; b) Torque loss

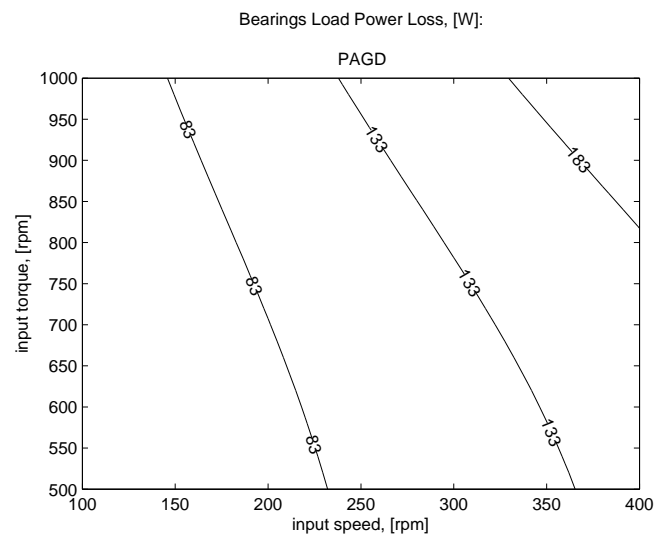

(a)

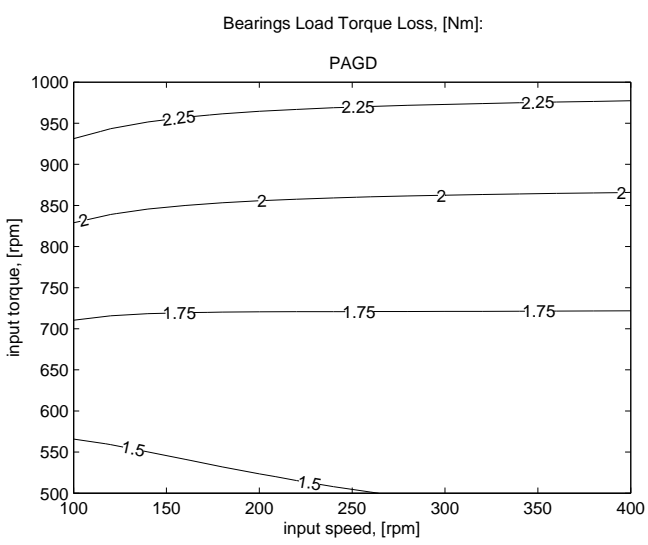

(b)

Figure B.14.: Bearing load losses depending on both input speed and input torque: a) Power loss; b) Torque loss

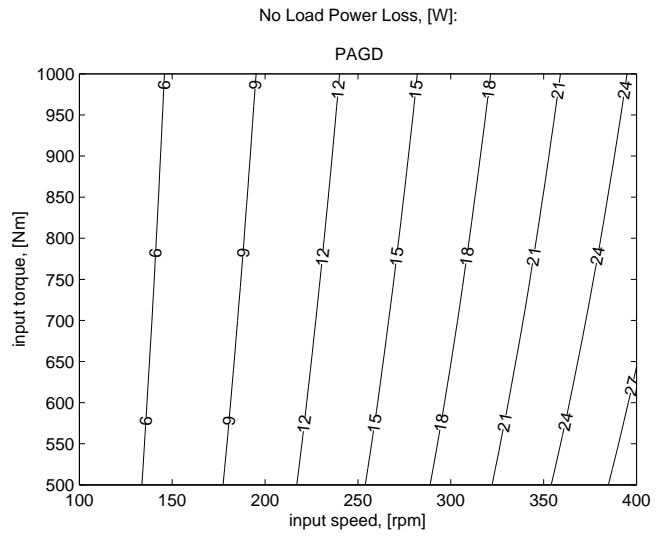

(a)

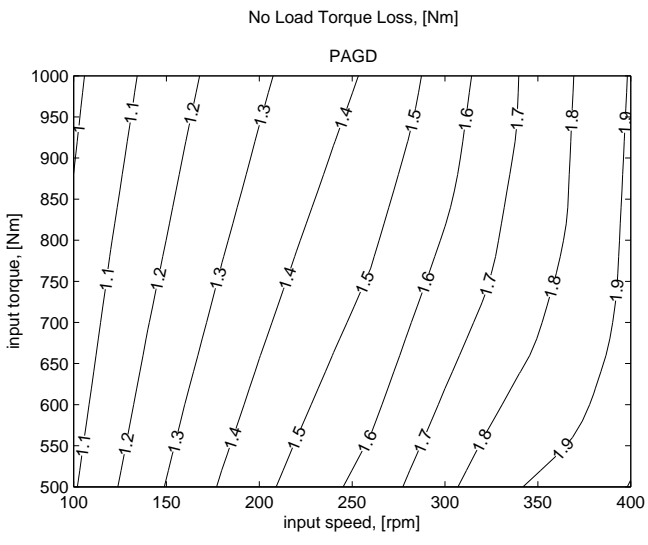

(b)

Figure B.15.: No-load losses depending on both input speed and input torque: a) Power loss; b) Torque loss 


\section{B.5.4. PAOR Oil}

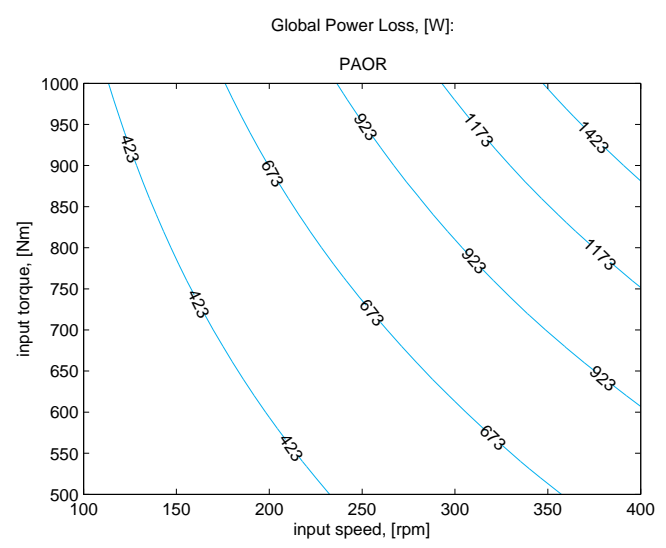

(a)

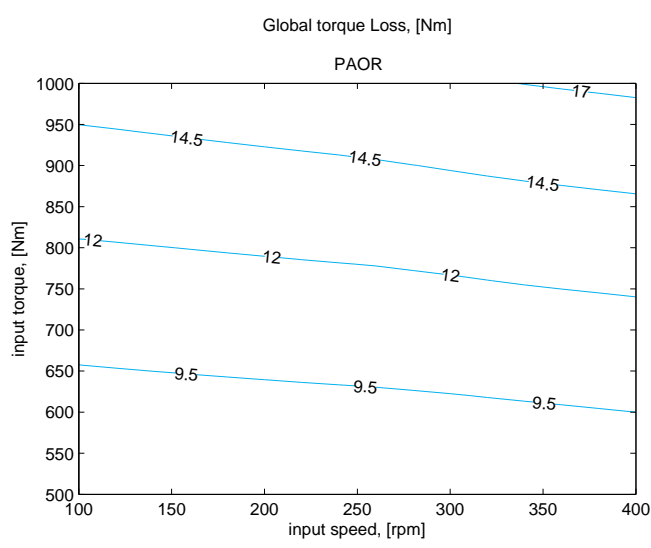

(b)

Figure B.16.: Global losses depending on both input speed and input torque: a) Power loss; b) Torque loss

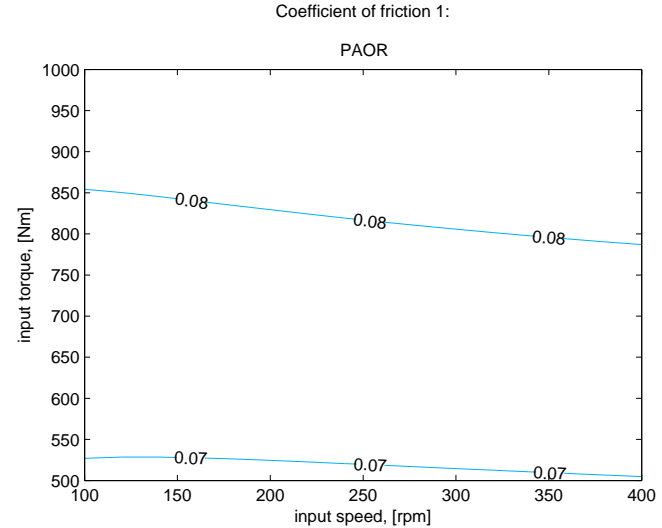

(a)

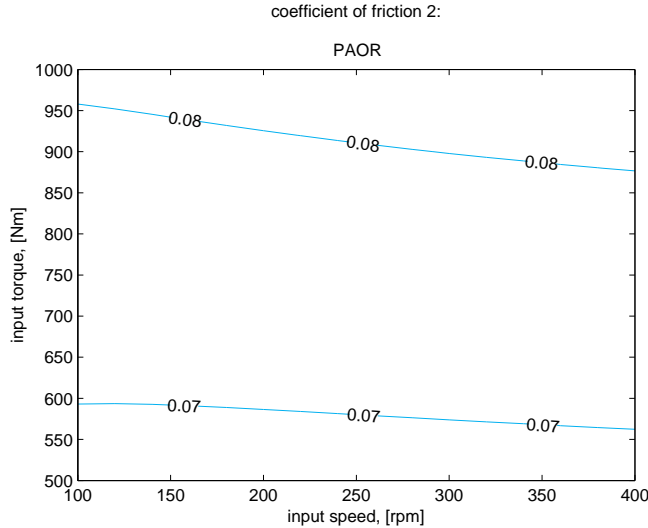

(b)

Figure B.17.: Mean coefficient of friction on both geared pairs: a) Meshing 1/2; b Meshing 3/5 


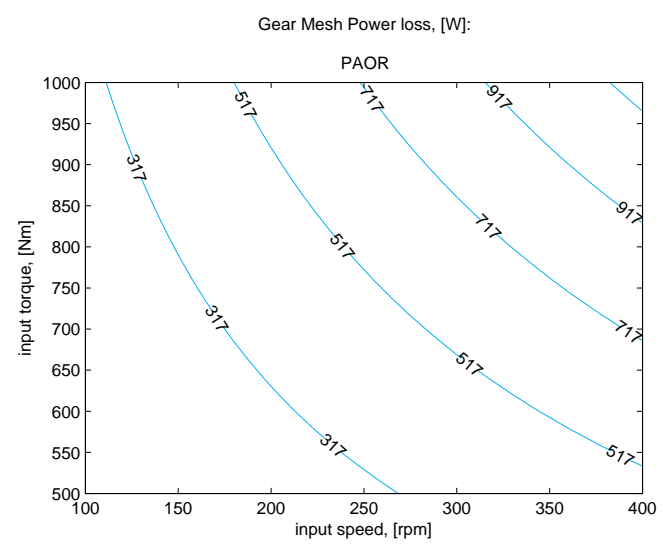

(a)

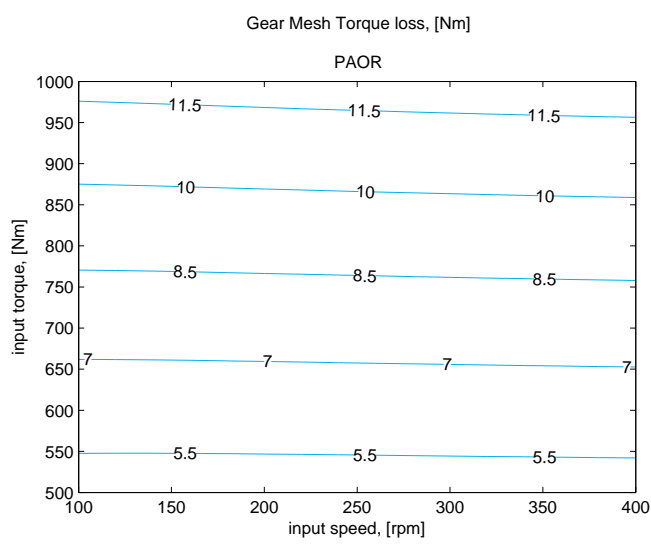

(b)

Figure B.18.: Gear Mesh losses depending on both input speed and input torque: a) Power loss; b) Torque loss

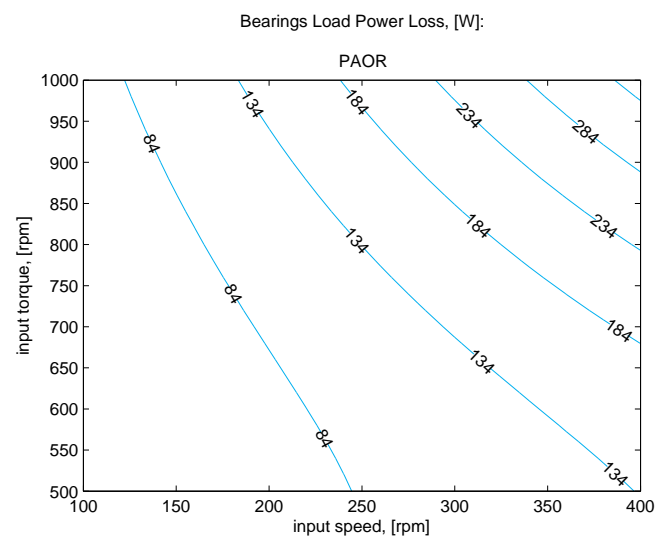

(a)

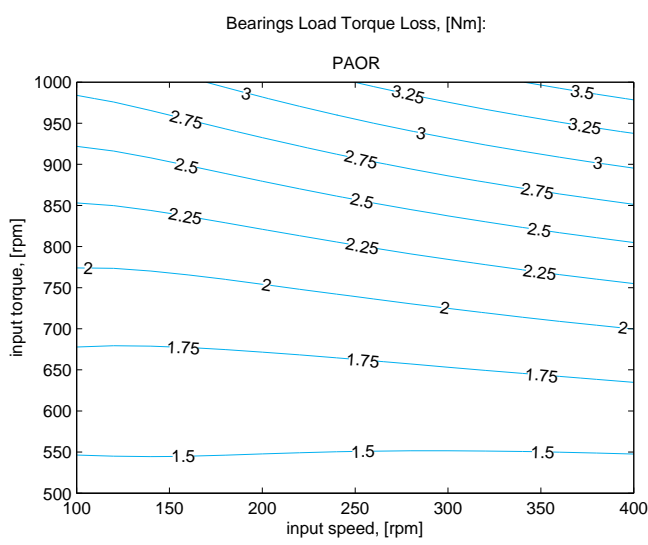

(b)

Figure B.19.: Bearing load losses depending on both input speed and input torque: a) Power loss; b) Torque loss

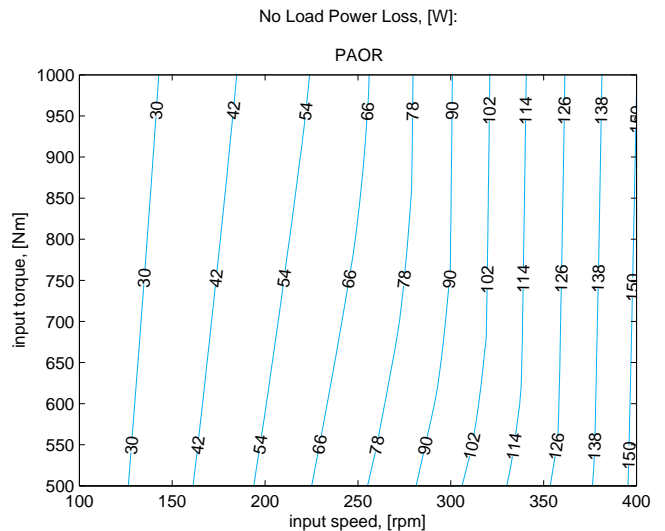

(a)

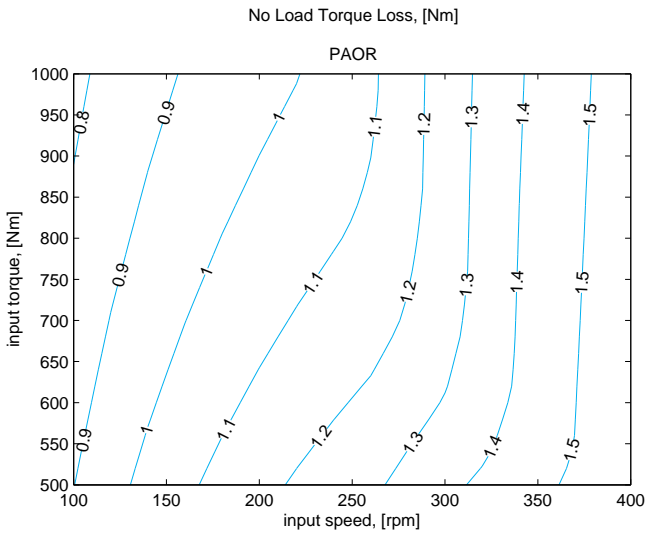

(b)

Figure B.20.: No-load losses depending on both input speed and input torque: a) Power loss; b) Torque loss 
B.6. Determination of the global heat transfer coefficient, (Extended results)

\section{B.6. Determination of the global heat transfer coefficient, (Extended results)}




\section{B.6.1. Results considering $\Delta T=T_{\text {wall }}-T_{a m b}$}

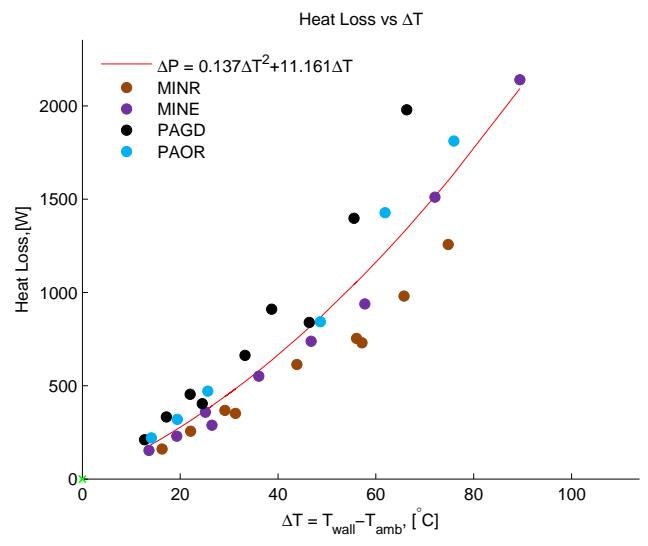

(a)

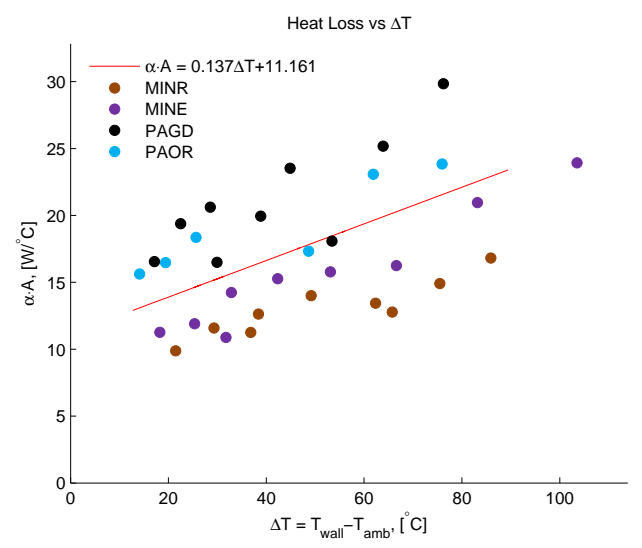

(b)

Figure B.21.: Heat Loss and $\alpha \cdot A$ against $\Delta T$

Table B.1.: Numerically adjusted coefficients for the prediction of the global heat transfer coefficient, $\left(\Delta T=T_{\text {wall }}-T_{a m b}\right)$

All Res. - Coefficients obtained from the results of all of the tests

\begin{tabular}{ccc}
\hline & $C_{1}$ & $C_{2}$ \\
\hline All Res. & 0.1368 & 11.1607 \\
\hline
\end{tabular}


C. Detailed results of the implemented Numerical

Approach, (Program Printouts) 
C. Detailed results of the implemented Numerical Approach, (Program Printouts)

\section{C.1. Results before numerical adjustment}




\section{C.1.1. MINE Oil}

\begin{tabular}{|c|c|c|}
\hline 'MINE' & 'Oil' & \\
\hline Coefficient & of fricti & $\mathrm{n}$ : Meshing 1 \\
\hline 0.0644 & 0.0581 & 0.0516 \\
\hline 0.0710 & 0.0645 & 0.0575 \\
\hline 0.0762 & 0.0696 & 0.0621 \\
\hline Coefficient & of fricti & $\mathrm{n}$ : Meshing 2 \\
\hline 0.0622 & 0.0561 & 0.0499 \\
\hline 0.0686 & 0.0623 & 0.0555 \\
\hline 0.0736 & 0.0672 & 0.0600 \\
\hline Global Loss & es [W] & \\
\hline $1.0 e+003$ & & \\
\hline 0.1714 & 0.3227 & 0.8848 \\
\hline 0.2539 & 0.4664 & 1.2808 \\
\hline 0.3500 & 0.6477 & 1.7610 \\
\hline Global Torq & e Loss [N & \\
\hline 6.9754 & 6.8526 & 7.3948 \\
\hline 10.3665 & 9.9091 & 10.7062 \\
\hline 14.3230 & 13.7692 & 14.7216 \\
\hline Meshing Los & ses [W] & \\
\hline $1.0 e+003$ & & \\
\hline 0.1125 & 0.1947 & 0.4396 \\
\hline 0.1852 & 0.3235 & 0.7320 \\
\hline 0.2644 & 0.4647 & 1.0544 \\
\hline Meshing Los & es $[\mathrm{Nm}]$ & \\
\hline 4.5798 & 4.1351 & 3.6742 \\
\hline 7.5628 & 6.8718 & 6.1186 \\
\hline 10.8169 & 9.8786 & 8.8142 \\
\hline
\end{tabular}


C. Detailed results of the implemented Numerical Approach, (Program Printouts)

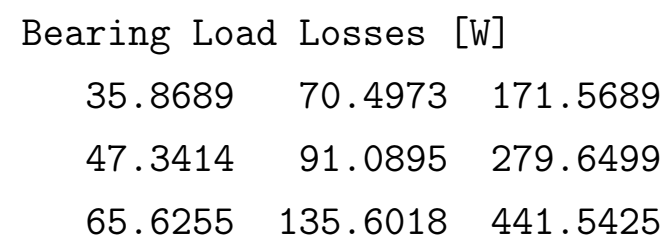

Bearing Load Losses [Nm]

$1.4599 \quad 1.4970 \quad 1.4339$

$1.9333 \quad 1.9352 \quad 2.3375$

$2.6853 \quad 2.8829 \quad 3.6911$

Bearing No Load Losses [W]
0.0133
$0.0939 \quad 1.5404$
0.0132
$0.0938 \quad 1.5398$
0.0131
$0.0936 \quad 1.5393$

Bearing No Load Losses [Nm]
0.0005
0.0020
0.0129
0.0005
0.0020
0.0129
0.0005
0.0020
0.0129

Churning Losses [W]

$\begin{array}{lll}22.9772 & 57.3841 & 272.0535 \\ 21.3005 & 51.7830 & 267.6505 \\ 20.0484 & 47.3056 & 263.5806\end{array}$

Churning Losses [Nm]

$\begin{array}{lll}0.9352 & 1.2185 & 2.2737 \\ 0.8698 & 1.1001 & 2.2372 \\ 0.8203 & 1.0057 & 2.2034\end{array}$

Seal Losses [W]

$1.0 \mathrm{e}-004 *$
0.0513
0.0984
0.2499
0.0511
0.0983
0.2499
0.0510
0.0982
0.2499 


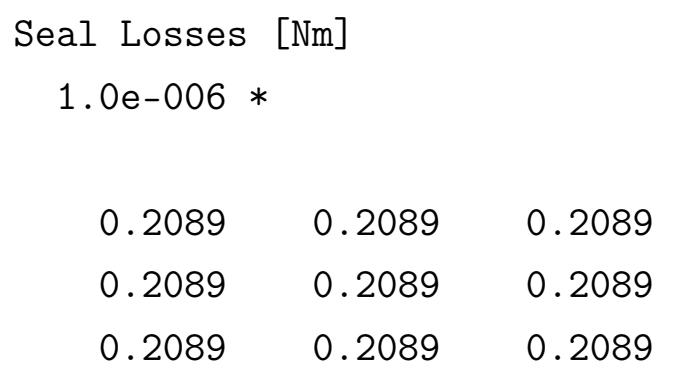

Axial Load [N]

$(:,:, 1)=$

$1.0 e+004 *$

$\begin{array}{llllll}0.2174 & 0 & 0.1728 & 0.6963 & 0.3061 & 0 \\ 0.3256 & 0 & 0.2588 & 1.0432 & 0.4587 & 0 \\ 0.4338 & 0 & 0.3450 & 1.3903 & 0.6116 & 0\end{array}$

$(:,:, 2)=$

$1.0 e+004 *$

0.2177

0.1729

0.6969

0.3063

0

0.3261

0.2591

1.0441

0.4590

0

0.4338

0.3449

1.3899

0.6112

0

$(:,:, 3)=$

$1.0 \mathrm{e}+004 *$

$\begin{array}{llllll}0.2177 & 0 & 0.1730 & 0.6971 & 0.3064 & 0 \\ 0.3256 & 0 & 0.2587 & 1.0427 & 0.4584 & 0 \\ 0.4336 & 0 & 0.3448 & 1.3894 & 0.6111 & 0\end{array}$

Radial Load [N] 
C. Detailed results of the implemented Numerical Approach, (Program Printouts)

$$
\begin{aligned}
& (:,:, 1)= \\
& 1.0 \mathrm{e}+004 *
\end{aligned}
$$

$\begin{array}{llllll}0.3733 & 0.2809 & 0.6564 & 0.8256 & 1.1622 & 0.2946 \\ 0.5592 & 0.4207 & 0.9833 & 1.2372 & 1.7417 & 0.4414 \\ 0.7449 & 0.5604 & 1.3102 & 1.6494 & 2.3221 & 0.5885\end{array}$

$(:,:, 2)=$ $1.0 \mathrm{e}+004 *$

$\begin{array}{llllll}0.3738 & 0.2812 & 0.6571 & 0.8262 & 1.1629 & 0.2947 \\ 0.5599 & 0.4212 & 0.9844 & 1.2380 & 1.7427 & 0.4417 \\ 0.7449 & 0.5604 & 1.3100 & 1.6486 & 2.3207 & 0.5882\end{array}$

$(:,:, 3)=$

$1.0 \mathrm{e}+004 *$

$\begin{array}{llllll}0.3739 & 0.2813 & 0.6573 & 0.8264 & 1.1632 & 0.2948 \\ 0.5591 & 0.4206 & 0.9831 & 1.2365 & 1.7406 & 0.4411 \\ 0.7446 & 0.5602 & 1.3095 & 1.6482 & 2.3202 & 0.5881\end{array}$

\section{C.1.2. MINR Oil}

'MINR' 'Oil'

Coefficient of friction: Meshing 1
0.0649
0.0592
0.0550
0.0718
0.0661
0.0615
0.0774
0.0722
0.0650

Coefficient of friction: Meshing 2
0.0627
0.0572
0.0531 

0.0693
0.0639
0.0594
0.0748
0.0697
0.0628
Global Losses [W]
$1.0 \mathrm{e}+003 *$
$\begin{array}{lll}0.1713 & 0.3198 & 0.6988\end{array}$
$\begin{array}{lll}0.2597 & 0.4922 & 1.0837\end{array}$
$\begin{array}{lll}0.3856 & 0.7152 & 0.8539\end{array}$

Global Torque Loss [Nm]

$\begin{array}{rrr}6.9808 & 6.7919 & 7.3071 \\ 10.5880 & 10.4585 & 11.3345 \\ 15.1513 & 15.2063 & 12.0052\end{array}$

Meshing Losses [W]

$113.5608 \quad 198.4970 \quad 374.7088$

$187.7307 \quad 331.7064 \quad 626.5161$

$279.4866 \quad 481.1264 \quad 525.5722$

$\begin{array}{rrr}\text { Meshing Losses }[\mathrm{Nm}] & \\ 4.6267 & 4.2150 & 3.9180 \\ 7.6540 & 7.0476 & 6.5526 \\ 10.9808 & 10.2301 & 7.3893\end{array}$

Bearing Load Losses [W]

$\begin{array}{lll}35.3056 & 67.8229 & 166.6956\end{array}$

$\begin{array}{lll}51.3602 & 113.5246 \quad 301.8009\end{array}$

$86.6299 \quad 191.4552 \quad 237.1136$

Bearing Load Losses [Nm]

$\begin{array}{lll}1.4384 & 1.4402 & 1.7430 \\ 2.0940 & 2.4120 & 3.1565 \\ 3.4036 & 4.0709 & 3.3337\end{array}$

Bearing No Load Losses [W]
0.0133
0.0939
0.7867 
C. Detailed results of the implemented Numerical Approach, (Program Printouts)
0.0133
0.0938
0.7860
0.0148
0.0935
0.3236

Bearing No Load Losses [Nm]
0.0005
0.0020
0.0082
0.0005
0.0020
0.0082
0.0006
0.0020
0.0045

Churning Losses [W]

$\begin{array}{rrr}22.4619 & 53.4355 & 156.6495 \\ 20.5880 & 46.9193 & 154.6230 \\ 19.5061 & 42.4789 & 90.8727\end{array}$

Churning Losses [Nm]
0.9151
1.1347
1.6379
0.8394
0.9969
1.6172
0.7664
0.9032
1. 2776

Seal Losses [W]

$1.0 \mathrm{e}-004 *$
0.0513
0.0984
0.1998
0.0512
0.0983
0.1997
0.0532
0.0982
0.1486

Seal Losses [Nm]

$1.0 \mathrm{e}-006 *$
0.2089
0.2089
0.2089
0.2089
0.2089
0.2089
0.2089
0.2089
0.2089

Axial Load [N]
$(:,:, 1)=$
$1.0 e+004 *$ 


$\begin{array}{llllll}0.2179 & 0 & 0.1731 & 0.6978 & 0.3068 & 0 \\ 0.3259 & 0 & 0.2591 & 1.0442 & 0.4592 & 0 \\ 0.4333 & 0 & 0.3448 & 1.3895 & 0.6114 & 0\end{array}$

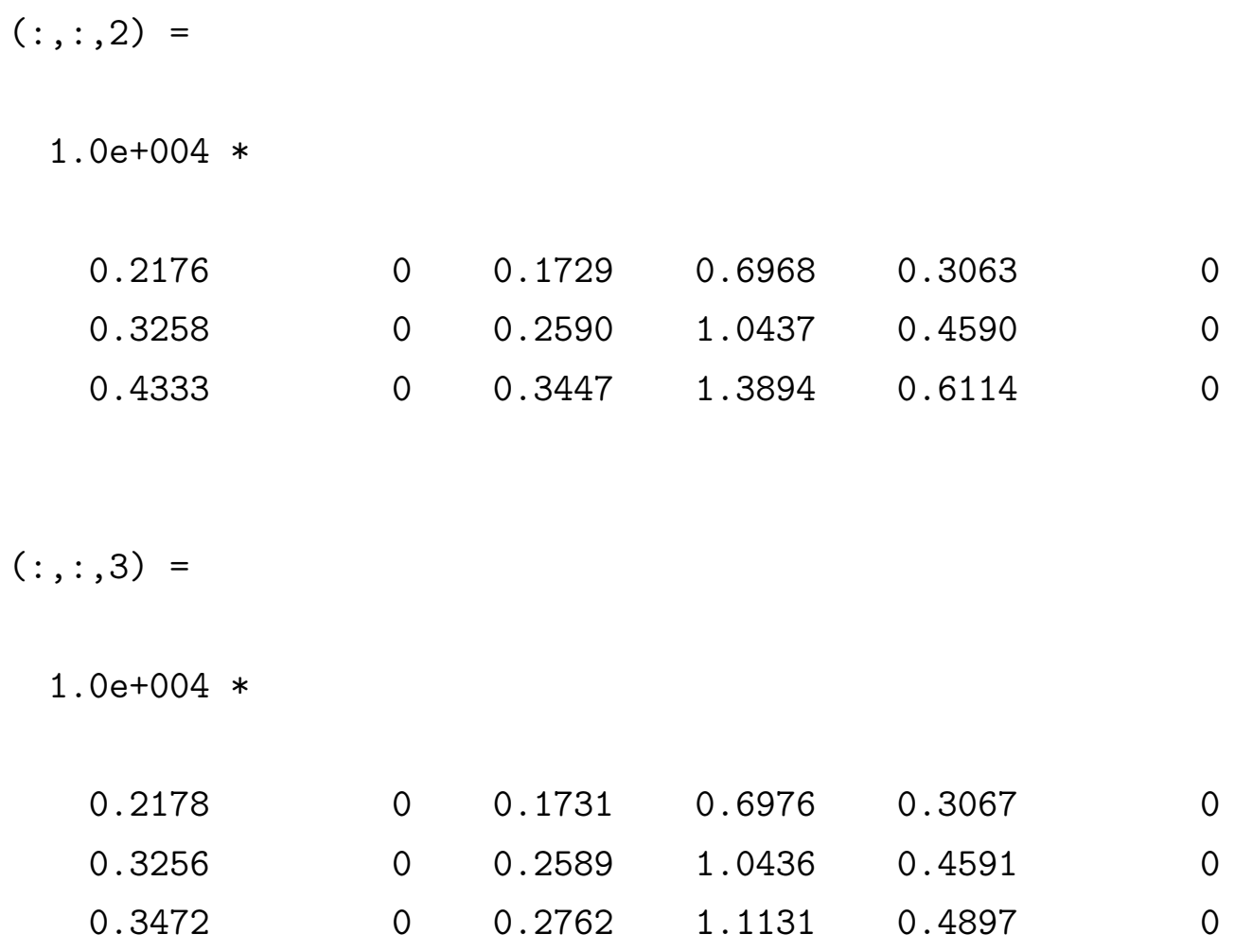

Radial Load [N]

$(:,:, 1)=$

$1.0 \mathrm{e}+004 *$

$\begin{array}{llllll}0.3741 & 0.2815 & 0.6579 & 0.8275 & 1.1648 & 0.2952\end{array}$

$\begin{array}{llllll}0.5596 & 0.4210 & 0.9842 & 1.2386 & 1.7437 & 0.4419\end{array}$

$\begin{array}{llllll}0.7441 & 0.5598 & 1.3090 & 1.6489 & 2.3215 & 0.5884\end{array}$

$(:,:, 2)=$

$1.0 e+004 *$ 
C. Detailed results of the implemented Numerical Approach, (Program Printouts)

$\begin{array}{llllll}0.3737 & 0.2811 & 0.6570 & 0.8262 & 1.1629 & 0.2947 \\ 0.5594 & 0.4208 & 0.9837 & 1.2379 & 1.7427 & 0.4417 \\ 0.7441 & 0.5598 & 1.3090 & 1.6488 & 2.3213 & 0.5883\end{array}$

$(:,:, 3)=$

$1.0 \mathrm{e}+004 *$

$\begin{array}{llllll}0.3740 & 0.2813 & 0.6576 & 0.8273 & 1.1646 & 0.2952\end{array}$

$\begin{array}{llllll}0.5591 & 0.4206 & 0.9834 & 1.2381 & 1.7431 & 0.4418\end{array}$

$\begin{array}{llllll}0.5963 & 0.4486 & 1.0488 & 1.3206 & 1.8592 & 0.4712\end{array}$ 


\title{
C.1.3. PAGD Oil
}

\author{
'PAGD' 'Oil' \\ Coefficient of friction: Meshing 1 \\ $\begin{array}{lll}0.0638 & 0.0575 & 0.0518\end{array}$ \\ $\begin{array}{lll}0.0699 & 0.0632 & 0.0570\end{array}$ \\ $\begin{array}{lll}0.0749 & 0.0683 & 0.0612\end{array}$ \\ Coefficient of friction: Meshing 2
$\begin{array}{lll}0.0616 & 0.0555 & 0.0501\end{array}$
$\begin{array}{lll}0.0675 & 0.0611 & 0.0551\end{array}$ \\ $\begin{array}{lll}0.0723 & 0.0659 & 0.0592\end{array}$ \\ Global Losses [W] \\ $1.0 \mathrm{e}+003 *$

$\begin{array}{lll}0.1740 & 0.3312 & 0.6806 \\ 0.2525 & 0.4665 & 0.9359 \\ 0.3410 & 0.6283 & 1.2357\end{array}$ \\ Global Torque Loss [Nm]

$\begin{array}{rrr}7.0861 & 7.0322 & 7.1167 \\ 10.3160 & 9.9107 & 9.7877 \\ 13.9665 & 13.3546 & 12.9271\end{array}$ \\ Meshing Losses [W] \\ $\begin{array}{lll}111.3808 & 192.5510 & 353.5038\end{array}$ \\ $182.1226 \quad 317.3176 \quad 581.3080$ \\ $259.5721 \quad 456.2461 \quad 831.2005$ \\ Meshing Losses [Nm]

$\begin{array}{rrr}4.5367 & 4.0887 & 3.6963 \\ 7.4417 & 6.7412 & 6.0796 \\ 10.6311 & 9.6978 & 8.6952\end{array}$ \\ Bearing Load Losses [W] \\ $\begin{array}{lll}35.0961 & 69.7107 & 139.6508\end{array}$
}


C. Detailed results of the implemented Numerical Approach, (Program Printouts)
$44.1550 \quad 84.7744 \quad 171.6154$
$56.6493 \quad 113.0541 \quad 223.5728$

Bearing Load Losses [Nm]
1.4295
$1.4802 \quad 1.4602$
1.8042
$1.8010 \quad 1.7948$
2.3201
$2.4030 \quad 2.3388$

Bearing No Load Losses [W]
0.0133
0.0939
0.7866
0.0132
0.0938
0.7861
0.0131
0.0936
0.7855

Bearing No Load Losses [Nm]
0.0005
0.0020
0.0082
0.0005
0.0020
0.0082
0.0005
0.0020
0.0082

Churning Losses [W]

$\begin{array}{lll}27.4793 & 68.8180 & 186.6759 \\ 26.1764 & 64.3241 & 182.1578 \\ 24.7741 & 58.8895 & 180.1833\end{array}$

Churning Losses [Nm]
1.1193
1.4613
1.9519
1.0696
1.3665
1.9051
1.0147
1. 2517
1.8849

Seal Losses [W]

1.0 e-004*
0.0513
0.0984
0.1998
0.0511
0.0983
0.1997
0.0510
0.0983
0.1997

Seal Losses [Nm]

1.0 e-006* 

0.2089
0.2089
0.2089
0.2089
0.2089
0.2089
0.2089
0.2089
0.2089

Axial Load [N]

$$
\begin{aligned}
& (:,:, 1)= \\
& 1.0 e+004 *
\end{aligned}
$$

$\begin{array}{llllll}0.2176 & 0 & 0.1729 & 0.6967 & 0.3063 & 0 \\ 0.3257 & 0 & 0.2589 & 1.0434 & 0.4588 & 0 \\ 0.4341 & 0 & 0.3451 & 1.3908 & 0.6117 & 0\end{array}$

$$
(:,:, 2)=
$$

$1.0 e+004 *$

$\begin{array}{llllll}0.2176 & 0 & 0.1729 & 0.6967 & 0.3062 & 0 \\ 0.3260 & 0 & 0.2590 & 1.0439 & 0.4589 & 0 \\ 0.4344 & 0 & 0.3452 & 1.3913 & 0.6117 & 0\end{array}$

$(:,:, 3)=$

$1.0 e+004 *$

$\begin{array}{llllll}0.2182 & 0 & 0.1733 & 0.6984 & 0.3069 & 0 \\ 0.3263 & 0 & 0.2591 & 1.0443 & 0.4589 & 0 \\ 0.4343 & 0 & 0.3450 & 1.3904 & 0.6111 & 0\end{array}$

Radial Load [N]

$(:,:, 1)=$ 
C. Detailed results of the implemented Numerical Approach, (Program Printouts)
$1.0 \mathrm{e}+004 *$
0.3736
0.2811
0.6569
0.8262
1.1630
0.2948
0.5593
0.4208
0.9836
1. 2374
1.7419
0.4415
0.7453
0.5607
1.3108
1.6498
2.3225
0.5886

$(:,:, 2)=$

$1.0 e+004 *$

$\begin{array}{llllll}0.3737 & 0.2811 & 0.6570 & 0.8261 & 1.1628 & 0.2947 \\ 0.5599 & 0.4212 & 0.9843 & 1.2378 & 1.7423 & 0.4416 \\ 0.7459 & 0.5611 & 1.3116 & 1.6500 & 2.3226 & 0.5887\end{array}$

$(:,:, 3)=$

$1.0 \mathrm{e}+004 *$

$\begin{array}{llllll}0.3746 & 0.2818 & 0.6586 & 0.8279 & 1.1653 & 0.2954 \\ 0.5603 & 0.4215 & 0.9849 & 1.2380 & 1.7426 & 0.4417 \\ 0.7457 & 0.5610 & 1.3111 & 1.6485 & 2.3204 & 0.5881\end{array}$




\section{C.1.4. PAOR Oil}

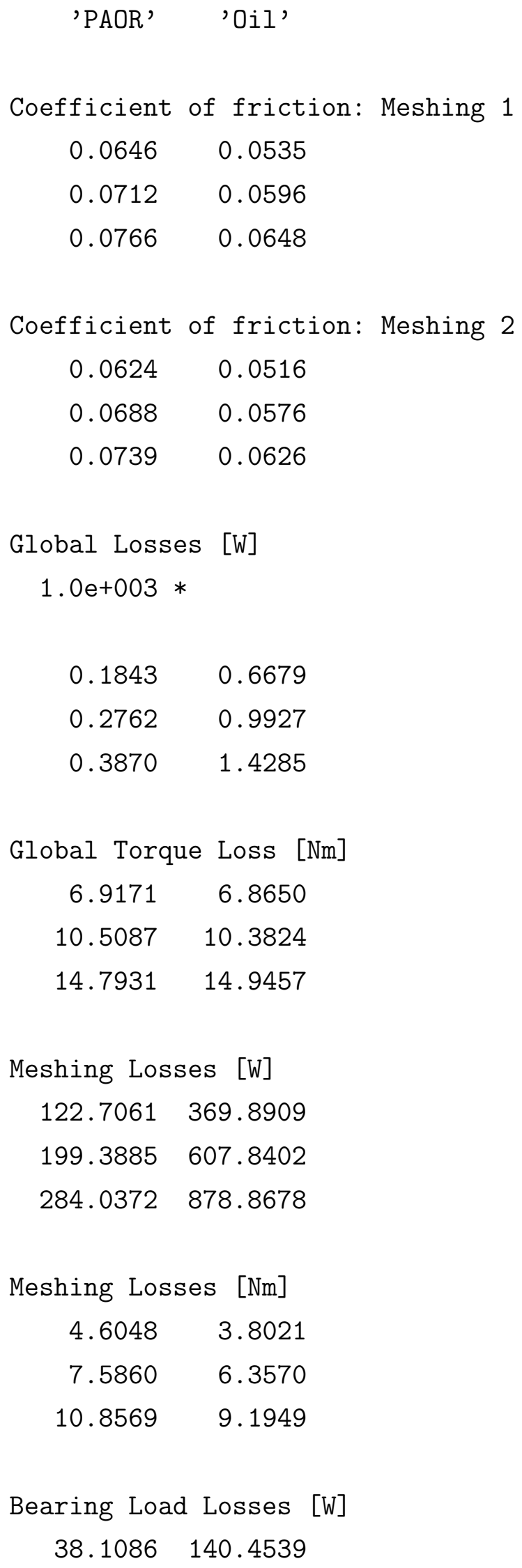


C. Detailed results of the implemented Numerical Approach, (Program Printouts)

$\begin{array}{ll}55.1789 & 235.5372 \\ 82.8238 & 402.4287\end{array}$

Bearing Load Losses [Nm]

$1.4301 \quad 1.4437$

$2.0993 \quad 2.4633$

$3.1658 \quad 4.2103$

Bearing No Load Losses [W]

$0.0170 \quad 0.8280$

$0.0163 \quad 0.7861$

$0.0161 \quad 0.7853$

Bearing No Load Losses $[\mathrm{Nm}]$
0.0006
0.0085
0.0006
0.0082
0.0006
0.0082

Churning Losses [W]

$23.4919 \quad 156.6939$

$21.6258 \quad 148.5695$

$20.1389 \quad 146.4661$

Churning Losses [Nm]
$0.8816 \quad 1.6107$
$0.8228 \quad 1.5538$
$0.7698 \quad 1.5324$

Seal Losses [W]
$\begin{array}{ll}1.0 \mathrm{~W}-004 * & \\ 0.0557 & 0.2032 \\ 0.0549 & 0.1997 \\ 0.0546 & 0.1996\end{array}$

Seal Losses [Nm]

$1.0 \mathrm{e}-006 *$ 


$$
\begin{array}{ll}
0.2089 & 0.2089 \\
0.2089 & 0.2089 \\
0.2089 & 0.2089
\end{array}
$$

Axial Load [N]

$$
\begin{gathered}
(:,:, 1)= \\
1.0 \mathrm{e}+004 * \\
0.2180 \\
0.3258 \\
0.4334 \\
(:,:, 2)= \\
1.0 \mathrm{e}+004 *
\end{gathered}
$$

$\begin{array}{llllll}0.2180 & 0 & 0.1732 & 0.6981 & 0.3069 & 0 \\ 0.3258 & 0 & 0.2590 & 1.0439 & 0.4591 & 0 \\ 0.4334 & 0 & 0.3448 & 1.3896 & 0.6114 & 0\end{array}$

$\begin{array}{llllll}0.2175 & 0 & 0.1728 & 0.6963 & 0.3060 & 0 \\ 0.3261 & 0 & 0.2592 & 1.0445 & 0.4592 & 0 \\ 0.4334 & 0 & 0.3447 & 1.3894 & 0.6112 & 0\end{array}$

Radial Load [N]

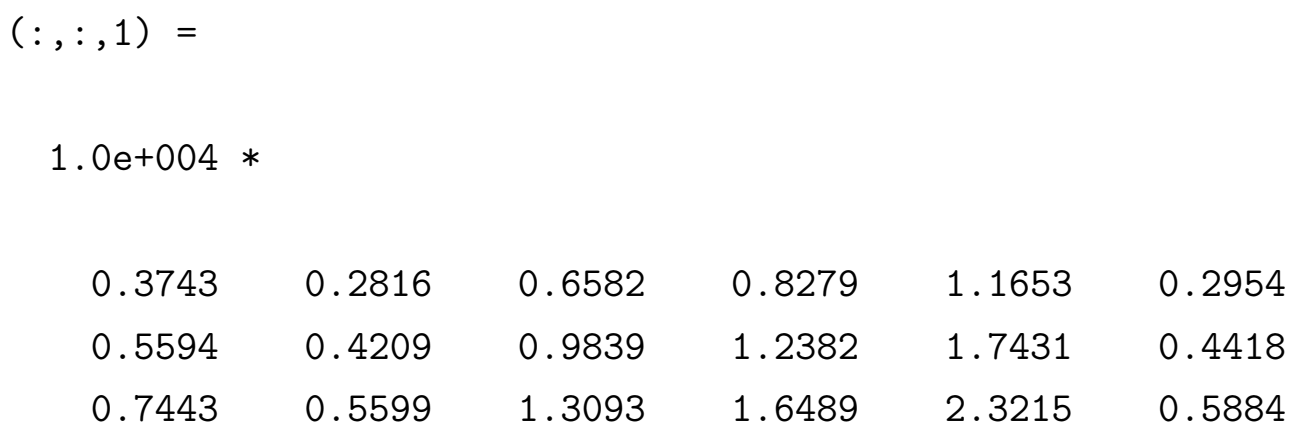


C. Detailed results of the implemented Numerical Approach, (Program Printouts)

$1.0 \mathrm{e}+004 *$

$\begin{array}{llllll}0.3735 & 0.2810 & 0.6567 & 0.8256 & 1.1620 & 0.2945 \\ 0.5599 & 0.4213 & 0.9846 & 1.2387 & 1.7437 & 0.4419 \\ 0.7442 & 0.5599 & 1.3092 & 1.6485 & 2.3208 & 0.5882\end{array}$




\section{C.2. Results after numerical adjustment}


C. Detailed results of the implemented Numerical Approach, (Program Printouts)

\title{
C.2.1. MINE Oil
}

\author{
'MINE' 'Oil' \\ Coefficients \\ 1.0000 \\ $-0.0461$ \\ 0.0812 \\ 1.0000 \\ Coefficient of friction: Meshing 1
0.0644
0.0581
0.0516
0.0710
0.0645
0.0575
0.0762
0.0696
0.0621 \\ Coefficient of friction: Meshing 2
0.0622
0.0561
0.0498
0.0686
0.0622
0.0555
0.0736
0.0672
0.0600 \\ Optimized coefficient of friction: Meshing 1
0.0783
0.0744
0.0713
0.0879
0.0841
0.0809
0.0956
0.0920
0.0886

Optimized coefficient of friction: Meshing 2
0.0748
0.0711
0.0681
0.0839
0.0803
0.0772
0.0912
0.0879
0.0846

Global Losses [W]

$1.0 \mathrm{e}+003 *$
0.1945
0.3754
1.0475
0.2960
$0.5615 \quad 1.5700$
0.4144
0.7920
2.1966

Global Torque Loss [Nm] 


$\begin{array}{rrr}7.9168 & 7.9716 & 8.7543 \\ 12.0871 & 11.9295 & 13.1233 \\ 16.9549 & 16.8384 & 18.3623\end{array}$

Meshing Losses [W]

$1.0 \mathrm{e}+003 *$

$\begin{array}{lll}0.1357 & 0.2475 & 0.6024 \\ 0.2274 & 0.4186 & 1.0215 \\ 0.3287 & 0.6092 & 1.4905\end{array}$

Meshing Losses [Nm]

$\begin{array}{lll}5.5220 & 5.2551 & 5.0349\end{array}$

$9.2849 \quad 8.8940 \quad 8.5383$

$\begin{array}{lll}13.4515 & 12.9511 & 12.4599\end{array}$

Bearing Load Losses [W]

$\begin{array}{lll}35.8486 & 70.4509 & 171.4283\end{array}$

$\begin{array}{lll}47.3031 & 91.0037 & 279.3421\end{array}$

$\begin{array}{lll}65.5593 & 135.4454 & 440.9511\end{array}$

Bearing Load Losses [Nm]

$\begin{array}{lll}1.4591 & 1.4960 & 1.4327 \\ 1.9317 & 1.9334 & 2.3349 \\ 2.6826 & 2.8796 & 3.6862\end{array}$

Bearing No Load Losses [W]
$\begin{array}{lll}0.0133 & 0.0939 & 1.5404\end{array}$
$\begin{array}{lll}0.0132 & 0.0938 & 1.5398\end{array}$
$\begin{array}{lll}0.0131 & 0.0936 & 1.5393\end{array}$

Bearing No Load Losses [Nm]
0.0005
0.0020
0.0129
0.0005
0.0020
0.0129
0.0005
0.0020
0.0129

Churning Losses [W] 
C. Detailed results of the implemented Numerical Approach, (Program Printouts)

$\begin{array}{lll}22.9772 & 57.3841 & 272.0535 \\ 21.3005 & 51.7830 & 267.6505 \\ 20.0484 & 47.3056 & 263.5806\end{array}$

Churning Losses $[\mathrm{Nm}]$

$\begin{array}{lll}0.9352 & 1.2185 & 2.2737 \\ 0.8698 & 1.1001 & 2.2372 \\ 0.8203 & 1.0057 & 2.2034\end{array}$

Seal Losses [W]

$1.0 \mathrm{e}-004 *$
0.0513
0.0984
0.2499
0.0511
0.0983
0.2499
0.0510
0.0982
0.2499
Seal Losses [Nm]
$1.0 \mathrm{e}-006 *$

$\begin{array}{lll}0.2089 & 0.2089 & 0.2089 \\ 0.2089 & 0.2089 & 0.2089 \\ 0.2089 & 0.2089 & 0.2089\end{array}$

Axial Load [N]

$(:,:, 1)=$

$1.0 e+004 *$

$\begin{array}{llllll}0.2170 & 0 & 0.1726 & 0.6957 & 0.3061 & 0 \\ 0.3249 & 0 & 0.2586 & 1.0421 & 0.4587 & 0 \\ 0.4326 & 0 & 0.3446 & 1.3888 & 0.6116 & 0\end{array}$

$(:,:, 2)=$

$1.0 e+004 *$ 


$\begin{array}{llllll}0.2172 & 0 & 0.1727 & 0.6962 & 0.3063 & 0 \\ 0.3252 & 0 & 0.2588 & 1.0429 & 0.4590 & 0 \\ 0.4325 & 0 & 0.3444 & 1.3881 & 0.6112 & 0\end{array}$

\begin{tabular}{|c|c|c|c|c|c|}
\hline $1.0 e+004$ & & & & & \\
\hline 0.2172 & 0 & 0.1728 & 0.6963 & 0.3064 & 0 \\
\hline 0.3245 & 0 & 0.2584 & 1.0413 & 0.4584 & 0 \\
\hline 0.4320 & 0 & 0.3442 & 1.3873 & 0.6111 & 0 \\
\hline
\end{tabular}

Radial Load [N]

$(:,:, 1)=$

$1.0 \mathrm{e}+004 *$

$\begin{array}{llllll}0.3726 & 0.2803 & 0.6555 & 0.8255 & 1.1622 & 0.2946 \\ 0.5579 & 0.4197 & 0.9816 & 1.2370 & 1.7417 & 0.4414 \\ 0.7429 & 0.5589 & 1.3075 & 1.6491 & 2.3221 & 0.5885\end{array}$

$(:,:, 2)=$

$1.0 e+004 *$

$\begin{array}{llllll}0.3729 & 0.2806 & 0.6560 & 0.8260 & 1.1629 & 0.2947\end{array}$

$\begin{array}{llllll}0.5584 & 0.4201 & 0.9824 & 1.2378 & 1.7427 & 0.4417\end{array}$

$\begin{array}{llllll}0.7426 & 0.5587 & 1.3069 & 1.6481 & 2.3207 & 0.5882\end{array}$

$(:,:, 3)=$

$1.0 e+004 *$ 
C. Detailed results of the implemented Numerical Approach, (Program Printouts)

$\begin{array}{llllll}0.3729 & 0.2805 & 0.6560 & 0.8262 & 1.1632 & 0.2948 \\ 0.5573 & 0.4192 & 0.9806 & 1.2362 & 1.7406 & 0.4411 \\ 0.7419 & 0.5581 & 1.3059 & 1.6477 & 2.3202 & 0.5881\end{array}$




\title{
C.2.2. MINR Oil
}

\author{
'MINR' 'Oil' \\ Coefficients \\ 1.0000 \\ $-0.0915$ \\ 0.1988 \\ 1.0000 \\ Coefficient of friction: Meshing 1
0.0649
0.0592
0.0550
0.0718
0.0661
0.0615
0.0722
0.0650 \\ 0.0774 \\ Coefficient of friction: Meshing 2
0.0627
0.0572
0.0531
0.0693
0.0638
0.0593
0.0747
0.0696
0.0627 \\ Optimized coefficient of friction: Meshing 1
0.0934
0.0970
0.1037
0.1072
0.1124
0.1203
0.1195
0.1258
0.1207 \\ Optimized coefficient of friction: Meshing 2
0.0886
0.0919
0.0982
0.1015
0.1064
0.1139
0.1132
0.1191
0.1142 \\ Global Losses [W] \\ $1.0 \mathrm{e}+003 *$

$\begin{array}{lll}0.2190 & 0.4417 & 1.0195 \\ 0.3482 & 0.7155 & 1.6620 \\ 0.5311 & 1.0594 & 1.2873\end{array}$

Global Torque Loss [Nm] 
C. Detailed results of the implemented Numerical Approach, (Program Printouts)

$\begin{array}{rrr}8.9222 & 9.3802 & 10.6604 \\ 14.1978 & 15.2015 & 17.3830 \\ 20.8671 & 22.5256 & 18.0986\end{array}$

Meshing Losses [W] $1.0 \mathrm{e}+003 *$
0.1613
0.3205
0.6958
0.2764
$0.5552 \quad 1.2057$
0.4251
0.8259
0.9596

Meshing Losses [Nm]
6.5698
6.8055
7.2749
11.2674
11.7959
12.6100
16.7037
17.5606
13.4917

Bearing Load Losses [W]
$\begin{array}{lll}35.2640 & 67.7164 & 166.3517\end{array}$
$51.2740 \quad 113.2782 \quad 300.9511$
$\begin{array}{lll}86.4454 & 190.9324 & 236.4741\end{array}$

Bearing Load Losses [Nm]
1.4367
1.4379
1.7394
2.0905
2.4068
3.1476
3.3964
4.0598
3.3247

Bearing No Load Losses [W]
0.0133
0.0939
0.7867
0.0133
0.0938
0.7860
0.0148
0.0935
0.3236

Bearing No Load Losses [Nm]
0.0005
0.0020
0.0082
0.0005
0.0020
0.0082
0.0006
0.0020
0.0045

Churning Losses [W] 


$\begin{array}{rrr}22.4619 & 53.4355 & 156.6495 \\ 20.5880 & 46.9193 & 154.6230 \\ 19.5061 & 42.4789 & 90.8727\end{array}$

$\begin{array}{crr}\text { Churning Losses }[\mathrm{Nm}] & \\ 0.9151 & 1.1347 & 1.6379 \\ 0.8394 & 0.9969 & 1.6172 \\ 0.7664 & 0.9032 & 1.2776\end{array}$

Seal Losses [W]

$1.0 \mathrm{e}-004 *$
0.0513
0.0984
0.1998
0.0512
0.0983
0.1997
0.0532
0.0982
0.1486

Seal Losses [Nm]

$1.0 \mathrm{e}-006 *$

$\begin{array}{lll}0.2089 & 0.2089 & 0.2089 \\ 0.2089 & 0.2089 & 0.2089 \\ 0.2089 & 0.2089 & 0.2089\end{array}$

Axial Load [N]

$(:,:, 1)=$

$1.0 \mathrm{e}+004 *$

$\begin{array}{llllll}0.2170 & 0 & 0.1729 & 0.6967 & 0.3068 & 0 \\ 0.3243 & 0 & 0.2586 & 1.0421 & 0.4592 & 0 \\ 0.4308 & 0 & 0.3439 & 1.3861 & 0.6114 & 0\end{array}$

$(:,:, 2)=$

$1.0 \mathrm{e}+004 *$ 
C. Detailed results of the implemented Numerical Approach, (Program Printouts)

$\begin{array}{llllll}0.2165 & 0 & 0.1725 & 0.6953 & 0.3063 & 0 \\ 0.3237 & 0 & 0.2583 & 1.0409 & 0.4590 & 0 \\ 0.4301 & 0 & 0.3437 & 1.3851 & 0.6114 & 0\end{array}$

\begin{tabular}{|c|c|c|c|c|c|}
\hline $1.0 \mathrm{e}+004$ & & & & & \\
\hline 0.2163 & 0 & 0.1726 & 0.6956 & 0.3067 & 0 \\
\hline 0.3229 & 0 & 0.2581 & 1.0401 & 0.4591 & 0 \\
\hline 0.3445 & 0 & 0.2753 & 1.1095 & 0.4897 & 0 \\
\hline
\end{tabular}

Radial Load [N]

$(:,:, 1)=$

$1.0 \mathrm{e}+004 *$

$\begin{array}{llllll}0.3727 & 0.2804 & 0.6559 & 0.8272 & 1.1648 & 0.2952 \\ 0.5568 & 0.4189 & 0.9805 & 1.2381 & 1.7437 & 0.4419 \\ 0.7397 & 0.5565 & 1.3032 & 1.6481 & 2.3215 & 0.5884\end{array}$

$(:,:, 2)=$

$1.0 \mathrm{e}+004 *$

$\begin{array}{llllll}0.3717 & 0.2797 & 0.6544 & 0.8258 & 1.1629 & 0.2947\end{array}$

$\begin{array}{llllll}0.5558 & 0.4181 & 0.9789 & 1.2372 & 1.7427 & 0.4417\end{array}$

$\begin{array}{llllll}0.7385 & 0.5556 & 1.3015 & 1.6477 & 2.3213 & 0.5883\end{array}$

$(:,:, 3)=$

$1.0 e+004 *$ 


$\begin{array}{llllll}0.3714 & 0.2794 & 0.6542 & 0.8268 & 1.1646 & 0.2952 \\ 0.5545 & 0.4172 & 0.9773 & 1.2373 & 1.7431 & 0.4418 \\ 0.5916 & 0.4451 & 1.0427 & 1.3198 & 1.8592 & 0.4712\end{array}$


C. Detailed results of the implemented Numerical Approach, (Program Printouts)

\title{
C.2.3. PAGD Oil
}

\author{
'PAGD' 'Oil' \\ Coefficients \\ 1.0000 \\ $-0.0124$ \\ 0.1091 \\ 1.0000
}

Coefficient of friction: Meshing 1
0.0638
0.0575
0.0518
0.0699
0.0632
0.0570
0.0749
0.0683
0.0612

Coefficient of friction: Meshing 2
0.0616
0.0555
0.0501
0.0675
0.0611
0.0551
0.0723
0.0659
0.0591

Optimized coefficient of friction: Meshing 1
0.0637
0.0617
0.0601
0.0702
0.0682
0.0664
0.0754
0.0739
0.0716

Optimized coefficient of friction: Meshing 2
0.0619
0.0599
0.0584
0.0681
0.0662
0.0645
0.0733
0.0718
0.0695

Global Losses [W]

$1.0 \mathrm{e}+003 *$
0.1743
0.3458
0.7379
0.2538
0.4924
1.0334
0.3438
$0.6671 \quad 1.3785$

Global Torque Loss [Nm] 


$\begin{array}{rrr}7.0989 & 7.3436 & 7.7160 \\ 10.3719 & 10.4598 & 10.8078 \\ 14.0815 & 14.1807 & 14.4209\end{array}$

$$
\begin{array}{ccc}
\text { Meshing Losses [W] } & \\
111.6959 & 207.2267 & 410.8533 \\
183.4891 & 343.1827 & 678.9164 \\
262.3828 & 495.1413 & 974.1161
\end{array}
$$

Meshing Losses [Nm]

$\begin{array}{rrr}4.5496 & 4.4003 & 4.2960 \\ 7.4975 & 7.2907 & 7.1004 \\ 10.7462 & 10.5246 & 10.1902\end{array}$

Bearing Load Losses [W]

$\begin{array}{rrr}35.0961 & 69.6999 & 139.6080 \\ 44.1545 & 84.7560 & 171.5446 \\ 56.6477 & 113.0233 & 223.4601\end{array}$

Bearing Load Losses [Nm]
1.4295
1.4800
1.4598
1.8042
1.8006
1.7941
2.3201
2.4024
2.3376

Bearing No Load Losses [W]
0.0133
0.0939
0.7866
0.0132
0.0938
0.7861
0.0131
0.0936
0.7855

Bearing No Load Losses [Nm]
0.0005
0.0020
0.0082
0.0005
0.0020
0.0082
0.0005
0.0020
0.0082

Churning Losses [W]
27.4793
$68.8180 \quad 186.6759$
26.1764
$64.3241 \quad 182.1578$ 
C. Detailed results of the implemented Numerical Approach, (Program Printouts)

$24.7741 \quad 58.8895 \quad 180.1833$

Churning Losses [Nm]

$\begin{array}{lll}1.1193 & 1.4613 & 1.9519 \\ 1.0696 & 1.3665 & 1.9051 \\ 1.0147 & 1.2517 & 1.8849\end{array}$

Seal Losses [W]

$1.0 \mathrm{e}-004 *$
0.0513
0.0984
0.1998
0.0511
0.0983
0.1997
0.0510
0.0983
0.1997

Seal Losses [Nm]

1.0 e-006*
0.2089
0.2089
0.2089
0.2089
0.2089
0.2089
0.2089
0.2089
0.2089

Axial Load [N]

$(:,:, 1)=$

$1.0 e+004 *$

$\begin{array}{llllll}0.2176 & 0 & 0.1729 & 0.6967 & 0.3063 & 0 \\ 0.3257 & 0 & 0.2589 & 1.0434 & 0.4588 & 0 \\ 0.4340 & 0 & 0.3451 & 1.3908 & 0.6117 & 0\end{array}$

$(:,:, 2)=$

$1.0 e+004 *$

0.2175

$0 \quad 0.1728$

0.6965

0.3062

0 


$\begin{array}{llllll}0.3258 & 0 & 0.2589 & 1.0436 & 0.4589 & 0 \\ 0.4340 & 0 & 0.3451 & 1.3908 & 0.6117 & 0\end{array}$
$(:,:, 3)=$
$1.0 e+004 *$

$\begin{array}{llllll}0.2179 & 0 & 0.1732 & 0.6980 & 0.3069 & 0 \\ 0.3258 & 0 & 0.2590 & 1.0438 & 0.4589 & 0 \\ 0.4337 & 0 & 0.3448 & 1.3896 & 0.6111 & 0\end{array}$

Radial Load [N]

$(:,:, 1)=$

$1.0 \mathrm{e}+004 *$

$\begin{array}{llllll}0.3736 & 0.2811 & 0.6569 & 0.8262 & 1.1630 & 0.2948 \\ 0.5593 & 0.4208 & 0.9835 & 1.2374 & 1.7419 & 0.4415 \\ 0.7453 & 0.5607 & 1.3108 & 1.6498 & 2.3225 & 0.5886\end{array}$

$(:,:, 2)=$

$1.0 e+004 *$

$\begin{array}{llllll}0.3735 & 0.2810 & 0.6567 & 0.8260 & 1.1628 & 0.2947 \\ 0.5595 & 0.4209 & 0.9838 & 1.2377 & 1.7423 & 0.4416 \\ 0.7453 & 0.5607 & 1.3108 & 1.6499 & 2.3226 & 0.5887\end{array}$

$(:,:, 3)=$

$1.0 e+004 *$
0.3742
0.2815
0.6580
0.8278
1.1653
0.2954 
C. Detailed results of the implemented Numerical Approach, (Program Printouts)

$\begin{array}{llllll}0.5595 & 0.4209 & 0.9839 & 1.2379 & 1.7426 & 0.4417 \\ 0.7447 & 0.5602 & 1.3097 & 1.6483 & 2.3204 & 0.5881\end{array}$




\section{C.2.4. PAOR Oil}

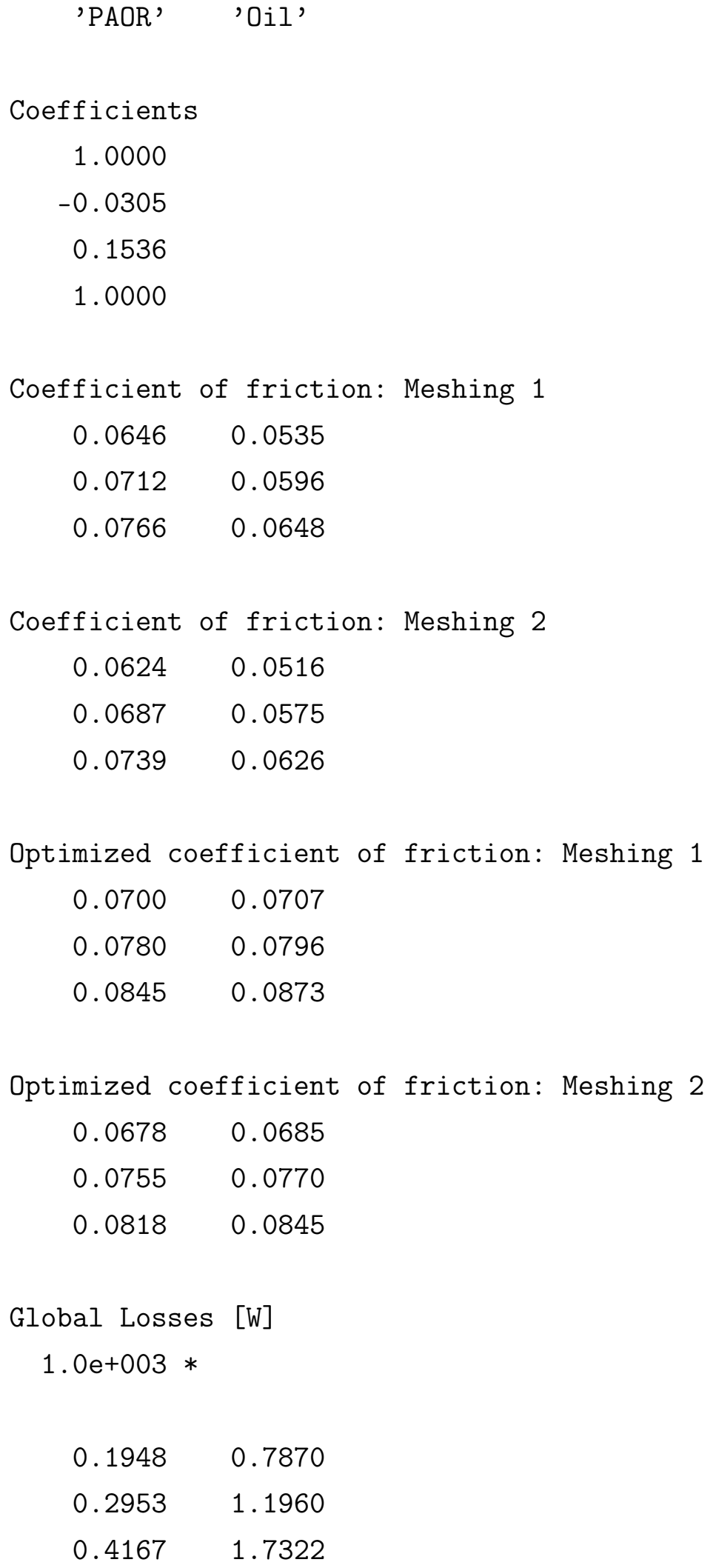

Optimized coefficient of friction: Meshing 1
$0.0700 \quad 0.0707$
$0.0780 \quad 0.0796$
$0.0845 \quad 0.0873$

Optimized coefficient of friction: Meshing 2
0.0678
0.0685
0.0755
0.0770
0.0818
0.0845

Global Losses [W]

$1.0 e+003 *$
$0.1948 \quad 0.7870$
$0.2953 \quad 1.1960$
$0.4167 \quad 1.7322$

Global Torque Loss [Nm] 
C. Detailed results of the implemented Numerical Approach, (Program Printouts)

$\begin{array}{rr}7.3088 & 8.0891 \\ 11.2368 & 12.5082 \\ 15.9291 & 18.1225\end{array}$

Meshing Losses [W] $1.0 \mathrm{e}+003 *$
0.1332
0.4891
0.2185
0.8113
0.3138
1.1829

Meshing Losses [Nm]
4.9968
5.0272
8.3147
8.4850
11.9941
12.3761

Bearing Load Losses [W]

$38.1007 \quad 140.3613$

$55.1628 \quad 235.3337$

$82.7932 \quad 401.9939$

Bearing Load Losses [Nm]
1.4298
1.4428
2.0987
2.4612
3.1647
4.2057

Bearing No Load Losses [W]
0.0170
0.8280
0.0163
0.7861
0.0161
0.7853

Bearing No Load Losses [Nm]
0.0006
0.0085
0.0006
0.0082
0.0006
0.0082

Churning Losses [W] 


$$
\begin{array}{ll}
23.4919 & 156.6939 \\
21.6258 & 148.5695 \\
20.1389 & 146.4661
\end{array}
$$

$$
\begin{array}{cr}
\text { Churning Losses } & {[\mathrm{Nm}]} \\
0.8816 & 1.6107 \\
0.8228 & 1.5538 \\
0.7698 & 1.5324 \\
\text { Seal Losses [W] } \\
1.0 \text { e-004 * } \\
\multicolumn{3}{l}{0.0557} & 0.2032 \\
0.0549 & 0.1997 \\
0.0546 & 0.1996
\end{array}
$$
$0.0557 \quad 0.2032$
$0.0549 \quad 0.1997$

$$
\begin{aligned}
& \text { Seal Losses }[\mathrm{Nm}] \\
& \begin{array}{ll}
1.0 \mathrm{e}-006 * & \\
0.2089 & 0.2089 \\
0.2089 & 0.2089 \\
0.2089 & 0.2089
\end{array}
\end{aligned}
$$

Axial Load [N]

$$
\begin{aligned}
& (:,:, 1)= \\
& 1.0 \mathrm{e}+004 *
\end{aligned}
$$

$\begin{array}{llllll}0.2178 & 0 & 0.1732 & 0.6979 & 0.3069 & 0 \\ 0.3255 & 0 & 0.2589 & 1.0435 & 0.4591 & 0 \\ 0.4329 & 0 & 0.3446 & 1.3890 & 0.6114 & 0\end{array}$

$$
(:,:, 2)=
$$

$1.0 e+004 *$ 
C. Detailed results of the implemented Numerical Approach, (Program Printouts)

$\begin{array}{llllll}0.2170 & 0 & 0.1726 & 0.6956 & 0.3060 & 0 \\ 0.3252 & 0 & 0.2589 & 1.0433 & 0.4592 & 0 \\ 0.4321 & 0 & 0.3443 & 1.3876 & 0.6112 & 0\end{array}$

Radial Load [N]

$(:,:, 1)=$

$1.0 \mathrm{e}+004 *$

$\begin{array}{llllll}0.3740 & 0.2814 & 0.6578 & 0.8278 & 1.1653 & 0.2954 \\ 0.5589 & 0.4205 & 0.9832 & 1.2381 & 1.7431 & 0.4418 \\ 0.7434 & 0.5593 & 1.3082 & 1.6488 & 2.3215 & 0.5884\end{array}$

$(:,:, 2)=$

$1.0 \mathrm{e}+004 *$

$\begin{array}{llllll}0.3726 & 0.2803 & 0.6555 & 0.8254 & 1.1620 & 0.2945 \\ 0.5584 & 0.4201 & 0.9825 & 1.2384 & 1.7437 & 0.4419 \\ 0.7419 & 0.5582 & 1.3060 & 1.6481 & 2.3208 & 0.5882\end{array}$


C.3. Torque sensors manufacturer specifications 


\section{Flange drive for use when short length is mandatory}
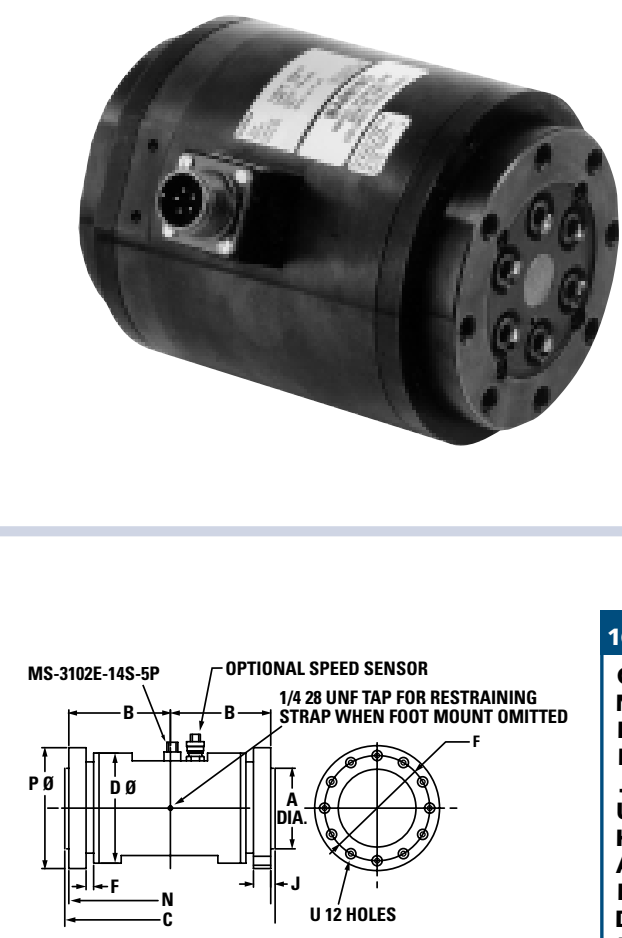

\begin{tabular}{|ccc|}
\hline $\mathbf{1 6 4 1}$ & $\mathbf{I N}$. & $\mathbf{C M}$. \\
\hline $\mathbf{C}$ & 11.88 & 30.16 \\
$\mathbf{N}$ & 11.63 & 29.50 \\
$\mathbf{P}$ & 7.00 & 17.70 \\
$\mathbf{F}$ & 0.44 & 1.11 \\
$\mathbf{J}$ & 0.13 & 0.32 \\
$\mathbf{U}$ & $1 / 2-20$ & - \\
$\mathbf{H}$ & 6.00 & 15.20 \\
$\mathbf{A}$ & 4.50 & 11.42 \\
$\mathbf{B}$ & 4.38 & 11.11 \\
$\mathbf{D}$ & 6.50 & 16.50 \\
$\mathbf{E}$ & $1 / 4-28$ & - \\
\hline
\end{tabular}

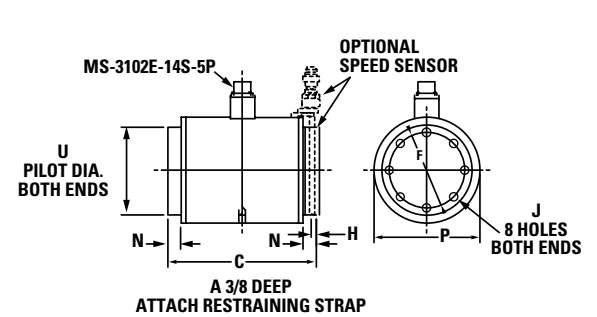

\begin{tabular}{|ccc|}
\hline $\mathbf{1 6 4 8}$ & $\mathbf{I N}$. & $\mathbf{C M}$ \\
\hline $\mathbf{C}$ & 6.38 & 16.19 \\
$\mathbf{N}$ & 0.56 & 1.43 \\
$\mathbf{P}$ & 5.00 & 12.70 \\
$\mathbf{F}$ & 3.63 & 9.20 \\
$\mathbf{J}$ & $3 / 8-24$ & - \\
$\mathbf{U}$ & 4.25 & 10.79 \\
$\mathbf{H}$ & 0.38 & 0.95 \\
$\mathbf{A}$ & $10-32$ & - \\
$\mathbf{B}$ & - & - \\
$\mathbf{D}$ & - & - \\
$\mathbf{E}$ & - & - \\
\hline
\end{tabular}

F E A T U R E S:

- Shortened drive length

- Extended speed range

- Minimal maintenance due to "bearings only" contact

- High overall performance accuracy

Safety Considerations: "It would be unsafe to operate Lebow ${ }^{\circledast}$ Torque Sensors and Load Cells beyond Static Overload or Ultimate Extraneous Load Limits as defined in the Glossary of Terms or, when applicable, higher than maximum speed. When in doubt, consult the factory.

Lebow ${ }^{\circledast}$ Products is not responsible for any property damage or personal injury which may result because of the misapplication of the Transducer."

\section{P E R F O R M A N C E S P E C S : $1641 / 1648$ SPECIFICATIONS}

\begin{tabular}{|c|c|}
\hline $\begin{array}{l}\text { Actual performance average: } \\
\text { Nonlinearity: } \\
\text { Hysteresis: }\end{array}$ & $\begin{array}{l}0.026 \% \\
0.031 \%\end{array}$ \\
\hline Nonlinearity: of rated output & $\pm 0.1 \%$ \\
\hline Hysteresis: of rated output & $\pm 0.1 \%$ \\
\hline $\begin{array}{l}\text { Output at rated capacity: } \\
\text { millivolts per volt, nominal }\end{array}$ & 2 \\
\hline Repeatability: of rated output & $\pm 0.05 \%$ \\
\hline Zero balance: of rated output & $\pm 1.0 \%$ \\
\hline Bridge resistance: ohms nominal & 350 \\
\hline Temperature range, compensated: ${ }^{\circ} \mathrm{F}$ & +70 to +170 \\
\hline Temperature range, compensated: ${ }^{\circ} \mathrm{C}$ & +21 to +77 \\
\hline Temperature range, usable: ${ }^{\circ} \mathrm{F}$ & -20 to +200 \\
\hline Temperature range, usable: ${ }^{\circ} \mathrm{C}$ & -29 to +93 \\
\hline $\begin{array}{l}\text { Temperature effect on output: } \\
\text { of reading per }{ }^{\circ} \mathrm{F}\end{array}$ & $\pm 0.002 \%$ \\
\hline $\begin{array}{l}\text { Temperature effect on output: } \\
\text { of reading per }{ }^{\circ} \mathrm{C}\end{array}$ & $\pm 0.0036 \%$ \\
\hline $\begin{array}{l}\text { Temperature effect on zero: } \\
\text { of rated output per }{ }^{\circ} \mathrm{F}\end{array}$ & $\pm 0.002 \%$ \\
\hline $\begin{array}{l}\text { Temperature effect on zero: } \\
\text { of rated output per }{ }^{\circ} \mathrm{C}\end{array}$ & $\pm 0.0036 \%$ \\
\hline Excitation voltage, 10 VAC max. rms: & $3.28 \mathrm{kHz}$ optimum \\
\hline $\begin{array}{l}\text { Insulation resistance, bridge/case: } \\
\text { megohms at } 50 \mathrm{VDC}\end{array}$ & $>5,000$ \\
\hline Number of bridges & 1 \\
\hline
\end{tabular}

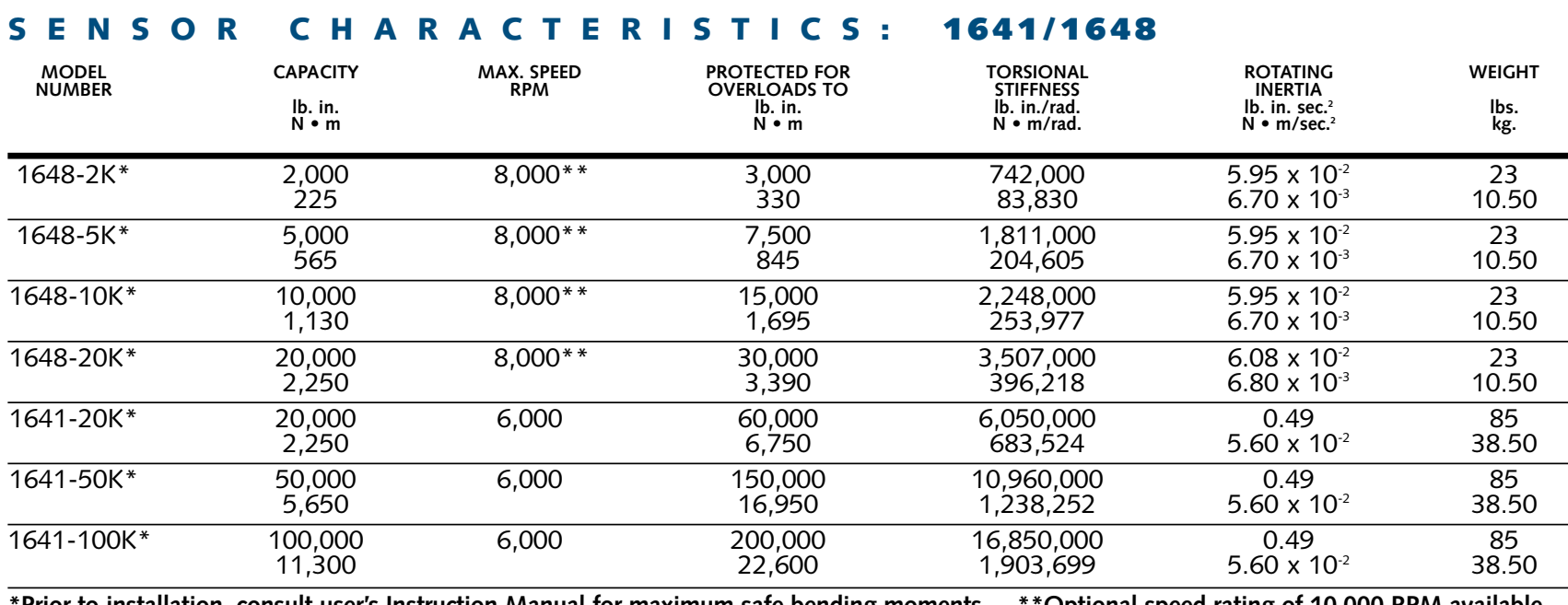

\footnotetext{
*Prior to installation, consult user's Instruction Manual for maximum safe bending moments. $\quad{ }^{*}$ *optional speed rating of 10,000 RPM available.
} 